ENVIRONMENTAL CONTROL OF CLOUD-TO-GROUND LIGHTNING

POLARITY IN SEVERE STORMS

\author{
A Thesis \\ by \\ KURT MATTHEW BUFFALO

\begin{abstract}
Submitted to the Office of Graduate Studies of Texas A\&M University

MASTER OF SCIENCE
\end{abstract} \\ in partial fulfillment of the requirements for the degree of
}

December 2007

Major Subject: Atmospheric Sciences 


\title{
ENVIRONMENTAL CONTROL OF CLOUD-TO-GROUND LIGHTNING POLARITY IN SEVERE STORMS
}

\author{
A Thesis \\ by \\ KURT MATTHEW BUFFALO
}

\begin{abstract}
Submitted to the Office of Graduate Studies of Texas A\&M University

in partial fulfillment of the requirements for the degree of

MASTER OF SCIENCE
\end{abstract}

Approved by:

Chair of Committee, Lawrence D. Carey

Committee Members, Richard E. Orville Anthony T. Cahill

Head of Department, Richard E. Orville

December 2007

Major Subject: Atmospheric Sciences 


\author{
ABSTRACT \\ Environmental Control of Cloud-to-Ground Lightning \\ Polarity in Severe Storms. (December 2007) \\ Kurt Matthew Buffalo, B.S., University of Northern Colorado \\ Chair of Advisory Committee: Dr. Lawrence D. Carey
}

In this study, it is hypothesized that the mesoscale environment can indirectly control the cloud-to-ground (CG) lightning polarity of severe storms by directly affecting their structural, dynamical, and microphysical properties, which in turn directly control cloud electrification and CG flash polarity. A more specific hypothesis, which has been supported by past observational and laboratory charging studies, suggests that broad, strong updrafts and associated large liquid water contents in severe storms lead to enhanced positive charging of graupel and hail via the noninductive charging mechanism, the generation of an inverted charge structure, and increased positive CG lightning production. The corollary is that environmental conditions favoring these kinematic and microphysical characteristics should support severe storms generating an anomalously high (> 25\%) percentage of positive CG lightning (i.e., positive storms), while environmental conditions relatively less favorable should sustain storms characterized by a typical $(\leq 25 \%)$ percentage of positive CG lightning (i.e., negative storms).

Forty-eight inflow proximity soundings were analyzed to characterize the environments of nine distinct mesoscale regions of severe storms (four positive and five negative) on six days during May - June 2002 over the central United States. This 
analysis clearly demonstrated significant and systematic differences in the mesoscale environments of positive and negative storms, which were consistent with the stated hypothesis. When compared to negative storms, positive storms occurred in environments associated with a drier low to midtroposphere, higher cloud base height, smaller warm cloud depth, stronger conditional instability, larger 0-3 km AGL wind shear, stronger 0-2 km AGL storm-relative wind speed, and larger buoyancy in the mixed-phase zone, at a statistically significant level. Differences in the warm cloud depth of positive and negative storms were by far the most dramatic, suggesting an important role for this parameter in controlling CG lightning polarity. Subjective visual inspection of radar imagery revealed no strong relationship between convective mode and CG lightning polarity, and also illustrated that positive and negative severe storms can be equally intense. 


\section{ACKNOWLEDGMENTS}

First and foremost, I would like to sincerely thank my advisor, Dr. Larry Carey, for his endless help and support. His passion for atmospheric science and learning in general is contagious, and his dedication and work ethic truly inspiring. I owe him special thanks for his patience and continued encouragement while trying to complete my thesis remotely. I am very appreciative for the genuine care he has for his students and their development, and for the fact that he is never too busy to promptly answer a question or respond to any concern. I would also like to thank my committee members, Dr. Richard Orville and Dr. Tony Cahill, for their generous assistance and support of my thesis work, and guidance in general during my time as a graduate student. I thank Scott Steiger and Brandon Ely for their valuable assistance and mentoring with IDL code. I also owe a big thank you to Bill Fortune, Meteorologist-in-Charge of the National Weather Service Forecast Office in Pueblo, CO for his support as I worked to complete my thesis remotely while employed as a Student Career Experience Program (SCEP) student at the Pueblo Weather Forecast Office.

Next, I would like to thank all of my family, and in particular my wife Julie, parents Joe and Laura, brother Kevin, and sister Kristi for their continual support, patience, and encouragement, especially during the most discouraging times. You are all core pieces to any success I have enjoyed, and without you I never would have survived graduate school. I would also like to thank Kent, Jill, and PJ Shillings for their kind hospitality during my stay in Texas. Finally, I would like to acknowledge the countless friends I made in College Station, who made my stay at Aggieland some of the best and 
most memorable years of my life. These lifelong friends are too many to name, but I would like to acknowledge a few in particular - Chrissy and Jeff Powell, Abby and Kevin Walter, and Dan Hawblitzel, who grew into family during my years at A\&M. 


\section{TABLE OF CONTENTS}

Page

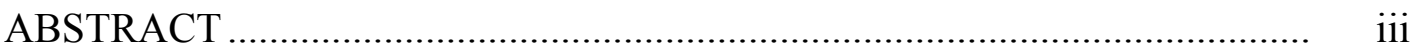

ACKNOWLEDGMENTS .......................................................................

TABLE OF CONTENTS .................................................................. vii

LIST OF FIGURES .........................................................................

LIST OF TABLES …................................................................................ xix

\section{CHAPTER}

I INTRODUCTION ........................................................... 1

II $\quad$ MOTIVATION ............................................................... 7

a. Frequency and preferred location of positive severe storm occurrence

b. Effects of the local mesoscale environment on $\mathrm{CG}$ lightning behavior........................................................ 10

c. Common characteristics of positive severe storms.............. 17

d. Hypothesis ................................................................... 21

III $\quad$ BACKGROUND ............................................................ 23

a. Thunderstorm electrification ........................................ 23

1) Charging mechanisms and typical charge structure ... 23

2) Cloud-to-ground lightning flash ............................. 27

3) Charge structure associated with positive $\mathrm{CG}$ lightning

b. Effects of updraft intensity on cloud thermodynamics and microphysics............................................................ 38

c. Updraft intensity ............................................................. 41

1) Parcel theory and its deficiencies .............................. 42

2) Observed effects of updraft intensity on $C G$ lightning polarity ................................................ 55

d. Warm cloud depth ........................................................ 56

e. Aerosol effects ........................................................... 58 
CHAPTER Page

IV DATA AND METHODOLOGY .............................................. 60

a. Cloud-to-ground lightning data ........................................... 60

b. Meteorological data ......................................................... 62

c. Analysis of storm structure, morphology, and intensity...... 63

d. Characterization of the mesoscale environment with

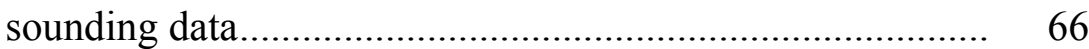

1) Sounding platforms ……………………………... 66

2) Proximity soundings ............................................... 68

3) Calculation of meteorological parameters .................. 71

4) Assessment of the mesoscale environment using sounding data ......................................................... 74

5) Statistical analysis of environmental parameters ....... 79

6) Analysis of dropsonde runs ...................................... 82

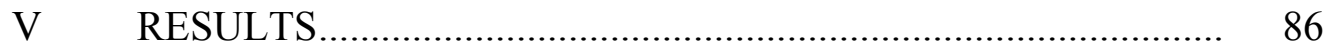

a. Cloud-to-ground lightning characteristics ............................ 86

b. Meteorological scenarios................................................... 100

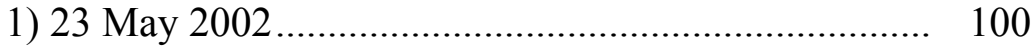

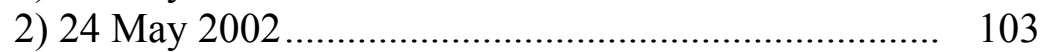

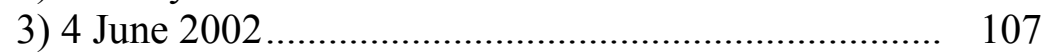

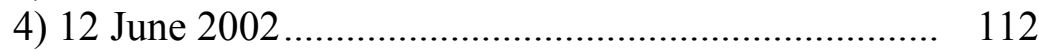

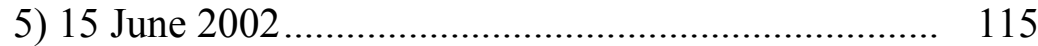

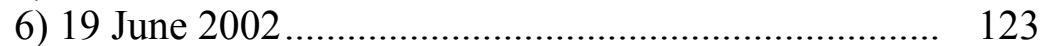

c. Storm structure, morphology, and intensity ........................ 128

1) 23 May 2002 ................................................... 128

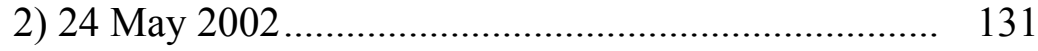

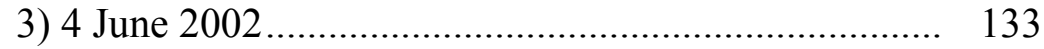

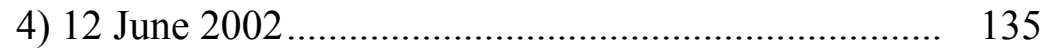

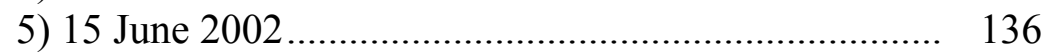

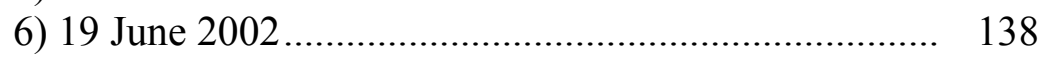

7) Storm intensity determined from radar analysis........ 139

8) Summary................................................................ 150

d. Mesoscale environmental properties of positive and negative storms................................................................ 151

1) Overall grouped comparisons....................................... 151

2) Regional comparisons …………………................... 173

3) Intraregional variation of environmental conditions .. 182 
$\begin{array}{lll}\text { CHAPTER Page } & \text { Par }\end{array}$

VI DISCUSSION _................................................................ 201

a. Large supercooled water contents in high-based severe storms: An apparent paradox......................................... 203

b. The relative roles of the various environmental factors in controlling CG lightning polarity ................................... 207

c. Environmental control of supercell type, large hail production, and CG lightning polarity: A comparison of results....................................................................... 210

d. Tornadoes, CG lightning polarity reversals, and the LCL ... 215

e. Secondary effects of updraft intensity on CG lightning polarity....................................................................... 216

f. Correlation between CAPE and other parameters .............. 218

VII CONCLUSIONS AND FUTURE WORK ............................... 221

REFERENCES .......................................................................... 226

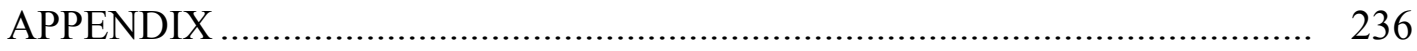

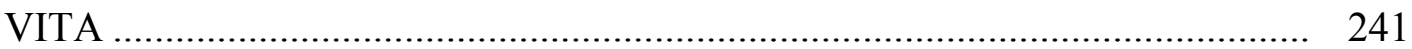




\section{LIST OF FIGURES}

FIGURE

Page

1 Percentage of severe storm reports associated with $>25 \%$ positive CG lightning during the warm season (April-September) from 1989-1998

2 Percentage of severe storm reports associated with $>50 \%$ positive CG lightning......

3 Conceptual model of CG lightning polarity as a function of location with respect to a near-surface $\theta_{\mathrm{e}}$ ridge.

4 Climatological values of (a) $\mathrm{CBH}$ and (b) wet bulb potential temperature $\left(\theta_{\mathrm{w}}\right)$ at noontime in July.

5 Charge transfer by collision in the NIC mechanism of cloud electrification.

6 Schematic of the basic charge structure in the convective region of a thunderstorm

$7 \quad$ Schematic diagrams illustrating the polarity of charge acquired by the rimer (graupel and hail) via the NIC mechanism as a function of cloud temperature and LWC.

8 Effect of vertical accelerations induced by parcel buoyancy on the pressure field.....

9 Illustration indicating that updraft diameter scales with $\mathrm{CBH}$ (heights in meters)

10 Schematic depiction of how a typical vortex tube contained within (westerly) environmental shear is deformed as it interacts with a convective cell (viewed from the southeast).

11 Schematic diagram illustrating the pressure and vertical vorticity perturbations arising as an updraft interacts with environmental vertical wind shear that (a) does not change direction with height and (b) turns clockwise with height

12 Schematic diagram showing how a buoyant updraft may be influenced by vertical wind shear and/or a cold pool. 
13 Illustration showing the effect of WCD on the amount of cloud water available to the mixed-phase region

14 Percentage of positive flashes (\%) for 1800 UTC 23 May 20020300 UTC 24 May 2002.

15 Total CG flash density (flashes $\mathrm{km}^{-2}$ year $^{-1}$ ) for 1800 UTC 23 May 2002-0300 UTC 24 May 2002.

16 Same as in Fig. 14 except for 2000 UTC 24 May 2002-0400 UTC 25 May 2002

17 Same as in Fig. 15 except for 2000 UTC 24 May 2002-0400 UTC 25 May 2002

18 Same as in Fig. 14 except for 1200 UTC 4 June 2002-0100 UTC 5 June 2002

19 Same as in Fig. 15 except for 1200 UTC 4 June 2002-0100 UTC 5 June $2002 .$.

20 Same as in Fig. 14 except for 2000 UTC 12 June 2002-0400 UTC 13 June 2002

21 Same as in Fig. 15 except for 2000 UTC 12 June 2002-0400 UTC 13 June 2002

22 Same as in Fig. 14 except for 1800 UTC 15 June 2002-0300 UTC 16 June 2002

23 Same as in Fig. 15 except for 1800 UTC 15 June 2002-0300 UTC 16 June 2002

24 Same as in Fig. 14 except for 1800 UTC 19 June 2002-0300 UTC 20 June 2002

25 Same as in Fig. 15 except for 1800 UTC 19 June 2002-0300 UTC 20 June 2002

$26250 \mathrm{hPa}$ analysis for $00 \mathrm{UTC} 24$ May 2002 101

$27850 \mathrm{hPa}$ analysis for 00 UTC 24 May 2002 102 
FIGURE Page

28 Surface observations and manual analysis for 22 UTC 23 May

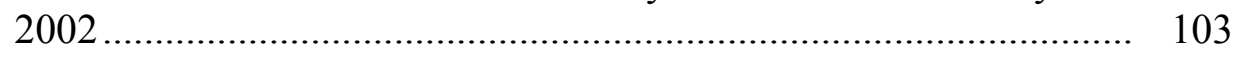

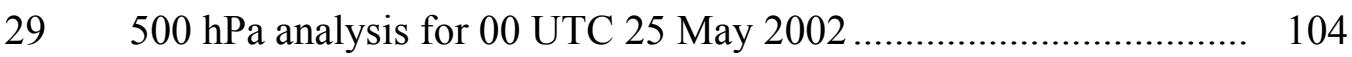

30 Surface observations and manual analysis for 20 UTC 24 May

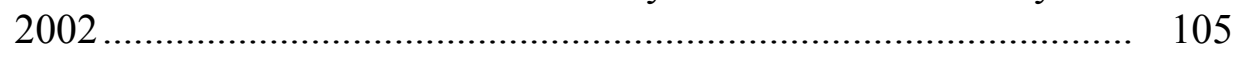

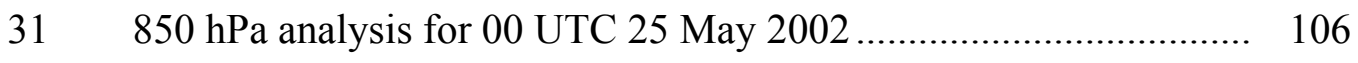

32 Analysis of CAPE (J/kg; shaded) and CIN (values $\geq 50 \mathrm{~J} / \mathrm{kg}$ and $\geq 100 \mathrm{~J} / \mathrm{kg}$ hatched) at $21 \mathrm{UTC} 24$ May 2002 from the FSL RUC model with $10-\mathrm{km}$ resolution .................................................... 107

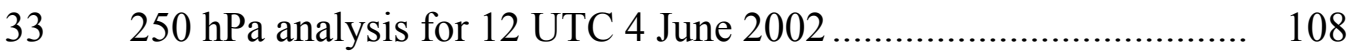

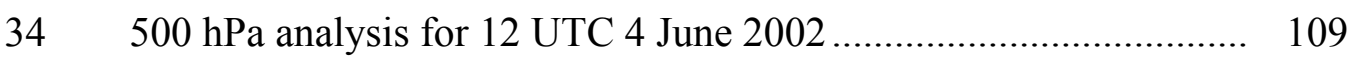

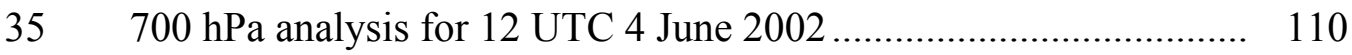

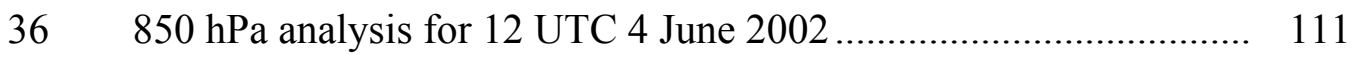

37 Surface observations and manual analysis for 15 UTC 4 June

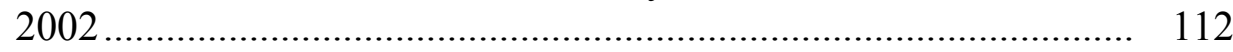

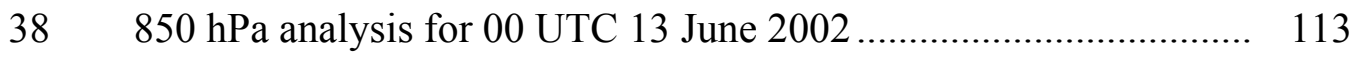

39 Surface observations and manual analysis for 21 UTC 12 June

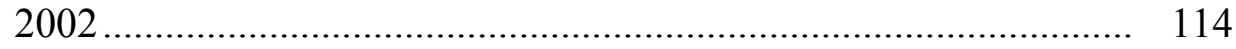

40 Visible satellite image from 2103 UTC 12 June 2002 ................... 115

41 Surface observations and manual analysis for 17 UTC 15 June

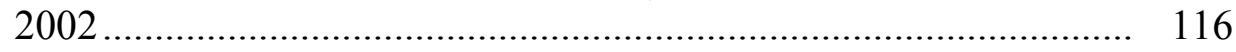

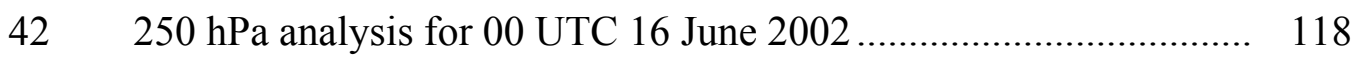

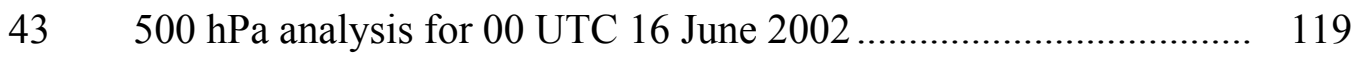

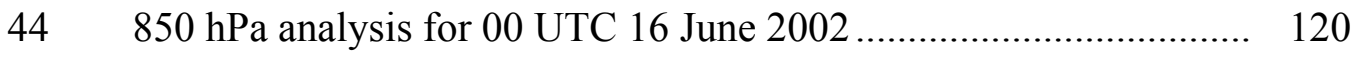


45 Analysis of CAPE (J/kg; shaded) and CIN (values $\geq 50 \mathrm{~J} / \mathrm{kg}$ and $\geq 100 \mathrm{~J} / \mathrm{kg}$ hatched) at 21 UTC 15 June 2002 from the FSL RUC model with $10-\mathrm{km}$ resolution

46 Surface observations and manual analysis for 20 UTC 15 June 2002

47 Visible satellite image from 1955 UTC 15 June 2002

$48 \quad 700 \mathrm{hPa}$ analysis for $00 \mathrm{UTC} 20$ June 2002

$49850 \mathrm{hPa}$ analysis for 00 UTC 20 June 2002 125

50 Analysis of CAPE (J/kg; shaded) and CIN (values $\geq 50 \mathrm{~J} / \mathrm{kg}$ and $\geq 100 \mathrm{~J} / \mathrm{kg}$ hatched) at $21 \mathrm{UTC} 19$ June 2002 from the FSL RUC model with $10-\mathrm{km}$ resolution

51 Surface observations and manual analysis for 21 UTC 19 June 2002

52 Visible satellite image from 2103 UTC 19 June 2002 128

53 WSI NOWRAD mosaic of low-level WSR-88D radar reflectivity over the IHOP_2002 domain at 22 UTC 23 May 2002

54 Low-level WSR-88D radar reflectivity from KAMA (Amarillo, TX) WSR-88D site at 0136 UTC 24 May 2002

55 Same as Fig. 53 except for 23 UTC 24 May 2002 132

56 Same as Fig. 53 except for 01 UTC 25 May 2002 132

57 Same as Fig. 53 except for 18 UTC 4 June 2002 134

$58 \quad$ Same as Fig. 53 except for 22 UTC 4 June 2002 ........................... 134

59 Same as Fig. 53 except for 00 UTC 13 June 2002 ........................ 135

$60 \quad$ Same as Fig. 53 except for 03 UTC 13 June 2002 ........................ 136

61 Same as Fig. 53 except for 22 UTC 15 June 2002 ....................... 137 
$\begin{array}{lll}\text { FIGURE Page } & \end{array}$

62 Same as Fig. 53 except for 02 UTC 16 June 2002 .......................... 138

63 Same as Fig. 53 except for 00 UTC 20 June 2002 ......................... 139

64 (a) $0.5^{\circ}$ radar reflectivity and (b) vertical cross-section of radar reflectivity along the white line depicted in (a) at 0116 UTC 24 May 2002 of a positive HP supercell storm in the 23 May positive mesoscale region

65 (a) $0.5^{\circ}$ radar reflectivity and (b) vertical cross-section of radar reflectivity along the white line depicted in (a) at 0327 UTC 24 May 2002 of a second positive HP supercell storm in the 23 May positive mesoscale region.

66 (a) $0.5^{\circ}$ radar reflectivity of two supercells embedded within a squall line in the 24 May positive mesoscale region at 2321 UTC 24 May 2002. (b) Vertical cross-section of radar reflectivity along the white line denoted as " $\mathrm{A}$ " in (a). (c) Vertical cross-section of radar reflectivity along the white line denoted as " $\mathrm{B}$ " in (a).............

67 (a) $0.5^{\circ}$ radar reflectivity and (b) vertical cross-section of radar reflectivity along the white line depicted in (a) at 1848 UTC 15 June 2002 of an intense ordinary multicell storm in the 15 June positive mesoscale region.

68 (a) $0.5^{\circ}$ radar reflectivity and (b) vertical cross-section of radar reflectivity along the white line depicted in (a) at 2003 UTC 15 June 2002 of a line of ordinary multicell convection in the 15 June positive mesoscale region

69 (a) $0.5^{\circ}$ radar reflectivity and (b) vertical cross-section of radar reflectivity along the white line depicted in (a) at 2222 UTC 19 June 2002 of an ordinary multicell storm in the 19 June positive mesoscale region

70 (a) $0.5^{\circ}$ radar reflectivity and (b) vertical cross-section of radar reflectivity along the white line depicted in (a) at 0028 UTC 20 June 2002 of another ordinary multicell storm in the 19 June positive mesoscale region. 
FIGURE Page

71 (a) $0.5^{\circ}$ radar reflectivity and (b) vertical cross-section of radar reflectivity along the white line depicted in (a) at 0027 UTC 25 May 2002 of an ordinary multicell storm in the 24 May negative mesoscale region

72 (a) $0.5^{\circ}$ radar reflectivity and (b) vertical cross-section of radar reflectivity along the white line depicted in (a) at 1346 UTC 4 June 2002 of an ordinary multicell storm in the 4 June negative mesoscale region

73 (a) $0.5^{\circ}$ radar reflectivity and (b) vertical cross-section of radar reflectivity along the white line depicted in (a) at 1411 UTC 4 June 2002 of the same ordinary multicell storm as shown in Fig. 72

74 (a) $0.5^{\circ}$ radar reflectivity of a supercell splitting into left- and right-moving supercells at 2229 UTC 12 June 2002 in the 12 June negative mesoscale region. (b) Radar reflectivity vertical cross-section through the right-moving supercell, along the white line denoted as " $A$ " in (a). (c) Radar reflectivity vertical cross-section through the right-moving supercell, along the white line denoted as " $\mathrm{B}$ " in (a).

75 (a) $0.5^{\circ}$ radar reflectivity and (b) vertical cross-section of radar reflectivity along the white line depicted in (a) at 0011 UTC 13 June 2002 of an HP supercell in the 12 June negative mesoscale region

76 (a) $0.5^{\circ}$ radar reflectivity and (b) vertical cross-section of radar reflectivity along the white line depicted in (a) at 2032 UTC 15 June 2002 of a supercell in the 15 June negative mesoscale region

77 Relative frequency histogram for LCL

160

78 Same as in Fig. 77 except for WCD

79 Same as in Fig. 77 except for surface dewpoint depression 162

80 Same as in Fig. 77 except for mean mixing ratio in the lowest 100 $\mathrm{hPa}$ 
FIGURE Page

81 Same as in Fig. 77 except for precipitable water between the

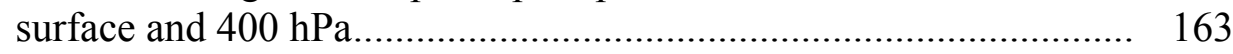

82 Same as in Fig. 77 except for low-level (0-3 km AGL) vertical wind shear ............................................................................ 163

83 Same as in Fig. 77 except for 0-2 km AGL storm-relative wind speed ............................................................................. 164

84 Same as in Fig. 77 except for $850-500 \mathrm{hPa}$ lapse rate.................. 166

85 Same as in Fig. 77 except for CAPE between the $-10^{\circ} \mathrm{C}$ and $-40^{\circ} \mathrm{C}$ levels.......................................................................... 166

86 Same as in Fig. 77 except for NCAPE between the LFC and $-40^{\circ} \mathrm{C}$ level ........................................................................... 167

87 Same as in Fig. 77 except for NCAPE between the $-10^{\circ} \mathrm{C}$ and $-40^{\circ} \mathrm{C}$ levels

88 Same as in Fig. 77 except for NCAPE between the LFC and EL (total NCAPE)

89 Same as in Fig. 77 except for CAPE between the LFC and EL (total CAPE)

90 Same as in Fig. 77 except for deep-layer (0-6 km AGL) vertical wind shear

91 Same as in Fig. 77 except for equivalent potential temperature $\left(\theta_{\mathrm{e}}\right)$ 170

92 Same as in Fig. 77 except for adiabatic LWC between the LCL and $0^{\circ} \mathrm{C}$ level

93 Same as in Fig. 77 except for the difference in adiabatic LWC between the $0^{\circ} \mathrm{C}$ and $-40^{\circ} \mathrm{C}$ levels

94 Median LCL values for the nine individual mesoscale regions ....... 176

95 Median WCD values for the nine individual mesoscale regions ..... 176 
FIGURE Page

96 Scatter plot of the median NCAPE between the LFC and $-40^{\circ} \mathrm{C}$ level versus the median LCL height for each of the nine mesoscale regions. The size of each bubble in the scatter plot is proportional to the median 0-3 km AGL shear magnitude in each region, which is indicated by the label on each bubble

97 Same as in Fig. 96 except for median 850-500 hPa lapse rate versus median WCD for each individual mesoscale region. As in Fig. 96, bubble size and labels represent median 0-3 km AGL shear for each region.

98 Visible satellite images in the vicinity of dropsondes released by the Learjet on (a) 24 May 2002 and (b) 19 June 2002

99 Percent positive flashes (\%) for 2000 UTC 24 May 2002-0200 UTC 25 May 2002.

100 Percent positive flashes (\%) for 1800 UTC 19 June 2002-0300 UTC 20 June 2002

101 NCAPE and low-level (0-3 km AGL) shear calculated from the 24 May 2002 dropsondes as a function of distance along the Learjet flight track

102 Same as in Fig. 101 except for WCD, LCL, freezing level, and 850-575 $\mathrm{hPa}$ lapse rate 188

103 Same as in Fig. 101 except for the 19 June 2002 dropsondes

104 Same as in Fig. 103 except for WCD, LCL, freezing level, and $850-500 \mathrm{hPa}$ lapse rate

105 Vertical cross-section of buoyancy (B) calculated from the dropsonde data as a function of horizontal distance along the Learjet flight track on 24 May 2002

106 Same as in Fig. 105 except for horizontal buoyancy gradient $(\mathrm{dB} / \mathrm{dH})$ on 24 May 2002, rather than buoyancy (B)

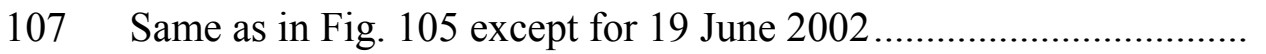

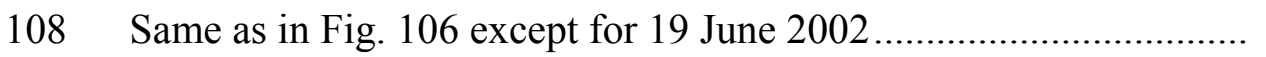


FIGURE Page

109 Scatter plot of total CAPE (LFC to EL) versus low-level equivalent potential temperature $\left(\theta_{\mathrm{e}}\right)$ for individual soundings within negative (blue) and positive (red) mesoscale regions .......... 237

110 Same as in Fig. 109 except for total CAPE (LFC to EL) versus mean mixing ratio in the lowest $100 \mathrm{hPa}$ 238

111 Same as in Fig. 109 except for total CAPE (LFC to EL) versus mean temperature in the lowest $100 \mathrm{hPa}$ 


\section{LIST OF TABLES}

TABLE

Page

1 Total number of soundings used to characterize each mesoscale region, and the numbers of these soundings which were full and truncated

2 List of parameters investigated using sounding data, along with the respective acronym used to refer to each parameter (if any) in this study

3 Characterization of mesoscale regions within the IHOP_2002 domain

4 Description of storm type and severity within each mesoscale region.

5 Mean (median) environmental properties of grouped negative and positive mesoscale regions. The number of soundings in each negative $(\mathrm{N}-)$ and positive $(\mathrm{N}+)$ parameter sample is also shown. For each parameter, the statistical significance level of the difference in means according to the Student's $t$ test was very highly significant $(99.9 \%$ level, $\mathrm{p} \leq 0.001)$.

6 Same as Table 5 except the difference in each mean environmental parameter was highly significant $(99 \%$ level, $0.001<\mathrm{p} \leq 0.01) \ldots \ldots .$.

$7 \quad$ Same as Table 5 except the difference in each mean environmental parameter was significant $(95 \%$ level, $0.01<\mathrm{p} \leq 0.05)$.

8 Same as Table 5 except the difference in each mean environmental parameter was insignificant at the $95 \%$ level but significant at the $90 \%$ level $(0.05<\mathrm{p} \leq 0.1)$

9 Same as Table 5 except the difference in each mean environmental parameter was insignificant at the $90 \%$ level $(\mathrm{p}>0.1)$

10 Median parameter values for the nine individual mesoscale regions investigated 


\section{CHAPTER I}

\section{INTRODUCTION}

The great majority of cloud-to-ground (CG) lightning flashes worldwide lower negative charge to ground (negative CG flashes) (MacGorman and Rust 1998; Rakov and Uman 2003). In a study of CG lightning across the continental United States (U.S.) during the first decade (1989-98) of operation of the National Lightning Detection Network (NLDN), Orville and Huffines (2001) found the annual percentage of lightning lowering positive charge to ground (positive CG flashes) to be less than $10 \%$. Although most CG lightning flashes are negative, certain types, stages, and regions of storms tend to produce high percentages of positive CG flashes. This enhanced positive CG flash production tends to be associated with one of the following situations: (1) with some winter storms, (2) with the stratiform precipitation region of mesoscale convective systems (MCSs), (3) with some relatively shallow thunderstorms of any type, including isolated thunderstorms, the convective region of squall lines, and rainbands, (4) with some severe storms, and (5) during the dissipating stage of many isolated storms (MacGorman and Rust 1998). This study focuses on positive CG flash production by severe convective storms during the warm season. Unlike most other types of storms in which positive CG flashes occur, severe storms can have positive CG flash rates and densities comparable to those typically observed for negative CG flashes in active thunderstorms (MacGorman and Burgess 1994; Stolzenburg 1994).

This thesis follows the style of Monthly Weather Review. 
The National Weather Service (NWS) classifies a convective storm as "severe" if it produces any of the following at the ground: a tornado, wind $\geq 26 \mathrm{~m} \mathrm{~s}^{-1}$, or hail with a diameter $\geq 1.9 \mathrm{~cm}$ (e.g., Johns and Doswell 1992). Severe storms are of great interest to the meteorological community from both a scientific standpoint, as the desire exists to understand the complex processes driving these impressive phenomena, as well as from a practical standpoint, as severe storms pose a great threat to life and property. Hence an improved ability to forecast severe storms can help prevent the devastation they often cause. Positive CG flashes produced by severe storms were first documented by Rust et al. (1981a,b). Since this time, numerous other studies have recognized the occurrence of positive CG flashes with severe storms (e.g., Rust et al. 1985; Reap and MacGorman 1989; MacGorman and Nielsen 1991; Curran and Rust 1992; Branick and Doswell 1992; Seimon 1993; Knapp 1994; MacGorman and Burgess 1994; Stolzenburg 1994; Perez et al. 1997; Bluestein and MacGorman 1998; Carey and Rutledge 1998; Smith et al. 2000; Gilmore and Wicker 2002; Lang and Rutledge 2002; Carey and Rutledge 2003; Carey et al. 2003a; Carey et al. 2003b; Lang et al. 2004; MacGorman et al. 2005; Wiens et al. 2005).

In a climatological study of thunderstorms occurring over the Great Plains of the United States during the 1985-86 warm seasons, Reap and MacGorman (1989) determined that the probability of severe weather increased rapidly as positive CG flash density increased. In agreement with this, MacGorman and Burgess (1994) noted that although many severe storms are dominated by negative CG flashes, severe storms constitute a small fraction of storms dominated by frequent negative CG flashes, but 
appear to constitute an overwhelming majority of storms dominated by frequent positive CG flashes. Carey and Rutledge (2003) found this notion to be true across a significant portion of the central U.S. In a region stretching from the Colorado/Kansas border northeastward to Minnesota, up to $30 \%-70 \%$ of warm season positive CG flashes in the ten year period from 1989-98 were associated with severe storms. Meanwhile, only $2 \%-$ $30 \%$ of warm season negative CG flashes in this region were associated with severe storms. This trend was not as pronounced farther to the south across Oklahoma and northern Texas, but still a significant fraction (20\%-50\%) of warm season positive CG flashes were associated with severe storms across this region (Carey and Rutledge 2003). The overwhelming majority of severe storms throughout the contiguous U.S. generate primarily ( $\geq 75 \%$ ) negative CG flashes (so-called negative storms). However, a certain subset of severe storms produces an anomalously high (>25\%) percentage of positive CG flashes (so-called positive storms). The frequency of these "anomalous" positive severe storms varies regionally and seasonally. While positive severe storms are atypical in the eastern region of the U.S. during the warm season, they are quite common in the northern and central plains during this time, where $30 \%-90 \%$ of all severe storms are positive storms (Fig. 1). Across the southern plains, positive severe storms are not (are) uncommon during the spring (summer) months (Carey et al. 2003b). 


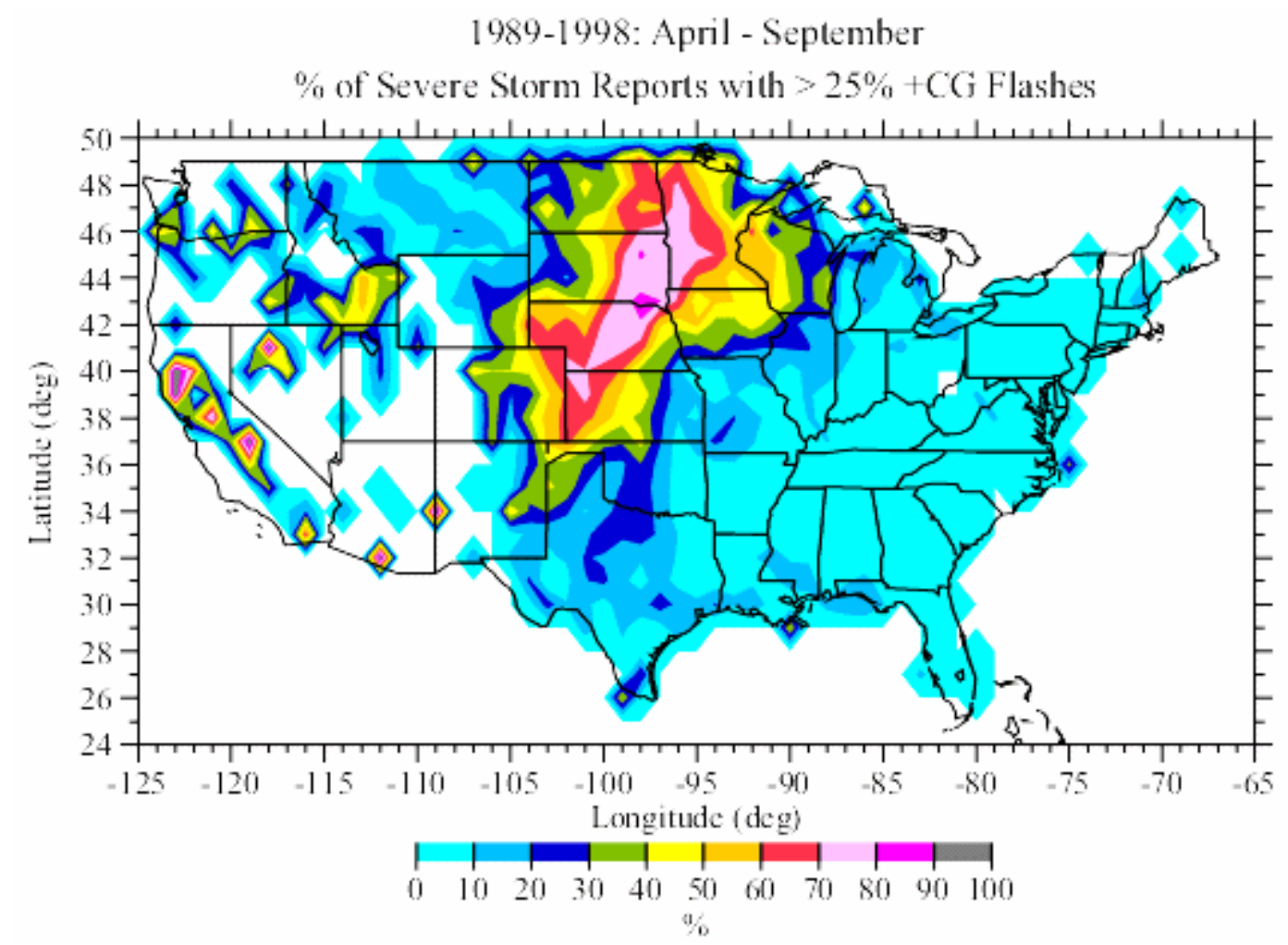

FIG. 1. Percentage of severe storm reports associated with $>25 \%$ positive CG lightning during the warm season (April-September) from 1989-1998. From Carey et al. (2003b).

The possible relationship between positive CG flashes and severe storms suggests that real-time CG lightning flash data available to forecasters through the NLDN may be useful in the short-term prediction of severe weather (Carey et al. 2003b). However, before such a nowcasting tool can be implemented, a better understanding of the relationship between the mesoscale environment, storm intensity and severity, and CG lightning polarity is necessary. Reliable nowcasting of severe weather based on positive CG flash production is not yet possible, as many severe storms are negative storms and not all positive storms are severe. Indeed, several studies have documented severe storms in which negative CG flashes were dominant (e.g., Curran and Rust 1992; 
Branick and Doswell 1992; Bluestein and MacGorman 1998). Thus, although there appears to be a relationship between increased positive $\mathrm{CG}$ lightning production and severe storms, Branick and Doswell (1992) point out that the relationship is only a general one. Not all severe storms produce elevated positive CG flash percentages, and not all storms with high positive CG flash percentages are severe (e.g., Lang et al. 2004). Branick and Doswell (1992) make the important point that "before we can use lightning polarity data effectively in warning operations, we must learn why only some severe storms produce high positive CG rates, and, in particular, which storms." MacGorman and Burgess (1994) echo this concern, stating that "before forecasters can use positive cloud-to-ground lightning to help diagnose severe weather in these cases, research is needed to determine systematically under what conditions positive ground flashes occur in severe storms." This study seeks to clear up much of the uncertainty with this issue by investigating the relationship between positive severe storms and the immediate meteorological environment in which they occur, thereby providing further insight into why only some severe storms are positive storms, and in particular, what conditions lead to this enhanced production of positive CG flashes. A determination of whether environmental conditions are systematically related to positive CG flash production by severe storms, and if so, what these conditions are, is a crucial step in determining the reliability of using NLDN real-time flash polarity data for nowcasting. Furthermore, determining the relationship between certain environmental conditions and positive severe storms will lead to an improved understanding of the cloud electrification mechanisms at work in these storms, which remains speculative at this time (e.g., 
MacGorman and Nielsen 1991; MacGorman and Burgess 1994; Carey and Rutledge 1998; Smith et al. 2000; Williams 2001; Gilmore and Wicker 2002; Lang and Rutledge 2002; Carey et al. 2003a; Carey et al. 2003b; Lang et al. 2004; MacGorman et al. 2005; Wiens et al. 2005).

Using data from the International $\mathrm{H}_{2} \mathrm{O}$ Project (IHOP_2002), this study explores the relationship between the local mesoscale environment and CG lightning behavior of severe storms. IHOP_2002 was conducted from 13 May to 25 June 2002 across the Southern Great Plains (Kansas, Oklahoma, and the Texas panhandle). The main goal of IHOP_2002 was to obtain more accurate and reliable measurements of moisture in the air, in an attempt to improve quantitative precipitation forecasts and increase understanding of convective initiation (Weckwerth et al. 2004). Thus, detailed measurements of the mesoscale environment in both the horizontal and vertical were obtained. Although the focus of this study differs from that of IHOP_2002, the detailed measurements obtained during IHOP_2002 can be used in the present study to help assess the relationship between the local mesoscale environment and positive severe storms. Of particular interest to this study is the multitude of environmental soundings taken during IHOP_2002, which provides a unique opportunity to investigate the meteorological conditions, both in the horizontal and vertical, associated with positive severe storms. 


\section{CHAPTER II}

\section{MOTIVATION}

Positive storms have been the topic of much interest in recent years for two primary reasons. First, the possible relationship between severe weather and positive storms suggests that CG lightning polarity may be a useful nowcasting tool for severe weather, if a better understanding of this relationship can be attained (e.g., Branick and Doswell 1992; Knapp 1994; MacGorman and Burgess 1994; Perez et al. 1997; Carey et al. 2003b). In addition, a great desire exists to learn why some severe storms produce an anomalously high percentage of positive CG flashes. In other words, what dynamical and microphysical processes are responsible for the generation of this anomalously high percentage of positive CG flashes by some severe storms? Rust et al. (1985) were first to note that positive CG flashes sometimes dominated ${ }^{1}$ the $\mathrm{CG}$ flash activity in severe storms. This anomalous CG lightning behavior has since motivated many studies seeking to determine: (a) how unusual these severe storms characterized by an anomalously large percentage of positive CG lightning really are, and (b) what causes this anomalous behavior.

\section{a. Frequency and preferred location of positive severe storm occurrence}

As more attention was devoted to positive severe storms, it was revealed that at least in some locations, such storms were perhaps not as rare as initially thought, as

\footnotetext{
${ }^{1}$ The dominance by positive (negative) CG flashes implies greater than $50 \%$ positive (negative) $\mathrm{CG}$ flashes. Positive CG flash-dominant storms (or storms with predominantly positive CG lightning) are therefore a subset of the positive storm category defined in Chapter I. However, as defined, storms dominated by negative CG flashes are not necessarily negative storms.
} 
indicated by their fairly frequent documentation by several of the early studies (e.g., Reap and MacGorman 1989; MacGorman and Nielsen 1991; Curran and Rust 1992; Branick and Doswell 1992; Seimon 1993) on this topic. Interestingly, the storms documented and investigated by these studies all occurred over the Great Plains. Looking at CG lightning data across the entire U.S. during two months of the warm season (June and July 1989), Stolzenburg (1994) noted that "there is a surprisingly large number of summertime thunderstorms that produce exclusively or predominantly positive CG lightning," all of which occurred over the Great Plains. Knapp (1994) investigated the CG lightning characteristics of 264 tornadic thunderstorms that occurred east of the Continental Divide during the spring of 1991. Of the 264 tornadic storms investigated, $62(23 \%)$ produced at least $30 \%$ positive $\mathrm{CG}$ flashes. These positive storms occurred primarily across the central and northern plains, with all but one occurrence located west of the Mississippi River.

Greatly expanding upon the results of Knapp (1994), Carey et al. (2003b) studied the CG lightning behavior of storms associated with over 67,000 severe storm reports across the contiguous U.S. during the warm seasons (April-September) of 1989-98. ${ }^{2}$ It was found that the majority $(61 \%)$ of severe storm reports across the contiguous U.S. during the 1989-98 warm seasons were associated with an overwhelmingly large (>90\%) percentage of negative CG lightning, while only $15 \%$ of severe storm reports were associated with predominantly positive CG (PPCG) lightning. However, significant regional and seasonal variability existed in the occurrence of storms with PPCG

\footnotetext{
${ }^{2}$ Only severe storm reports of large hail (diameter $\geq 1.9 \mathrm{~cm}$ ) and tornadoes were investigated (i.e., severe storm reports of straight-line winds were not studied).
} 
lightning. Similar to the results of Knapp (1994), Carey et al. (2003b) found the overwhelming majority of severe storms with PPCG lightning to be located east of the Rocky Mountains and west of the Mississippi River. This also agrees with the locations of nearly all severe storms characterized by anomalous positive CG lightning activity upon which past case studies have focused (e.g., Curran and Rust 1992; Branick and Doswell 1992; Seimon 1993; MacGorman and Burgess 1994; Stolzenburg 1994; Bluestein and MacGorman 1998; Gilmore and Wicker 2002; Carey et al. 2003a). Dividing the contiguous U.S. east of the Continental Divide into regions, Carey et al. (2003b) determined the percentage of severe storms characterized by PPCG lightning to be $2 \%$ across the eastern U.S., $11 \%$ across the southern plains, $35 \%$ across the central plains, and $43 \%$ across the northern plains (Fig. 2). Within the southern plains region, the Texas and Oklahoma panhandles were an exception, with $15 \%-40 \%$ of severe storms in these locations associated with PPCG lightning. Also, it was found that severe storms producing PPCG lightning were not uncommon over the southern plains during the spring months, but were uncommon during the summer months. Across the Great Plains region, which Carey et al. (2003b) defined as the combination of the southern, central, and northern plains regions, $26 \%$ of severe storms produced PPCG lightning. Based on the results of Carey et al. (2003b), Knapp (1994), and many case studies, it is apparent that although positive severe storms are atypical across the contiguous U.S. as a whole, these phenomena are actually fairly common across much of the Great Plains region during the warm season. 


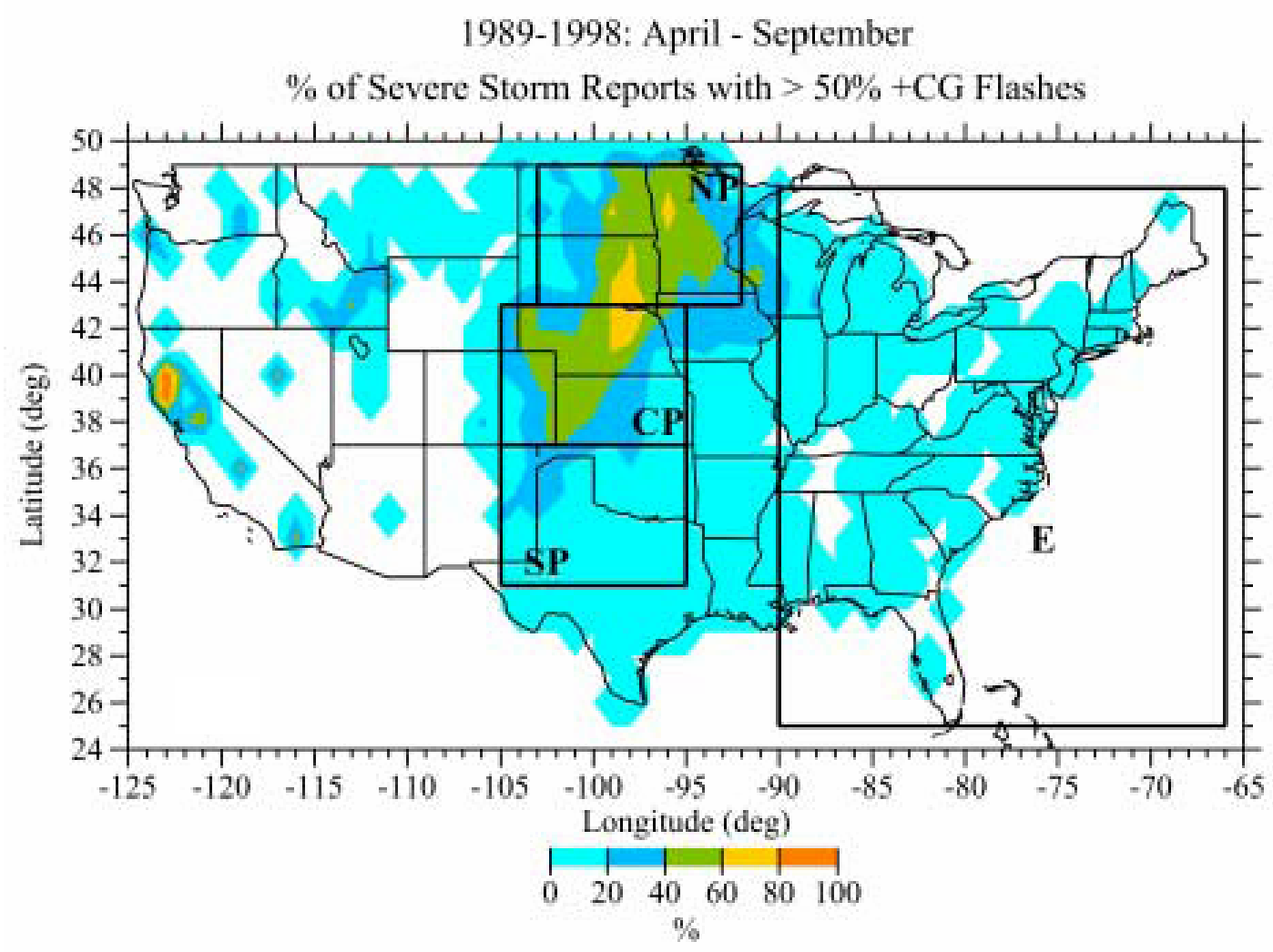

FIG. 2. Percentage of severe storm reports associated with $>50 \%$ positive CG lightning. Regions (NP, northern plains; CP, central plains; SP, southern plains; E, eastern U.S.) defined by Carey et al. (2003b) are also shown. From Carey et al. (2003b).

\section{b. Effects of the local mesoscale environment on CG lightning behavior}

The fact that positive severe storms are not uncommon across much of the Great Plains region during the warm season, but are a rarity across the remainder of the U.S., suggests that such storms may be linked to meteorological conditions that are much more prevalent across the Great Plains than other regions. Several studies have noted that severe storms passing through similar mesoscale regions on a given day tend to exhibit similar CG lightning behavior (Branick and Doswell 1992; MacGorman and Burgess 1994; Smith et al. 2000; Gilmore and Wicker 2002). MacGorman and Burgess 
(1994) were among the first to hypothesize that the dominant polarity of CG lightning is strongly influenced by mesoscale properties of the atmosphere, possibly through systematic effects on other storm properties related to severe weather. In their study of fifteen severe storms that occurred over four different days, MacGorman and Burgess (1994) determined that the geographic region in which positive or negative CG flashes dominated on a given day was consistent from storm to storm. The dominant polarity switched in roughly the same region for sequential storms following similar tracks. This behavior was similar to that noted by Branick and Doswell (1992), in which the tornadic supercell thunderstorms they studied were dominated by positive CG flashes from northern Oklahoma northward into Kansas and Nebraska, while negative CG flashes were dominant in the storms across central and southern Oklahoma.

More recent studies have found further evidence that $\mathrm{CG}$ lightning behavior is strongly influenced by the local mesoscale environment. In a study of three tornadic outbreaks, Smith et al. (2000) found that the majority of thunderstorms whose CG lightning activity was dominated by negative flashes formed in regions of weak nearsurface equivalent potential temperature $\left(\theta_{\mathrm{e}}\right)$ gradient, downstream of a $\theta_{\mathrm{e}}$ maximum (e.g., storm track $\mathrm{C}$ in Fig. 3). The majority of thunderstorms whose initial CG lightning activity was dominated by positive flashes formed in regions of strong $\theta_{\mathrm{e}}$ gradient associated with surface drylines, fronts, or other mesoscale boundaries, upstream of a $\theta_{\mathrm{e}}$ maximum. Some of the initially positive CG flash-dominant storms moved adjacent to the $\theta_{\mathrm{e}}$ maximum (remaining in the $\theta_{\mathrm{e}}$ gradient region) and were dominated by positive CG flashes throughout their lifetimes (e.g., storm track B in Fig. 3). Other initially 


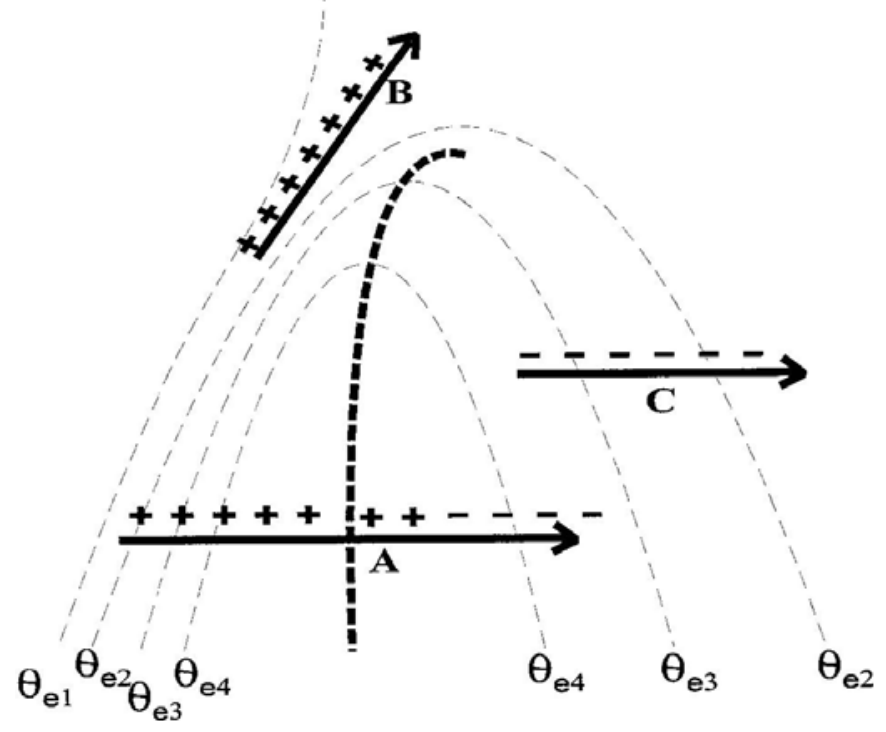

FIG. 3. Conceptual model of CG lightning polarity as a function of location with respect to a near-surface $\theta_{\mathrm{e}}$ ridge. Storm tracks are shown by bold arrows, with predominant CG lightning polarity depicted by plus (minus) signs for positive (negative) CG lightning. Thin dashed lines are contours of near-surface $\theta_{\mathrm{e}}$, where $\theta_{\mathrm{e} 4}$ is a local maximum and $\theta_{\mathrm{e} 1}$ a local minimum. Thick dashed line denotes the $\theta_{\mathrm{e}}$ ridge axis. From Smith et al. (2000).

positive CG flash-dominant storms moved through the $\theta_{\mathrm{e}}$ maximum, and experienced a shift in dominant CG flash polarity from positive to negative after crossing the $\theta_{\mathrm{e}}$ maximum (e.g., storm track A in Fig. 3). A study on climatological temporal and spatial scales by Carey et al. (2003b) revealed similar relationships as found by Smith et al. (2000) relating CG lightning polarity to position of the $\theta_{\mathrm{e}}$ ridge. Carey et al. (2003b) determined that the locations of the monthly frequency maxima of severe storms that produced predominantly positive and predominantly negative CG flashes ${ }^{3}$ were systematically offset with respect to the climatological monthly position of the nearsurface $\theta_{\mathrm{e}}$ ridge on severe weather outbreak days. Severe storms dominated by positive

\footnotetext{
${ }^{3}$ In Carey et al. (2003b), predominantly negative CG lightning storms are defined as producing greater than $90 \%$ negative CG flashes.
} 
CG flashes generally occurred west and northwest of the $\theta_{\mathrm{e}}$ ridge in the upstream $\theta_{\mathrm{e}}$ gradient region. Severe storms dominated by negative CG flashes typically occurred southeast of the PPCG lightning maxima, closer to the axis of the $\theta_{\mathrm{e}}$ ridge, in a weak $\theta_{\mathrm{e}}$ gradient region and in higher mean values of $\theta_{\mathrm{e}}$. As described by Carey et al. (2003b), the subtle shift of their climatological negative CG lightning maximum upstream toward the $\theta_{\mathrm{e}}$ ridge axis compared to its position in Smith et al. (2000) is likely due to a difference in approach between the two studies. While Smith et al. (2000) investigated CG lightning associated with the full lifecycles of severe storms and other storms in the vicinity, Carey et al. (2003b) limited their sample to CG lightning immediately in the vicinity of severe weather. Due to the mesoscale ingredients required for severe weather (e.g., high CAPE, midlevel dry air, low-level convective inhibition (CIN), large low to midlevel shear), severe weather would likely be biased toward the upstream side of the $\theta_{\mathrm{e}}$ ridge. Thus, based on this difference in approach, it is consistent for the climatological negative CG lightning maximum in Carey et al. (2003b) to be shifted upstream relative to its location in the conceptual model of Smith et al. (2000).

Gilmore and Wicker (2002) also found links between the local mesoscale environment and CG lightning behavior. The study by Gilmore and Wicker (2002) was unique in that it had detailed temporal and spatial resolution soundings to characterize the local mesoscale environment in both the horizontal and vertical. The dominant CG lightning polarity of many of the supercells studied by Gilmore and Wicker (2002) switched from negative to positive as the storms crossed a mesoscale outflow boundary dividing warmer, drier air from cooler, moister air. The air mass on the cooler, moister 
side of the boundary where the majority of storms were dominated by positive CG flashes was characterized by enhanced values of convective available potential energy (CAPE), CAPE below the in-cloud freezing level, boundary layer mixing ratio, and lowlevel $(0-3 \mathrm{~km})$ vertical wind shear.

Many other studies have also investigated the relationship between local meteorological conditions and CG lightning behavior. Rust et al. (1985) suggested that perhaps strong deep-layer vertical wind shear was needed for the production of positive CG flashes in severe storms. However, Reap and MacGorman (1989) and Curran and Rust (1992) did not find a relationship between stronger shear and positive CG flash production, leading these authors to conclude that strong deep-layer shear may be a necessary, but not sufficient, condition for the production of positive CG flashes. So while deep-layer shear may contribute to positive CG flash production in some storms, it alone is insufficient to predict the dominant CG flash polarity, indicating that other variables also play a role in determining the dominant polarity. Rust et al. (1985), Reap and MacGorman (1989), and Curran and Rust (1992) compared the heights of temperature levels between the environments of positive and negative CG flashdominant storms, on the basis that perhaps lower heights of the $0^{\circ} \mathrm{C}$ and $-10^{\circ} \mathrm{C}$ temperature levels would reduce the distance between the in-cloud positive charge region and the ground, thereby leading to increased production of positive CG flashes. However, Rust et al. (1985) and Reap and MacGorman (1989) did not find the height of the freezing level to be an important parameter in determining dominant CG flash polarity. Similarly, Curran and Rust (1992) found the heights of the $-10^{\circ} \mathrm{C}$ level to be 
nearly identical between positive and negative CG flash-dominant storms. Knapp (1994), based on his study of 264 tornadic thunderstorms east of the Continental Divide, noted that more (less) positive storms occurred in regions where the atmosphere tends to be less (more) vertically saturated. Williams et al. (2005) suggested that high cloud base heights (CBHs) favor the generation of positive CG flashes, ${ }^{4}$ and noted that the Great Plains region, which harbors the large majority of positive severe storms, is characterized by both high CBHs and large instability (Fig. 4). Of course instability is necessary to support the strong updrafts characteristic of severe storms. Thus, Williams et al. (2005) suggested that it is the overlap of high CBHs and large instability over the Great Plains that makes this region the preferred location for positive severe storms. To the west, CBHs increase but instability decreases. To the east and especially southeast, instability is still often large but CBHs are reduced. The Great Plains region is therefore the only location in which sufficiently high CBHs and sufficiently large instability, both hypothesized to be important for positive CG lightning production, consistently exist during the warm season.

It should be noted that one study (Bluestein and MacGorman 1998) documented severe storms that formed in approximately the same area and traveled across roughly the same region, yet CG lightning behavior differed from storm to storm. This case marks an exception to the many cases described above (e.g., Branick and Doswell 1992; MacGorman and Burgess 1994; Smith et al. 2000; Gilmore and Wicker 2002), in which severe storms passing through similar mesoscale regions on a given day exhibited

\footnotetext{
${ }^{4}$ The physical reasoning for why high CBHs are thought to be favorable for positive CG flash production will be discussed in Chapter III.
} 
(a)

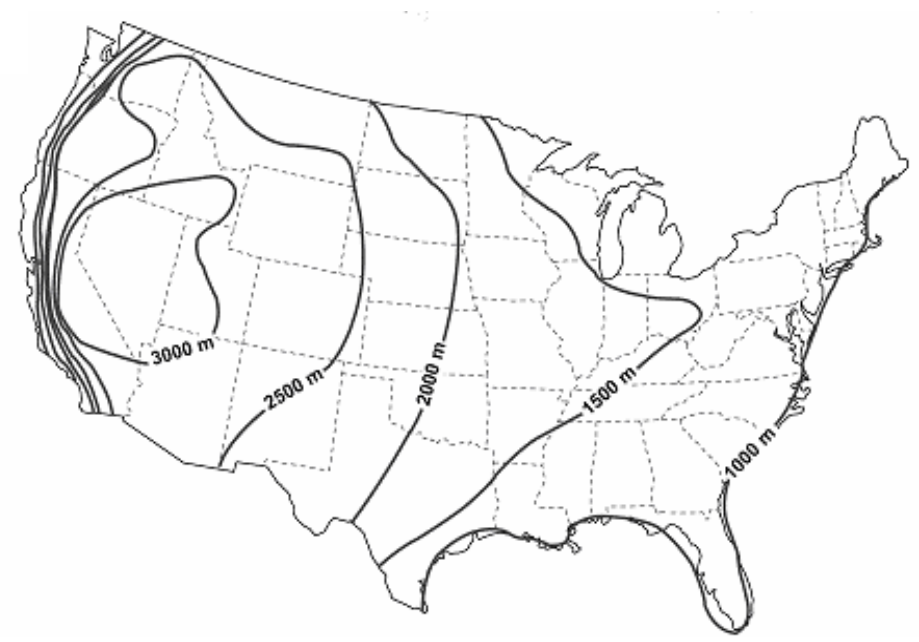

(b)

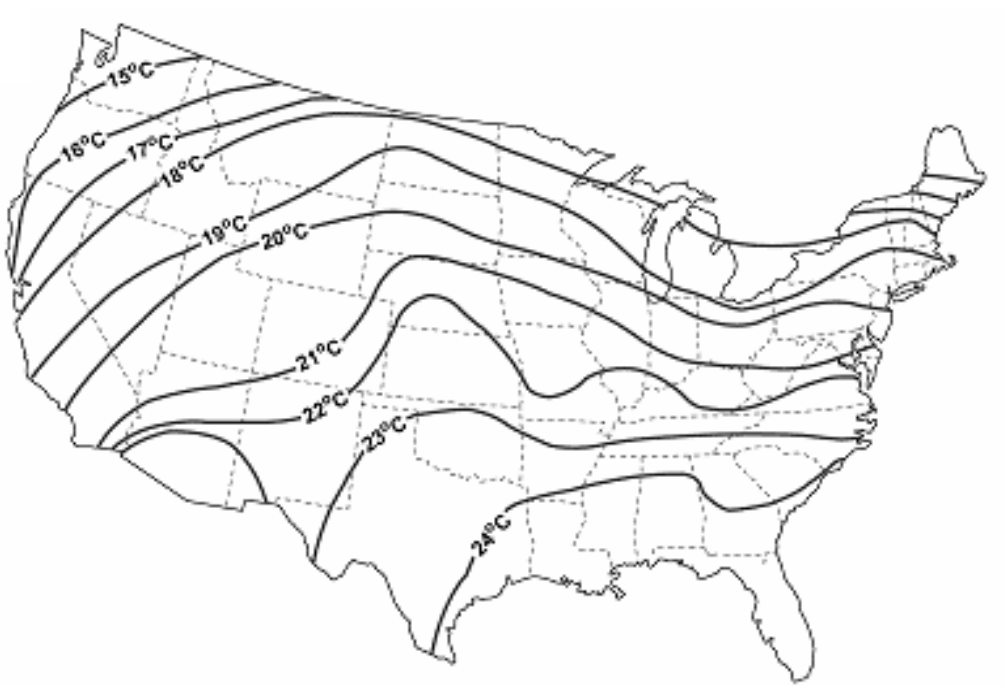

FIG. 4. Climatological values of (a) $\mathrm{CBH}$ and (b) wet bulb potential temperature $\left(\theta_{\mathrm{w}}\right)$ at noontime in July. Values are based on surface station observations of temperature and dewpoint from Albright (1939). $\theta_{\mathrm{w}}$ has been shown to be a good proxy for CAPE (i.e., instability) in the tropical atmosphere by Williams and Renno (1993). From Williams et al. (2005).

similar CG lightning behavior. No positive CG flashes were detected with the first two supercells studied by Bluestein and MacGorman (1998). However, positive CG flashes dominated approximately the first hour of existence of the third and fourth supercells 
during the same day. Even though these four supercells formed in approximately the same area and tracked across the same general region, it is still very possible that changing meteorological conditions with time were responsible for the differences in CG lightning behavior in the mesoscale region of interest. No detailed spatial or temporal resolution sounding data were available for this case, and thus changes in the mesoscale environment between times of occurrence of the subsequent supercells could have easily gone undetected. In fact, the authors did note changes in boundary layer temperature and moisture fields in response to a retreating dryline after dark. So while this case may represent an exception to the often-noted relationship between the local mesoscale environment and CG lightning behavior, it is also possible that changes in the mesoscale environment that could have impacted CG flash behavior simply went undetected. The ability to detect such changes via enhanced spatial and temporal resolution sounding data is one of the driving reasons for using the IHOP_2002 dataset in the present study.

\section{c. Common characteristics of positive severe storms}

Along with the apparent correlation between certain mesoscale environmental conditions and CG lightning polarity, numerous studies have noted a possible relationship between certain storm properties and CG lightning polarity. For instance, many studies have noted that severe storms that produce an anomalously high percentage of positive CG flashes also tend to produce large hail (Reap and MacGorman 1989; Curran and Rust 1992; Seimon 1993; MacGorman and Burgess 1994; Stolzenburg 1994; Gilmore and Wicker 2002; Lang et al. 2004). However, exceptions to this 
tendency exist. No large hail was reported with the fourth supercell studied by Bluestein and MacGorman (1998) when positive ground flashes were dominant. In the severe hailstorm studied by Carey and Rutledge (1998), large hail at the surface preceded the peak in positive CG flash production by tens of minutes. Carey et al. (2003a) found no in situ and little radar evidence for the presence of significant quantities of large hail during the peak positive CG flash production by the Spencer, South Dakota tornadic supercell of 30 May 1998. Furthermore, Carey et al. (2003b) clearly showed that large hail and PPCG lightning are not synonymous. Rather, the relationship between large hail and PPCG lightning was strongly influenced by geography, and hence, likely mesoscale environment. Based on the results of these latter studies (Bluestein and MacGorman 1998; Carey and Rutledge 1998; Carey et al. 2003a; Carey et al. 2003b), it appears that despite its frequent occurrence with positive severe storms, large hail does not likely play a direct role in the anomalous electrification of such storms. Williams (2001) supports this conclusion, arguing that large hailstones are unlikely to play a major role in the overall noninductive charging process because of their low number concentration and associated small integrated surface area, which limits their charge carrying capacity. ${ }^{5}$ Graupel and small hail particles, which are believed to be of much greater importance to the noninductive charging process, typically have an integrated surface area that is one to three orders of magnitude greater than that of large hail (Williams 2001). So while large hail likely does not play a direct role in the anomalous charging of positive severe storms, its repeated occurrence with such storms seems to

\footnotetext{
${ }^{5}$ The noninductive cloud electrification mechanism will be described in detail in Chapter III.
} 
suggest that the same conditions may lead to the production of both large hail and an anomalously high percentage of positive CG flashes. Namely, these conditions may be a strong updraft and abundant cloud water, both of which are key ingredients for the growth of large hail (Knight and Knight 2001; Williams 2001; Williams et al. 2005), and as will be discussed later, are hypothesized to be important in the generation of positive CG flashes as well.

Some of the early studies of positive severe storms noted a correlation between low-precipitation (LP) supercells (e.g., Bluestein and Parks 1983) and enhanced generation of positive CG lightning. Curran and Rust (1992) documented a case in which most CG flashes associated with LP thunderstorms were positive in polarity. One of the LP supercells evolved into a classic supercell (e.g., Browning 1964), and nearly all CG flashes produced by the classic supercell were negative. The results of Branick and Doswell (1992) support those of Curran and Rust (1992), as the former study found that storms dominated by positive CG flashes during a tornado outbreak across Oklahoma, Kansas, and Nebraska possessed characteristics of LP supercells, while storms dominated by negative CG flashes occupied the high-precipitation (HP; e.g., Moller et al. 1994) portion of the supercell spectrum. The Plainfield, Illinois F5 tornadic storm of 28 August 1990 appeared to follow this trend, as it experienced a polarity reversal from predominantly positive to predominantly negative as it transitioned from an LP/classic supercell to an HP supercell (Seimon 1993; Doswell and Brooks 1993; MacGorman and Burgess 1994). Focusing on the period from August 1990 to May 1991, MacGorman and Burgess (1994) found that most storms dominated by positive 
CG flashes were LP or classic supercells, while most storms dominated by negative CG flashes were HP or classic supercells. Also, storms often changed from LP to classic supercells or from classic to HP supercells at approximately the same time as the dominant CG flash polarity switched from positive to negative. MacGorman and Burgess (1994) also found that dominant positive CG flash behavior was not unique to LP supercells. Some classic supercells and strong multicell storms were also positive CG flash-dominant. Similarly, Carey and Rutledge (1998) present evidence of a severe hailstorm complex that transitioned between classic supercell, multicell, and squall-line phases, and all of these different phases were dominated by positive CG flashes. Bluestein and MacGorman (1998) were first to document HP supercells in which positive CG flashes were dominant. They also documented an LP supercell that was dominated by negative CG flashes, leading the authors to conclude that "while there appears to be a tendency for ground flash activity in LP supercell storms to be dominated by positive ground flashes and in HP supercell storms to be dominated by negative ground flashes, there are exceptions to this tendency." Results from the Severe Thunderstorm Electrification and Precipitation Study (STEPS), conducted in western Kansas and eastern Colorado during the summer of 2000, provide further evidence that positive CG flash-dominant storms can span vastly different organizational categories, as positive CG-dominant storms in STEPS ranged from small isolated convection to various types of large multicell storms to supercells (including both LP and non-LP supercells; Lang et al. 2004). So while in a probabilistic sense LP supercells may be most likely to produce anomalously high percentages of positive CG flashes (Williams 
2004), such enhanced positive CG production is by no means unique to LP supercells. However, similar to the relationship between large hail and positive CG flashes, the frequent occurrence of anomalous positive CG lightning activity with LP supercells appears to suggest that perhaps some of the same meteorological conditions that tend to favor LP supercells also favor an enhanced production of positive CG flashes.

\section{d. Hypothesis}

The repeated observation of similar CG lightning behavior in similar mesoscale regions on a given day has led to the hypothesis that the local mesoscale environment indirectly influences CG lightning polarity by directly controlling storm structure, dynamics, and microphysics, which in turn control storm electrification and CG flash polarity (e.g., MacGorman and Burgess 1994). A more specific hypothesis suggests that broad, strong updrafts and associated high liquid water contents (LWCs) in positive storms lead to positive charging of graupel and hail via the noninductive charging mechanism, the generation of an inverted charge structure, and enhanced positive CG lightning production (e.g., Gilmore and Wicker 2002; Carey et al. 2003b; Williams et al. 2005). The corollary is that environmental conditions favoring these kinematic and microphysical characteristics should support positive storms, while environmental conditions relatively less favorable should support negative storms.

Based on the above hypothesis and corollary, the main objective of this study is to determine if systematic differences exist between the mesoscale environments of positive and negative severe storms, and if so, to document these differences. In light of 
the more specific hypothesis described above, emphasis will be placed on those mesoscale conditions that dictate updraft intensity. A handful of past studies have explored the detailed relationship between the mesoscale environment and CG lightning behavior of severe storms (Reap and MacGorman 1989; Curran and Rust 1992; Smith et al. 2000; Gilmore and Wicker 2002; Carey et al. 2003b). However, detailed environmental measurements in both the horizontal and vertical were often lacking in these previous studies. Therefore, the studies were limited to either studying only the relationship between near-surface conditions and positive severe storms (e.g., Smith et al. 2000; Carey et al. 2003b), or using sounding data from the standard synoptic scale observing system (NWS upper-air sites) to characterize the vertical structure of the nearstorm environment (e.g., Reap and MacGorman 1989). Because severe storms by their very nature typically occur in environments characterized by spatial and temporal inhomogeneity on scales smaller than are observable by the synoptic sounding network, whose sites are separated by an average distance of $300-500 \mathrm{~km}$, it is very difficult to obtain proximity soundings that are truly representative of conditions experienced by the storms (Brooks et al. 1994a). Very few studies that have investigated the relationship between environmental conditions and CG lightning behavior of severe storms have had access to enhanced spatial and temporal resolution sounding data (e.g., Curran and Rust 1992; Gilmore and Wicker 2002). Thus, further study utilizing enhanced temporal and spatial resolution data in both the horizontal and vertical is necessary to determine whether systematic differences do indeed exist between mesoscale regions associated with positive and negative severe storms. 


\section{CHAPTER III}

\section{BACKGROUND}

\section{a. Thunderstorm electrification}

\section{1) CHARGING MECHANISMS AND TYPICAL CHARGE STRUCTURE}

Numerous mechanisms have been suggested to explain the electrification of thunderstorms. Suggested mechanisms include the inductive mechanism, the convective mechanism, the selective ion capture mechanism, drop breakup theory, charging during the melting of ice, the Workman-Reynolds effect, and the noninductive, graupel-ice mechanism. Overviews of these thunderstorm electrification mechanisms can be found in MacGorman and Rust (1998), Jayaratne (2003), and Rakov and Uman (2003). Although the electrification of thunderstorms is not completely understood, the noninductive, graupel-ice charging mechanism (hereafter NIC mechanism) is the most widely supported mechanism for thunderstorm electrification (MacGorman and Rust 1998; Williams 2001; Gilmore and Wicker 2002; Rakov and Uman 2003; Williams 2004). The other suggested mechanisms all have drawbacks (Jayaratne 2003) that make their acceptance as the probable primary thunderstorm electrification mechanism difficult. Meanwhile, detailed laboratory, observational, and modeling studies have all suggested that the NIC mechanism is fully capable of electrifying clouds enough to become thunderstorms. In further support of the NIC mechanism, the observed dependence of this mechanism on environmental parameters has appeared to explain qualitatively in almost all cases examined thus far why some storms are thunderstorms and others are not (MacGorman and Rust 1998). Based on the wide support of the NIC 
mechanism and growing consensus that it is the dominant electrification mechanism (Rakov and Uman 2003), the present study focuses on this particular cloud electrification mechanism.

The NIC mechanism was first proposed by Reynolds et al. (1957). In contrast to inductive mechanisms, this noninductive mechanism does not require a preexisting electric field to induce charge on the surface of hydrometeors. Rather, equal and opposite charges are exchanged by colliding hydrometeors. When ice crystals and rimed ice particles (ice hydrometeors growing by accretion of supercooled water; i.e., graupel and hail) undergo rebounding collisions in the presence of supercooled liquid water, the rimed ice particles and ice crystals acquire equal and opposite charges through the NIC mechanism. The presence of supercooled liquid water droplets is necessary for significant charge transfer to occur during collisions between the rimed ice particles and ice crystals (Reynolds et al. 1957; Takahashi 1978; Gaskell and Illingworth 1980; Jayaratne et al. 1983). The microphysical basis for the NIC mechanism is still not understood, so most knowledge of this mechanism comes from laboratory studies. Such empirical results have shown that temperature significantly impacts charging via the NIC mechanism (e.g., Takahashi 1978; Jayaratne et al. 1983; Keith and Saunders 1990; Saunders et al. 1991; Brooks et al. 1997; Saunders and Peck 1998). At temperatures cooler than the so-called charge reversal temperature $\left(T_{R}\right)$, which has been found to range from approximately $-10^{\circ} \mathrm{C}$ (e.g., Takahashi 1978 ) to $-20^{\circ} \mathrm{C}$ (e.g., Jayaratne et al. 1983) for typical cloud LWCs $\left(1 \mathrm{~g} \mathrm{~m}^{-3}\right)$, graupel and hail charge negatively while ice crystals charge positively. Gravitational sedimentation and convective motions cause 
the smaller, positively charged ice crystals to be transported upward, and the larger, negatively charged graupel and hail to be transported downward. This separation results in a main negative charge region located below an upper positive charge region. At temperatures warmer than $T_{R}$ (i.e., lower in the cloud), graupel and hail charge positively and ice crystals charge negatively (Fig. 5). A lower positive charge region, which is typically weaker in magnitude than the two aforementioned charge regions, likely forms below the main negative charge region as the positively charged graupel and hail descend. The lighter, negatively charged ice crystals are carried upward and strengthen the main negative charge region. These three charge regions make up the thunderstorm charge configuration known as the electric tripole (Krehbiel 1986; Williams 1989; MacGorman and Rust 1998). The main negative charge region is typically located between the $-10^{\circ} \mathrm{C}$ and $-25^{\circ} \mathrm{C}$ temperature levels, with the upper (lower) positive charge region at cooler (warmer) temperatures than this (Rakov and Uman 2003). A fourth charge region, called a screening layer, is typically present in thunderstorms as well. This screening layer is a relatively shallow negative charge layer that forms on the upper cloud boundary. It is formed as the upper positive charge region attracts negative ions to the cloud top from the surrounding environmental air. These negative ions attach to small cloud particles at the edge of the cloud, thereby producing the negative screening layer (Krehbiel 1986; MacGorman and Rust 1998).

The electric tripole plus the upper negative screening layer structure is a commonly used conceptual model for the gross charge distribution of thunderstorms. Although this charge configuration is a very reasonable conceptual model, actual 


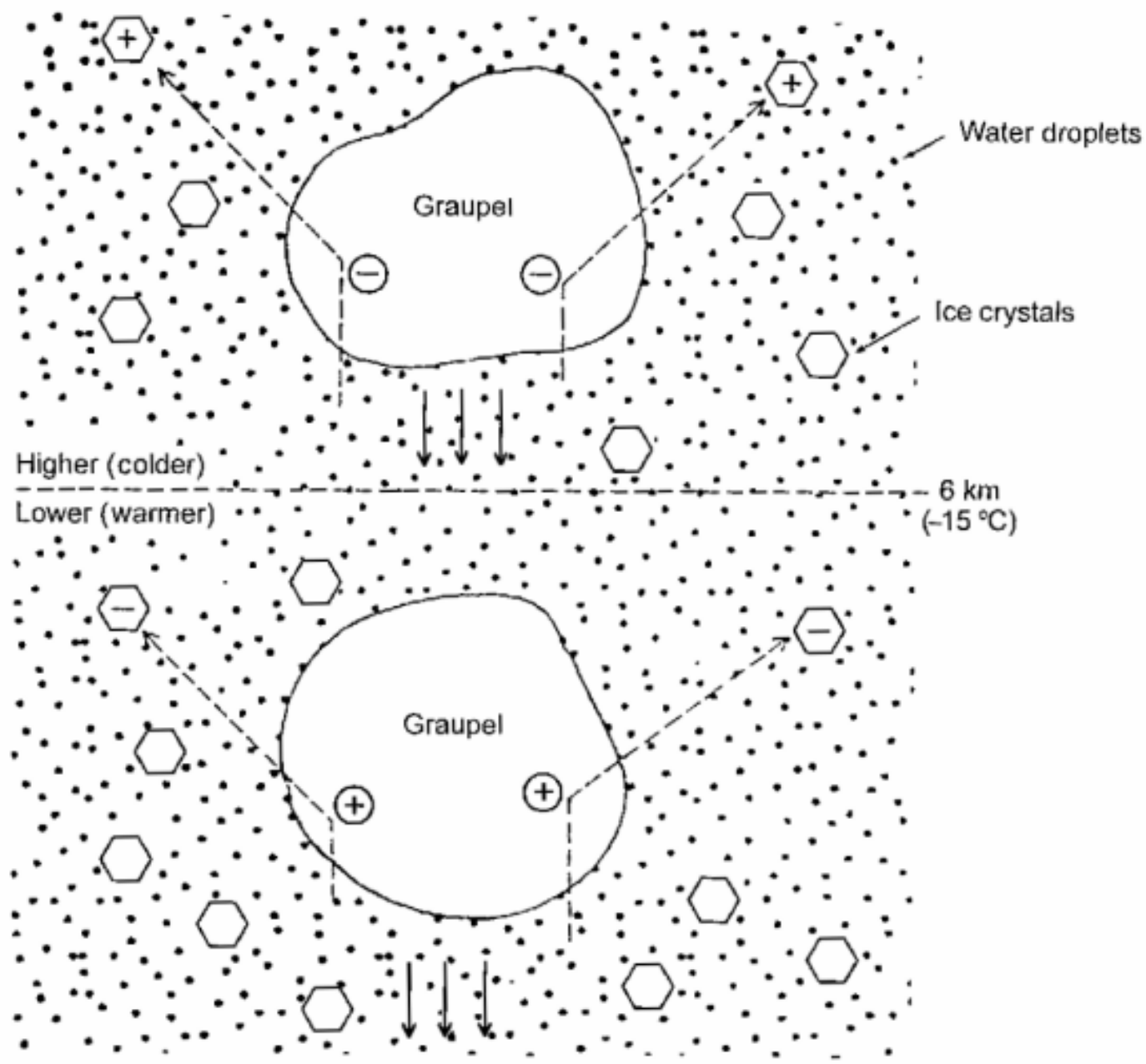

FIG. 5. Charge transfer by collision in the NIC mechanism of cloud electrification. It is assumed that $T_{R}$ is $-15^{\circ} \mathrm{C}$ and occurs at a height of $6 \mathrm{~km}$. From Rakov and Uman (2003).

thunderstorm charge distributions are often much more complex. Despite its inherent simplifications of true thunderstorm charge structure, Stolzenburg et al. (1998) found this conceptual model to agree well with the basic charge structure within convective updrafts of MCSs, isolated supercells, and isolated New Mexican mountain storms. However, a more complex charge structure was found to exist outside updrafts of 
convection. In these nonupdraft convective regions, at least two additional charge layers of opposite polarity were typically present below the main negative charge region, resulting in at least six layers of charge, alternating in polarity, with the lowest being positive. It is not known why these additional charge layers are present in nonupdraft convective regions. Perhaps additional charging mechanisms are at work in the nonupdraft regions, or differences in gravitational sedimentation and convective motions between updraft and nonupdraft regions are responsible for the formation of the additional charge layers (Stolzenburg et al. 1998). Based on their findings, Stolzenburg et al. (1998) suggest the use of a conceptual model of thunderstorm charge structure as depicted in Fig. 6, in which convective updraft (nonupdraft) regions consist of four (at least six) charge layers of alternating polarity, the lowest of which is positive.

\section{2) CLOUD-TO-GROUND LIGHTNING FLASH}

Two main types of lightning flashes exist: CG flashes and cloud flashes, the latter of which include intracloud, intercloud, and cloud-to-air flashes (Rakov and Uman 2003). This study focuses exclusively on CG flashes, and hence the following discussion is confined to CG flashes. A CG lightning flash is initiated when the electric stresses between two regions of opposing charge grow large enough that electrical breakdown occurs (Krehbiel 1986). It has been suggested that a CG flash may also be initiated by energetic electrons at electric field magnitudes much smaller than needed for initial breakdown (MacGorman and Rust 1998). Several underlying processes are involved in the occurrence of a CG lightning flash, as described in the following 


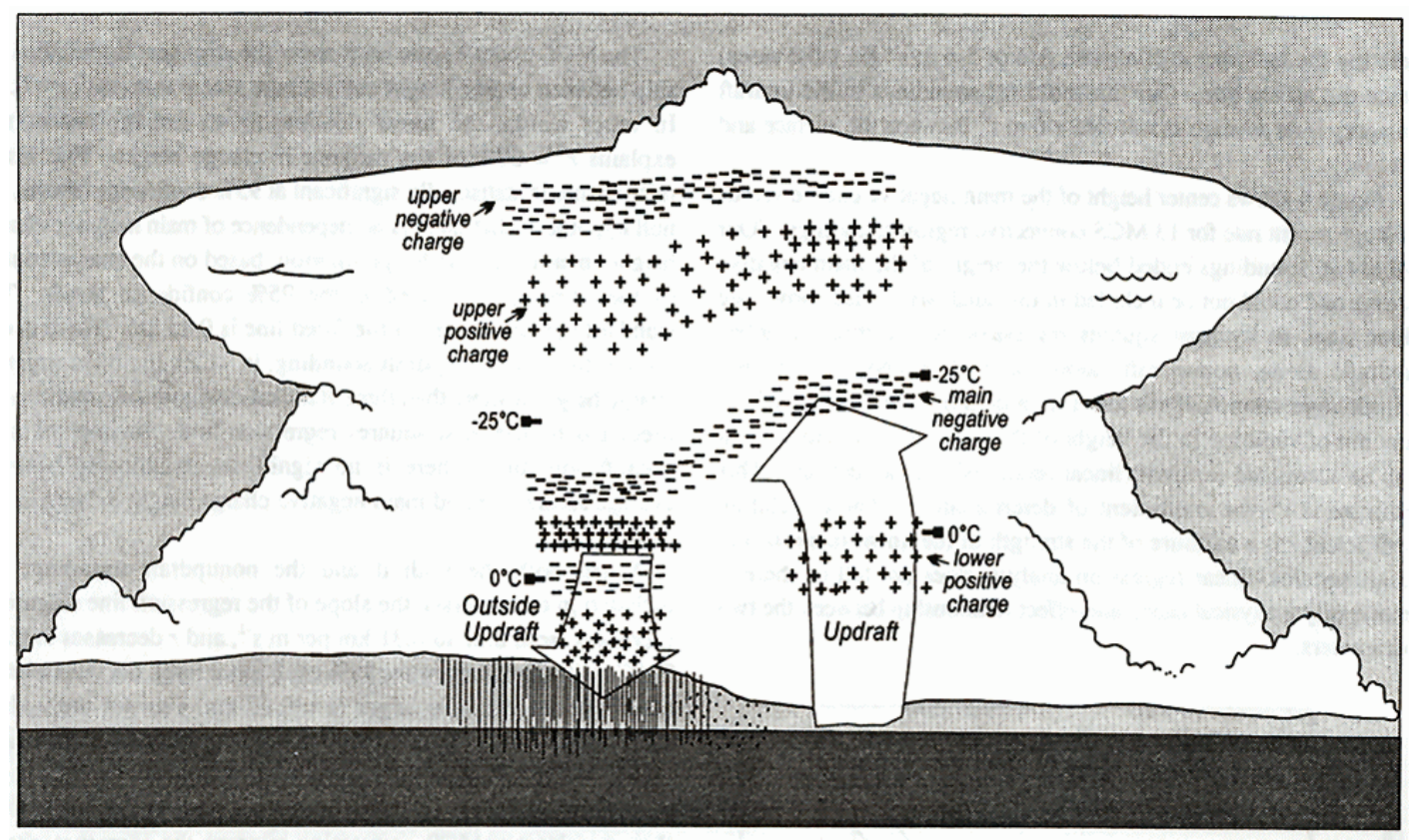

FIG. 6. Schematic of the basic charge structure in the convective region of a thunderstorm. Four charge regions exist in the updraft region, while two additional charge layers exist at low levels outside the updraft within the convective precipitation region. Actual heights and temperatures of charge regions may vary from storm to storm. The tripole plus upper negative screening layer structure is evident in the updraft region. From Stolzenburg et al. (1998).

discussion adapted from Uman (1987) and Rakov and Uman (2003) for a negative CG flash. Preliminary or initial breakdown in the cloud begins the CG flash process, and leads to formation of the stepped leader. The stepped leader progresses toward the ground in a series of discrete steps, transporting negative charge toward the ground along its path. Each step is typically tens of meters in length and $1 \mu \mathrm{s}$ in duration, and the time interval between steps is usually 20 to $50 \mu \mathrm{s}$. As the leader approaches ground, the electric field at the ground surface increases until electrical breakdown occurs, forming one or more upward-connecting leaders, often called streamers, which are of opposite polarity to the charge in the stepped leader. At a point typically tens of meters 
above ground, the downward-moving stepped leader contacts one of the streamers, thereby connecting the stepped leader to ground potential. This initiates the return stroke, which propagates continuously up the leader path and serves to lower the negative charge present in the stepped leader channel and at the top of the channel to ground, thereby neutralizing the channel. The return stroke typically travels at a speed one-third to one-half the speed of light, and produces an average peak current near ground around $30 \mathrm{kA}$. If the flash is a single-stroke flash, this completes the CG flash process.

Often more charge is made available in the cloud near the top of the lightning channel and multiple return strokes within the same channel result. When this additional charge is available, a dart leader moves continuously (i.e., not in a series of steps) down the residual first-stroke channel, depositing charge along its path. When the dart leader nears the ground, it contacts a streamer, initiating a subsequent return stroke that lowers the charge in the channel to ground. This process of generating subsequent return strokes can continue as long as additional charge is made available near the top of the lightning channel in the cloud.

The process in which a positive CG flash develops is similar to that for a negative CG flash as described above, but there are some differences. The downwardmoving positive leader associated with a positive CG flash can move either continuously or in a stepped fashion, whereas the initial downward-moving negative leader (stepped leader) associated with a negative CG flash always moves in a stepped fashion. The negative streamers involved in the positive CG flash process can be much longer than 
the positive streamers associated with a negative CG flash, sometimes extending up to 1 to $2 \mathrm{~km}$ above the surface. Positive CG flashes typically have larger peak currents than negative CG flashes. Also, positive CG flashes are usually single-stroke flashes, whereas negative CG flashes typically consist of three to five strokes (Uman 1987; Rakov and Uman 2003).

\section{3) CHARGE STRUCTURE ASSOCIATED WITH POSITIVE CG LIGHTNING}

As mentioned in Chapter II, it is hypothesized that enhanced positive CG

lightning production results from the generation of an inverted charge structure. Many previous studies have hypothesized that increased positive CG flash production results from an enhancement of the lower positive charge region ${ }^{6}$ (MacGorman and Nielsen 1991; MacGorman and Burgess 1994; Carey and Rutledge 1998; Williams 2001; Gilmore and Wicker 2002; Carey et al. 2003a; Carey et al. 2003b; Lang et al. 2004; Williams et al. 2005). Formation of the lower positive charge region likely results from the effect of temperature on the NIC mechanism, as discussed above (i.e., rimed ice particles charge positively at temperatures warmer than $T_{R}$ and descend to form this charge region). Several other factors, in addition to temperature, affect the sign and magnitude of charge deposited on colliding rimed ice particles and ice crystals. In particular, LWC has a large impact on charging via the NIC mechanism. Several studies (e.g., Takahashi 1978; Jayaratne et al. 1983; Keith and Saunders 1990; Saunders et al.

\footnotetext{
${ }^{6}$ A storm with an enhanced lower positive charge region is sometimes referred to as having an inverted dipole (e.g., MacGorman and Nielsen 1991; Carey and Rutledge 1998; Lang and Rutledge 2002; Lang et al. 2004). This is because the dominant positive charge region is now located below the main negative charge region, rather than above it, thereby inverting the typical polarity of the dipole.
} 
1991; Brooks et al. 1997; Saunders and Peck 1998) have investigated the effects of both temperature and LWC on charging. The results from these studies show that as cloud LWCs increase, $T_{R}$ decreases (becomes cooler). Thus, in the presence of enhanced cloud LWCs, $\mathrm{T}_{\mathrm{R}}$ is located at a higher height (cooler temperature) and positive charging of graupel and hail occurs over a greater depth of the cloud, thereby increasing the depth of the lower positive charge region. It has also been found that the magnitude of positive charge placed on the rimer increases as cloud temperature and LWCs increase (e.g., Takahashi 1978; Saunders et al. 1991). However, there appears to be an upper limit on the increased magnitude of charge placed on the rimer. If LWCs become large enough that the graupel/hail transitions from dry growth to wet growth (i.e., the latent heat released by the large quantity of freezing droplets warms the hail/graupel surface to $0^{\circ} \mathrm{C}$ so that the ice surface is wet), the amount of charge transferred between collisions is reduced to insignificant levels (Saunders and Brooks 1992; Jayaratne 1993). Saunders and Brooks (1992) suggested that the lack of charge transfer results from ice crystals rarely rebounding from wet graupel/hail. Diagrams of charging via the NIC mechanism as a function of cloud temperature and LWC from several different laboratory studies are shown in Fig. 7. Although differences exist in the results of these studies, they share two important themes. First of all, all studies consistently show that the rimer charges positively when LWCs are large ( $>\sim 2 \mathrm{~g} \mathrm{~m}^{-3}$; e.g., Williams 2004). Also, they show that the rimer tends to charge positively at warm in-cloud temperatures. Reduced cloud temperatures and LWCs, meanwhile, favor negative charging of the rimer. It is therefore hypothesized that elevated cloud temperatures and particularly LWCs, 
(a)

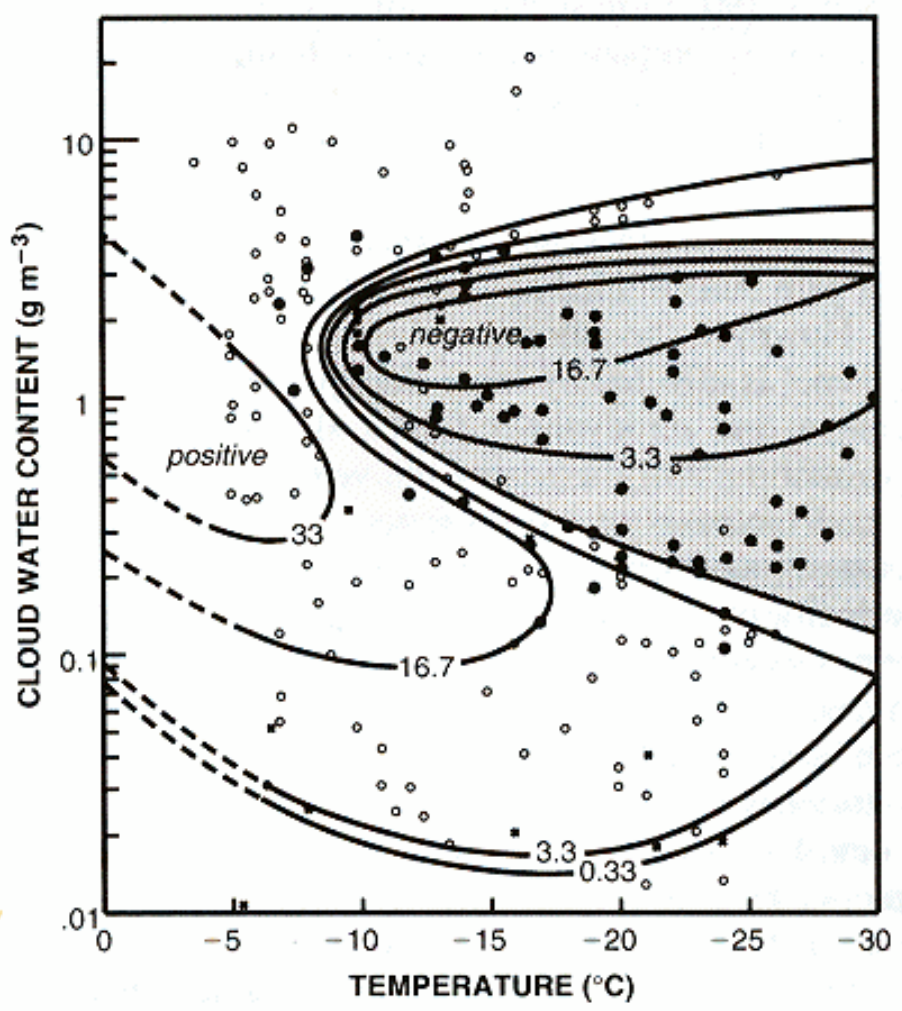

(b)

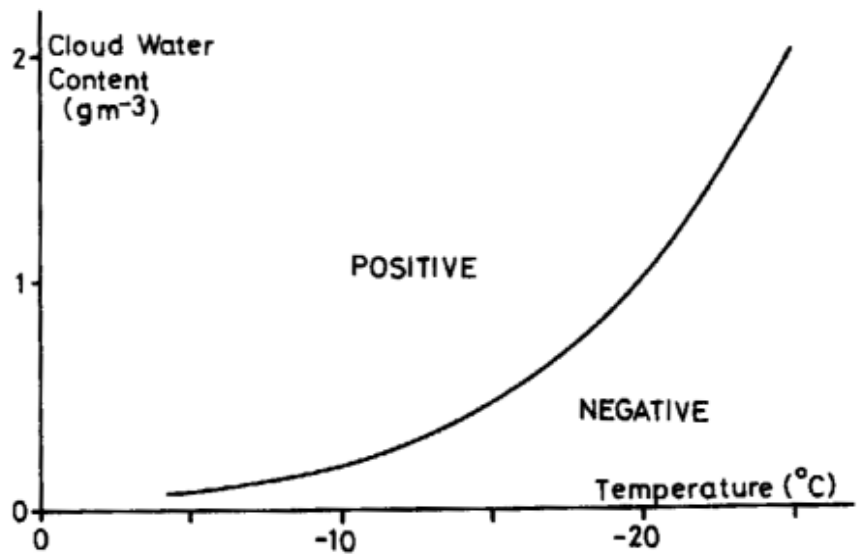

FIG. 7. Schematic diagrams illustrating the polarity of charge acquired by the rimer (graupel and hail) via the NIC mechanism as a function of cloud temperature and LWC. Diagrams are based on the laboratory results of (a) Takahashi (1978), (b) Jayaratne et al. (1983), (c) Saunders et al. (1991), (d) Brooks et al. (1997), and (e) Saunders and Peck (1998). Despite some differences, all diagrams show that large LWCs and warm temperatures result in positive charging of the rimer. Effective LWC (EW) and rime accretion rate (RAR) are alternative measures of LWC, and are described further in the text. These diagrams also show that $T_{R}$ decreases (becomes cooler) as LWCs increase. 
(c)

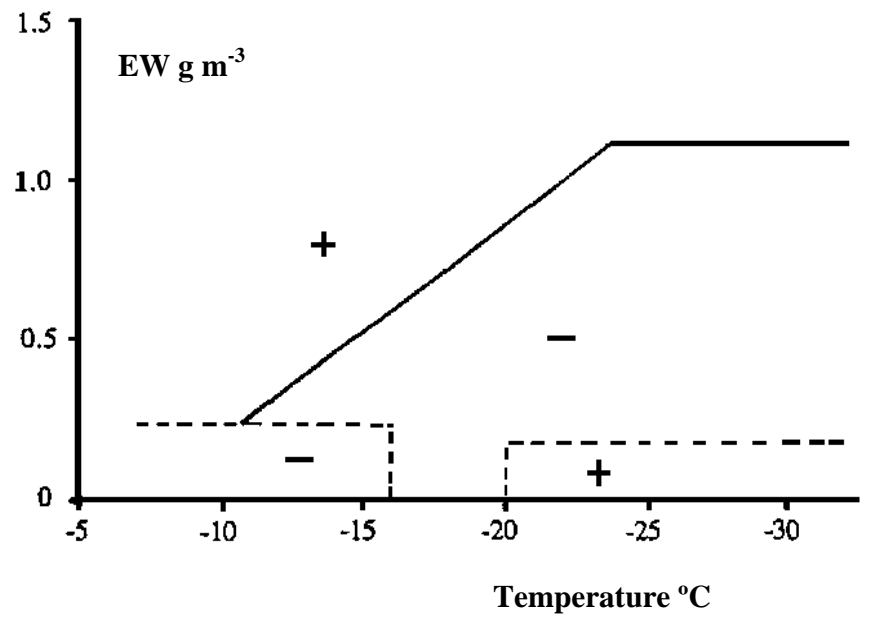

(d)

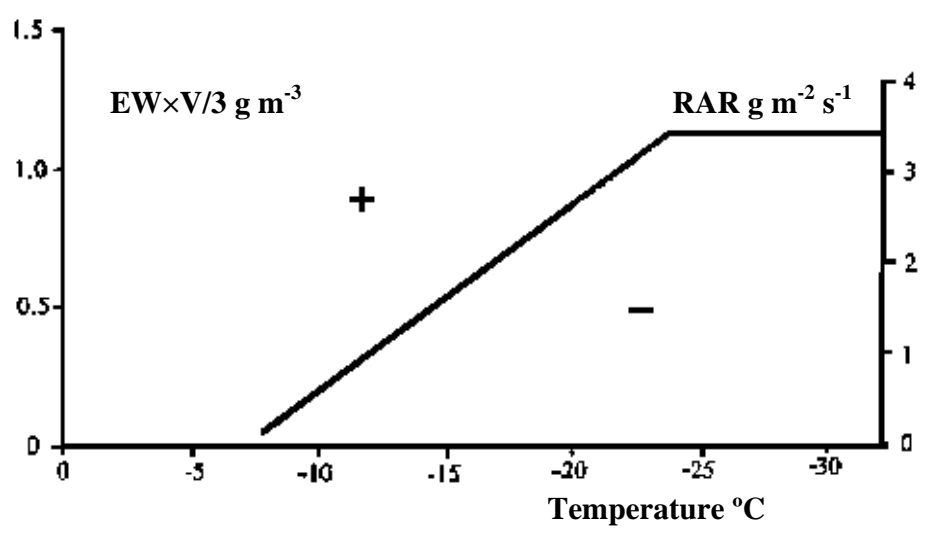

(e)

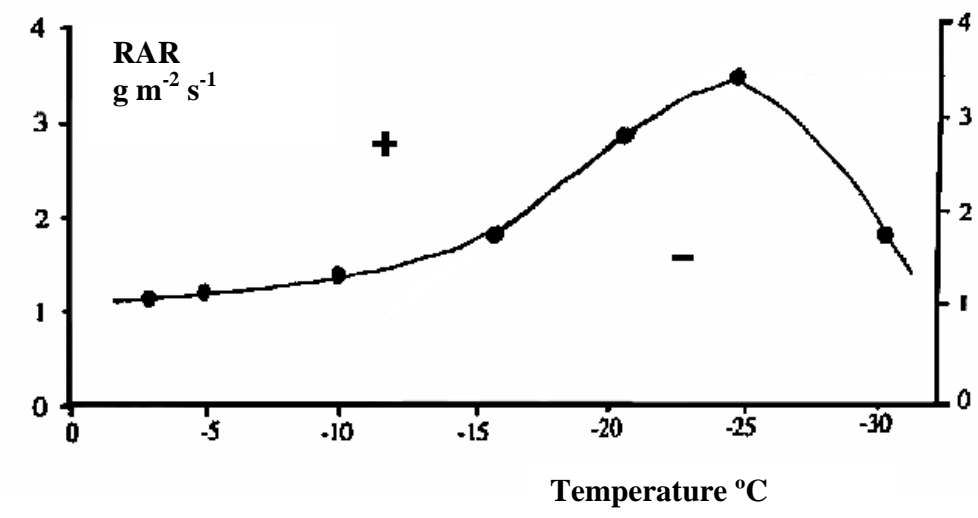

FIG. 7 Continued. 
favorable for the positive charging of graupel and hail, lead to an enhanced (in both magnitude and depth) lower positive charge region (i.e., inverted dipole) and an associated increased production of positive CG lightning.

For the NIC mechanism, temperature and LWC largely control charging, but other factors also affect the sign and magnitude of charge acquired by colliding rimed ice particles and ice crystals. These other factors include ice crystal size, chemical impurities in the hydrometeors, the cloud droplet size spectrum, and relative velocity of the colliding hydrometeors (Rakov and Uman 2003). The magnitude of charge transferred per collision increases with increasing ice crystal size (Jayaratne et al. 1983; Keith and Saunders 1990). The effects of chemical impurities on the sign and magnitude of charge separated during collisions can vary widely (e.g., Jayaratne 2003). Avila and Pereyra (2000) found that positive charging of graupel and hail occurs at colder temperatures and smaller LWCs as the cloud droplet spectrum narrows, and thus a narrow droplet spectrum enhances the size of the rimer positive charging zone. Hence, Avila and Pereyra (2000) suggest that a narrow (broad) cloud droplet spectrum is favorable (unfavorable) for the development of an enhanced lower positive charge region and increased production of positive CG flashes. As noted by Lucas et al. (1996), clouds with narrow droplet spectra are much less efficient at producing rain through coalescence, and hence more cloud liquid water will remain in the updrafts of such clouds. So the finding by Avila and Pereyra (2000) is consistent with the idea that enhanced cloud LWCs lead to increased frequency of positive CG lightning (i.e., all else being equal, narrow droplet spectra result in precipitation inefficiency in the warm cloud 
layer and hence higher cloud LWCs are maintained, and available to the mixed-phase region where significant electrification occurs). Increased relative velocity (i.e., larger impact velocity) between the rimer and ice crystals increases the magnitude of charge separated during collisions (Jayaratne et al. 1983; Keith and Saunders 1990). Brooks et al. (1997) later determined that increasing the velocity of the rimer not only increases the magnitude of charge transferred per collision by increasing the impact velocity, but also affects the sign of charge transferred. A greater rimer velocity increases the rate of collisions between the rimer and cloud droplets, which results in an increased rate of rime accretion. Higher rime accretions rates $(\mathrm{RAR}=\mathrm{EW} \times \mathrm{V}$, where $\mathrm{EW}$ is the effective liquid water content (LWC times the collection efficiency of cloud droplets by the rimer) and $\mathrm{V}$ is the differential velocity between the rimer and the cloud droplets) favor positive charging of the rimer. Increasing the velocity of the rimer has the same effect on the sign of charging as does increasing the cloud LWC; an increase in either variable increases the RAR, and therefore favors positive charging of the rimer (Brooks et al. 1997). Furthermore, a greater rimer velocity increases the collision rate between the rimer and ice crystals, and this increased number of collisions increases the amount of charge transfer occurring in the cloud (MacGorman and Rust 1998; Gilmore and Wicker 2002). So, the velocity of the rimer affects both the sign and magnitude of charge transferred during collisions. Of particular importance to the hypothesis of this study, a greater rimer velocity: (1) favors positive charging of the rimer by increasing the RAR (Brooks et al. 1997), (2) increases the magnitude of positive charge deposited on the rimer per collision (Jayaratne et al. 1983; Keith and Saunders 1990), and (3) 
increases the rate of charge-transferring collisions between the rimer and ice crystals (MacGorman and Rust 1998; Gilmore and Wicker 2002).

Recent studies continue to support the hypothesis that enhanced positive CG flash production results from the generation of an inverted charge structure, but suggest that the process may be more complex than just inverting the main dipole through enhancement of the lower positive charge region. Observations from balloon-borne electric field meters (Rust and MacGorman 2002; MacGorman et al. 2005) and (very high frequency) VHF-based total lightning mapping networks (Lang et al. 2004; Wiens et al. 2005) suggest that positive storms are characterized by an inverted-polarity vertical electric field structure, meaning that the vertical configuration of the inferred charge polarity structure is nearly opposite to the arrangement found in the more typical negative storms. In the updraft region of inverted-polarity storms, the lowest significant charge layer of the thunderstorm tripole is negative, the midlevel charge is positive, and the main upper-level charge is negative (i.e., opposite to the conventional tripole). The highest charge layer, which is likely a screening layer, is positive. Similar to negative storms (e.g., Stolzenburg et al. 1998), MacGorman et al. (2005) found additional charge layers at lower altitudes outside the updraft in positive storms, which may result from inductive charging mechanisms and/or lightning.

These more recent studies (e.g., Rust and MacGorman 2002; MacGorman et al. 2005; Wiens et al. 2005) are similar to many previous studies (e.g., MacGorman and Nielsen 1991; MacGorman and Burgess 1994; Carey and Rutledge 1998; Williams 2001; Gilmore and Wicker 2002; Carey et al. 2003a; Carey et al. 2003b; Lang et al. 
2004; Williams et al. 2005) in hypothesizing that an enhancement of the positive charge region at low to midlevels of a storm leads to increased positive CG flash production, but differ in that they stress the importance of a lower negative charge region located below this zone of enhanced positive charge. Also of note is that the recent observations indicate that the lower positive charge region extends well into the midlevels of the storm, occupying the temperature range (i.e., $-10^{\circ} \mathrm{C}$ to $-20^{\circ} \mathrm{C}$ ) that is usually occupied by the main negative charge region in the more typical negative storms. As discussed above, this much increased depth of the lower positive charge region apparently results from enhanced LWCs cooling $\mathrm{T}_{\mathrm{R}}$ and thus allowing positive charging of graupel and hail over a much greater storm depth.

The recent observations of a lower negative charge layer below the robust positive charge layer in positive CG flash-producing storms is consistent with the modeling study results of Mansell et al. (2002), in which positive CG flashes occurred in the model simulations only when a layer of negative charge existed below the positive charge region. Similarly, negative CG flashes occurred only when a region of positive charge existed below the main negative charge region. Hence, simply enhancing the lower positive charge region may not be sufficient to generate positive storms.

Observations of negative CG flashes from storms consisting of a weaker positive charge region below the main negative charge region (e.g., Williams 1989) are consistent with the results of Mansell et al. (2002), and by analogy, seem to suggest that perhaps a lower negative charge layer is necessary below the enhanced positive charge region to generate positive CG flashes. The mechanism(s) responsible for generation of the lower negative 
charge layer remain(s) uncertain. Lang and Rutledge (2002) suggested that in view of the Stolzenburg et al. (1998) conceptual model, this negative charge layer would have to be a minor or screening charge layer like one of the many charge layers found in the nonupdraft regions of the Stolzenburg et al. (1998) model. Modeling results from Mansell et al. (2003) suggest that inductive charging may play a role in forming the small, lower negative (positive) charge region in storms that produce predominantly positive (negative) CG lightning. Wiens et al. (2005) and the numerical simulations by Kuhlman (2004) suggest that the lower negative charge region could be a product of negative charging of graupel and hail via the more typical NIC process on the periphery of the updraft (where LWCs are more moderate).

\section{b. Effects of updraft intensity on cloud thermodynamics and microphysics}

As previously discussed, many factors (LWC, temperature, ice crystal size, chemical impurities in the hydrometeors, cloud droplet spectrum, relative velocity of the colliding hydrometeors) affect electrification via the NIC mechanism. Updraft intensity directly impacts several of these factors, namely LWC, temperature, cloud droplet spectrum, and the relative velocity of colliding hydrometeors. Due to its effects on these factors, which are described below, updraft intensity is hypothesized to largely affect storm electrification and CG lightning behavior. The updrafts of convective storms are the location of condensation of water vapor into cloud droplets (Knight and Knight 2001). As an air parcel rises, it cools adiabatically (either dry or moist), causing the water vapor in the air parcel to condense, thereby producing liquid water droplets. The 
cooling of the parcel is proportional to the magnitude of the lifting. Thus, rapid lifting of an air parcel by an intense updraft causes strong cooling of the parcel, which results in high condensation rates and a large quantity of liquid water droplets (Houze 1993). Latent heat is released during condensation (and freezing at greater heights), and this warms the updraft air. The amount of latent heat released and associated warming are therefore proportional to the amount of condensation occurring. Due to this chain of physical processes, temperature, LWC, and intensity of the updraft are positively correlated (e.g., Rogers and Yau 1989; Knight and Knight 2001). Therefore, assuming all else is equal (i.e., amount of water vapor in the air, type and concentration of condensation and ice nuclei, etc.), a stronger updraft will result in warmer temperatures and higher LWCs in the cloud than would result from a weaker updraft.

Other processes associated with an intense updraft also contribute to high cloud LWCs. Hydrometeors that grow by collecting ${ }^{7}$ cloud droplets (i.e., collectors) cannot grow to precipitation-sized particles (and subsequently fall out of the cloud) while being swept upward through an intense updraft because their residence time within the updraft is too short to allow significant collection of cloud droplets, due to the high velocities of the updraft air. Hence, the liquid water in the updraft is not depleted through the growth and fallout of precipitation particles (Knight and Knight 2001; Williams et al. 2005). Rather, the liquid water remains in the updraft in the form of small droplets. This retention of liquid water droplets in the updraft region maintains high cloud LWCs. An intense updraft also provides a continual flow of boundary layer air into the storm.

\footnotetext{
${ }^{7}$ Riming, coalescence, and accretion are all types of collection. They are similar in that hydrometeors grow by collecting cloud droplets in all of these processes (Knight and Knight 2001).
} 
Since boundary layer air is typically moister than air at higher altitudes, this feeds moist air into the storm as long as the updraft persists. As this moist air cools and condenses, more liquid water droplets are formed in the cloud. So in summary, the updraft serves as a source of cloud liquid water, while precipitation serves as a sink (e.g., Rogers and Yau 1989; Houze 1993; Knight and Knight 2001; Williams et al. 2005). Hence, an intense updraft, in combination with reduced precipitation, results in high cloud LWCs.

Updraft intensity also affects the cloud droplet size spectrum and the relative velocity of colliding hydrometeors. In a weak updraft, collectors spend a sufficient amount of time in the updraft to grow to appreciable sizes. This broadens the cloud droplet size spectrum. The droplet spectrum continues to broaden via growth by collection, as the growing collectors of different sizes have different terminal fall speeds from one another and from the cloud droplets, and this difference in terminal fall velocities promotes further growth through collection. As described previously, droplets in a strong updraft have less time to grow, so they remain small and the droplet spectrum remains narrow (Rogers and Yau 1989; Avila and Pereyra 2000; Knight and Knight 2001). The relative velocity of colliding hydrometeors is strongly affected by the velocity of the rimer ${ }^{8}$, which is indirectly controlled by updraft intensity since the rimer's terminal fall velocity is proportional to its size, and its size depends on updraft intensity (i.e., stronger updrafts are able to grow larger rimers by keeping them suspended aloft longer). An intense updraft therefore leads to the growth of larger

\footnotetext{
${ }^{8}$ Cloud droplets and ice crystals have negligible terminal fall velocities due to their small size and can be considered to be traveling at the airflow velocity. However, the terminal fall velocity of the rimer can be, and typically is, much greater than that of the cloud droplets and ice crystals (Knight and Knight 2001; Gilmore and Wicker 2002).
} 
rimers with greater terminal fall velocities (Knight and Knight 2001; Gilmore and Wicker 2002). As previously discussed, an increased velocity of the rimer increases the RAR (Brooks et al. 1997), the magnitude of charge separated per collision (Jayaratne et al. 1983; Keith and Saunders 1990), and the number of charge-separating collisions (MacGorman and Rust 1998; Gilmore and Wicker 2002), and thereby likely results in enhanced positive charging of graupel and hail. So through these effects of increasing the rimer velocity and narrowing the cloud droplet size spectrum, an intense updraft is favorable for the development of an inverted charge structure and associated increased production of positive CG lightning.

\section{c. Updraft intensity}

Based on the hypothesis that intense updrafts lead to increased cloud LWCs, positive charging of graupel and hail, an inverted charge structure, and increased production of positive CG lightning, a primary objective of this study is to determine if updrafts of positive storms are indeed more intense than those of negative storms. Since direct, accurate measurements of storm updrafts are lacking, updraft intensity must be addressed through an alternate method. The alternate method chosen utilizes measurements of the mesoscale environment to assess updraft intensity.

Factors affecting vertical air motions in convective clouds include: (1) parcel buoyancy, (2) pressure perturbations associated with parcel buoyancy, (3) water loading, (4) entrainment of environmental air, and (5) dynamical effects, including dynamic pressure perturbations and surface cold pool/environmental wind shear interactions, 
associated with gradients in the wind field. The anelastic form of the vertical momentum equation, which is applicable to convective clouds, is

$$
\frac{\mathrm{Dw}}{\mathrm{Dt}}=-\frac{1}{\rho_{0}} \frac{\partial \mathrm{p}^{\prime}}{\partial \mathrm{z}}+\mathrm{B}
$$

where friction is neglected, D/Dt denotes the Lagrangian derivative $(\mathrm{D} / \mathrm{Dt} \equiv \partial / \partial \mathrm{t}+\mathbf{v}$

- $\nabla), \mathrm{t}$ is time, $\mathrm{w}$ is vertical velocity, $\rho_{0}$ is the reference-state density, $\mathrm{p}^{\prime}$ is the deviation of pressure from its reference-state value, $\mathrm{z}$ is height, and B is buoyancy. Buoyancy is defined as

$$
B \equiv-g \frac{\rho^{\prime}}{\rho_{0}}
$$

where $\rho^{\prime}$ represents the perturbation density (Bluestein 1993; Houze 1993). Thus, it is apparent from Equation (1) that forcing induced by pressure perturbations (first term on the right) and forcing resulting from density differences between the parcel and environmental air (second term on the right) drive vertical motions in convective clouds.

\section{1) PARCEL THEORY AND ITS DEFICIENCIES}

Parcel theory is often used to assess vertical motions associated with convective storms. Based on parcel theory, a parcel which is less dense (owing to both temperature and water vapor content of the air) than its environment will be positively buoyant, and will thus experience rising motion. The magnitude of vertical motion in a storm updraft is proportional to the buoyancy of the parcel. Hence, based solely on parcel theory, increased positive parcel buoyancy will enhance updraft intensity. However, the deficiencies of parcel theory are widely recognized, as it neglects many other factors that 
affect updraft intensity, including pressure perturbations associated with parcel buoyancy, water loading, entrainment of environmental air, and dynamical effects (e.g., Bluestein 1993; Houze 1993; Doswell and Rasmussen 1994; Emanuel 1994; Lucas et al. 1994; Williams 1995; Williams and Stanfill 2002; Zipser 2003; Doswell and Markowski 2004). These other factors are all significant to vertical motions in convective clouds, and warrant consideration when assessing updraft intensity.

(i) Pressure perturbations associated with parcel buoyancy

Pressure perturbations that develop in association with a buoyancy anomaly form a downward-directed pressure gradient force that opposes, to varying degrees, the upward-directed buoyancy force (Bluestein 1993; Houze 1993; Doswell and Markowski 2004). As parcels of air accelerate upward in response to the buoyancy force, the nearby mass field must adjust to preserve mass continuity, and a distinctive pressure field is required to accomplish this adjustment (Houze 1993). Air must move out of the way just above the air parcel to make room for it, while below the parcel air must move back in to fill the volume it vacates. These lateral accelerations above and below the air parcel are associated with horizontal perturbation-pressure gradients that act outward above the air parcel and inward below it, as shown in Fig. 8. If the pressure field far from the air parcel is not disturbed by the parcel, then there is a perturbation highpressure area above the air parcel and a perturbation low-pressure area below it. This creates a downward-directed perturbation pressure gradient force, which opposes the upward-directed buoyancy force (Bluestein 1993). 


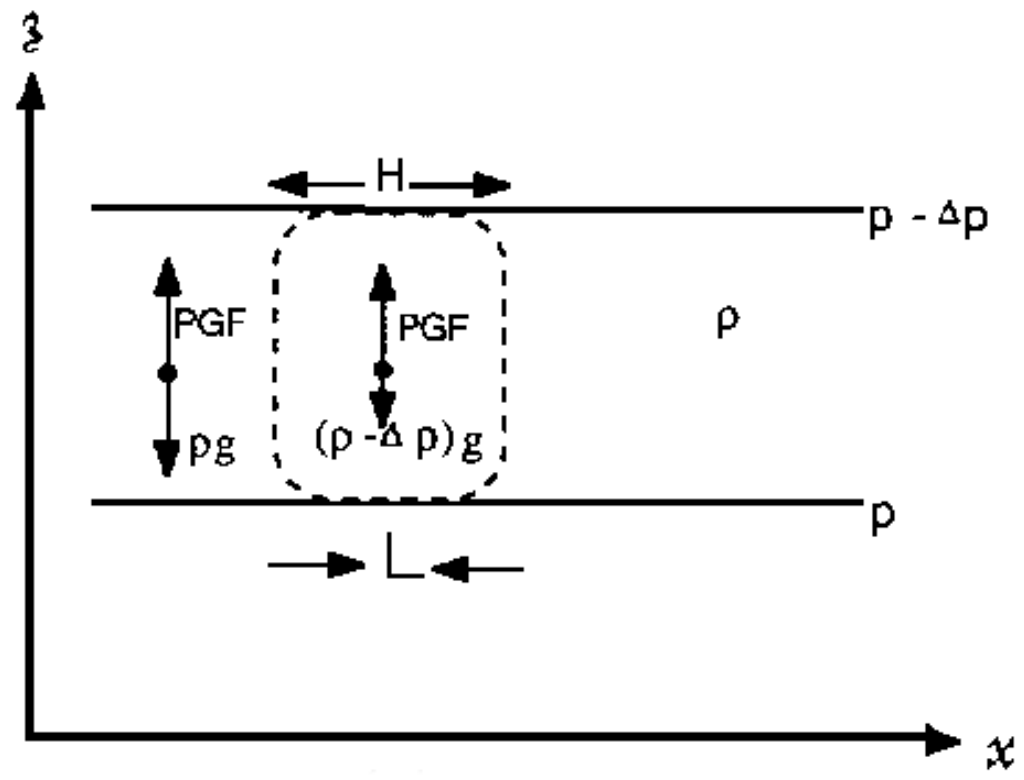

FIG. 8. Effect of vertical accelerations induced by parcel buoyancy on the pressure field. The positively buoyant air parcel (enclosed by dashed line) is less dense $(\rho-\Delta \rho)$ than the surrounding environmental air of density $\rho$. The upward-directed pressure gradient force (PGF) acting on the parcel is greater in magnitude than the downward-directed force of gravity $[-(\rho-\Delta \rho) \mathrm{g}]$, and hence the parcel is displaced upward. Perturbation high $(\mathrm{H})$ and low (L) pressure areas associated with air moving outward above and inward below the rising parcel are shown. These perturbation pressures create a downward-directed perturbation pressure gradient force that opposes the positive parcel buoyancy. Adapted from Bluestein (1993).

\section{(ii) Water loading}

Water loading also opposes the upward-directed buoyancy force. Condensed water, in the form of cloud droplets or precipitation, exerts a downward force on ascending air parcels equal to its weight. Frozen hydrometeors contribute to this weighting as well (Rogers and Yau 1989; Houze 1993). Also, as precipitation particles fall toward the ground, they drag air downward with them (Houze 1993). These two forces oppose the updraft and serve to weaken it. 


\section{(iii) Entrainment of environmental air}

Entrainment of environmental air into convective clouds reduces updraft intensity as well. The environmental air is generally cooler and drier, and hence less buoyant, than the updraft air. Entrainment thus dilutes the buoyant updraft air, thereby weakening the updraft. The mixing of drier environmental air into the updraft also leads to increased evaporative cooling, which weakens the updraft further (Rogers and Yau 1989; Houze 1993). Parcel diameter, which is not considered in parcel theory, strongly affects the amount of entrainment an updraft experiences and thus indirectly impacts updraft intensity. The amount of updraft dilution through entrainment of environmental air is a strong inverse function of updraft diameter (McCarthy 1974; Houze 1993; McCaul and Cohen 2002; Zipser 2003). Hence, wide updrafts experience less entrainment than narrow updrafts, as the wider updrafts are more sheltered from entrainment (McCarthy 1974; Houze 1993; Lucas et al. 1994; Michaud 1996; Lucas et al. 1996; McCaul and Cohen 2002; Williams and Stanfill 2002; Zipser 2003; Williams 2004; Williams et al. 2005). In turn, updraft diameter scales with CBH, or boundary layer depth (Lucas et al. 1994; Michaud 1996; Lucas et al. 1996; Williams and Stanfill 2002; Williams 2004; Williams et al. 2005). Therefore, clouds with higher CBHs tend to have wider updrafts and thus experience less entrainment (Fig. 9). Williams and Stanfill (2002) and Williams et al. (2005) suggest that this reduction of entrainment allows for a greater conversion efficiency of CAPE to vertical kinetic energy, thereby leading to more intense updrafts. This led the authors of these studies to suggest that $\mathrm{CBH}$ needs to be considered when evaluating updraft intensity and its effects on cloud 
electrification and lightning behavior. Similarly, a modeling study by McCaul and Cohen (2002) revealed that the conversion efficiency of CAPE to vertical kinetic energy was enhanced by increases in updraft diameter, and the highest conversion efficiencies resulted when the lifting condensation level (LCL; a measure of $\mathrm{CBH}$ ), which was equal to the level of free convection (LFC) in much of their study, was in the range of 1.5-2.5 $\mathrm{km}$ AGL. Conversion efficiencies were reduced significantly for lower LCL $=$ LFC heights. Motivated by these results, CBHs will be investigated in this study to assess updraft diameter, since the latter influences the degree of entrainment experienced by an updraft and hence updraft intensity.

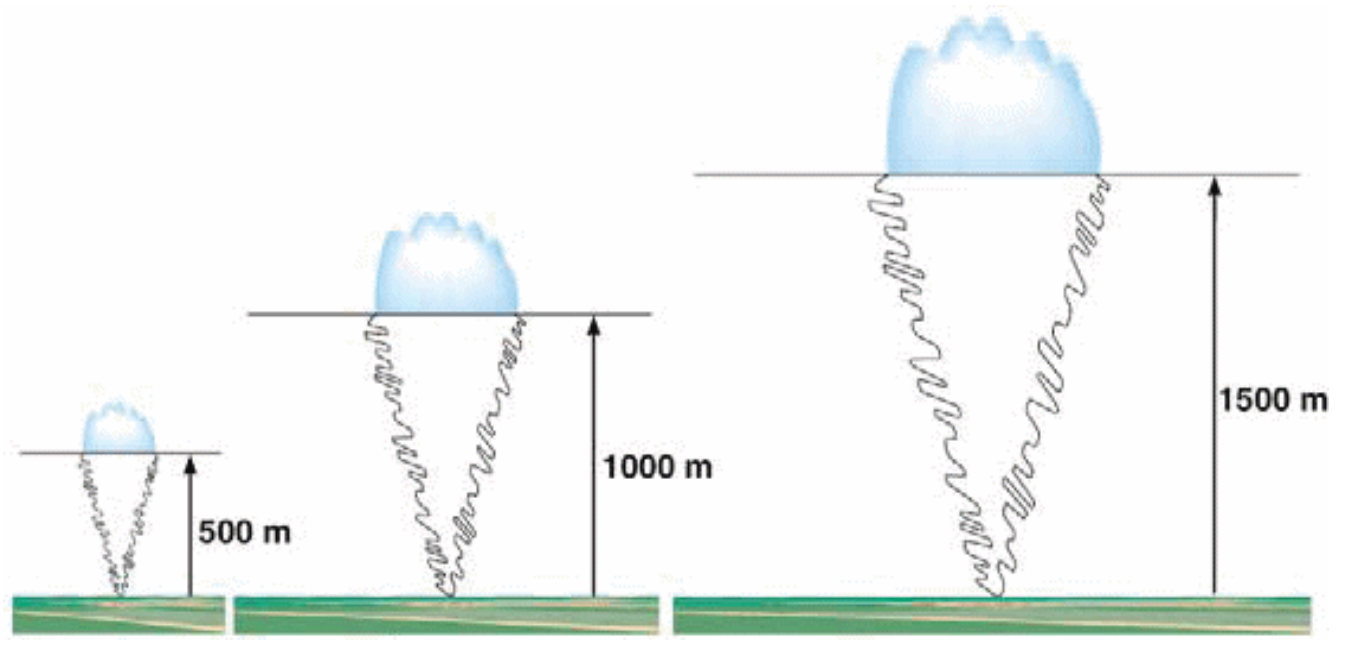

FIG. 9. Illustration indicating that updraft diameter scales with $\mathrm{CBH}$ (heights in meters). Clouds with higher $\mathrm{CBHs}$ thus have wider updrafts and experience less entrainment. Adapted from Williams and Stanfill (2002). 


\section{(iv) Dynamic pressure perturbations}

Along with the pressure perturbations resulting from buoyancy, pressure perturbations also develop in response to gradients in the wind field. In environments characterized by strong wind shear (e.g., the IHOP_2002 domain), the forcing from dynamic pressure perturbations can become the dominant forcing mechanism (Houze 1993). It is these dynamic pressure perturbations that drive supercell dynamics. Dynamic pressure perturbations can be partitioned into linear and nonlinear parts. The nonlinear dynamic pressure perturbations are associated with in-cloud rotation. Rotation ultimately results from environmental wind shear, as vertical shear of the horizontal wind generates a horizontal vortex tube, which is then tilted into the vertical by the storm updraft, producing a cyclonic-anticyclonic vertical vortex couplet straddling the updraft (Fig. 10a). These two vortices, located on the flanks of the updraft, are intensified by stretching resulting from mechanisms such as surface convergence and increased parcel buoyancy. The nonlinear perturbation pressure $\left(\mathrm{p}_{\mathrm{NL}}^{\prime}\right)$ is proportional and opposite in sign to the square of the perturbation vertical vorticity ( $\zeta$ '), i.e. (Rotunno and Klemp 1982; Klemp 1987; Bluestein 1993; Houze 1993),

$$
\mathrm{p}_{\mathrm{NL}}^{\prime} \sim-\zeta^{\prime 2} .
$$

By this relation, pressure perturbation minima are associated with both the cyclonic and anticyclonic vortices. These pressure perturbation minima cause an upward-directed 
pressure gradient force to develop below the level at which the vortices (and hence pressure perturbation minima) are most intense, which is usually at midlevels. This intensifies the upward vertical motion on the flanks of the updraft. The absence of an upward-directed perturbation pressure gradient force at the center of the updraft, in combination with the formation of a precipitation-induced downdraft, causes the initial updraft to collapse. However, the upward motions beneath the pressure perturbation minima on the flanks of the initial updraft persist, and hence two separate updrafts are formed (Fig. 10b). The repetition of this process results in the continual regeneration of the updrafts on the two storm flanks normal to the vertical shear vector, and this continual updraft regeneration results in the quasi-steady, long-lived nature of supercell storms. By promoting updraft growth on the flanks of the initial cell, the nonlinear dynamic pressure perturbations also result in storm splitting (Rotunno 1981; Rotunno and Klemp 1982; Klemp 1987; Bluestein 1993; Houze 1993). 

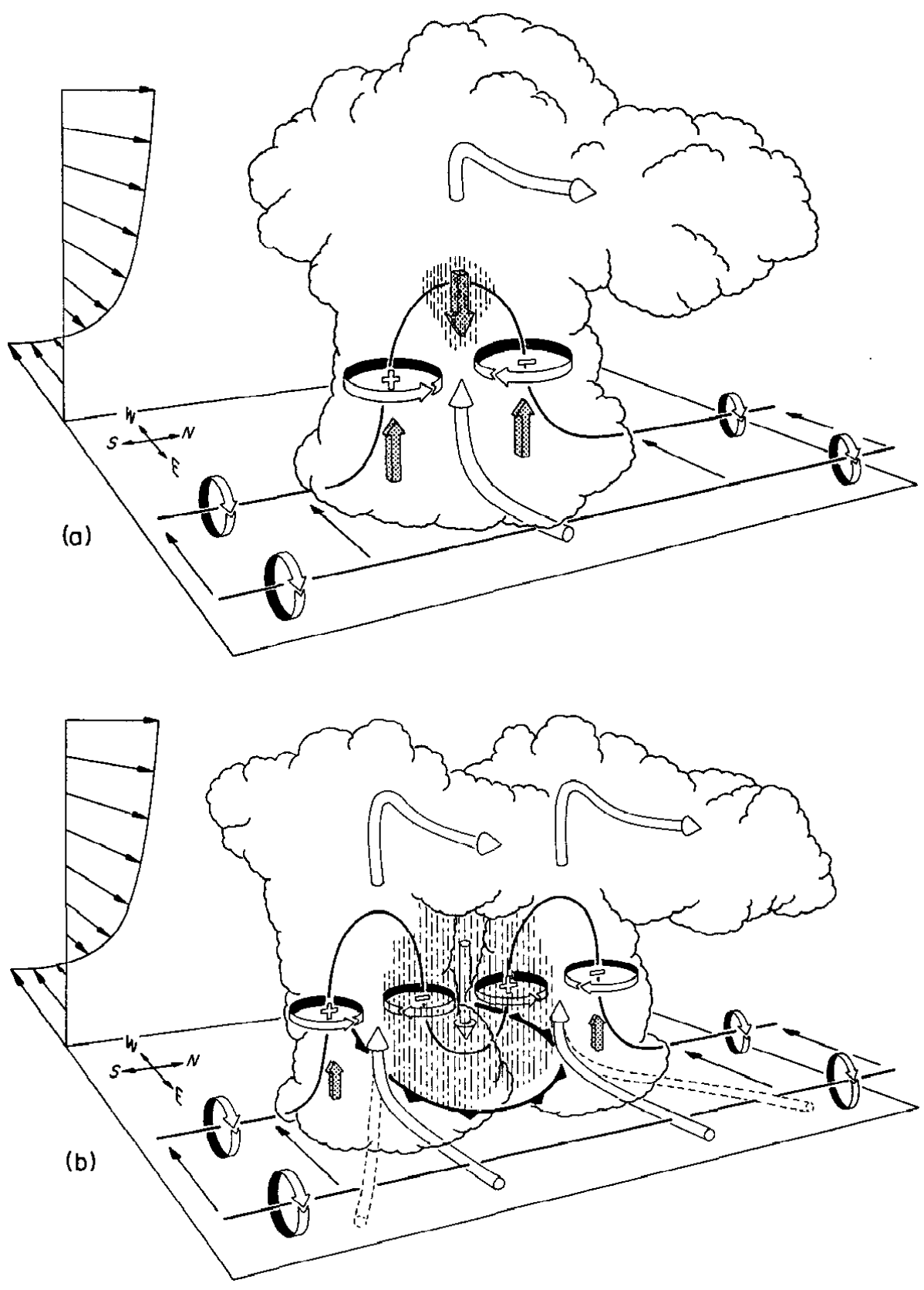

FIG. 10. Schematic depiction of how a typical vortex tube contained within (westerly) environmental shear is deformed as it interacts with a convective cell (viewed from the southeast). Cylindrical arrows show the direction of cloud-relative airflow, and heavy solid lines represent vortex lines with the sense of rotation indicated by circular arrows. Shaded arrows represent the forcing influences that promote new updraft and downdraft growth. Vertical dashed lines denote areas of precipitation. (a) Initial stage: Vortex tube loops into the vertical as it is swept into the updraft. (b) Splitting stage: Downdraft forming between the splitting updraft cells tilts vortex tube downward, producing two vortex pairs. Cold front symbol at the surface marks the boundary of cold air spreading out beneath the storm. From Klemp (1987); adapted from Rotunno (1981). 
The linear dynamic pressure perturbations result from interaction between the storm updraft and environmental wind shear, as indicated by the relationship (Rotunno and Klemp 1982; Klemp 1987; Bluestein 1993; Houze 1993)

$$
\mathrm{p}_{\mathrm{L}}^{\prime} \sim \frac{\partial \overline{\mathbf{v}}}{\partial \mathrm{z}} \bullet \nabla_{\mathrm{H}} \mathrm{W}^{\prime}
$$

where $\mathrm{p}_{\mathrm{L}}^{\prime}$ is the linear dynamic pressure perturbation, $\overline{\mathbf{v}}=(\overline{\mathrm{u}}, \overline{\mathrm{v}}, 0)$ represents the environmental wind profile, $\nabla_{\mathrm{H}}$ is the horizontal gradient operator $(\partial / \partial \mathrm{x}, \partial / \partial \mathrm{y}, 0)$, and $\mathrm{w}^{\prime}$ represents the vertical velocity field associated with the storm updraft. So, the first term in the dot product represents the environmental wind shear, while the second term represents the horizontal gradient of the updraft. In unidirectional shear, a perturbation pressure minimum forms on the downshear side of the updraft, and a perturbation pressure maximum forms on the upshear side of the updraft (Fig. 11a). These pressure perturbations develop at the height at which the horizontal gradient of vertical velocity is the strongest, which is typically at midlevels (where the updraft is typically strongest). The perturbation pressure minimum (maximum) results in the development of an upward-directed (a downward-directed) pressure gradient force at levels below the perturbation. This forcing promotes new updraft and hence cell growth on the downshear side, while suppressing new updraft growth on the upshear side. If the environmental wind shear is not unidirectional, but rather veers or backs with height, the linear pressure perturbations promote new updraft and cell growth on a preferred storm flank. For a wind profile that veers (backs) with height, new updraft and cell growth associated with the upward-directed perturbation pressure gradient force occurs on the 

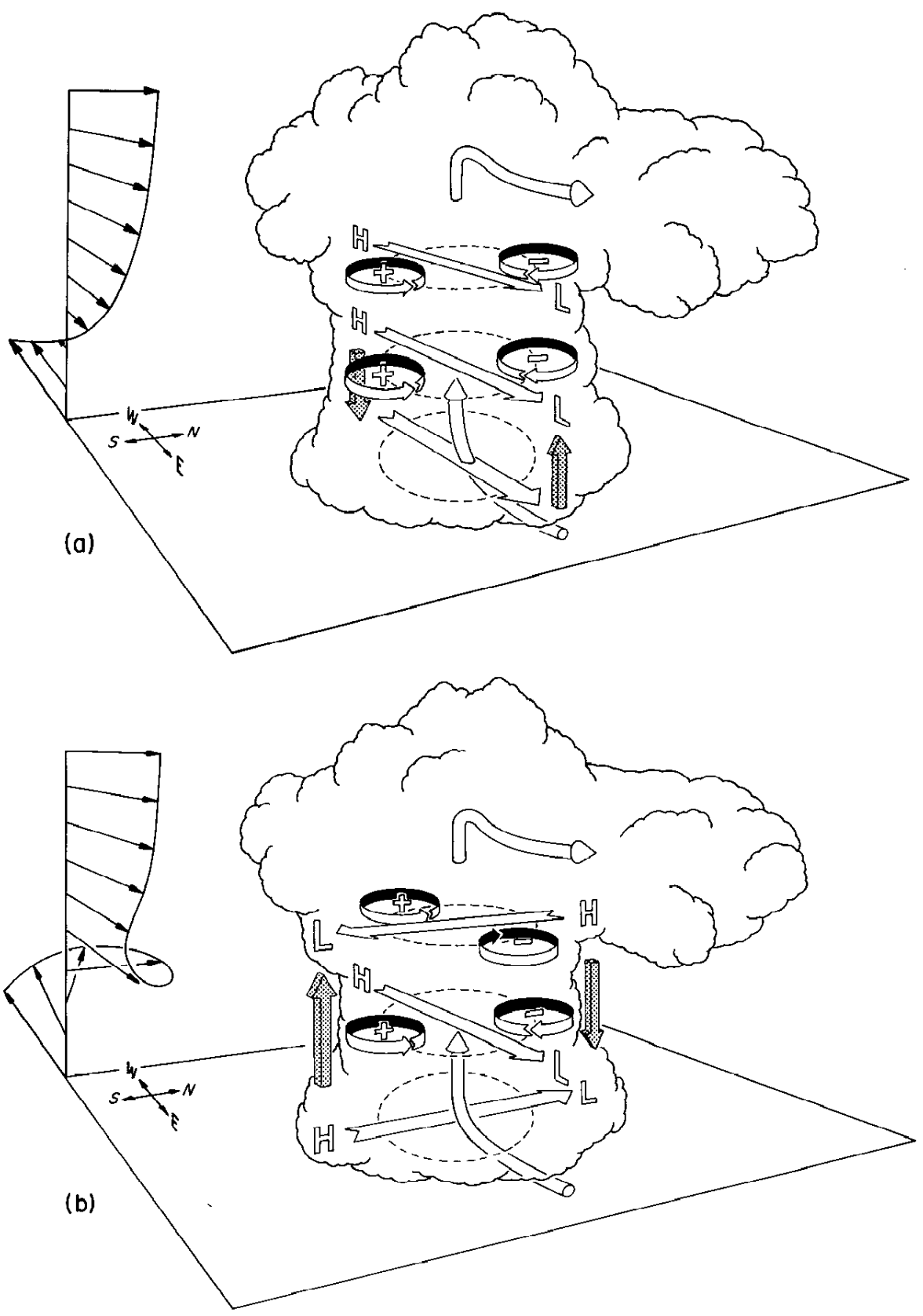

FIG. 11. Schematic diagram illustrating the pressure and vertical vorticity perturbations arising as an updraft interacts with environmental vertical wind shear that (a) does not change direction with height and (b) turns clockwise with height. The high $(\mathrm{H})$ to low $(\mathrm{L})$ horizontal pressure gradient forces that develop across the updraft in the direction of the local shear vector (flat arrows) at each level are labeled, along with the preferred location of cyclonic (+) and anticyclonic (-) vorticity. Shaded arrows depict the orientation of the resulting vertical pressure gradient forces. From Klemp (1987); adapted from Rotunno and Klemp (1982). 
right (left) flank of the storm (e.g., Fig. 11b for a veering shear profile). The linear dynamic pressure perturbations thus affect storm motion by dictating whether updraft growth is favored on the left or right flank of the storm. In veering (backing) flow, forcing from both the linear and nonlinear pressure perturbations is in the upward vertical direction on the right (left) storm flank, thereby favoring right-moving, cyclonically-rotating (left-moving, anticyclonically-rotating) storms (Rotunno and Klemp 1982; Klemp 1987; Bluestein 1993; Houze 1993).

It should be noted that in addition to the generation of horizontal vorticity by environmental wind shear as described in the above discussion of nonlinear pressure perturbations, horizontal vorticity can also be generated by buoyancy gradients (i.e., baroclinic generation of vorticity). This baroclinic generation of horizontal vorticity is governed by the 2-D horizontal vorticity tendency equations for inviscid Boussinesq flow, neglecting the Coriolis effect, as

$$
\begin{gathered}
\frac{\mathrm{D} \eta}{\mathrm{Dt}}=\frac{\partial \mathrm{B}}{\partial \mathrm{y}} \\
\frac{\mathrm{D} \xi}{\mathrm{Dt}}=-\frac{\partial \mathrm{B}}{\partial \mathrm{x}}
\end{gathered}
$$

where $\eta$ is the horizontal vorticity in the $\mathrm{x}$-direction and $\xi$ is the horizontal vorticity in the y-direction (e.g., Rotunno et al. 1988; Houze 1993; Rasmussen et al. 2000). This horizontal vorticity can then be tilted into the vertical and stretched by the updraft, and have the same effects on updraft intensity as described in the nonlinear pressure perturbation discussion above (e.g., Houze 1993; Markowski et al. 1998; Rasmussen et al. 2000). 


\section{(v) Surface cold pool and wind shear interaction}

The interaction between surface cold pools and environmental wind shear is an important factor in the development and sustenance of multicell storm systems. The surface cold pool, marked at its leading edge by a gust front, is formed as precipitation falling from a storm cell evaporates and cools the air. Surface convergence along the gust front can sometimes produce strong enough vertical motions to lift air to its LCL and LFC, thereby promoting new cell growth. However, the presence of low-level (i.e., over the depth of the surface cold pool, which is usually 2 or $3 \mathrm{~km}$ ) vertical wind shear can greatly enhance upward vertical motions along the gust front, and thereby provide a much better chance of new cell development. This is because the horizontal vorticity that is generated by the low-level vertical wind shear counterbalances the horizontal vorticity of the opposite sign that is generated by the buoyancy gradient at the gust front, and this balance results in enhanced lifting of air parcels (Fig. 12). Air parcels are lifted more vigorously and for a longer period of time when this balance exists, so that the LCL is reached and new cells are formed. Of particular significance to this study, the updrafts of storm cells will likely be stronger when low-level environmental wind shear exists along with a surface cold pool because: (1) the more vigorous lifting that results from the balance of horizontal vorticity associated with these two features will directly increase the magnitude of vertical motions in the updraft, (2) the more vigorous lifting and longer period of lifting will allow air parcels to reach the LFC, and thus they will be able to make use of the CAPE in the environment, and (3) the more erect updraft minimizes the amount of cooler, negatively buoyant outflow air mixing into the updraft 
(Rotunno et al. 1988; Bluestein 1993). Weisman and Rotunno (2004) confirmed the importance of horizontal vorticity balance in multicellular convection, and also determined that shear extending to greater depths (surface to $2.5-5 \mathrm{~km} \mathrm{AGL}$ ) than emphasized in the earlier study by Rotunno et al. (1988) (surface to 2-3 km AGL) was conducive to balancing the cold pool vorticity and hence enhancing storm strength.

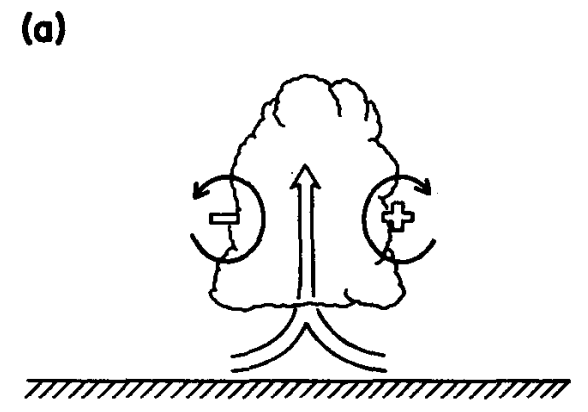

(c)

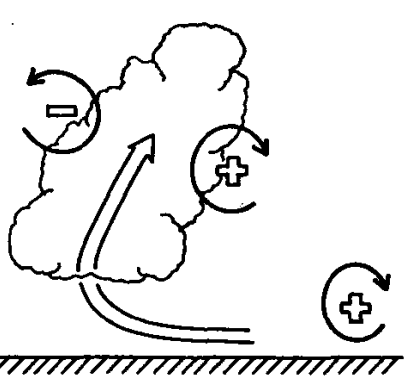

(b)
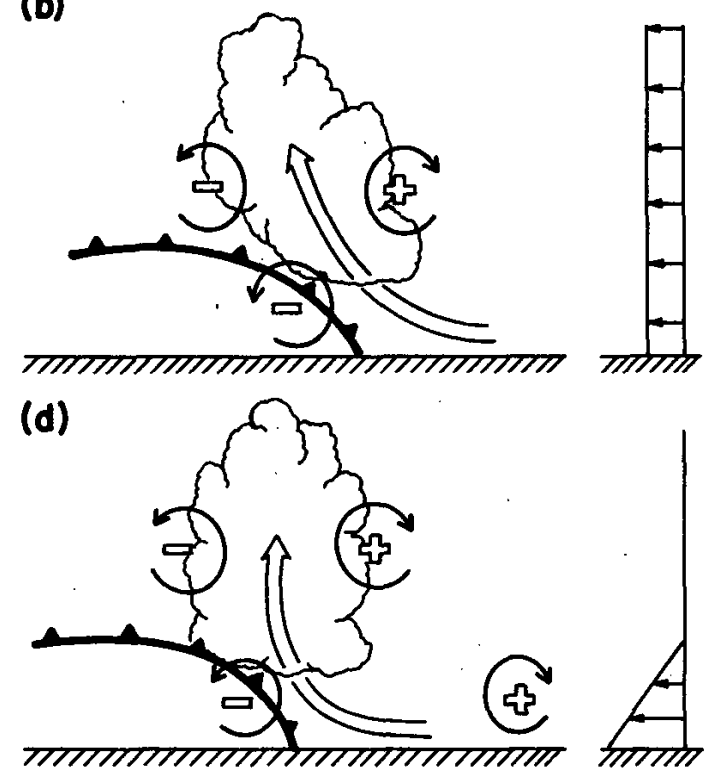

FIG. 12. Schematic diagram showing how a buoyant updraft may be influenced by vertical wind shear and/or a cold pool. (a) With no vertical wind shear and no cold pool, the axis of the updraft (thick arrow) produced by the thermally created, symmetric vorticity (sense of rotation indicated by thin arrows and + (positive) or - (negative) signs) distribution is vertical. (b) With a cold pool (underneath cold front symbol) and no shear, the distribution is biased by the negative vorticity of the underlying cold pool and causes the updraft to lean as shown. (c) With shear and no cold pool, the distribution is biased toward positive vorticity, causing the updraft to lean as shown. (d) With both a cold pool and shear, the two effects may balance each other, and allow an erect, intense updraft. Environmental wind profile indicated at the top right for (a) and (b) and at the bottom right for (c) and (d). From Rotunno et al. (1988). 


\section{(2) OBSERVED EFFECTS OF UPDRAFT INTENSITY ON CG LIGHTNING}

\section{POLARITY}

Observations from past studies support a link between enhanced updraft intensity and increased production of positive CG lightning. For instance, Stolzenburg (1994) found the production of positive CG flashes to be associated with exceptionally tall storms experiencing a rapid increase in radar echo top height. Williams et al. (2005) noted that the preferred region for positive severe storms, the Great Plains, is climatologically where large CAPE and high CBHs, both favorable for the development of intense updrafts, coexist. Several case studies have documented the occurrence of anomalous positive CG lightning activity with severe storms likely undergoing updraft intensification. ${ }^{9}$ For instance, in Smith et al. (2000), increased generation of positive CG flashes was associated with hypothesized increased intensities of tornadic supercell updrafts as the storms passed through the gradient region of a near-surface $\theta_{\mathrm{e}}$ ridge toward the $\theta_{\mathrm{e}}$ maximum. In Gilmore and Wicker (2002), the enhancement of updraft intensities (inferred from 40-dBZ echo-top heights) and positive CG flash production occurred as storms traversed a mesoscale outflow boundary. The merger between two supercells directly preceded the enhanced generation of positive CG flashes in Carey and Rutledge (1998). Similarly, the enhanced production of positive CG lightning in Carey et al. (2003a) shortly followed the merger of a supercell and squall line. As discussed by

\footnotetext{
${ }^{9}$ It is important to note that updraft intensities were measured indirectly or not measured in these case studies (Smith et al. 2000; Gilmore and Wicker 2002; Carey and Rutledge 1998; Carey et al. 2003a), as well as in the studies by Stolzenburg (1994) and Williams et al. (2005). However, the indirect measurements of updraft intensity (e.g., Stolzenburg 1994; Gilmore and Wicker 2002) and hypothesized increases in updraft intensity (e.g., Williams et al. 2005; Smith et al. 2000; Carey and Rutledge 1998; Carey et al. 2003a) support a positive correlation between the generation of positive CG lightning and updraft strength.
} 
Carey et al. (2003a), the merging of storms (e.g., Carey and Rutledge 1998; Carey et al.

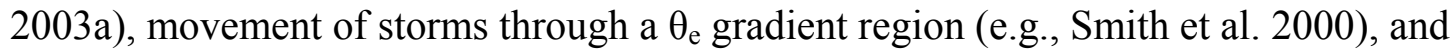
movement of storms across an outflow boundary (e.g., Gilmore and Wicker 2002) all likely have similar dynamical, microphysical, and electrical impacts on the storms. These events can all lead to updraft intensification, associated increases in cloud temperature and LWCs, positive charging of graupel and hail, development of an inverted charge structure, and increased positive CG flash production. Recent studies have provided more direct evidence of a link between increased updraft intensity and positive CG flash production. Using multi-Doppler data to synthesize the threedimensional wind field of a tornadic supercell observed during STEPS, Tessendorf et al. (2005) and Wiens et al. (2005) showed that increased positive CG flash production by the supercell was nearly coincident with dramatic intensification of the storm updraft.

\section{d. Warm cloud depth}

Another topic of particular interest to this study is whether a systematic difference in warm cloud depth (i.e., depth between cloud base and the $0^{\circ} \mathrm{C}$ level; WCD) exists between negative and positive storms. It has been hypothesized that shallow WCDs favor positive CG flash production (Williams et al. 2005). The warm cloud layer is a favorable region for the growth of precipitation particles through collision and coalescence, which is a very efficient precipitation process (Rogers and Yau 1989; Williams 1995; Knight and Knight 2001; Rosenfeld and Woodley 2003). In the warm cloud layer, cloud droplets are collected by larger liquid water drops, as these larger 
collector drops grow into precipitation-sized particles. This efficient growth of precipitation, and its eventual fallout as rain, depletes the cloud water in the warm cloud layer. The removal of cloud water from the warm cloud layer reduces the amount of cloud water available for transport by the updraft into the mixed-phase region $\left(0^{\circ} \mathrm{C}\right.$ to $40^{\circ} \mathrm{C}$ ) of the cloud (Fig. 13), where electrification occurs (Williams et al. 2005). There will thus be less supercooled water available in the mixed-phase region for the growth of ice crystals, graupel, and hail, which are of course critical to the charging process. Furthermore, reduced LWCs in the mixed-phase region favor negative charging of graupel and hail (e.g., Takahashi 1978; Saunders et al. 1991), which is not favorable for the development of an inverted charge structure and increased production of positive CG lightning. Therefore, it is hypothesized that small WCDs are favorable for positive CG flash production, as the reduced collision/coalescence zone associated with a shallow warm cloud layer results in a greater amount of cloud water available to the mixed-phase region (e.g., Williams et al. 2005), all else being equal. Small WCDs result from high CBHs (which LCL is a proxy for) and/or low freezing level heights (see Fig. 13 for effect of $\mathrm{CBH})$. 


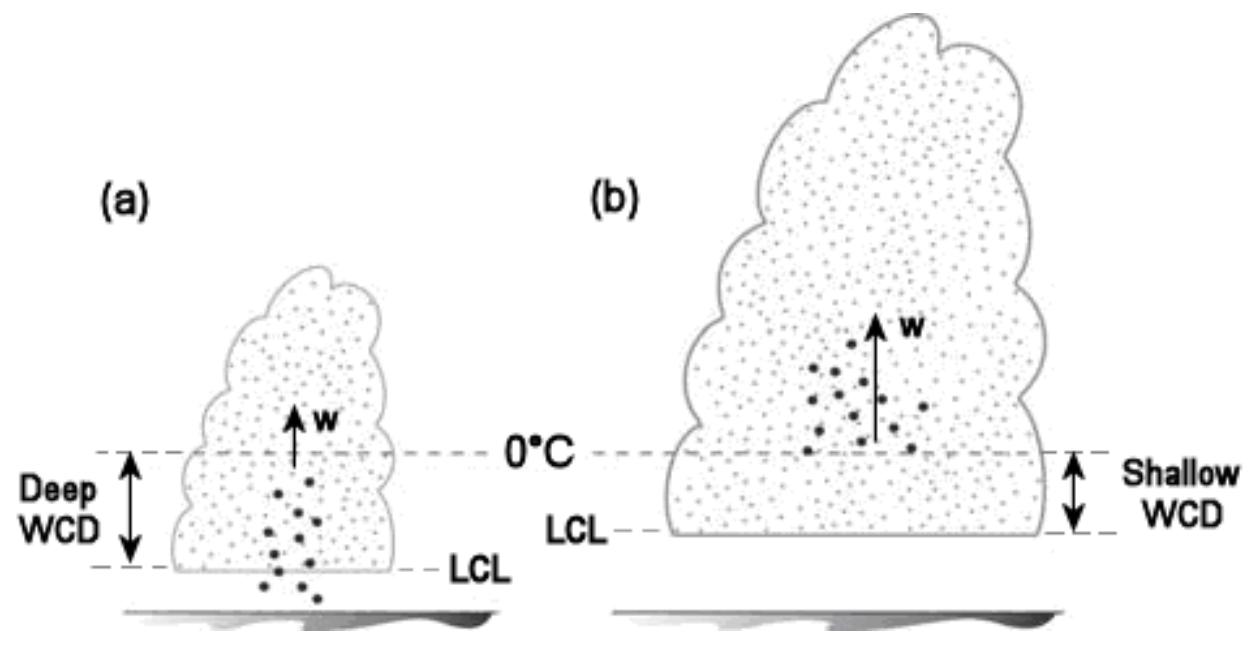

FIG. 13. Illustration showing the effect of WCD on the amount of cloud water available to the mixedphase region. The freezing level is at the same height for both clouds, but cloud (a) has a lower CBH than cloud (b), resulting in a greater depth of warm cloud in cloud (a). The cloud water supply of cloud (a) is depleted by collision/coalescence in its deep warm cloud layer and subsequent rainout. The shallow warm cloud layer of cloud (b) suppresses coalescence and thus more cloud water is available for transport into the mixed-phase region by the updraft. The reduction of entrainment due to a higher $\mathrm{CBH}$ and hence wider updraft results in a stronger updraft (w; magnitude indicated by arrow length) in cloud (b). Adapted from Williams (2004).

\section{e. Aerosol effects}

Some studies (e.g., Lyons et al. 1998; Murray et al. 2000) have suggested that increased aerosol concentrations may be responsible for anomalous positive $\mathrm{CG}$ lightning behavior. As reported by Lyons et al. (1998) and Murray et al. (2000), smoke from forest fires in Mexico was advected into the central U.S. during the spring of 1998, and storms during this time produced unusually large numbers and percentages of positive CG flashes. Enhanced aerosol concentrations result in a large number of small cloud droplets, due to more cloud condensation nuclei (CCN) competing for the available liquid water supply. This narrow cloud droplet spectrum of small drops suppresses coalescence and subsequent rainout, thereby maintaining cloud water that can 
be transported vertically into the mixed-phase region (Williams et al. 2002). As described previously, increased LWCs and narrow cloud droplet spectra in the mixedphase region favor positive charging of graupel and hail (e.g., Takahashi 1978; Saunders et al. 1991; Avila and Pereyra 2000), and are thus thought to result in an increased production of positive CG lightning. Williams et al. (2005) point out that thermodynamic conditions (e.g., elevated CBHs), rather than increased aerosol concentrations, could have led to the enhanced production of positive CG flashes during the spring of 1998, as conditions during this time were abnormally hot and dry compared to climatology (Lyons et al. 1998; Smith et al. 2003). As pointed out by Williams et al. (2005) and shown by Lang and Rutledge (2006), the roles of extraordinary thermodynamic, dynamic, and CCN concentrations are often difficult to distinguish since they often occur simultaneously. Nonetheless, Lang and Rutledge (2006) showed that positive CG lightning enhancements downwind of a forest fire in Colorado were more consistent with a causative role for elevated $\mathrm{CBH}$ and reduced WCD than for smoke aerosols. The results of Williams et al. (2002) cast further doubt on a primary role for aerosols in enhancing cloud electrification. A lack of distinction was found in the electrical parameters (peak flash rate, lightning yield per unit rainfall) investigated by Williams et al. (2002) between an aerosol-rich regime and an aerosol-poor regime in the Amazon basin. The present study does not have the adequate data to, nor attempts to, assess the effects of aerosols on CG lightning polarity. However, it is worth noting that aerosols may potentially influence CG flash polarity. 


\section{CHAPTER IV}

\section{DATA AND METHODOLOGY*}

The relationship between CG lightning behavior and the local mesoscale environment was investigated for six different days (23, 24 May 2002; 4, 12, 15, 19 June 2002) during IHOP_2002. The chosen days were selected based on the occurrence of severe weather, the prevalence of positive and/or negative storms, and the availability of enhanced spatial and temporal resolution sounding data to characterize the local mesoscale environments of these storms. Within these six days, nine distinct storm systems were identified based on their CG lightning polarity. Four of these storm systems were positive storms, and the remaining five were negative storms. Multiple positive and negative storm systems were investigated to help determine whether any observed differences in the meteorological environments between the two storm types (positive and negative) were indeed systematic and consistent.

\section{a. Cloud-to-ground lightning data}

Cloud-to-ground lightning data analyzed in this study were collected by the NLDN, which is owned and operated by Vaisala (Tucson, Arizona). The NLDN consists of 106 sensors across the continental U.S., with typical distances between the sensors of 275-325 km. The NLDN records the time, location, polarity, peak current, and multiplicity (number of strokes per flash) of CG lightning flashes. The time,

\footnotetext{
* Part of this chapter is reprinted with permission from Carey, L. D., and K. M. Buffalo, 2007: Environmental control of cloud-to-ground lightning polarity in severe storms. Mon. Wea. Rev., 135, 1327 1353. C 2007 American Meteorological Society.
} 
location, polarity, and peak current reported for a flash are those measured for the first return stroke of the flash. Typically, a stroke with a peak current of $5 \mathrm{kA}$ can be detected by 2-4 sensors, a 25-kA stroke can be detected by 6-8 sensors, and a 100-kA stroke can be detected by 20 or more sensors. Over most of the continental U.S., including the IHOP_2002 domain, the NLDN has a median location accuracy of $0.5 \mathrm{~km}$, a flash detection efficiency of $80 \%-90 \%$ for strokes with peak currents greater than 5 $\mathrm{kA}$, and a temporal resolution of 0.1 seconds (Cummins et al. 1998).

The CG lightning data recorded by the NLDN were analyzed using Interactive Data Language (IDL) programs developed by the Lightning Research Group at Texas A\&M University, under the direction of Dr. Richard E. Orville. The programs were originally written by Dr. Gary Huffines, with additional contributions and modifications made by Brandon Ely, Stephen Phillips, and Scott Steiger. Some further modifications were made to these programs to fit the purposes of the present study. Using these IDL programs, plots of total CG flash density and percent positive flashes were created with a horizontal resolution of $5 \mathrm{~km}$. Since positive flashes with peak currents less than $10 \mathrm{kA}$ were likely associated with misidentified cloud flashes (Cummins et al. 1998; Wacker and Orville 1999a,b), they were removed from the data sample. ${ }^{10}$

\footnotetext{
${ }^{10}$ Cummins et al. (2006) reported that the recent NLDN upgrade increased the detection of low amplitude flashes and thus the potential for misclassifying cloud flashes as ground discharges of either polarity. To test the sensitivity of the regional CG polarity classification to peak current thresholding, all NLDNdetected CG flashes with peak currents less than 10, 15, and $20 \mathrm{kA}$ were removed (K. Cummins 2006, personal communication). The mean positive $\mathrm{CG}$ percentage in positive (negative) $\mathrm{CG}$ polarity regions after removing all CG flashes with peak currents less than 10,15 , and $20 \mathrm{kA}$ was $53 \%, 66 \%$, and $81 \%$ $(10 \%, 9 \%$, and $11 \%)$, respectively. Since the CG polarity classification was insensitive to the choice of a peak current threshold, the suggestion of Cummins et al. (1998) was followed until ongoing NLDN flash classification improvements are completed.
} 
The plots of percent positive flashes over the IHOP_2002 domain were visually inspected to define mesoscale regions across which either positive storms or negative storms prevailed. The overall percentage of positive flashes within each of these defined regions was then calculated to confirm that the mesoscale region was indeed characterized by positive storms (i.e., overall percent positive flashes for the mesoscale region $>25 \%$; termed positive mesoscale regions) or negative storms (i.e., overall percent positive flashes for the mesoscale region $\leq 25 \%$; termed negative mesoscale regions). The plots were also visually inspected to insure that the CG lightning polarity was consistent across the entire mesoscale region. In other words, a mesoscale region defined as positive contained anomalously high percentages of positive CG flashes across its entire domain, as opposed to containing a mix of positive and negative storms that happened to average out to make the mesoscale region positive. Plots of flash density were used as checks to make sure that positive (negative) storm systems identified were not simply an artifact of isolated flashes of positive (negative) polarity. Through this method, four positive (23, 24 May; 15, 19 June) and five negative (23, 24 May; 4, 12, 15 June) storm systems were identified. The meteorological environments of the nine mesoscale regions encompassing these respective storm systems serve as the focus for the remainder of the study.

\section{b. Meteorological data}

Several different data sources were used to investigate the general meteorological environment associated with each case studied, and to identify key weather features 
associated with each event. Upper-air analyses were obtained from the Storm Prediction Center (SPC) Severe Thunderstorm Events archive at http://www.spc.noaa.gov/exper/archive/events/. Surface observations used were from the National Center for Atmospheric Research (NCAR) Research Applications Program (RAP), and were obtained from the UCAR Mesoscale and Microscale Meteorology (MMM) Division's online image archive at http://locust.mmm.ucar.edu/case-selection/. Additional surface observations were obtained from the University Corporation for Atmospheric Research (UCAR) Joint Office for Science Support (JOSS) IHOP_2002 website (http://www.eol.ucar.edu/projects/ihop/). Geostationary Operational Environmental Satellite (GOES) visible satellite images from GOES-8 and GOES-11 were obtained from the UCAR JOSS IHOP_2002 website. Analyses from the Forecast Systems Lab (FSL) Rapid Update Cycle (RUC) model with 10-km resolution, available from the UCAR JOSS IHOP_2002 website, were also used to investigate the meteorological environment for each case. Eta model analyses of vorticity, heights, and winds at the 500-hPa level, produced by NCAR RAP, were obtained from the UCAR MMM image archive.

\section{c. Analysis of storm structure, morphology, and intensity}

Storm structure and morphology were analyzed using radar reflectivity and velocity data. Storm intensity was determined via radar reflectivity data and severe storm reports compiled by the NWS. The severe storm reports were obtained from the National Climatic Data Center (NCDC) Storm Events Database, which can be accessed 
online at http://www4.ncdc.noaa.gov/cgi-win/wwcgi.dll?wwEvent $\sim$ Storms. As noted by Carey et al. (2003b), severe storm reports are unfortunately not synonymous with severe storms. For instance, severe weather can be misreported, can go completely unreported, or a single severe weather event (tornado, hail, or winds) can result in multiple reports (e.g., Kelly et al. 1978; Kelly et al. 1985; Carey et al. 2003b). However, severe storm reports still represent the most comprehensive and reliable record of severe weather available, and thus are used in this study to provide a measure of storm intensity. From the severe storm reports, the number of severe wind $\left(\geq 26 \mathrm{~m} \mathrm{~s}^{-1}\right)$, hail (diameter $\geq 1.9$ cm), and tornado (F0-F5) events (e.g., Johns and Doswell 1992) observed within each of the nine mesoscale regions during the respective analysis periods for each region were determined. These numbers provide a general picture of storm intensity in each mesoscale region, and also portray the nature of severe weather that occurred in each region.

Radar data used in this study were collected by the Weather Surveillance Radar1988 Doppler (WSR-88D) radars located in the vicinity of the IHOP_2002 domain. Regional radar summaries of low-level WSR-88D radar reflectivity produced by Weather Services International (WSI) Corporation, referred to as WSI NOWRAD images, were used to view the storm systems as a whole. WSI NOWRAD images centered over the IHOP_2002 domain were obtained from the UCAR JOSS IHOP_2002 website, and have a spatial resolution of $2 \mathrm{~km}$ and temporal resolution of 1 hour. Additional WSI NOWRAD images were obtained from the UCAR MMM website. These WSI NOWRAD images from the UCAR MMM website have a 2-km spatial 
resolution and a 30-minute temporal resolution. To view the individual convective cells composing the MCSs at an enhanced resolution, low-level radar reflectivity imagery from individual WSR-88D sites was used. These images were obtained from the UCAR JOSS IHOP_2002 website, and have an average temporal resolution of 10-20 minutes. The Warning Decision Support System-Integrated Information (WDSS-II; see http://www.wdssii.org/ for details on WDSS-II software), developed at the National Severe Storms Laboratory (NSSL) and the Cooperative Institute for Mesoscale Meteorological Studies (CIMMS) at the University of Oklahoma, was used for detailed analysis of storm structure, morphology, and intensity. Level II WSR-88D radar data analyzed via WDSS-II were obtained from NCDC. WDSS-II allows the user to zoom in on individual convective features to provide an enhanced view of storm structure and intensity. Also, the Level II data have an increased temporal resolution of 5 minutes, allowing for more detailed analysis of storm morphology. WDSS-II allows for the analysis of storm structure in the vertical as well. Vertical cross-sections of radar reflectivity from convective cells deemed to be representative of the individual cells composing the respective MCSs were created for each mesoscale region. These crosssections were used to compare vertical storm structure between positive and negative storms, and were also used to investigate differences in storm intensity between the two storm types. The study of horizontal storm structure and intensity at different vertical levels was also possible with WDSS-II, and composite reflectivity images provided an additional means for analyzing convective intensity. Radial velocity data were used in 
conjunction with reflectivity data in the study of cell structure to help identify supercells through the detection of mesocyclones.

\section{d. Characterization of the mesoscale environment with sounding data}

\section{1) SOUNDING PLATFORMS}

The mesoscale environments of positive and negative storms in this study were characterized using sounding data collected during IHOP_2002. The multitude of soundings launched during IHOP_2002 greatly enhanced the spatial and temporal resolution of sounding data available, and allowed for detailed characterization of the mesoscale environments of storms. Data from several different sounding platforms operating during IHOP_2002 were used to characterize the nine mesoscale regions of interest. Sounding platforms included NWS upper-air sites, Atmospheric Radiation Measurement-Clouds and Radiation Testbed (ARM-CART) sites, the National Center for Atmospheric Research/Atmospheric Technology Division (NCAR/ATD)-Integrated Sounding System (ISS) facility, the NSSL Mobile Cross-chain LORAN Atmospheric Sounding System (MCLASS) facility, and NCAR/ATD Mobile GPS/LORAN Atmospheric Sounding System (MGLASS) facilities. Dropsondes ${ }^{11}$ launched from a Flight International (FI) Learjet were also used (see Weckwerth et al. (2004) and the UCAR JOSS IHOP_2002 website (http://www.eol.ucar.edu/projects/ihop/) for more details on sounding platforms). Sounding data from these platforms were interpolated to

\footnotetext{
${ }^{11}$ A dropsonde is a radiosonde, or in this case a rawinsonde, with a parachute attached that is dropped from an airplane carrying receiving equipment for the purpose of obtaining an upper-air sounding during descent (Glickman 2000).
} 
a constant vertical resolution of $5 \mathrm{hPa}$ by UCAR JOSS. All sounding data went through a quality control (QC) procedure conducted by JOSS, in addition to any QC processing conducted at each individual platform. The QC procedure performed by JOSS consisted of a set of automated internal consistency checks of two different types - gross limit checks on all parameters (pressure, altitude, temperature, dewpoint, relative humidity, $\mathrm{u}$ wind component, v wind component, wind speed, wind direction, and ascent rate) and vertical consistency (i.e., rate-of-change) checks on temperature, pressure, and ascent rate. Any data marked as "bad" by the JOSS QC procedure were automatically discarded from this study. Data marked as "questionable" by the JOSS QC procedure were manually inspected and it was then subjectively decided whether to keep or discard the data. This decision was based on comparisons of the "questionable" data with data values at adjacent vertical levels, comparisons with surface data if the data in question were at low levels, and comparisons with nearby soundings if available. Often, the "questionable" data resulted from a sounding being launched just ahead of or behind a surface boundary (e.g., fronts, drylines, outflow boundaries), and the data were indeed an accurate measurement of the meteorological conditions sampled and were thus retained in the data sample. Also, any sounding data that appeared "questionable" when plotted were subjectively discarded or retained based on the comparisons mentioned above. 


\section{2) PROXIMITY SOUNDINGS}

As described in detail by Brooks et al. (1994a), obtaining proximity soundings that are truly representative of meteorological conditions experienced by a convective system is not a trivial task. The goal in selecting proximity soundings is to select only those soundings that sampled the inflow air of the cell(s) of interest. However, spatial and temporal variability within the environments of severe storms is the rule, rather than the exception, and it is thus often difficult to obtain soundings that truly are representative of the environmental conditions experienced by a given storm. The multitude of soundings launched during IHOP_2002 provided the opportunity to obtain proximity soundings that are truly representative of conditions experienced by the storms of interest, and this is one reason why anomalous positive CG lightning events that occurred during IHOP_2002 were chosen as the focus of this study.

Three issues need to be considered and accounted for when selecting representative proximity soundings: (1) spatial variability of environmental conditions, (2) temporal variability of environmental conditions, and (3) the sampling of conditions that are not representative of the inflow air of the storm(s) of interest, due to factors such as convective contamination and the presence of boundaries (e.g., fronts, drylines, outflow boundaries; Brooks et al. 1994a). To account for issues (1) and (2), distance and time constraints were placed on the soundings used. A distance constraint of $100 \mathrm{~km}$ and a time constraint of 3 hours were used. In other words, the CG lightning-producing storms of interest were within $100 \mathrm{~km}$ of the sounding site within 3 hours before or 3 hours after the sounding release time. To account for issue (3), all soundings satisfying 
criteria (1) and (2) were manually inspected for signatures of convective contamination (e.g., the lower troposphere cooled and stabilized by outflow, the upper troposphere moistened by anvils, the wind structure altered dramatically, etc.) and for signatures that the sounding sampled a different air mass than that in which the storms of interest developed (e.g., the sounding was launched on the opposite side of a front, dryline, or outflow boundary from where the convection developed). In addition, surface observations, radar reflectivity imagery, visible satellite imagery, and CG flash plots from the time of sounding release were used to compare the sounding location to the location of ongoing convection and any boundaries. This provided an additional check to insure that the sounding was not convectively contaminated and that it sampled the same air mass in which storms developed and were sustained. Since the proximity sounding dataset compiled strongly dictates the results of a study, great detail and care were taken in assembling this dataset. From hundreds of soundings launched on the six days investigated in this study, 48 soundings were chosen as representative inflow proximity soundings. Half of these (24) represent the mesoscale environments of positive storms and the other half (24) represent the mesoscale environments of negative storms.

In compiling a proximity sounding dataset, competing forces exist between assembling a large dataset by enforcing less stringent requirements on the soundings used, and assembling a dataset truly representative of storm inflow air by enforcing more stringent requirements on the soundings used. Naturally, the latter approach results in a smaller proximity sounding dataset (Brooks et al. 1994a). The study at hand placed 
greater emphasis on using only those proximity soundings truly representative of inflow air than on the assemblage of a large dataset. At the same time, the size of the proximity sounding dataset compiled for this study is sufficiently large to produce statistically significant and robust results (as will be shown in Chapter V), although it would be worthwhile for subsequent studies to verify the results of this study with a larger dataset. It is worth noting that there is an alternate method to the somewhat subjective method used in this study, in which soundings were manually inspected and compared to storm and boundary positions to account for issue (3) above. The alternate method employs a purely objective approach. Time and distance constraints are defined as in the present study, but checks regarding criterion (3) are based on simple objective guidelines, such as the presence of a given amount of CAPE in the sounding (e.g., Brooks et al. 1994a; Rasmussen and Blanchard 1998) or dewpoint depressions being greater than some chosen value (indicating that convection has not contaminated the sounding through moistening). However, such objective guidelines cannot possibly identify all soundings contaminated by convection or that sampled a different air mass than that in which a given storm developed, especially when boundaries and small-scale environmental variability exist. Thus, it was decided that using a subjective approach applied uniformly to all soundings would produce a more representative proximity sounding dataset than would employing a strictly objective approach. 


\section{3) CALCULATION OF METEOROLOGICAL PARAMETERS}

The National Centers Advanced Weather Interactive Processing System Skew-T Hodograph Analysis and Research Program (NSHARP; Hart and Korotky 1991) was used for sounding display and analysis, including the calculations of most soundingderived parameters. NSHARP includes a virtual temperature correction (Doswell and Rasmussen 1994) in the calculations of thermodynamic parameters to account for the effects of water vapor. A mean-layer parcel, using mean temperature and dewpoint in the lowest $100 \mathrm{hPa}$ (approximately $1 \mathrm{~km}$ in depth), was used to calculate thermodynamic parameters. Craven et al. (2002a) determined that a mean-layer parcel is more representative of the actual parcel associated with convective cloud development than is a surface-based parcel, and thus recommended using a mean-layer parcel in the calculations of thermodynamic parameters. Thompson et al. (2003) also found a meanlayer parcel to be superior to a surface-based parcel in accurately calculating thermodynamic parameters in convective storm environments.

A FORmula TRANslation (FORTRAN) program developed by Dr. Kerry A. Emanuel at the Massachusetts Institute of Technology (Emanuel 1994) and modified by Dr. Walter A. Petersen while at Colorado State University (currently affiliated with the University of Alabama in Huntsville), was used in the calculations of some environmental parameters. This program (hereafter referred to as the E/P (Emanuel/Petersen) program) was used to calculate adiabatic LWCs through various sounding depths. It was also used to calculate the mean temperature in the lowest 100 $\mathrm{hPa}$ of soundings, which was used in the calculation of $\theta_{\mathrm{e}}$. Using this mean temperature 
in the lowest $100 \mathrm{hPa}$ and mean mixing ratio in the lowest $100 \mathrm{hPa}$ (output by NSHARP), $\theta_{\mathrm{e}}$ was computed using the following formula from Bolton (1980) for a pseudoadiabatic process:

$$
\theta_{\mathrm{e}}=\mathrm{T}_{\mathrm{K}}\left(\frac{1000}{\mathrm{p}}\right)^{0.2854\left(1-0.28 \times 10^{-3} \mathrm{r}\right)} \times \exp \left[\left(\frac{3.376}{\mathrm{~T}_{\mathrm{L}}}-0.00254\right) \times \mathrm{r}\left(1+0.81 \times 10^{-3} \mathrm{r}\right)\right],
$$

where $\mathrm{T}_{\mathrm{K}}, \mathrm{p}$, and $\mathrm{r}$ are the absolute temperature (degrees Kelvin), pressure (hPa), and mixing ratio $\left(\mathrm{g} \mathrm{kg}^{-1}\right)$, respectively, at the initial level (i.e., for this study $\mathrm{T}_{\mathrm{K}}=$ mean absolute temperature in the lowest $100 \mathrm{hPa}, \mathrm{r}=$ mean mixing ratio in the lowest $100 \mathrm{hPa}$, $\mathrm{p}=$ surface pressure). $\mathrm{T}_{\mathrm{L}}$ is the absolute temperature at the LCL, given by (Bolton 1980)

$$
\mathrm{T}_{\mathrm{L}}=\frac{2840}{3.5 \ln \mathrm{T}_{\mathrm{K}}-\ln \mathrm{e}-4.805}+55
$$

where e is water vapor pressure $(\mathrm{hPa})$, and is obtained from $\mathrm{r}$ through the relationship (Bolton 1980)

$$
\mathrm{e}=\frac{\mathrm{pr}}{622+\mathrm{r}}
$$

IDL programs were developed to reformat the sounding data available from the IHOP_2002 dataset into the format required by NSHARP and the E/P program. IDL programs were also utilized to calculate CAPE in various sounding layers. Using these programs, vertical sounding levels were filtered out by temperature, so that only those levels at temperatures warmer than a specified temperature value $\left(\mathrm{T}_{\mathrm{S}}\right)$ were retained in the sounding file. This modified sounding file was then passed to NSHARP, which calculated CAPE between the LFC and $\mathrm{T}_{\mathrm{S}}$. CAPE values between various temperature levels were then calculated using these CAPE values computed from the filtered 
sounding data. For instance, to calculate the amount of CAPE between the $-10^{\circ} \mathrm{C}$ and $-40^{\circ} \mathrm{C}$ levels, the amount of CAPE between the LFC and $-10^{\circ} \mathrm{C}$ level was subtracted from the amount of CAPE between the $\mathrm{LFC}$ and $-40^{\circ} \mathrm{C}$ level.

In calculating environmental parameters from the sounding data, obviously only those soundings that contained the necessary data and extended through the necessary depth to accurately calculate each respective parameter were used. For instance, total CAPE values from soundings that did not extend to the equilibrium level (EL) were discarded from the data sample. As another example, storm motions could not be estimated by NSHARP for soundings that did not extend through at least $6 \mathrm{~km}$ AGL, so any parameters dependent on storm motion were discarded from such soundings. Many of the mobile (MCLASS, MGLASS) soundings launched during IHOP_2002, as well as the dropsondes, did not extend through the full depth of the troposphere, since IHOP_2002 investigators were primarily concerned with measuring low-level moisture fields. Hence, many of these soundings could not be used for calculating parameters that require measurements through a significant depth of the troposphere (e.g., total CAPE, storm motion and dependent parameters, deep layer (0-6 km AGL) shear, precipitable water, etc.). Table 1 displays the total number of soundings used to characterize each mesoscale region, the number of these soundings that were full (extended through the depth of the troposphere), and the number that were truncated (did not extend through the depth of the troposphere) along with the pressure level of truncation. 
TABLE 1. Total number of soundings used to characterize each mesoscale region, and the numbers of these soundings which were full and truncated. The pressure level of truncation $(\mathrm{hPa})$ is also provided, with the number in parentheses following the pressure level indicating the number of soundings truncated at that respective level (unless only one sounding was truncated at the given level). Sounding numbers and levels of truncation are also provided for the total number of positive (negative) soundings from all positive (negative) mesoscale regions combined.

\begin{tabular}{|c|c|c|c|c|}
\hline \multicolumn{5}{|c|}{ POSITIVE MESOSCALE REGIONS - Mesoscale regions containing $>25 \%+C G$ lightning. } \\
\hline Date & $\begin{array}{l}\text { Total Number of } \\
\text { Soundings }\end{array}$ & $\begin{array}{c}\text { Full } \\
\text { Soundings }\end{array}$ & $\begin{array}{l}\text { Truncated } \\
\text { Soundings }\end{array}$ & $\begin{array}{l}\text { Pressure Level of } \\
\text { Truncation }(\mathrm{hPa})\end{array}$ \\
\hline 23 May & 1 & 1 & 0 & N/A \\
\hline 24 May & 8 & 1 & 7 & $350,505,575(5)$ \\
\hline 15 June & 7 & 4 & 3 & $340,440,485$ \\
\hline 19 June & 8 & 4 & 4 & $365,455(3)$ \\
\hline All Positive Soundings & 24 & 10 & 14 & $\begin{array}{c}340,350,365,440,455 \\
(3), 485,505,575(5)\end{array}$ \\
\hline \multicolumn{5}{|c|}{ NEGATIVE MESOSCALE REGIONS - Mesoscale regions containing $\leq 25 \%+C G$ lightning. } \\
\hline Date & $\begin{array}{c}\text { Total Number of } \\
\text { Soundings }\end{array}$ & $\begin{array}{c}\text { Full } \\
\text { Soundings }\end{array}$ & $\begin{array}{l}\text { Truncated } \\
\text { Soundings }\end{array}$ & $\begin{array}{l}\text { Pressure Level of } \\
\text { Truncation }(\mathrm{hPa})\end{array}$ \\
\hline 23 May & 3 & 3 & 0 & $\mathrm{~N} / \mathrm{A}$ \\
\hline 24 May & 3 & 3 & 0 & N/A \\
\hline 4 June & 9 & 9 & 0 & $\mathrm{~N} / \mathrm{A}$ \\
\hline 12 June & 8 & 6 & 2 & 450,485 \\
\hline 15 June & 1 & 1 & 0 & N/A \\
\hline All Negative Soundings & 24 & 22 & 2 & 450,485 \\
\hline
\end{tabular}

\section{4) ASSESSMENT OF THE MESOSCALE ENVIRONMENT USING}

\section{SOUNDING DATA}

In characterizing the mesoscale environments of positive and negative storms, special emphasis was placed on those meteorological parameters that allowed testing of the hypothesis discussed earlier. As described in Chapter II, the hypothesis states that the local mesoscale environment indirectly influences CG lightning polarity by directly controlling storm structure, dynamics, and microphysics, while the associated corollary more specifically states that broad, intense updrafts and associated high LWCs in 
positive storms lead to positive charging of graupel and hail in mixed-phase conditions via the NIC mechanism, an inverted-polarity charge structure, and increased frequency of positive CG lightning. Based on this hypothesis and corollary, those environmental parameters that strongly influence storm organization, updraft intensity, and associated cloud LWCs were emphasized. CAPE, vertical wind shear, and the bulk Richardson number (BRN) were investigated with regard to storm organization (e.g., Weisman and Klemp 1982, 1984, 1986). As discussed in Chapter III, depth of the warm cloud layer can affect the amount of cloud liquid water available to the mixed-phase region, and hence is hypothesized to affect storm electrification and CG lightning polarity. Warm cloud layer depth was calculated by subtracting the LCL height (a measure of CBH) from the height of the $0^{\circ} \mathrm{C}$ level. Many environmental parameters were investigated to assess updraft intensity, as described below.

It was discussed in Chapter III that multiple factors affect updraft intensity in convective clouds. These factors include: (1) parcel buoyancy, (2) pressure perturbations associated with parcel buoyancy, (3) water loading, (4) entrainment of environmental air, and (5) dynamical effects, including dynamic pressure perturbations and surface cold pool/environmental wind shear interactions, associated with gradients in the wind field. Low to midlevel lapse rates and CAPE were used to assess the first factor listed, parcel buoyancy. The formal definition of CAPE is given by

$$
\mathrm{CAPE}=\mathrm{g} \int_{\mathrm{ZLFC}_{\mathrm{LFL}}}^{\mathrm{Z}_{\mathrm{EL}}}\left(\frac{\mathrm{T}_{\mathrm{v}}(\mathrm{z})-\overline{\mathrm{T}}_{\mathrm{v}}(\mathrm{z})}{\overline{\mathrm{T}}_{\mathrm{v}}(\mathrm{z})}\right) d \mathrm{z}
$$


where $T_{v}$ is the virtual temperature of the parcel, $\bar{T}_{v}$ is the virtual temperature of the environment, $\mathrm{Z}_{\mathrm{LFC}}$ is the height of the $\mathrm{LFC}, \mathrm{Z}_{\mathrm{EL}}$ is the height of the equilibrium level, and $g$ is gravity (e.g., Blanchard 1998). Along with evaluating total CAPE values (i.e., CAPE between the LFC and EL), the vertical distribution or "shape of the CAPE" was also evaluated, since this can have an equally important effect as the amount of CAPE on convective updraft strength (Lucas et al. 1994; Williams 1995; Lucas et al. 1996; Blanchard 1998; McCaul and Weisman 2001). As evident from Equation (10), CAPE depends on two parameters: (1) the depth of the free convective layer (FCL) from the LFC to the EL, and (2) the magnitude of buoyancy, characterized by the virtual temperature excess $\Delta \mathrm{T}_{\mathrm{v}}$ between the lifted parcel and environment. Normalized CAPE $(\mathrm{NCAPE}=\mathrm{CAPE} / \mathrm{FCL})$ was devised to provide an index that is independent of the depth of the FCL (Blanchard 1998). NCAPE, calculated by dividing CAPE by the depth over which the integration takes place, is a convenient measure of mean parcel buoyancy in the layer it is calculated for. NCAPE distinguishes between environments with similar CAPE but different buoyancies and integration depths (i.e., "short and wide" versus "tall and thin" CAPE; Blanchard 1998), and thereby provides a better measure of instability than CAPE. NCAPE has units of acceleration $\left(\mathrm{m} \mathrm{s}^{-2}\right)$. Thus, it is clear that greater NCAPE values support greater updraft accelerations and velocities (Blanchard 1998). NCAPE values were therefore investigated along with CAPE values to assess updraft intensity. Also, CAPE and NCAPE in different vertical layers partitioned by temperature were studied to provide a better measure of the vertical distribution of buoyancy. Since storm electrification occurs in the mixed-phase region $\left(0^{\circ} \mathrm{C}\right.$ to $\left.-40^{\circ} \mathrm{C}\right)$, 
any buoyant energy at temperature levels colder than $-40^{\circ} \mathrm{C}$ is essentially unrelated to storm electrification. At such cold temperatures, no supercooled water exists (i.e., the cloud is glaciated) and hence no significant charge transfer occurs, according to NIC theory. Thus, values of CAPE and NCAPE at temperature levels warmer than $-40^{\circ} \mathrm{C}$ were emphasized.

Unfortunately, pressure perturbations associated with parcel buoyancy could not be measured or quantified in this study, and are thus not accounted for in the assessment of updraft intensity. However, as mentioned in Chapter III, these pressure perturbations create a downward-directed pressure gradient force that opposes the upward-directed buoyancy force. Mid to upper-level storm-relative wind speeds were utilized to assess the degree of water loading in updrafts. Strong mid to upper-level storm-relative winds transport hydrometeors formed in the updraft sufficiently far downstream from the updraft that they fall toward the ground outside of the updraft region, and thus reduce the amount of water loading in the updraft. Conversely, when mid to upper-level stormrelative winds are weak, hydrometeors formed in the updraft remain in the updraft region, thereby increasing the degree of water loading in the updraft (e.g., Brooks et al. 1994b; Rasmussen and Straka 1998). Thus, strong storm-relative winds at mid to upperlevels favor stronger updrafts through a reduction of water loading. Adiabatic LWCs calculated by the E/P program were also used to investigate water loading in updrafts. Adiabatic LWCs represent an upper threshold for actual LWCs, and actual LWCs can differ markedly from adiabatic LWCs due to factors such as entrainment of dry environmental air into the cloud and depletion of cloud water by growing precipitation 
(Rogers and Yau 1989; Knight and Knight 2001). Hence, definitive conclusions cannot be drawn based on adiabatic LWC values, but it is appealing to speculate on the implications on updraft intensity of any drastic differences in adiabatic LWCs between positive and negative storms. LCL heights, used as a proxy for $\mathrm{CBH}$, were utilized to assess the effects of entrainment on updraft intensity. As discussed previously, updraft diameter scales with CBH (Lucas et al. 1994; Michaud 1996; Lucas et al. 1996; Williams and Stanfill 2002; Williams 2004; Williams et al. 2005), and the amount of entrainment an updraft experiences is a strong inverse function of updraft diameter (McCarthy 1974; Houze 1993; McCaul and Cohen 2002; Zipser 2003). Based on this relationship, LCL heights can be used to indirectly evaluate the amount of entrainment experienced by storm updrafts.

Measures of environmental vertical wind shear were used to investigate the dynamical effects that impact updraft intensity. Specifically, shear vector magnitudes were used to characterize the environmental vertical wind shear. As discussed in Chapter III, given the existence of an updraft, vertical wind shear is the critical ingredient required for the development of both linear and nonlinear dynamic pressure perturbations. Both low-level (0-2 km AGL, 0-3 km AGL) and deep-layer (0-6 km AGL) shear were compared between positive and negative mesoscale regions. $0-3 \mathrm{~km}$ AGL storm-relative environmental helicity (SREH), which provides a means of assessing the tendency for mesocyclone formation in supercells (Davies-Jones et al. 1990) and hence dynamical forcing of the updraft (e.g., Weisman and Klemp 1982), was also investigated. Equally important to its role in the development of dynamic pressure 
perturbations, wind shear can also enhance updraft intensity through its interaction with a surface cold pool. It is low-level shear that is important in this process, and thus wind shear in the 0-2 km AGL and 0-3 km AGL layers was used to account for this effect on updraft intensity.

Low-level (0-2 km AGL) storm-relative wind speeds were investigated as a proxy for low-level inflow strength. Modeling studies have shown that low-level outflow strength is detrimental to supercell maintenance and intensity when it is too strong relative to the low-level inflow (e.g., Weisman and Klemp 1982; Brooks et al. 1994b) because it undercuts the warm inflow into the updraft, thereby weakening the convection. As a result, stronger inflow may allow the sustenance of storms in the presence of strong outflow. A list of the parameters investigated using sounding data is presented in Table 2 .

\section{5) STATISTICAL ANALYSIS OF ENVIRONMENTAL PARAMETERS}

The environmental parameters obtained from sounding data were analyzed to identify systematic differences in the local mesoscale environments of positive and negative storms. Using Microsoft Excel, statistical analysis of these parameters was conducted. The samples for each parameter in positive and negative storm environments were compared for location using the arithmetic mean and median. The two-sample, two-tailed Student's $t$ test assuming unequal variances was used to identify significant differences in the mean values of environmental variables between positive and negative storms. The two-tailed test was used rather than the one-tail version to avoid the 
TABLE 2. List of parameters investigated using sounding data, along with the respective acronym used to refer to each parameter (if any) in this study.

\begin{tabular}{|c|c|}
\hline Parameter & Acronym \\
\hline Adiabatic liquid water content & Adiabatic LWC \\
\hline Bulk Richardson number & BRN \\
\hline Convective available potential energy (LFC to EL) & CAPE \\
\hline CAPE between LFC and $-10^{\circ} \mathrm{C}$ level & ---------- \\
\hline CAPE between LFC and $-40^{\circ} \mathrm{C}$ level & ---------- \\
\hline CAPE between $-10^{\circ} \mathrm{C}$ and $-40^{\circ} \mathrm{C}$ levels & --------- \\
\hline Convective inhibition & $\mathrm{CIN}$ \\
\hline Energy helicity index (using 0-3 km AGL SREH) & $\mathrm{EHI}$ \\
\hline Equilibrium level & $\mathrm{EL}$ \\
\hline Equivalent potential temperature & $\theta_{\mathrm{e}}$ \\
\hline Free convective layer depth & $\mathrm{FCL}$ \\
\hline Freezing level height & $\mathrm{FL}$ \\
\hline Level of free convection & LFC \\
\hline Lifted index & LI \\
\hline Lifting condensation level & LCL \\
\hline Mean mixing ratio in the lowest $100 \mathrm{hPa}$ & -------- \\
\hline Midlevel relative humidity (700 to $500 \mathrm{hPa}$ layer) & ---------- \\
\hline Normalized CAPE (LFC to EL) & NCAPE \\
\hline NCAPE between LFC and $-10^{\circ} \mathrm{C}$ level & --------- \\
\hline NCAPE between LFC and $-40^{\circ} \mathrm{C}$ level & --------- \\
\hline NCAPE between $-10^{\circ} \mathrm{C}$ and $-40^{\circ} \mathrm{C}$ levels & --------- \\
\hline Precipitable water in surface to $400 \mathrm{hPa}$ layer & --------- \\
\hline Storm-relative wind speed at EL & ---------- \\
\hline Surface dewpoint & $\mathrm{T}_{\mathrm{d}}$ \\
\hline Surface dewpoint depression & $T-T_{d}$ \\
\hline Surface temperature & $T$ \\
\hline Warm cloud depth & WCD \\
\hline Wet-bulb zero height & WBZ height \\
\hline $0-2$ km AGL shear & --------- \\
\hline 0-3 km AGL shear & --------- \\
\hline 0-6 km AGL shear & --------- \\
\hline 0-3 km AGL storm-relative environmental helicity & 0-3 km AGL SREH \\
\hline 0-2 km AGL storm-relative wind speed & --------- \\
\hline 4-6 km AGL storm-relative wind speed & --------- \\
\hline 6-10 km AGL storm-relative wind speed & ---------- \\
\hline 9-11 km AGL storm-relative wind speed & -------- \\
\hline $700-500 \mathrm{hPa}$ lapse rate & ---------- \\
\hline $850-500 \mathrm{hPa}$ lapse rate & --------- \\
\hline
\end{tabular}


assumption that the mean value of a given environmental variable should be greater for positive storms than negative storms, or vice versa (e.g., Wilks 1995). For each test, it was assumed that the two samples compared were independent and that the sample distribution for each variable was Gaussian. The null hypothesis in these $t$ tests stated that the difference in sample means was zero (i.e., the sample means were equal), and the alternative hypothesis was simply that the difference in sample means was not zero (i.e., the sample means were different). For cases in which the absolute value of the computed $t$ statistic was greater than the absolute value of the critical test value (i.e., the $t$ statistic lied in one of the tails of the distribution), the null hypothesis was rejected, meaning that the means were different. Tests were conducted at significance levels of $10 \%, 5 \%, 1 \%$, and $0.1 \%$, corresponding to respective confidence levels of $90 \%, 95 \%$, $99 \%$, and $99.9 \%$. For instance, if the null hypothesis was rejected at the $5 \%$ significance level, one could say with $95 \%$ confidence that the sample means were indeed different. ${ }^{12}$ Different plotting schemes (e.g., scatter plots, line plots, histograms, etc.) were also incorporated into the analysis to visually detect systematic differences between positive and negative storms.

Four levels of comparisons were conducted to evaluate differences between the mesoscale environments of positive and negative storms. First, overall grouped comparisons were conducted in which soundings characterizing positive storm environments from all days were combined into one group and soundings characterizing

\footnotetext{
${ }^{12}$ A more rigorous statistical approach (Carey and Buffalo 2007) was used to check the $t$-test results regarding difference in location between the samples of positive and negative storm environments for each parameter. This more rigorous approach described in Carey and Buffalo (2007) confirmed all the results of the $t$ tests, thereby proving the robustness of the results.
} 
negative storm environments from all days were lumped into a second group.

Environmental variables were compared between these two groups to identify systematic differences between the environments of positive and negative storms. Next, regional comparisons were conducted. Sounding data were grouped by mesoscale region, and comparisons were conducted between the nine individual mesoscale regions ( 4 positive and 5 negative regions). These regional comparisons focused on those parameters that were found to differ significantly between positive and negative storms in the overall grouped comparisons to determine if the differences identified remained evident in the comparisons of individual mesoscale regions. The next level of comparisons focused on daily differences between positive and negative storms. Days in which both positive and negative storms occurred (23, 24 May; 15 June) were investigated for differences between positive and negative storm environments. Finally, dropsonde data from the 24 May and 19 June cases were investigated to determine if differences identified in the three previous types of comparisons were also present in this enhanced spatial and temporal resolution dataset.

\section{6) ANALYSIS OF DROPSONDE RUNS}

Two lines of dropsondes released during IHOP_2002 were analyzed to investigate differences in the environments of positive and negative storms at an enhanced spatial and temporal resolution. One dropsonde run is from 24 May 2002 and the other is from 19 June 2002. The lines of dropsondes were oriented roughly perpendicular to the $\theta_{\mathrm{e}}$ ridge on each respective day, permitting investigation of the 
vertical structure of the $\theta_{\mathrm{e}}$ gradient region, which has been found to be a preferred location for the occurrence of positive storms (e.g., Smith et al. 2000; Carey et al. 2003b). On 24 May 2002, nine dropsondes were released between 2022 and 2046 UTC, with a time interval between each release of 3 minutes, resulting in an average distance between dropsonde locations of approximately $27 \mathrm{~km}$. The dropsondes were released from roughly $4 \mathrm{~km}$ AGL. Seven of the nine dropsondes contained good data and could be used for analysis. Eight dropsondes were released on 19 June 2002 between the times of 2110 and 2131 UTC, with each release separated by a time step of 3 minutes and distance of approximately $24 \mathrm{~km}$. These dropsondes were released from roughly $5.5 \mathrm{~km}$ AGL. All eight of the 19 June dropsondes were used for analysis. Parameters investigated with the dropsonde data include LCL heights, NCAPE, low to midlevel lapse rates, depth of the warm cloud layer, freezing level heights, and 0-3 km AGL vertical wind shear. For the 24 May case, any vertical levels at pressures less than 575 $\mathrm{hPa}$ were removed from the dropsonde data files, since $575 \mathrm{hPa}$ was the lowest pressure (greatest height) measured by all dropsondes. This insured that NCAPE was calculated through the same vertical level for all dropsondes within the dropsonde line, thereby allowing for more equal comparisons of NCAPE between all dropsondes in the line. Similarly, any vertical levels at pressures less than $455 \mathrm{hPa}$ were removed from the 19 June dropsonde files. Since dropsondes on 24 May did not measure to the $500 \mathrm{hPa}$ level, lapse rates within the $850-575 \mathrm{hPa}$ layer were computed in place of 850-500 $\mathrm{hPa}$ lapse rates. 
The 19 June storms were all characterized by very high percentages of positive CG lightning. However, as will be shown in Chapter V, storms along the 24 May dropsonde line transitioned from positive to negative storms. This provided an excellent opportunity to determine if the relationships between environmental conditions and CG flash polarity discovered in the larger sounding dataset also held true when investigated at a much greater spatial and temporal resolution. To characterize the CG lightning polarity behavior in the immediate environment of each of the 24 May dropsondes, the number of positive flashes, negative flashes, and total flashes, as well as the percentage of positive flashes within a rectangular area centered on each dropsonde location were computed. These rectangular boxes were created with dimensions of $80 \mathrm{~km}$ in the northsouth direction and $27.4 \mathrm{~km}$ in the east-west direction. This east-west dimension was the largest possible without allowing any overlap between adjacent boxes.

Vertical cross-sections of parcel buoyancy B, where

$$
\mathrm{B}=\mathrm{g}\left(\frac{\mathrm{T}_{\mathrm{v}}(\mathrm{z})-\overline{\mathrm{T}}_{\mathrm{v}}(\mathrm{z})}{\overline{\mathrm{T}}_{\mathrm{v}}(\mathrm{z})}\right)
$$

were created using the 24 May and 19 June dropsonde data. The E/P program was used to calculate $\mathrm{B}$ at each vertical level (every $5 \mathrm{hPa}$ ) for each dropsonde using the mean temperature and dewpoint in the lowest $100 \mathrm{hPa}$ and assuming pseudoadiabatic ascent, producing a vertical buoyancy profile for each dropsonde location. An IDL program was developed that used these vertical buoyancy profiles at each dropsonde location to create vertical cross-sections of buoyancy along the two dropsonde lines. The buoyancy values at each dropsonde location were used to create a regular grid of interpolated 
buoyancy values, and then these regularly-gridded buoyancy values were contoured. The buoyancy data were interpolated by using the "IRREGULAR" keyword with IDL's “CONTOUR” procedure, which performs a Delaunay triangulation to interpolate irregularly-gridded data to a regular grid. The vertical cross-sections of buoyancy were used to investigate the distribution of buoyancy (both horizontally and vertically) in the $\theta_{\mathrm{e}}$ gradient region. Since the dropsondes were released from near the $500 \mathrm{hPa}$ level (575 $\mathrm{hPa}$ on $24 \mathrm{May}, 455 \mathrm{hPa}$ on 19 June), only the low to midtropospheric buoyancy distributions could be studied. These low to midtropospheric buoyancy cross-sections were also used to assess the magnitude of horizontal vorticity produced by the buoyancy gradients (i.e., baroclinic generation of vorticity) in the $\theta_{\mathrm{e}}$ gradient region, since the tilting of this horizontal vorticity into the vertical by a storm updraft can lead to the development of nonlinear dynamic pressure perturbations, and associated increases in updraft intensity. 


\section{CHAPTER V}

\section{RESULTS*}

\section{a. Cloud-to-ground lightning characteristics}

Characteristics of the four positive and five negative mesoscale regions identified are presented in Table 3. The latitude/longitude boundaries and time period of analysis for each region are listed. Also provided are the percentage of positive CG flashes, mean total CG flash density, number of positive flashes, and number of negative flashes produced by storms within each mesoscale region. Plots of percent positive flashes and total CG flash density for the nine mesoscale regions are shown in Figs. 14-25. As expected from Carey et al. (2003b) and Fig. 1, negative mesoscale regions were found generally east of positive mesoscale regions on days when both were present. Positive storms produced from $32 \%-72 \%$ positive CG lightning in mesoscale regions over the IHOP_2002 domain, while negative storms produced from $7 \%-17 \%$ positive $\mathrm{CG}$ lightning. Mean flash densities ranged from 0.099-0.183 (0.104-0.384) flashes $\mathrm{km}^{-2}$ year $^{-1}$ for positive (negative) storms. The three greatest flash densities were associated with negative mesoscale regions. The numbers of positive and negative flashes are provided along with flash density values simply to give the reader a feel for the quantity of CG flashes produced by these storm systems. Hundreds to thousands of positive and negative flashes were produced within each mesoscale region. Whereas flash density is independent of the area of each defined mesoscale region, the number of flashes

\footnotetext{
* Part of this chapter is reprinted with permission from Carey, L. D., and K. M. Buffalo, 2007: Environmental control of cloud-to-ground lightning polarity in severe storms. Mon. Wea. Rev., 135, 13271353. (c) 2007 American Meteorological Society.
} 
produced within a region is dependent on the area of the region. The nine mesoscale regions varied substantially in area, and hence direct comparisons of numbers of flashes between regions could be misleading and was not the intent of providing these numbers.

TABLE 3. Characterization of mesoscale regions within the IHOP_2002 domain. Spatial and temporal boundaries for each mesoscale region are listed, along with the overall percentage of positive CG lightning $\left(+\mathrm{CG} \%\right.$ ), mean total CG flash density (flashes $\mathrm{km}^{-2}$ year $^{-1}$ ), number of positive CG flashes, and number of negative CG flashes produced by storms within each region.

\begin{tabular}{|c|c|c|c|c|c|c|}
\hline Date & $\begin{array}{l}\text { Time } \\
\text { (UTC) }\end{array}$ & $\begin{array}{l}\text { Latitude/ } \\
\text { Longitude }\end{array}$ & +CG \% & $\begin{array}{l}\text { Mean Flash Density } \\
\left(\text { flashes } \mathbf{k m}^{-2} \mathrm{yr}^{-1}\right)\end{array}$ & $\begin{array}{l}\text { Positive } \\
\text { Flashes }\end{array}$ & $\begin{array}{l}\text { Negative } \\
\text { Flashes }\end{array}$ \\
\hline 23 May & $18-03$ & $\begin{array}{c}33^{\circ} \text { to } 38^{\circ} / \\
-103^{\circ} \text { to }-100^{\circ}\end{array}$ & 60.7 & 0.146 & 722 & 467 \\
\hline 24 May & $20-04$ & $\begin{array}{c}33.5^{\circ} \text { to } 37^{\circ} / \\
-101.5^{\circ} \text { to }-98.5^{\circ}\end{array}$ & 32.2 & 0.183 & 1,783 & 3,755 \\
\hline 15 June & $18-03$ & $\begin{array}{c}33^{\circ} \text { to } 39^{\circ} / \\
-103^{\circ} \text { to }-99^{\circ}\end{array}$ & 43.4 & 0.099 & 3,395 & 4,436 \\
\hline 19 June & $18-03$ & $\begin{array}{l}37^{\circ} \text { to } 43^{\circ} \% \\
-103^{\circ} \text { to }-97^{\circ}\end{array}$ & 71.5 & 0.160 & 4,540 & 1,807 \\
\hline \multicolumn{7}{|c|}{ NEGATIVE MESOSCALE REGIONS - Mesoscale regions containing $\leq 25 \%+C G$ lightning. } \\
\hline Date & $\begin{array}{l}\text { Time } \\
\text { (UTC) }\end{array}$ & $\begin{array}{l}\text { Latitude/ } \\
\text { Longitude }\end{array}$ & +CG \% & $\begin{array}{l}\text { Mean Flash Density } \\
\left(\text { flashes } \mathrm{km}^{-2} \mathrm{yr}^{-1} \text { ) }\right.\end{array}$ & $\begin{array}{l}\text { Positive } \\
\text { Flashes }\end{array}$ & $\begin{array}{c}\text { Negative } \\
\text { Flashes }\end{array}$ \\
\hline 23 May & $18-03$ & $\begin{array}{l}34^{\circ} \text { to } 40^{\circ} \% \\
-100^{\circ} \text { to }-94^{\circ}\end{array}$ & 6.5 & 0.126 & 540 & 7,760 \\
\hline 24 May & $20-04$ & $\begin{array}{l}32.5^{\circ} \text { to } 38^{\circ} / \\
-98.5^{\circ} \text { to }-95^{\circ}\end{array}$ & 7.5 & 0.186 & 790 & 9,757 \\
\hline 4 June & $12-01$ & $\begin{array}{l}33^{\circ} \text { to } 40^{\circ} / \\
-103^{\circ} \text { to }-95^{\circ}\end{array}$ & 9.2 & 0.210 & 3,414 & 33,819 \\
\hline 12 June & $20-04$ & $\begin{array}{l}32^{\circ} \text { to } 39^{\circ} \% \\
-103^{\circ} \text { to }-95^{\circ}\end{array}$ & 8.9 & 0.384 & 3,340 & 34,169 \\
\hline 15 June & $18-03$ & $\begin{array}{c}33^{\circ} \text { to } 39^{\circ} / \\
-99^{\circ} \text { to }-95.5^{\circ}\end{array}$ & 17.1 & 0.104 & 1,418 & 6,865 \\
\hline
\end{tabular}


Percent Positive Flashes 05/23/02 18:00:00-03:00:00Z

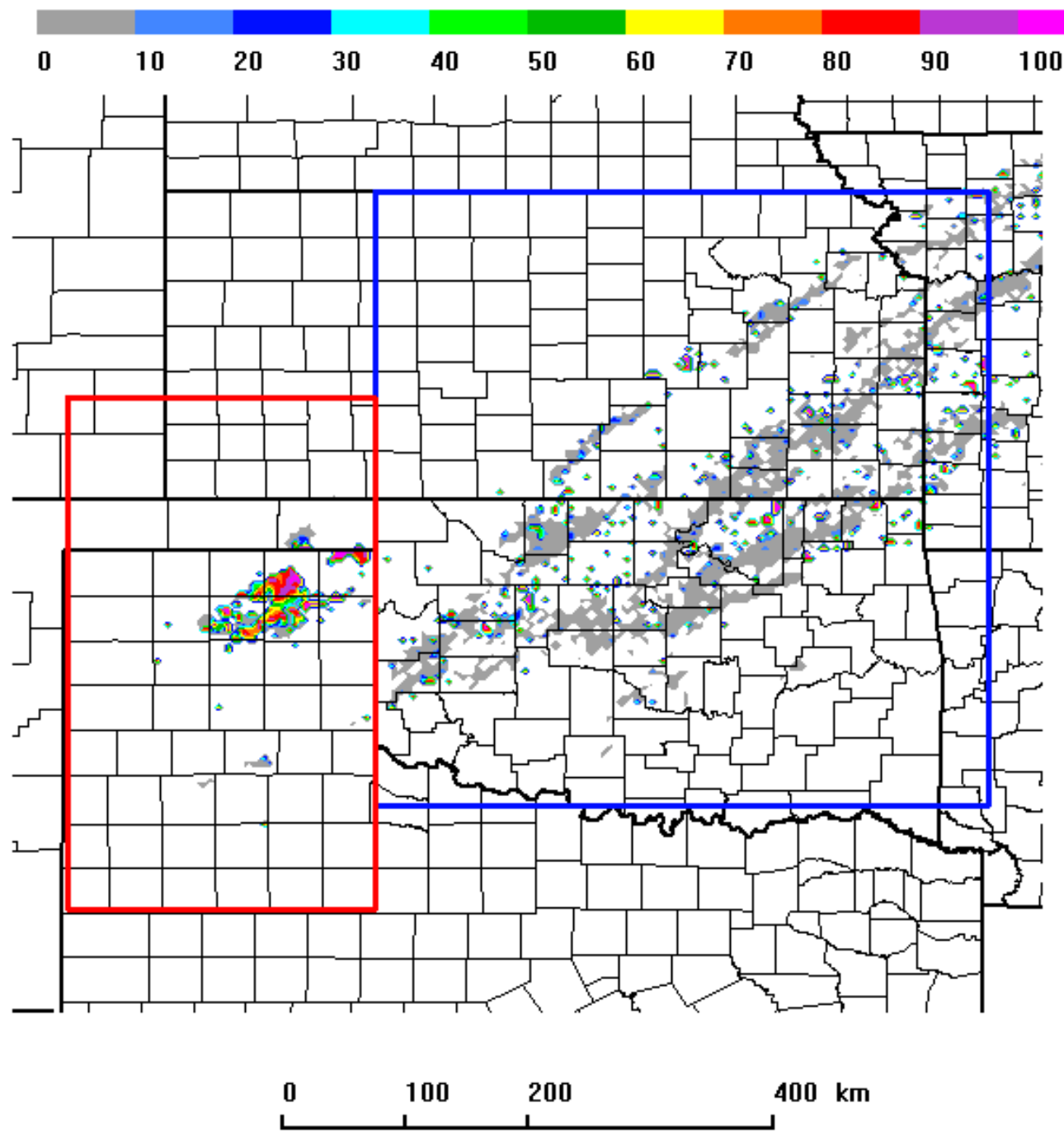

FIG. 14. Percentage of positive flashes (\%) for 1800 UTC 23 May 2002-0300 UTC 24 May 2002. Positive mesoscale region is outlined in red and negative mesoscale region is outlined in blue. Thick (thin) black lines indicate state (county) borders. Plot is centered on the IHOP_2002 domain (Kansas, Oklahoma, and northern Texas). 
Flash Density [Flashes km^-2 yr^-1] 05/23/02 18:00:00-03:00:00Z

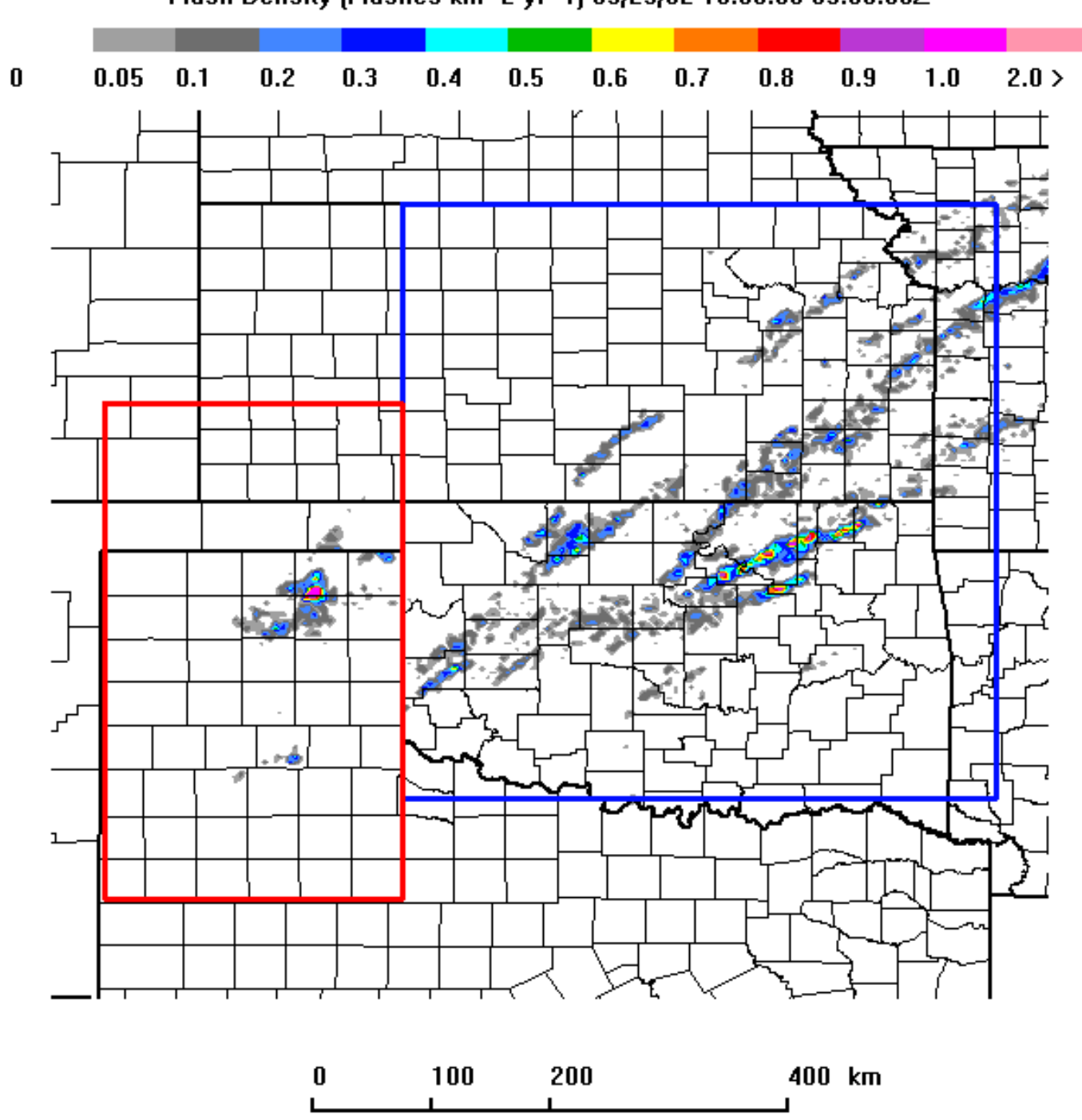

FIG. 15. Total CG flash density (flashes $\mathrm{km}^{-2}$ year $^{-1}$ ) for 1800 UTC 23 May 2002-0300 UTC 24 May 2002. Positive mesoscale region is outlined in red and negative mesoscale region is outlined in blue. Thick (thin) black lines indicate state (county) borders. Plot is centered on the IHOP_2002 domain (Kansas, Oklahoma, and northern Texas). 
Percent Positive Flashes 05/24/02 20:00:00-04:00:00Z
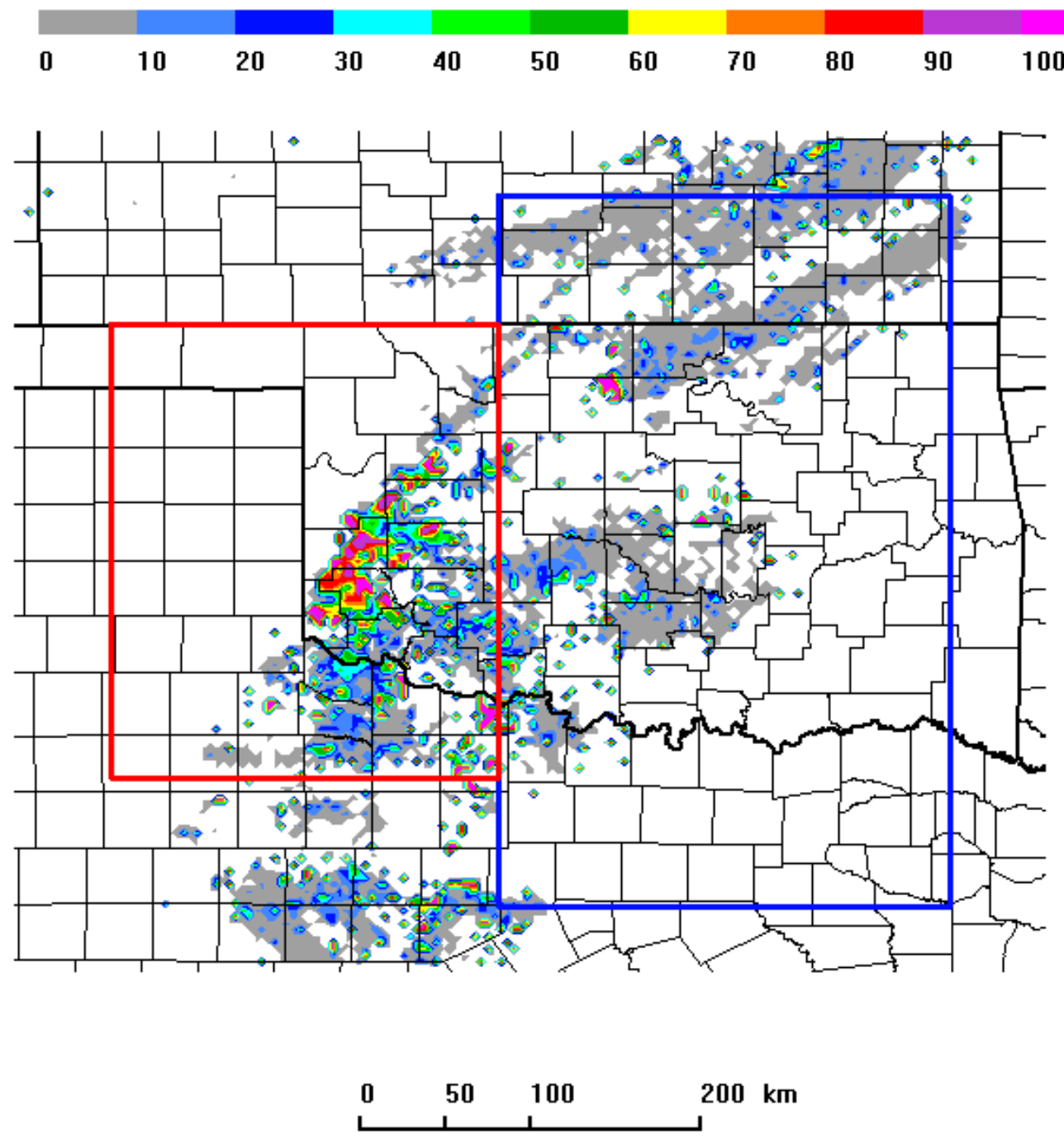

FIG. 16. Same as in Fig. 14 except for 2000 UTC 24 May 2002-0400 UTC 25 May 2002. Positive mesoscale region is outlined in red and negative mesoscale region is outlined in blue. 
Flash Density [Flashes km^-2 y $\left.\mathbf{r}^{\wedge}-1\right]$ 05/24/02 20:00:00-04:00:00Z

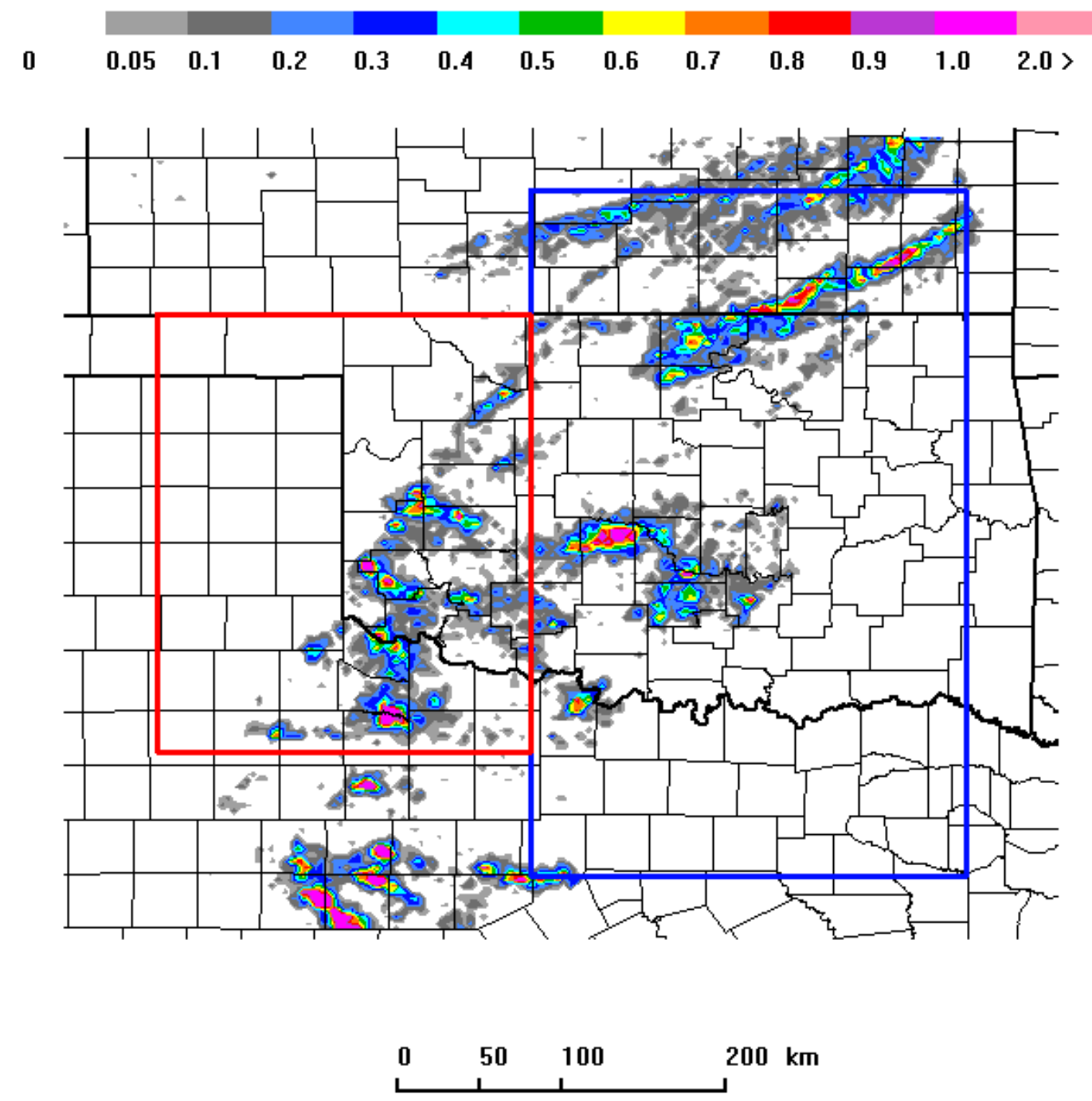

FIG. 17. Same as in Fig. 15 except for 2000 UTC 24 May 2002-0400 UTC 25 May 2002. Positive mesoscale region is outlined in red and negative mesoscale region is outlined in blue. 
Percent Positive Flashes 06/04/02 12:00:00-01:00:00Z

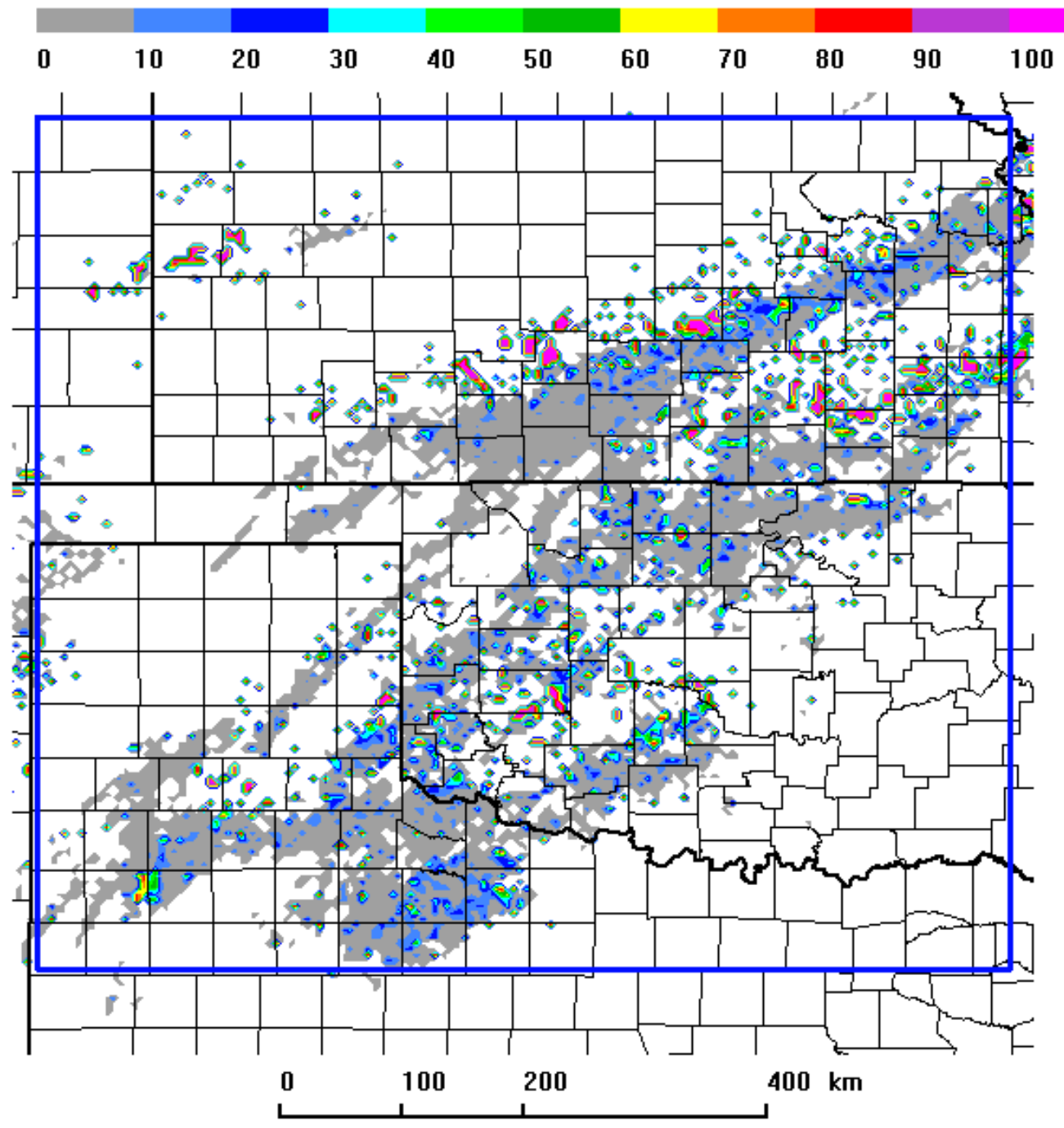

FIG. 18. Same as in Fig. 14 except for 1200 UTC 4 June 2002-0100 UTC 5 June 2002. Negative mesoscale region is outlined in blue. 
Flash Density [Flashes $\left.\mathrm{km}^{\wedge}-2 \mathrm{yr}^{\wedge}-1\right]$ 06/04/02 12:00:00-01:00:00Z

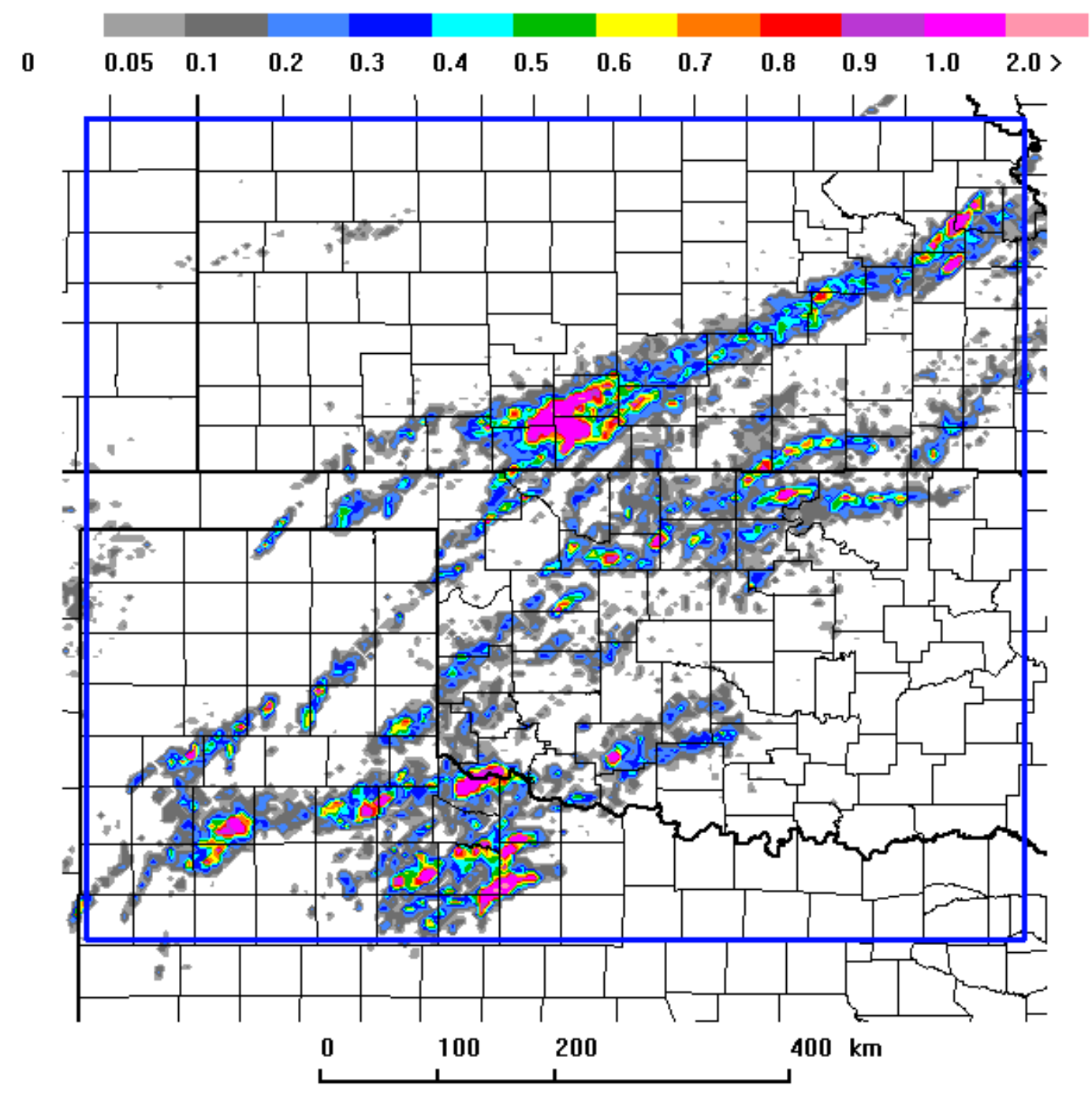

FIG. 19. Same as in Fig. 15 except for 1200 UTC 4 June 2002-0100 UTC 5 June 2002. Negative mesoscale region is outlined in blue. 
Percent Positive Flashes 06/12/02 20:00:00-04:00:00Z

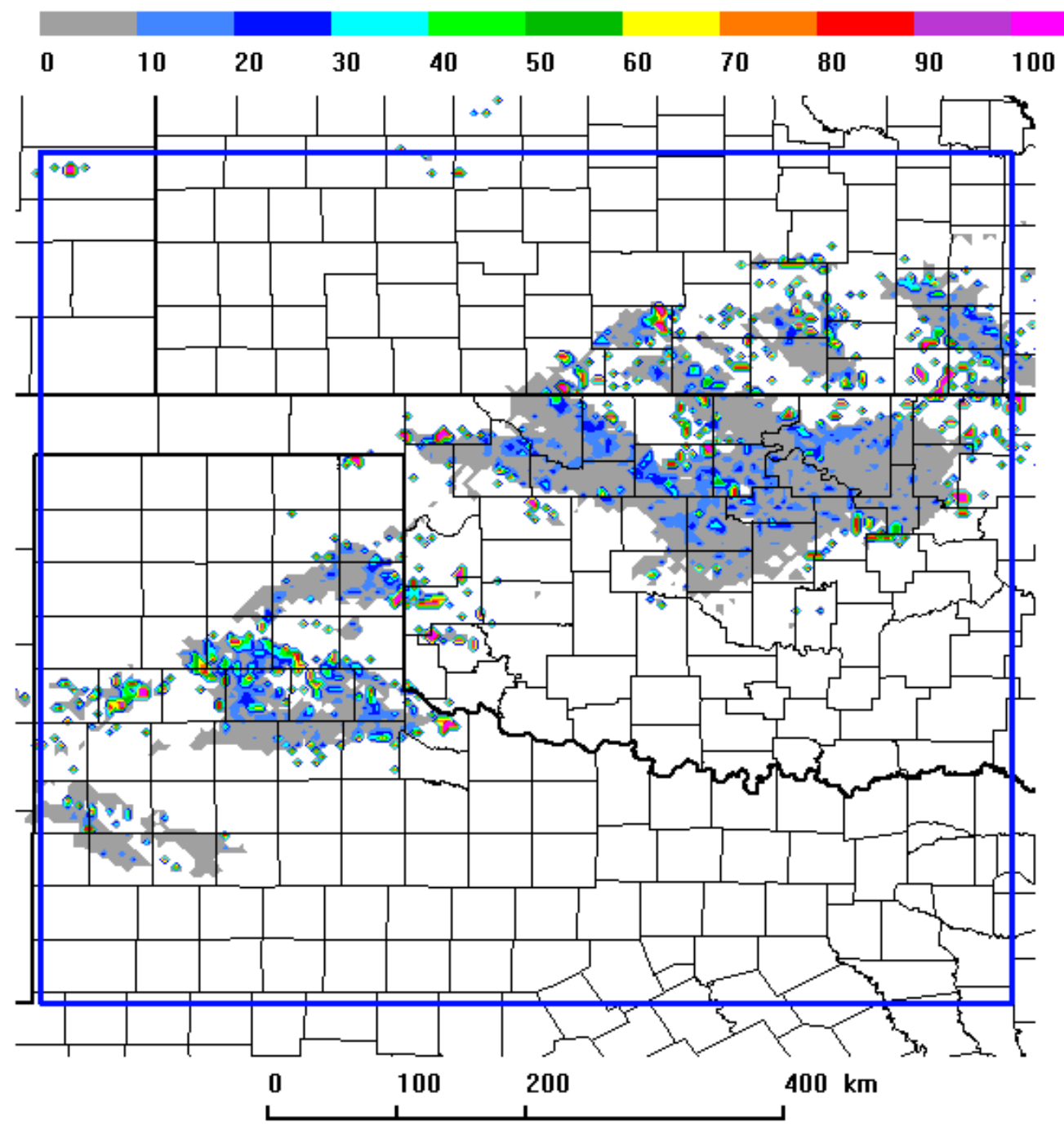

FIG. 20. Same as in Fig. 14 except for 2000 UTC 12 June 2002-0400 UTC 13 June 2002. Negative mesoscale region is outlined in blue. 
Flash Density [Flashes km^-2 yr^-1] 06/12/02 20:00:00-04:00:00Z

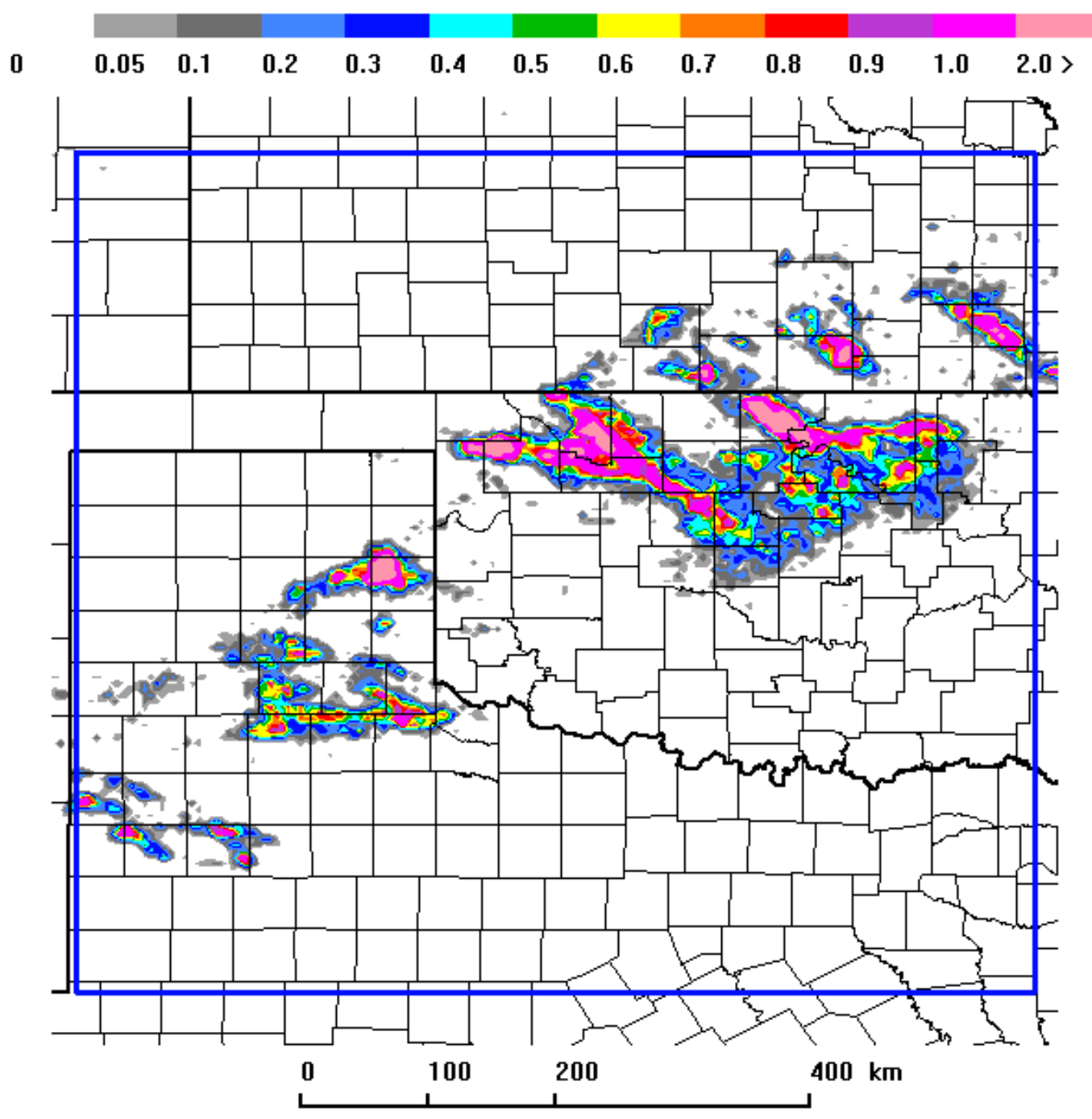

FIG. 21. Same as in Fig. 15 except for 2000 UTC 12 June 2002-0400 UTC 13 June 2002. Negative mesoscale region is outlined in blue. 
Percent Positive Flashes 06/15/02 18:00:00-03:00:00Z
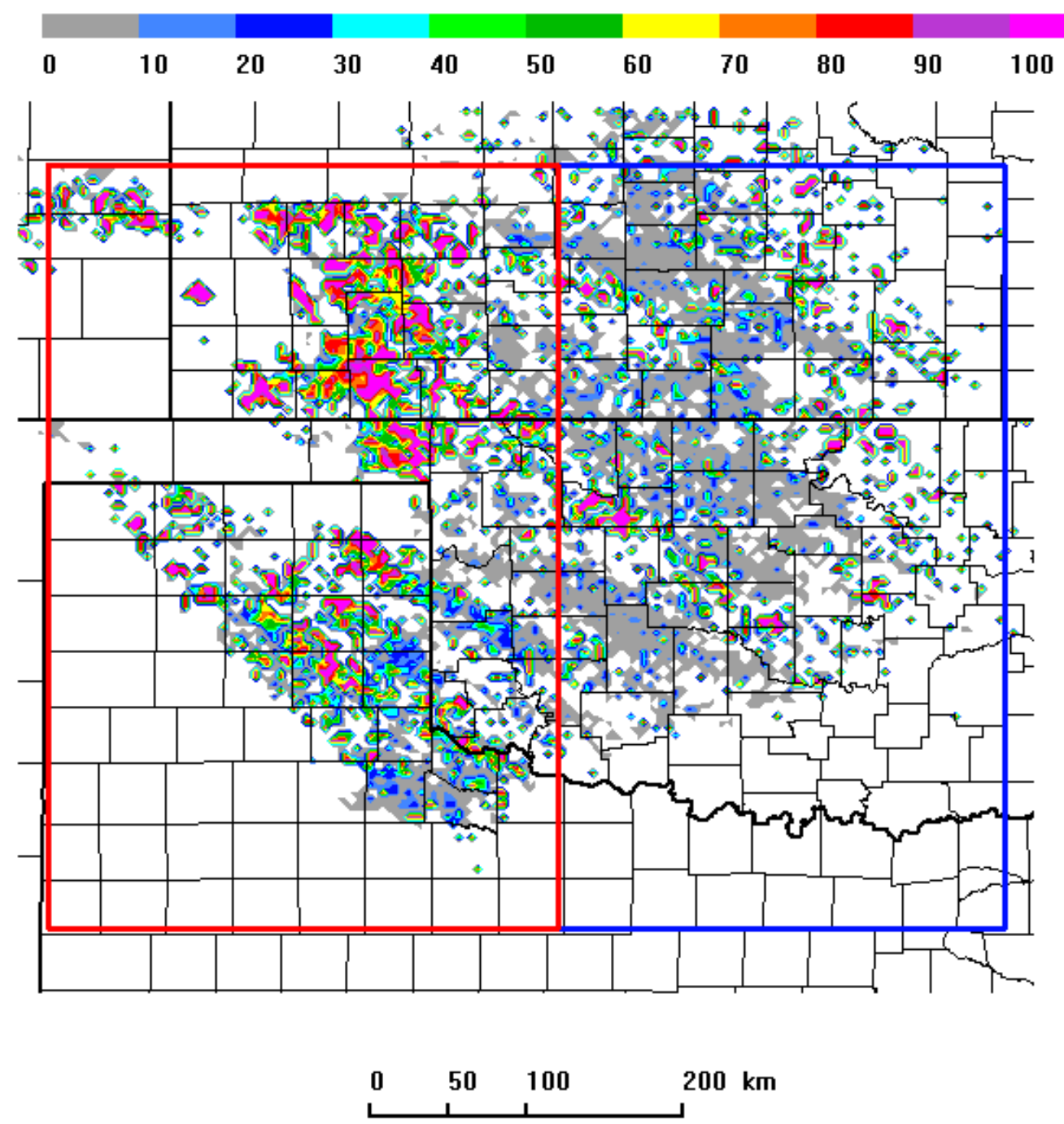

FIG. 22. Same as in Fig. 14 except for 1800 UTC 15 June 2002-0300 UTC 16 June 2002. Positive mesoscale region is outlined in red and negative mesoscale region is outlined in blue. 
Flash Density [Flashes km^-2 yr^-1] 06/15/02 18:00:00-03:00:00Z

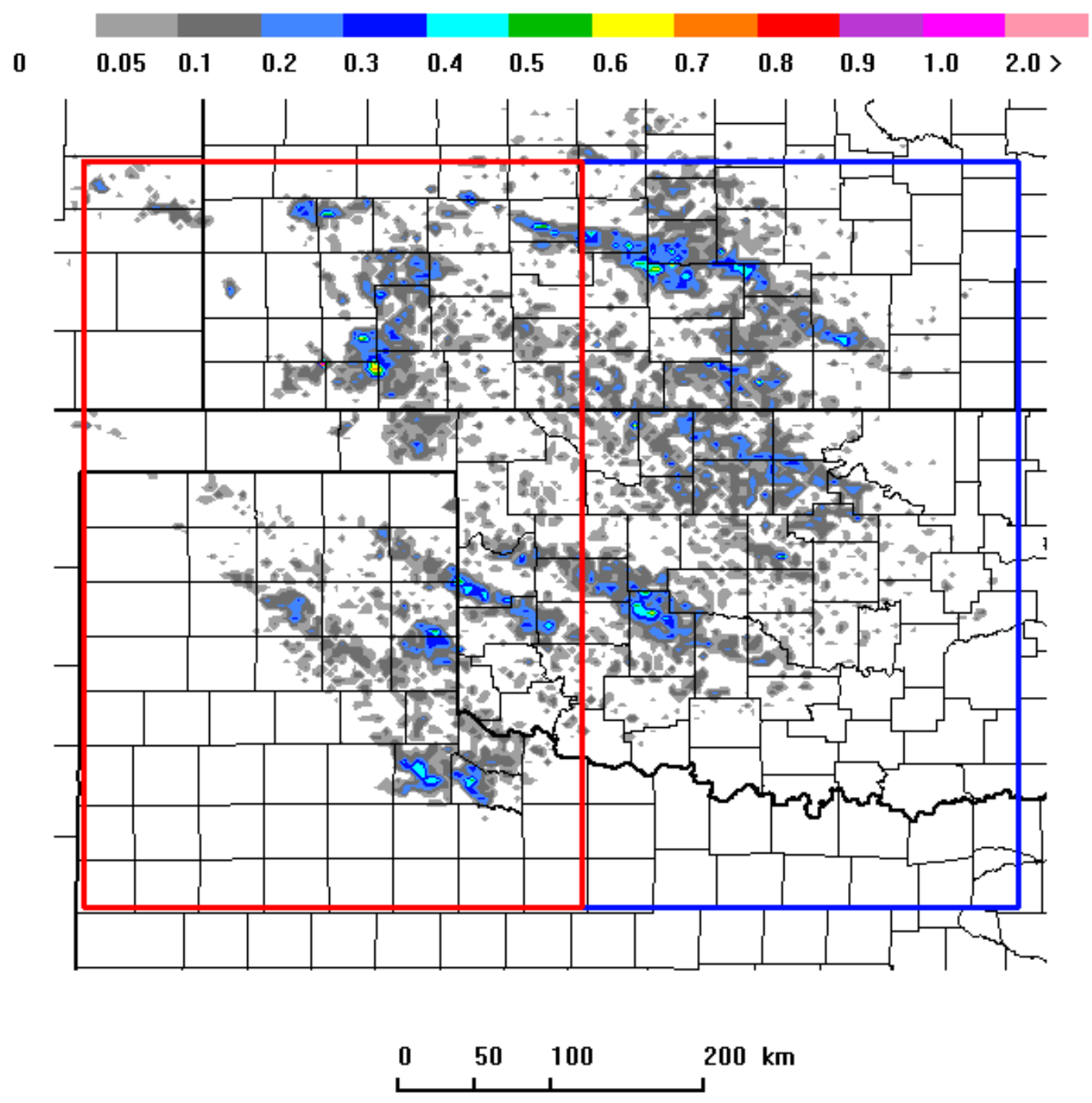

FIG. 23. Same as in Fig. 15 except for 1800 UTC 15 June 2002-0300 UTC 16 June 2002. Positive mesoscale region is outlined in red and negative mesoscale region is outlined in blue. 
Percent Positive Flashes 06/19/02 18:00:00-03:00:00Z

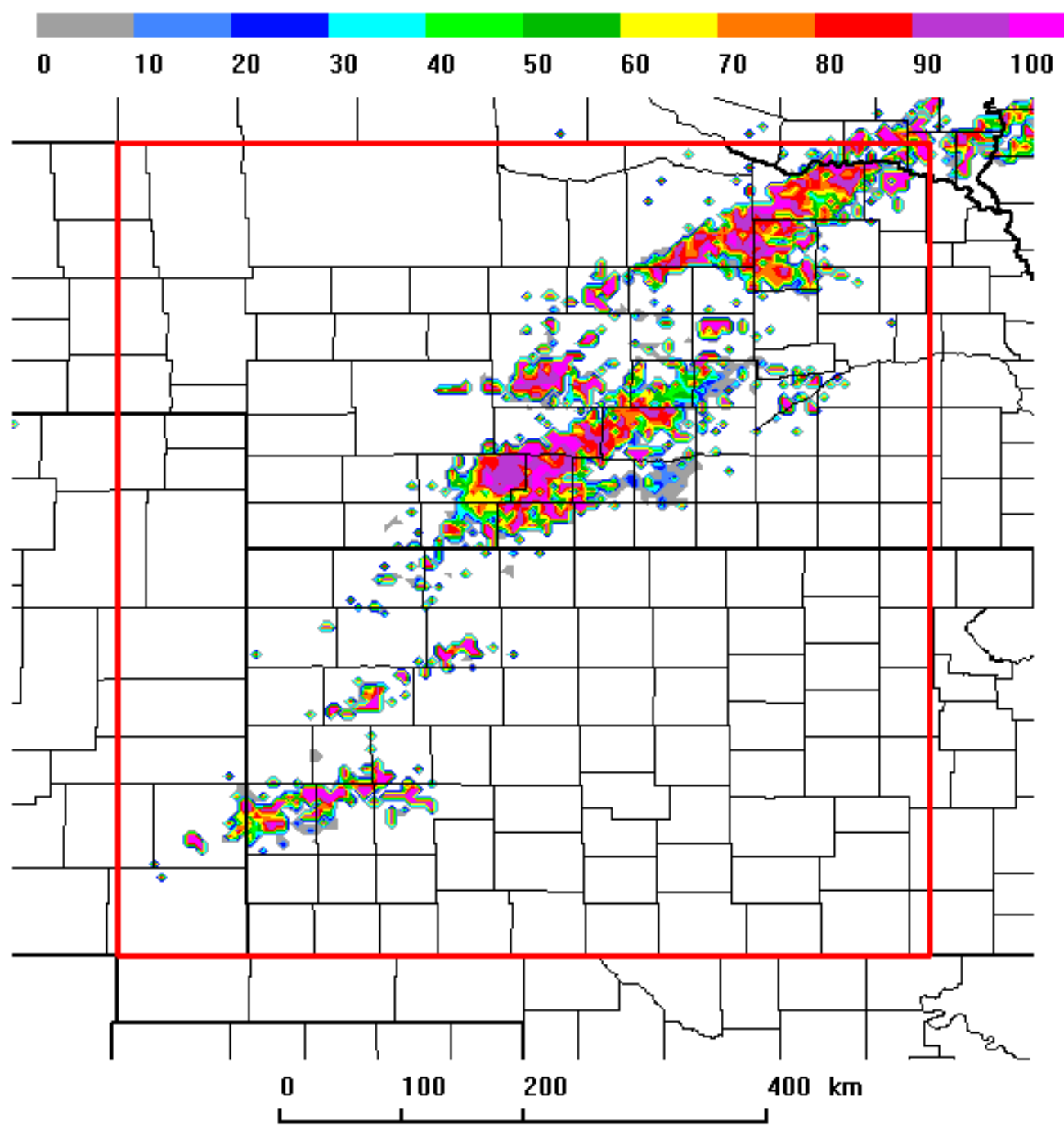

FIG. 24. Same as in Fig. 14 except for 1800 UTC 19 June 2002-0300 UTC 20 June 2002. Positive mesoscale region is outlined in red. 
Flash Density [Flashes km^-2 yr^-1] 06/19/02 18:00:00-03:00:00Z

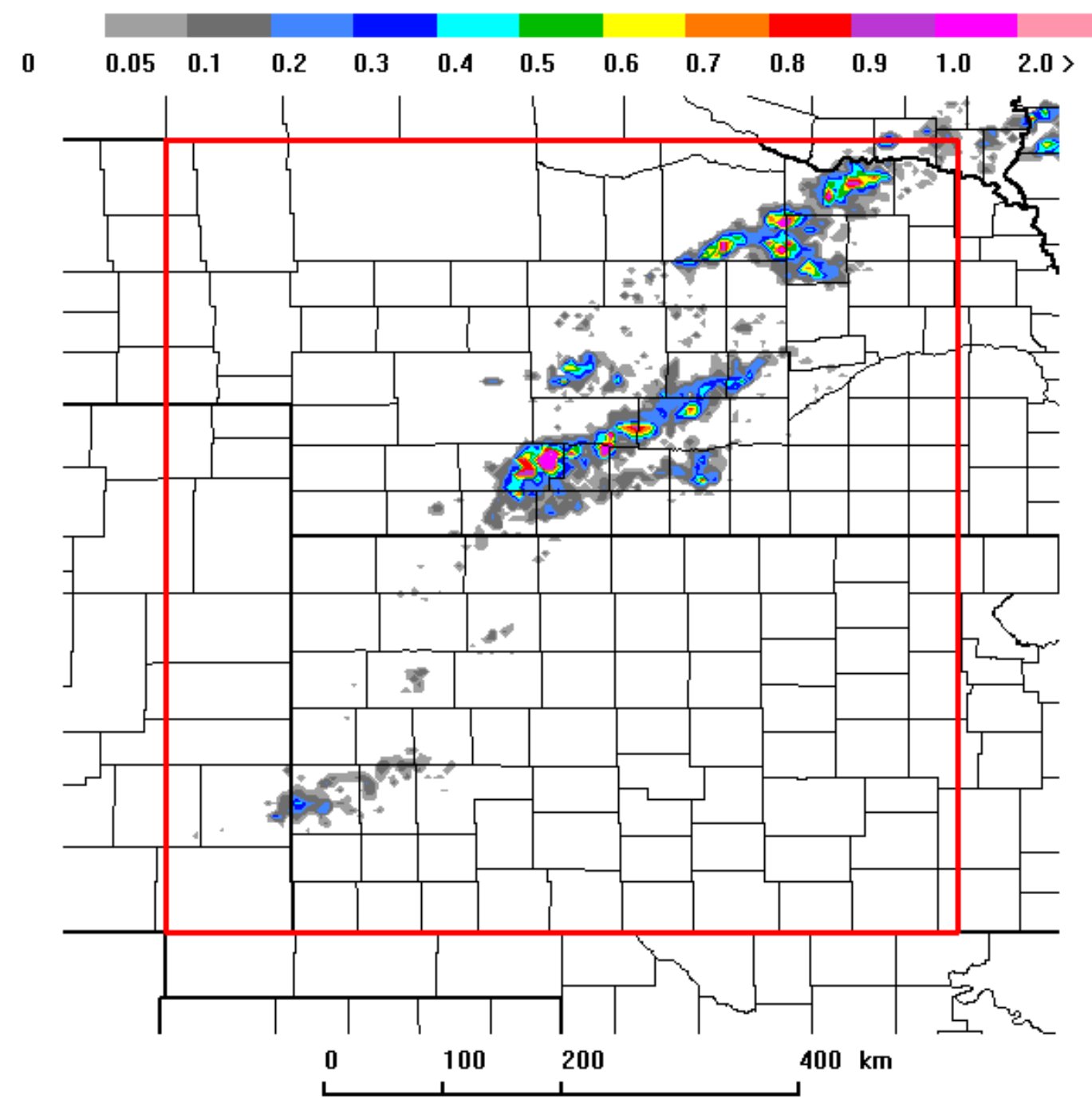

FIG. 25. Same as in Fig. 15 except for 1800 UTC 19 June 2002-0300 UTC 20 June 2002. Positive mesoscale region is outlined in red. 


\section{b. Meteorological scenarios}

1) 23 MAY 2002

The meteorological environment on 23 May consisted of a broad shortwave trough at mid and upper levels across the western U.S., with the center of the trough positioned over northern Utah. Downstream of the trough, the negative mesoscale region was under an area of upper-level divergence, resulting in synoptic-scale lift. This upper-level divergence was associated with diffluence of the upper-level winds, along with the right entrance region of a jet streak positioned over the region (Fig. 26). Warm air advection (WAA) and moisture advection into both the positive and negative mesoscale regions by southerly flow at the 700 and $850 \mathrm{hPa}$ levels also aided in the development of convection (Fig. 27). At the surface, a cold front stretched from northwest Missouri across Kansas into Oklahoma and the northern Texas panhandle (Fig. 28). Surface convergence along the cold front acted with upper-level forcing across the negative mesoscale region to initiate negative storms. The cold front also helped to initiate positive storms over the northern Texas panhandle later in the day. As depicted in Fig. 28, a dryline across the Texas panhandle intersected the cold front, forming a triple point in the northern Texas panhandle. Positive storms initiated at this triple point, where surface forcing was maximized. Synoptic-scale lift associated with the aforementioned shortwave trough likely provided additional support for these positive storms. 


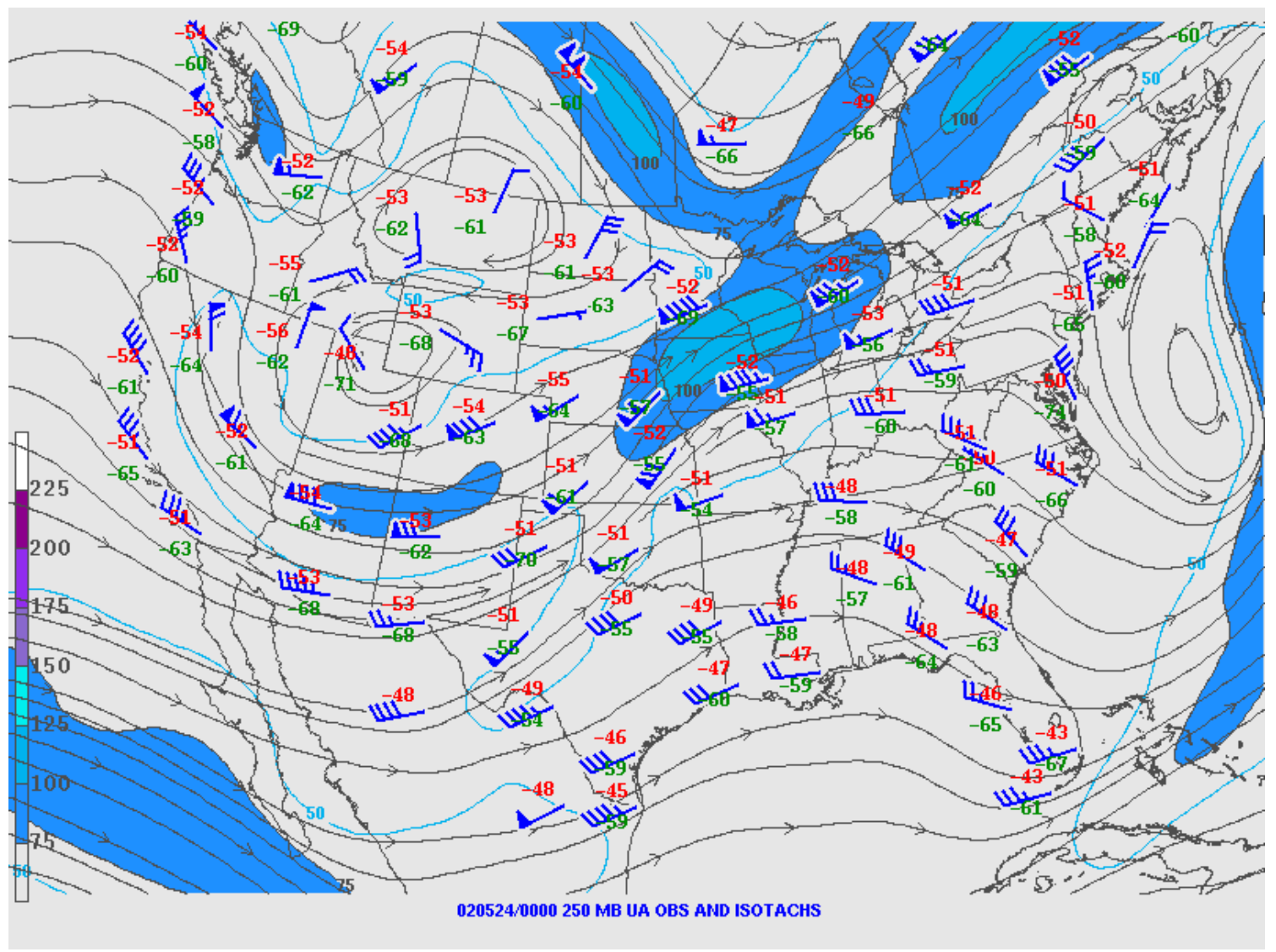

FIG. 26. $250 \mathrm{hPa}$ analysis for 00 UTC 24 May 2002. Streamlines are solid black lines, wind speeds $\geq 50$ knots are outlined with light blue contours, and wind speeds $\geq 75$ knots are shaded according to the color bar on the left. 


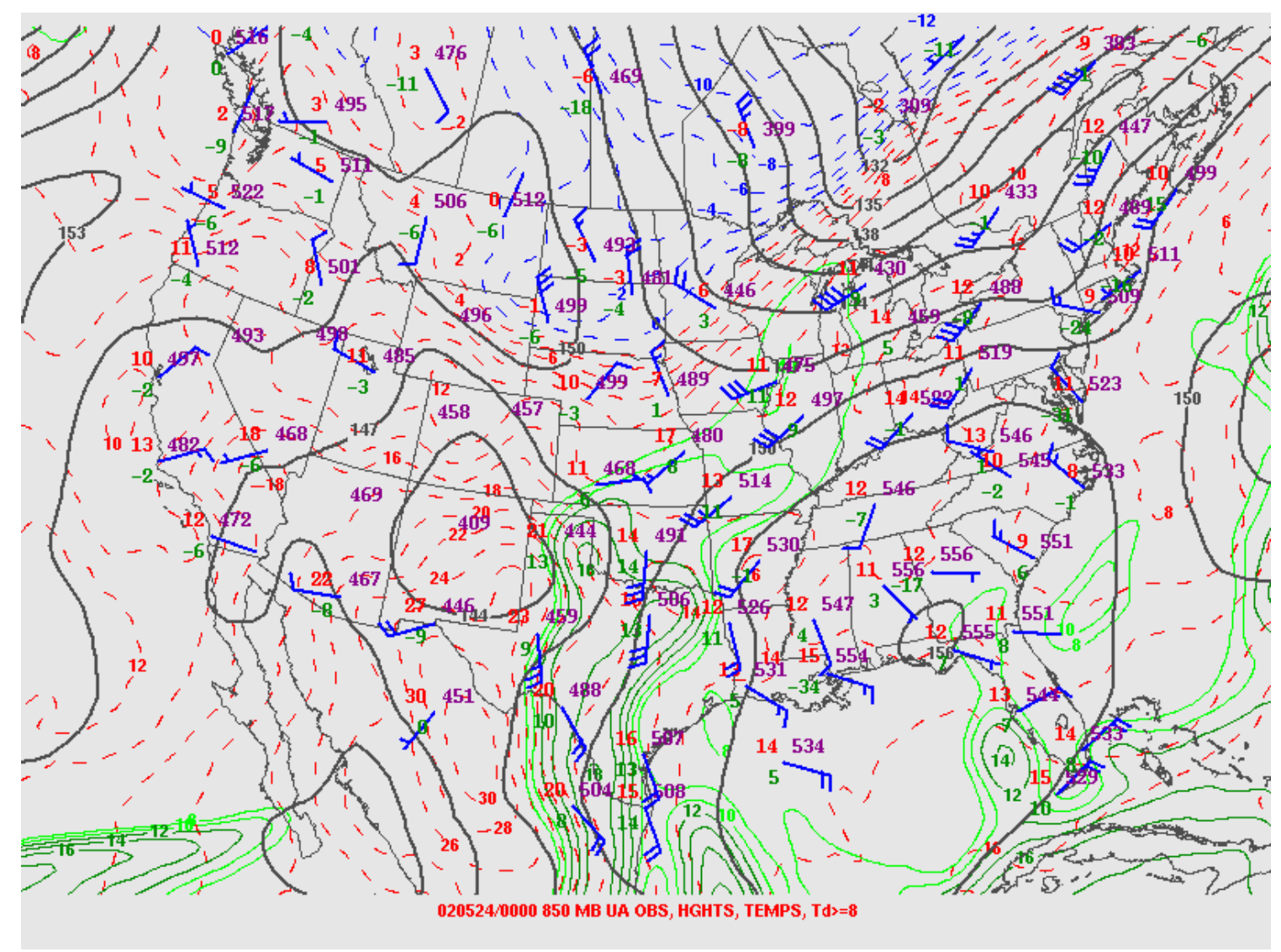

FIG. 27. $850 \mathrm{hPa}$ analysis for 00 UTC 24 May 2002. Height contours (dm) are solid black lines, isotherms $\left({ }^{\circ} \mathrm{C}\right)$ are dashed red and blue lines, and dewpoint contours $\geq 8^{\circ} \mathrm{C}$ are solid green lines. 


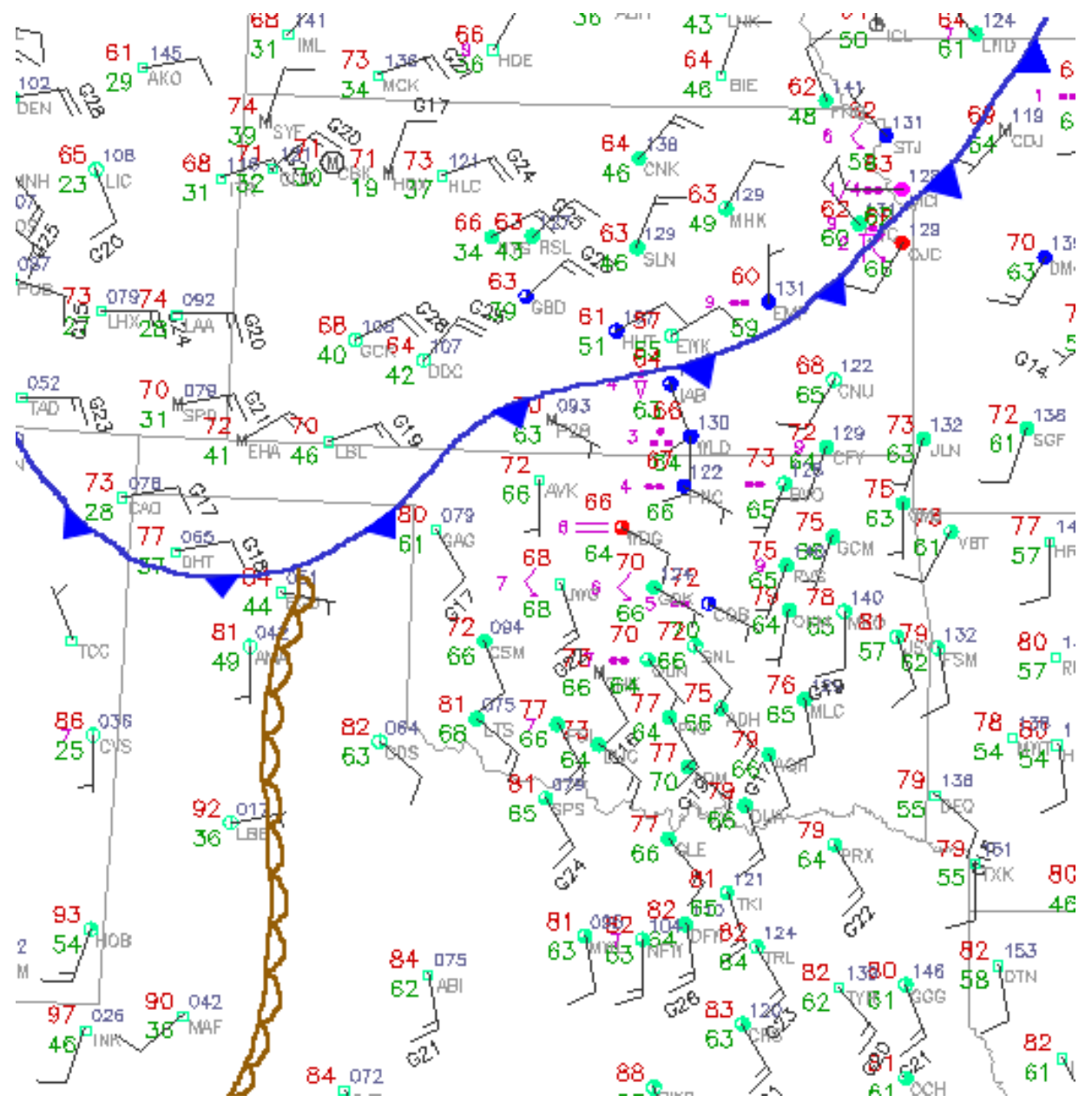

FIG. 28. Surface observations and manual analysis for 22 UTC 23 May 2002. Cold front and dryline are indicated with conventional symbols.

\section{2) 24 MAY 2002}

The well-defined shortwave trough that was centered over northern Utah on 23

May moved eastward, providing synoptic-scale ascent across the IHOP_2002 domain on

24 May (Fig. 29). At the surface, a cold front was pushing slowly southward across

southeast Kansas, Oklahoma, and the Texas panhandle. A dryline intersected the cold front in the Texas panhandle, forming a triple point, and the dryline extended 
southwestward from this point (Fig. 30). As evident in Fig. 31, low-level southerly winds advected warm, moist air into northern Texas, Oklahoma, and southern Kansas, priming the air mass across this region for moist convection. The advection of warm, moist air resulted in the development of a pronounced $\theta_{\mathrm{e}}$ ridge, reflected in the CAPE field shown in Fig. 32. This $\theta_{\mathrm{e}}$ ridge was bounded by the cold front to the north and dryline to the west.

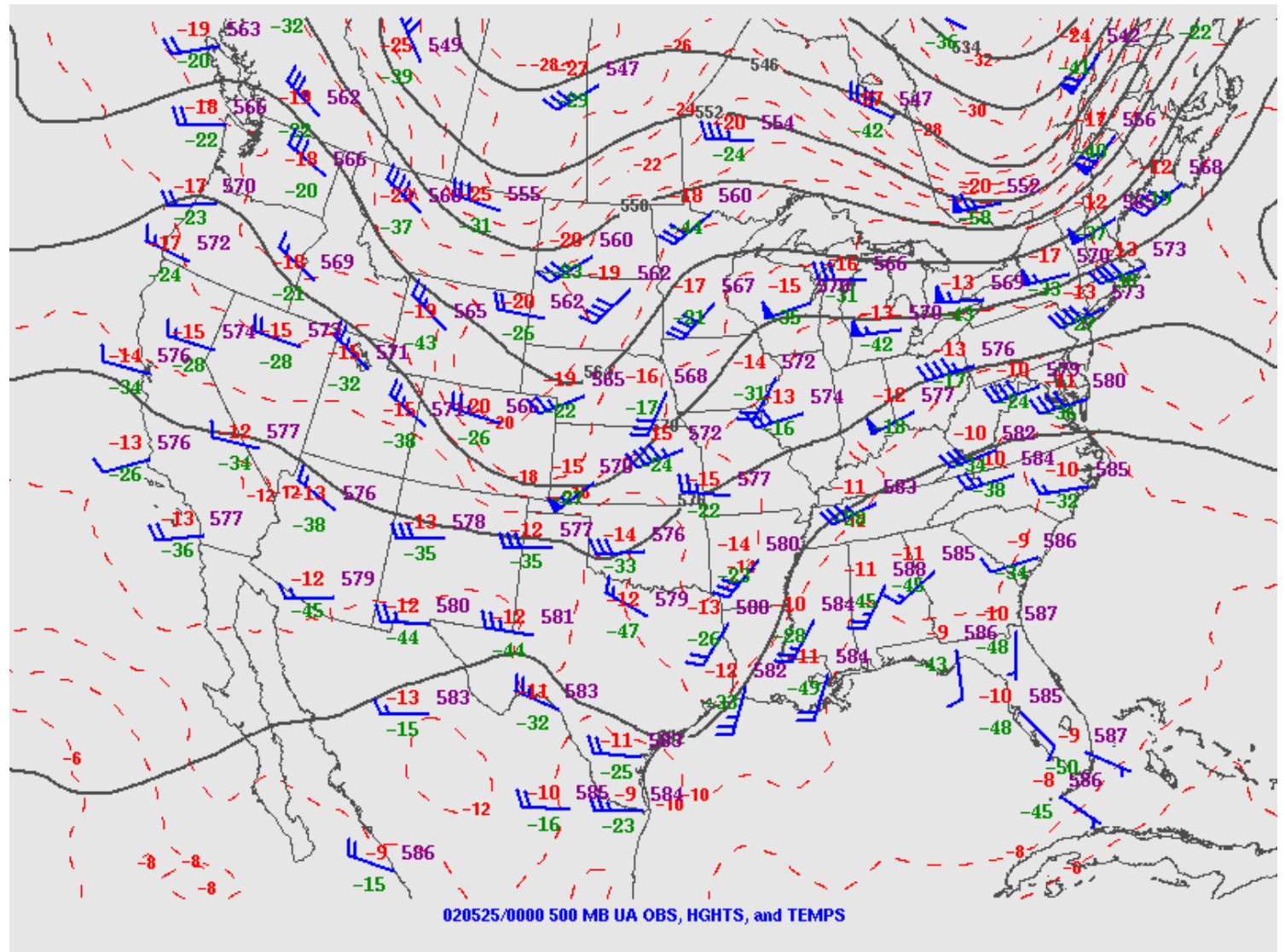

FIG. 29. $500 \mathrm{hPa}$ analysis for 00 UTC 25 May 2002. Height contours (dm) are solid black lines and isotherms $\left({ }^{\circ} \mathrm{C}\right)$ are dashed red lines. 


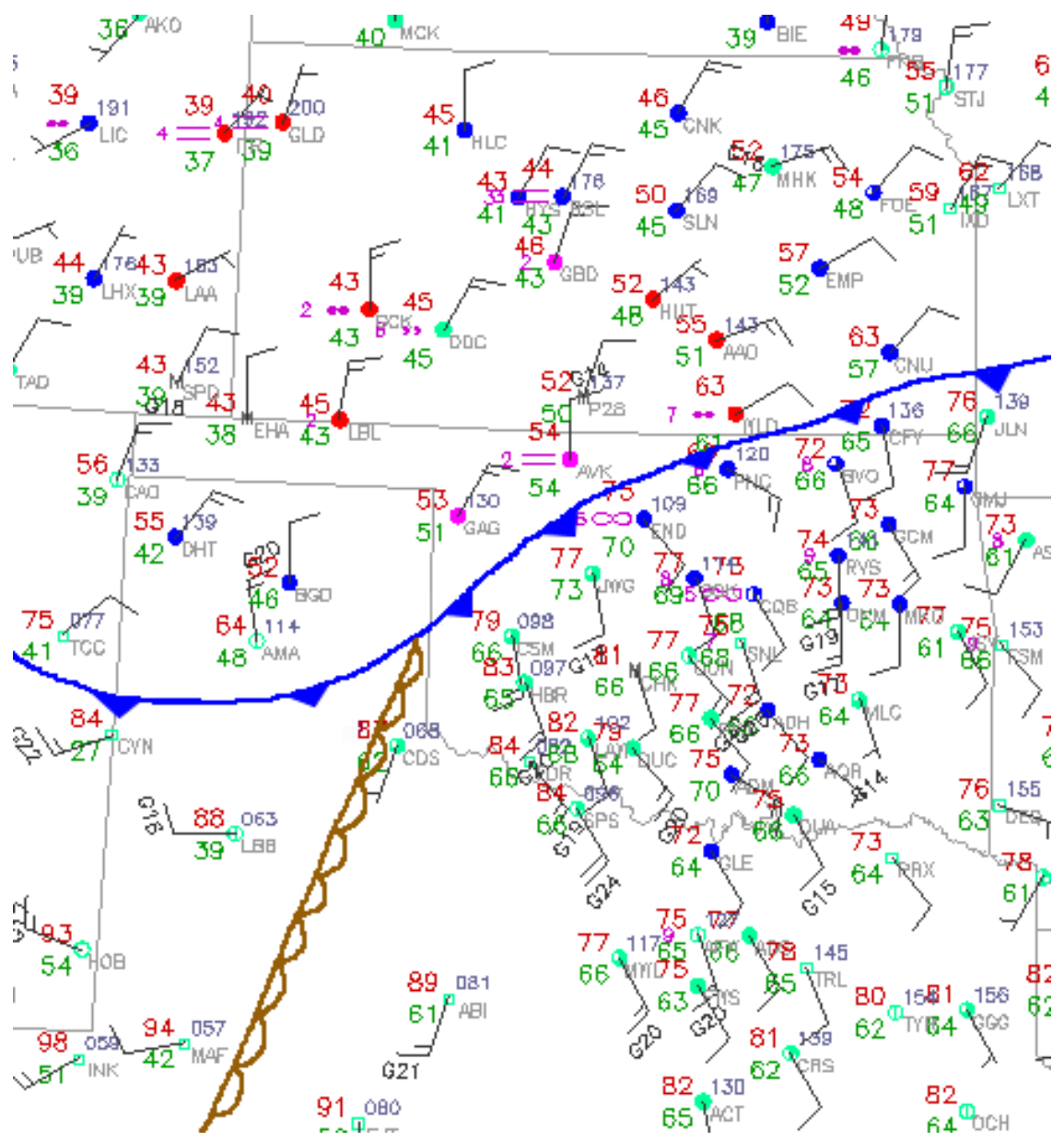

FIG. 30. Surface observations and manual analysis for 20 UTC 24 May 2002. Cold front and dryline are indicated with conventional symbols. 


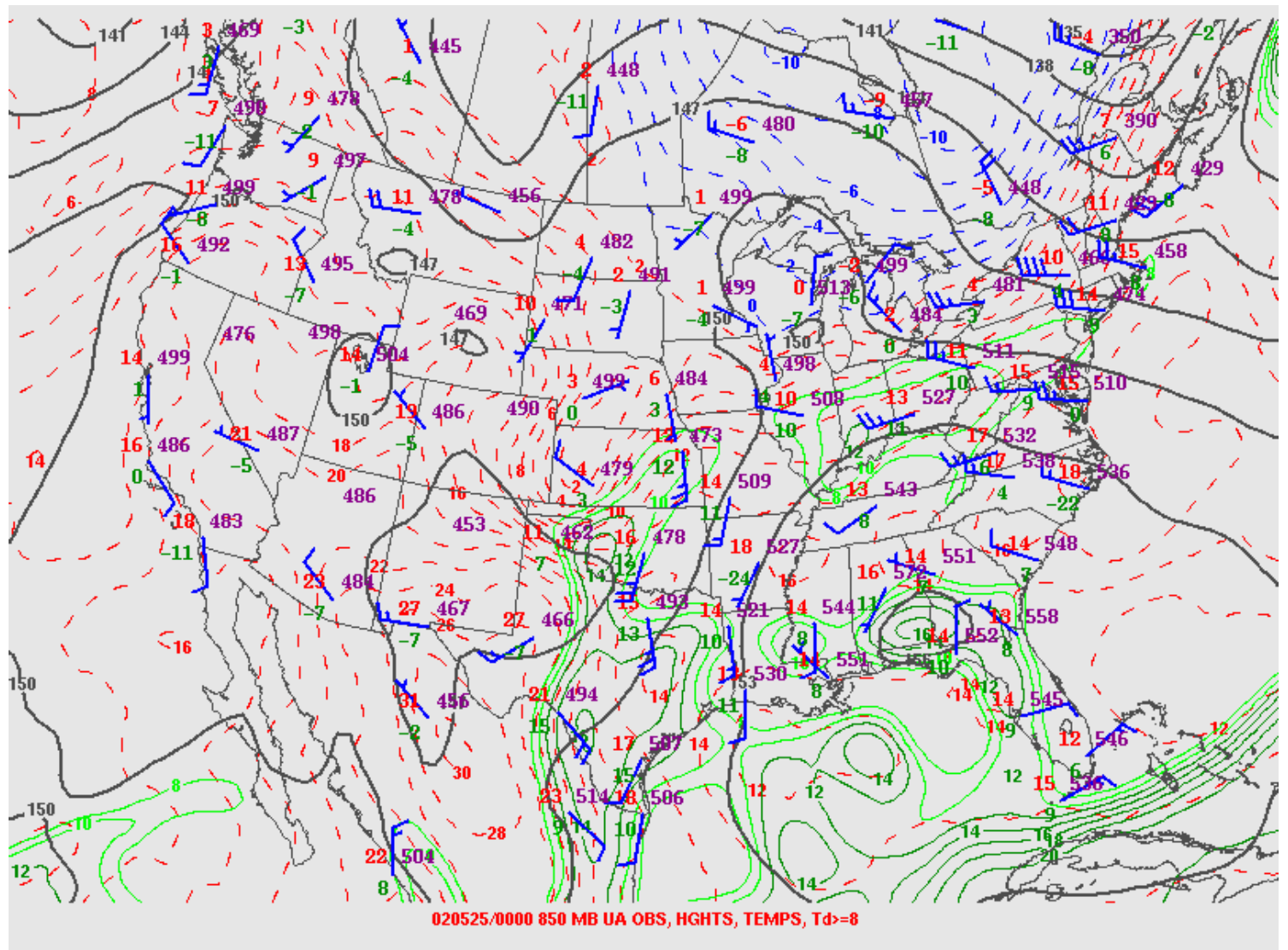

FIG. 31. $850 \mathrm{hPa}$ analysis for 00 UTC 25 May 2002. Height contours (dm) are solid black lines, isotherms $\left({ }^{\circ} \mathrm{C}\right)$ are dashed red and blue lines, and dewpoint contours $\geq 8^{\circ} \mathrm{C}$ are solid green lines. 


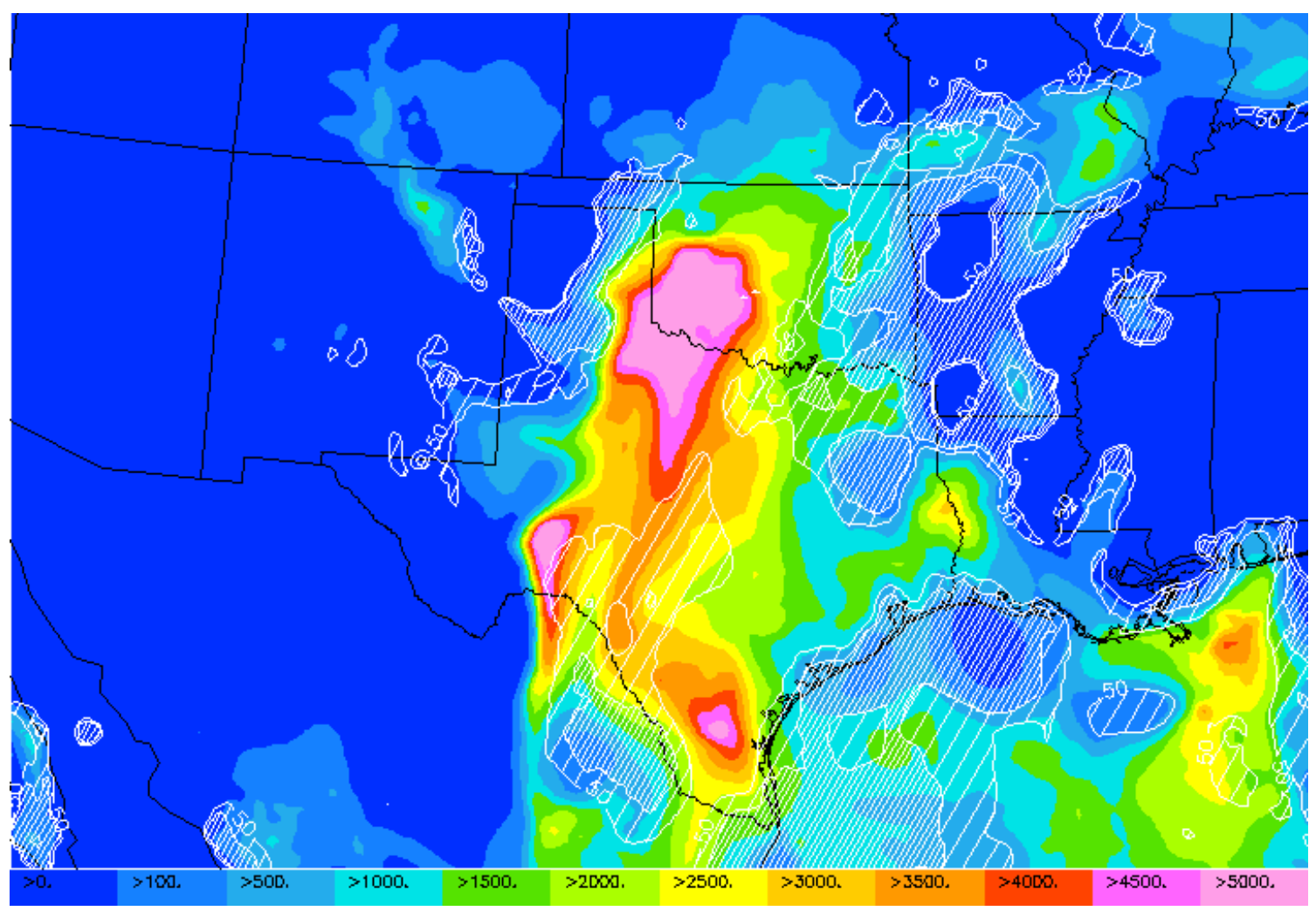

FIG. 32. Analysis of CAPE (J/kg; shaded) and CIN (values $\geq 50 \mathrm{~J} / \mathrm{kg}$ and $\geq 100 \mathrm{~J} / \mathrm{kg}$ hatched) at $21 \mathrm{UTC}$ 24 May 2002 from the FSL RUC model with 10-km resolution.

\section{3) 4 JUNE 2002}

The meteorological environment on 4 June consisted of an amplified shortwave trough at mid and upper levels across the Rocky Mountain region (Figs. 33 and 34). Downstream of this trough, the negative mesoscale region was under a broad area of divergence aloft, resulting in upward vertical motion across the region. Enhanced moisture associated with the shortwave propagating eastward was evident at the $700 \mathrm{hPa}$ level (Fig. 35), while southerly winds at the $850 \mathrm{hPa}$ level advected abundant amounts of moisture and warm air northward into Kansas, Oklahoma, and north Texas (Fig. 36). At the surface, a cold front stretched from an area of low pressure in Iowa southwestward 
across Kansas, Oklahoma, and the Texas panhandle (Fig. 37). This front moved slowly to the southeast through the day, and provided additional forcing for convection. In response to the forcing both aloft and at the surface, and unstable air mass in place ahead of the cold front, widespread convection developed across the negative mesoscale region.

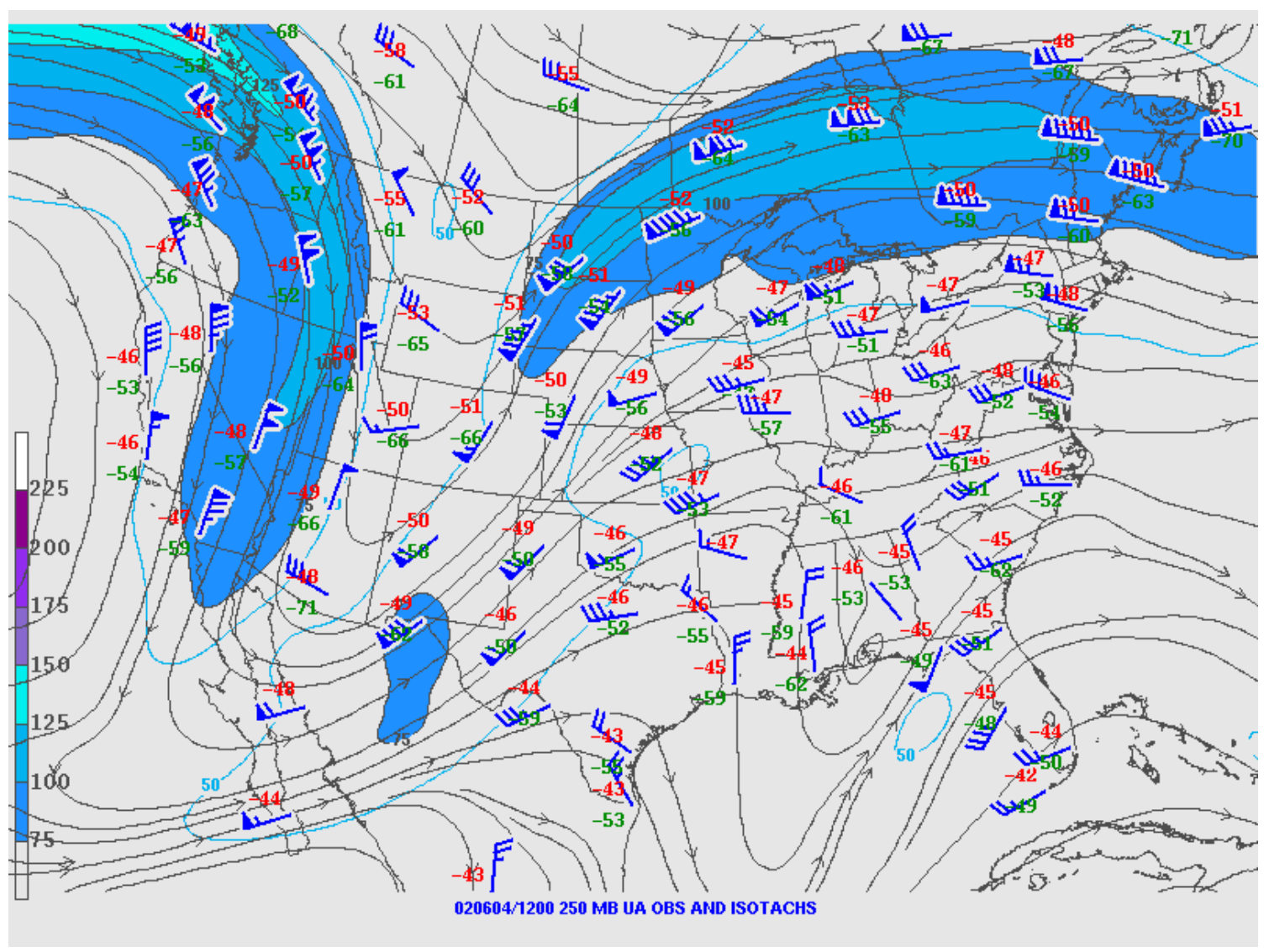

FIG. 33. $250 \mathrm{hPa}$ analysis for 12 UTC 4 June 2002. Streamlines are solid black lines, wind speeds $\geq 50$ knots are outlined with light blue contours, and wind speeds $\geq 75$ knots are shaded according to the color bar on the left. 


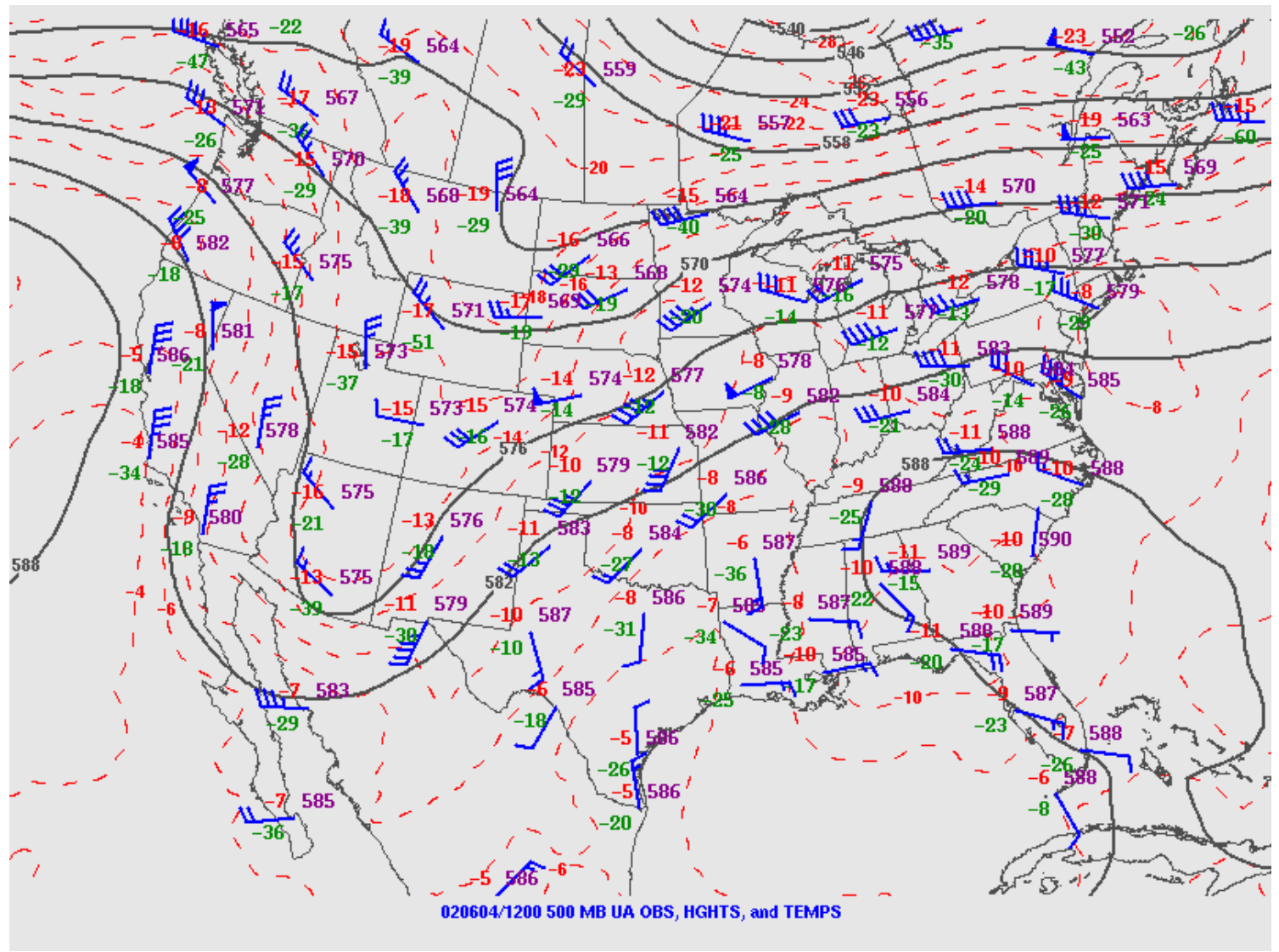

FIG. 34. $500 \mathrm{hPa}$ analysis for 12 UTC 4 June 2002. Height contours (dm) are solid black lines and isotherms $\left({ }^{\circ} \mathrm{C}\right)$ are dashed red lines. 


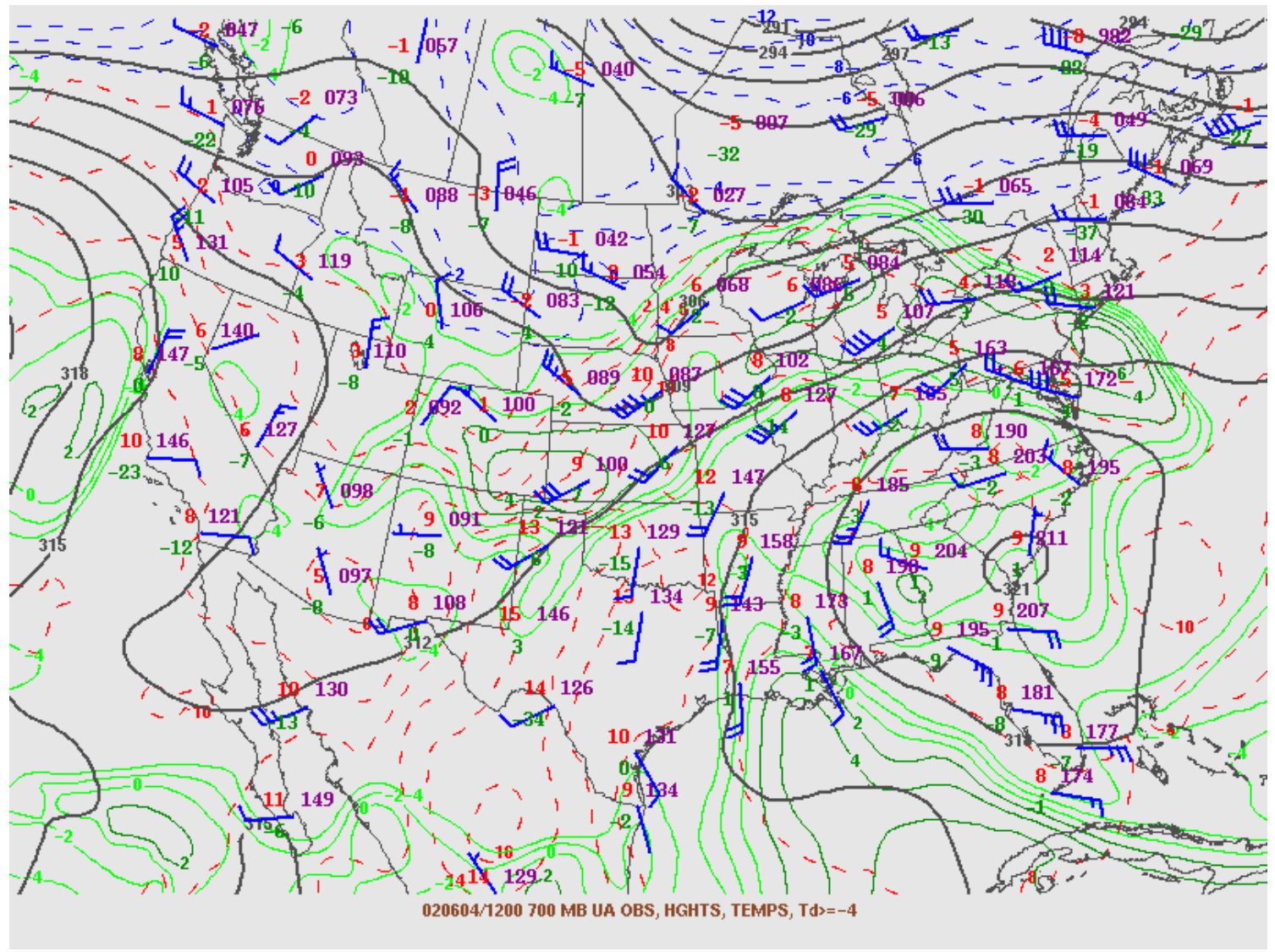

FIG. 35. $700 \mathrm{hPa}$ analysis for 12 UTC 4 June 2002. Height contours (dm) are solid black lines, isotherms $\left({ }^{\circ} \mathrm{C}\right)$ are dashed red and blue lines, and dewpoint contours $\geq-4^{\circ} \mathrm{C}$ are solid green lines. 


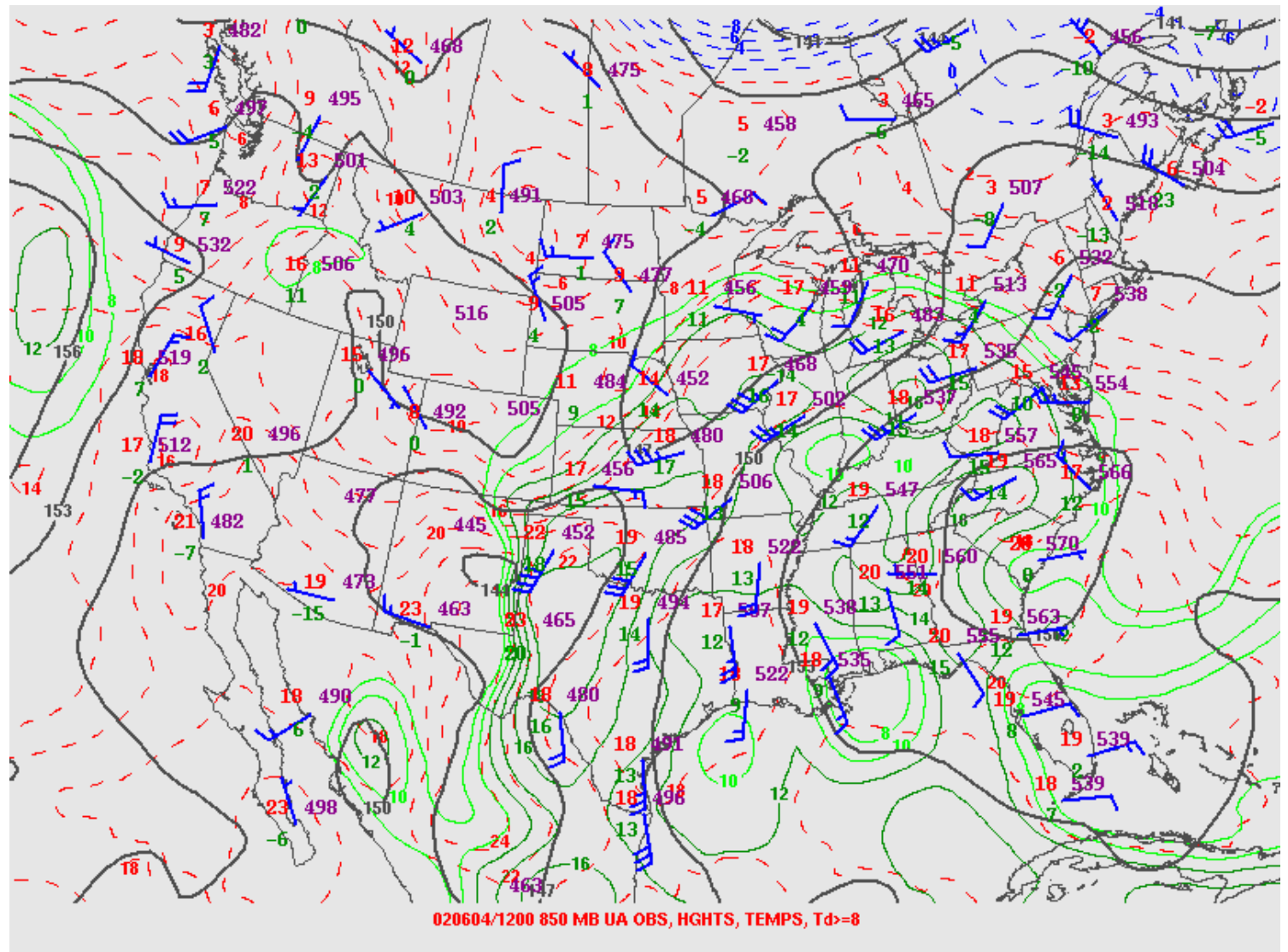

FIG. 36. $850 \mathrm{hPa}$ analysis for 12 UTC 4 June 2002. Height contours (dm) are solid black lines, isotherms $\left({ }^{\circ} \mathrm{C}\right)$ are dashed red and blue lines, and dewpoint contours $\geq 8^{\circ} \mathrm{C}$ are solid green lines. 


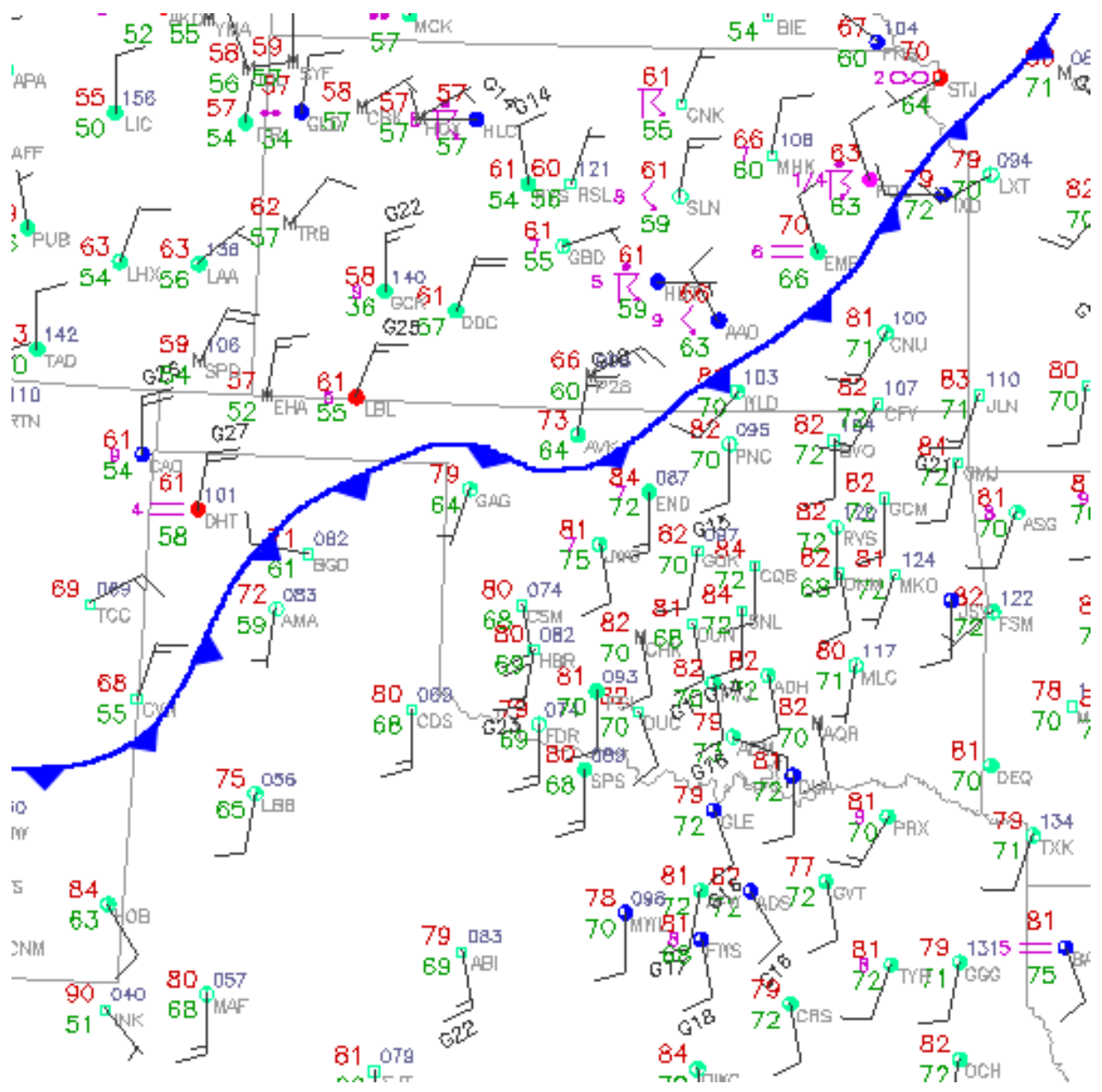

FIG. 37. Surface observations and manual analysis for 15 UTC 4 June 2002. Cold front is indicated with conventional symbol.

\section{4) 12 JUNE 2002}

A large upper-level high pressure area centered over northern Mexico placed the IHOP_2002 domain under west-northwest flow at mid and upper levels. As is typical for severe weather events across this region, low-level winds were south-southeasterly, advecting warm air and moisture northward into northern Texas, Oklahoma, and southern Kansas (Fig. 38). A surface low was positioned over far southwest Kansas and the eastern Oklahoma panhandle (Fig. 39). A surface trough wrapped from the northeast 
side of the low southwestward across the Texas panhandle. As can be seen in Figs. 39 and 40, a remnant outflow boundary from an MCS intersected the surface trough just east of the low and extended southeastward from this intersection into northern and eastern Oklahoma. Surface dewpoints were very high (generally $70-75^{\circ} \mathrm{F}$ ) both north and south of the MCS outflow boundary, with temperatures a few degrees cooler to its north. Convergence of surface winds along the boundary provided low-level forcing for convection. Storms initiated along the MCS outflow boundary and surface trough, and at the intersection of these two features.

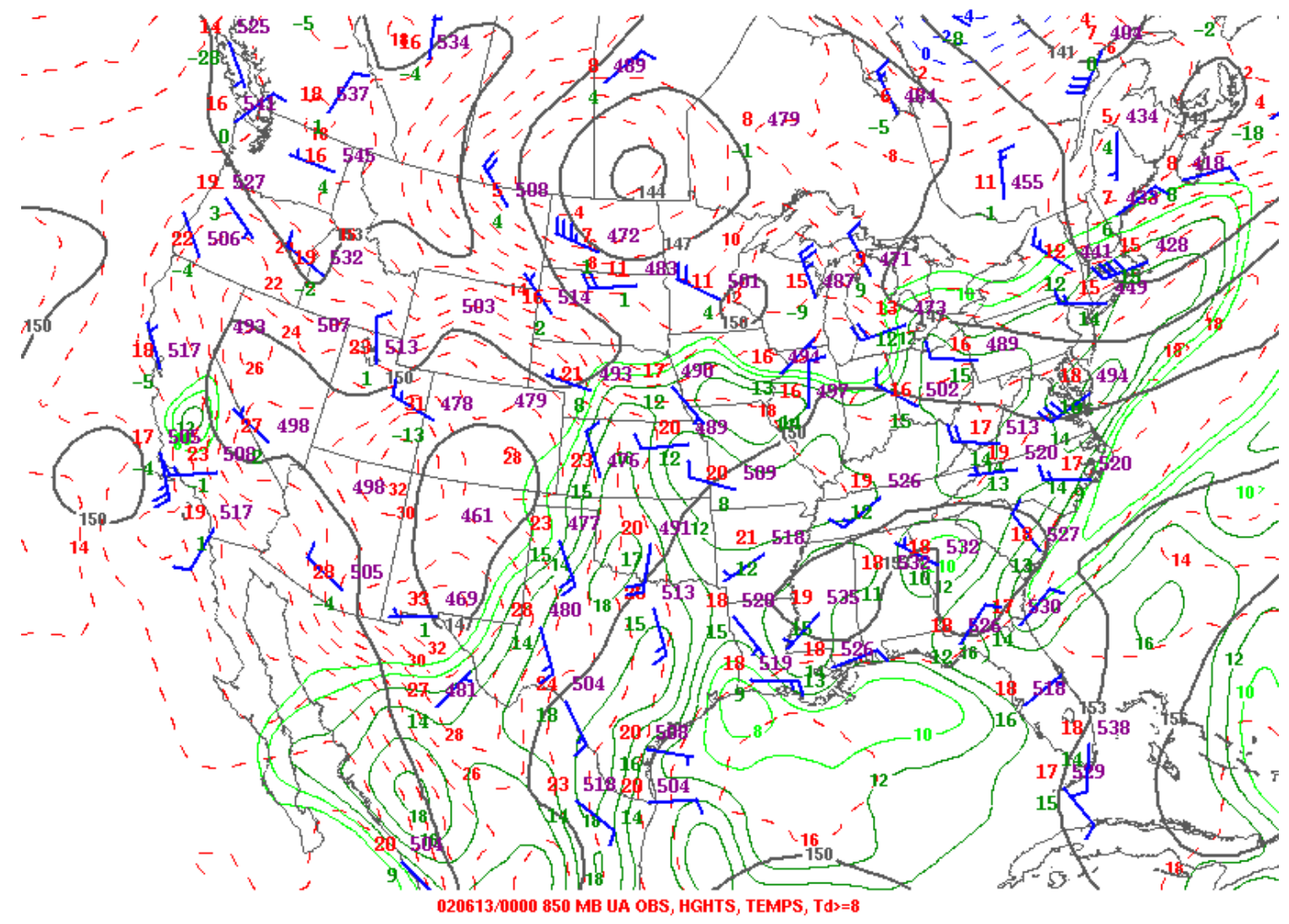

FIG. 38. $850 \mathrm{hPa}$ analysis for 00 UTC 13 June 2002. Height contours (dm) are solid black lines, isotherms $\left({ }^{\circ} \mathrm{C}\right)$ are dashed red and blue lines, and dewpoint contours $\geq 8^{\circ} \mathrm{C}$ are solid green lines. 


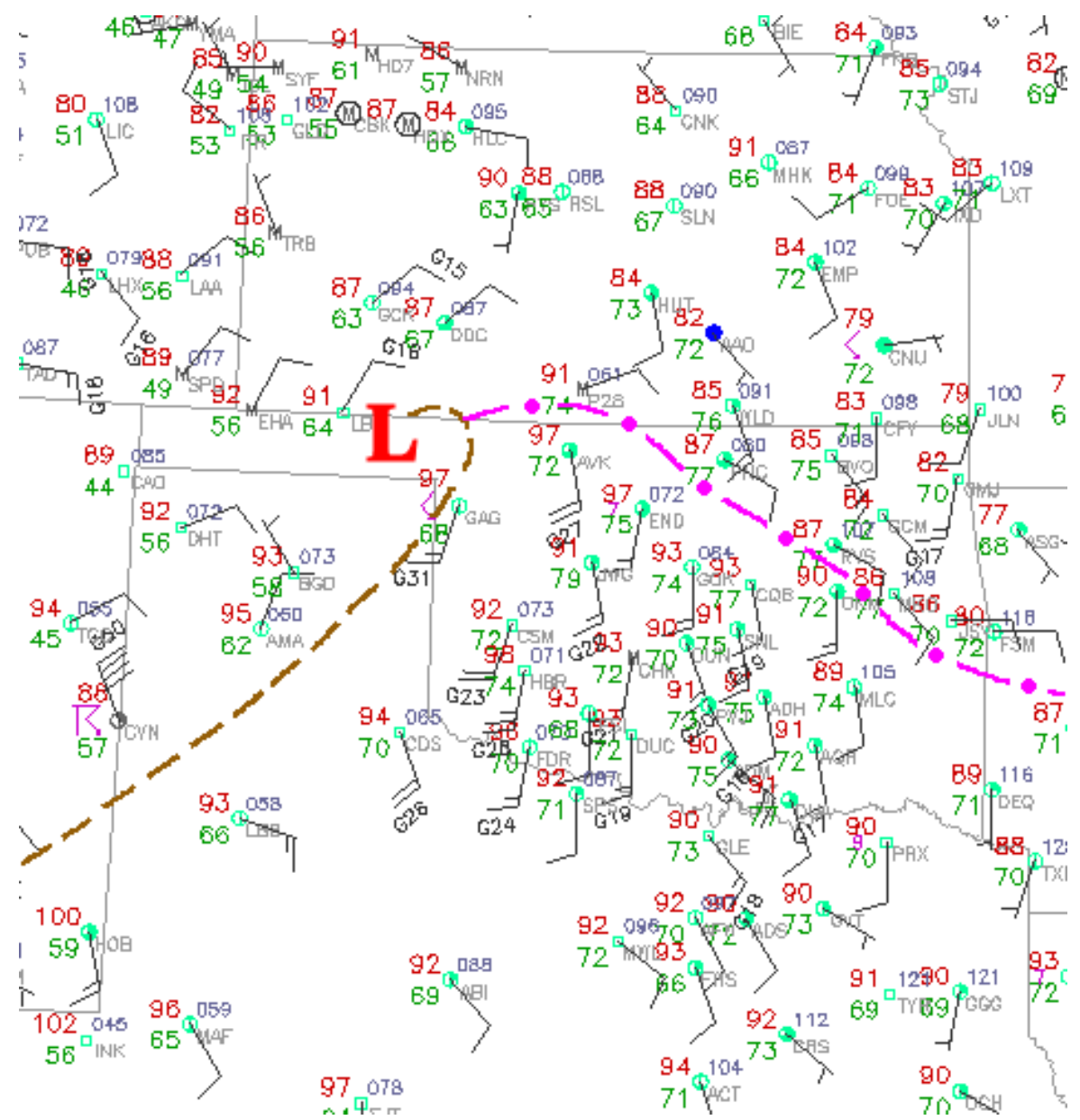

FIG. 39. Surface observations and manual analysis for 21 UTC 12 June 2002. Center of low pressure area is indicated with red ' $\mathrm{L}$ ', trough of low pressure is indicated with dashed brown line, and MCS outflow boundary is indicated with magenta dash-dot line. 


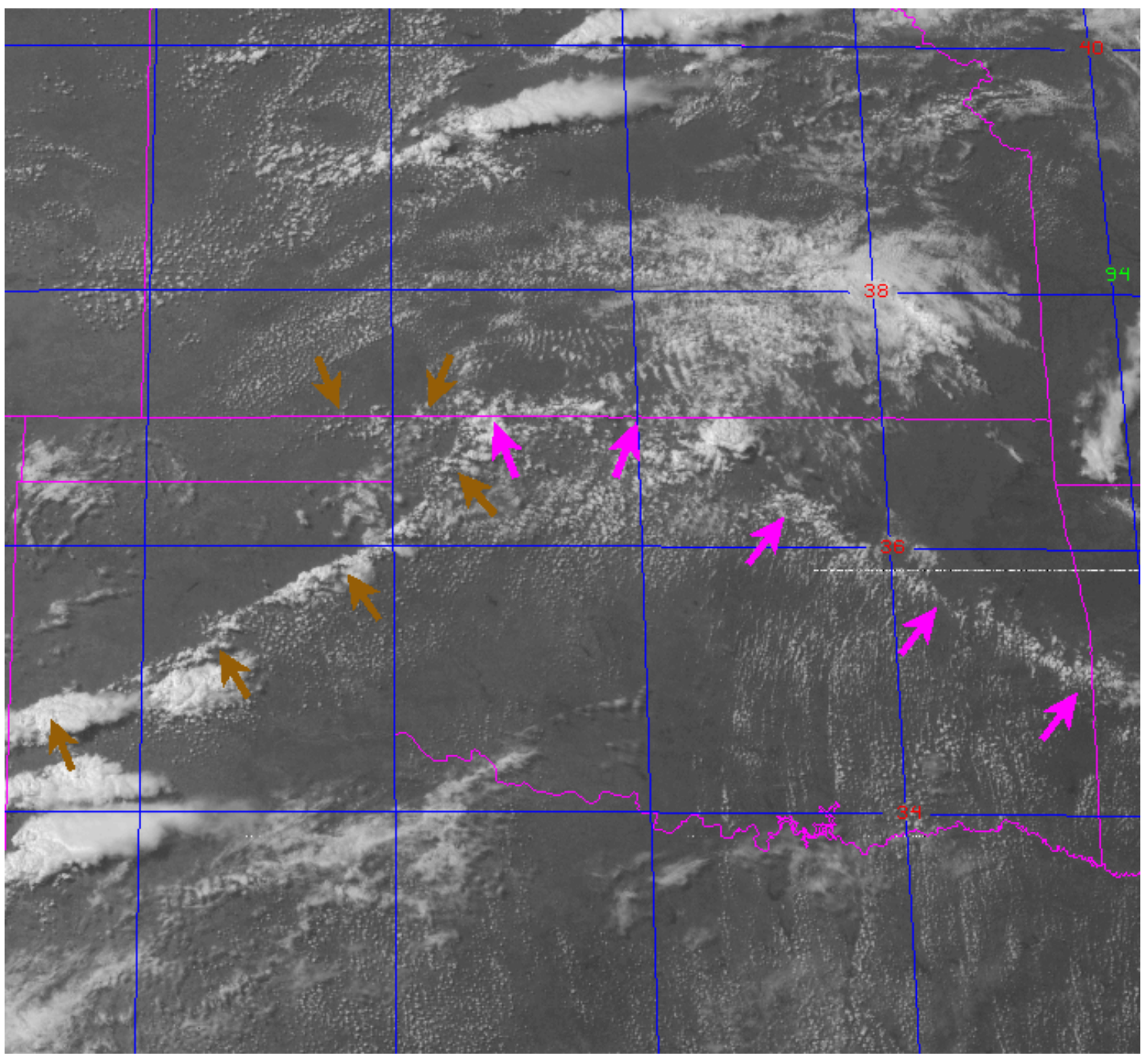

FIG. 40. Visible satellite image from 2103 UTC 12 June 2002. Position of surface trough is indicated with brown arrows and position of MCS outflow boundary is indicated with magenta arrows.

\section{5) 15 JUNE 2002}

Northwest flow at mid and upper levels prevailed across the IHOP_2002 region on 15 June, resulting from a broad ridge of high pressure stationed across the western U.S. and a trough across the eastern U.S. At 12 UTC 15 June, the right entrance region of a jet streak at the $250 \mathrm{hPa}$ level was positioned over southeast Colorado. Upper-level divergence associated with this feature supported development of a surface low in 
southeast Colorado. A surge of cooler air moved southward in response to this surface low, initiating convection in eastern Colorado and western Kansas around 17 UTC (Fig. 41). A shortwave trough at the 500 and $700 \mathrm{hPa}$ levels located near the Wyoming/Nebraska border at 12 UTC forced a northwest-southeast oriented line of storms to form across western Nebraska and north-central Kansas during the early morning hours. As this line of storms and the storms across eastern Colorado and

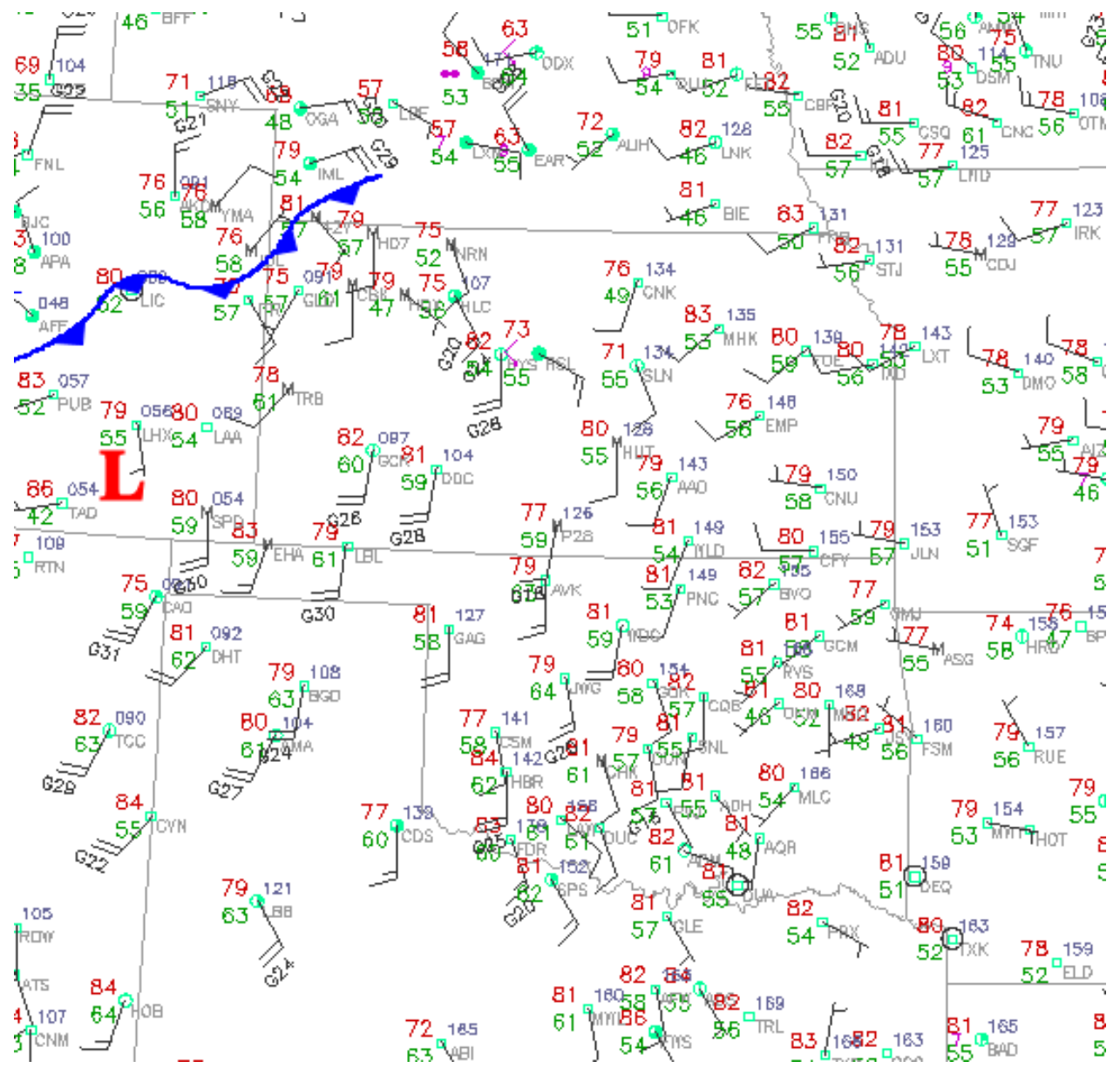

FIG. 41. Surface observations and manual analysis for 17 UTC 15 June 2002. Center of low pressure area is indicated with red ' $\mathrm{L}$ ' and cold front is indicated with conventional symbol. 
western Kansas moved to the southeast, they all merged into an east-west oriented squall line across Kansas. This squall line evolved into a leading line/trailing stratiform (LL/TS) MCS as it continued to move to the south-southeast across Kansas, Oklahoma, and Texas.

Upper-level divergence associated with the left exit region of a jet streak nosing into the Texas panhandle around 00 UTC 16 June produced synoptic-scale lift to sustain strong storms across the region (Fig. 42). Upper-level divergence is also evident in Fig. 42 across Oklahoma and southern Kansas. A shortwave trough over western Oklahoma and the Texas panhandle at the 500 and $700 \mathrm{hPa}$ levels provided additional vertical motion for further development and maintenance of storms (Fig. 43). Moisture advection and WAA at the $850 \mathrm{hPa}$ level were much stronger across the positive mesoscale region compared to the negative mesoscale region (Fig. 44), resulting in larger CAPE values across the positive region (Fig. 45). Also of note for this case, a surface trough within the positive mesoscale region stretched south-southwestward from southwest Kansas into the Oklahoma and northern Texas panhandles (Figs. 46 and 47). Surface winds were convergent along this boundary, and the storm on the western edge of the squall line propagated directly along this boundary and became supercellular, producing two F0 tornadoes. 


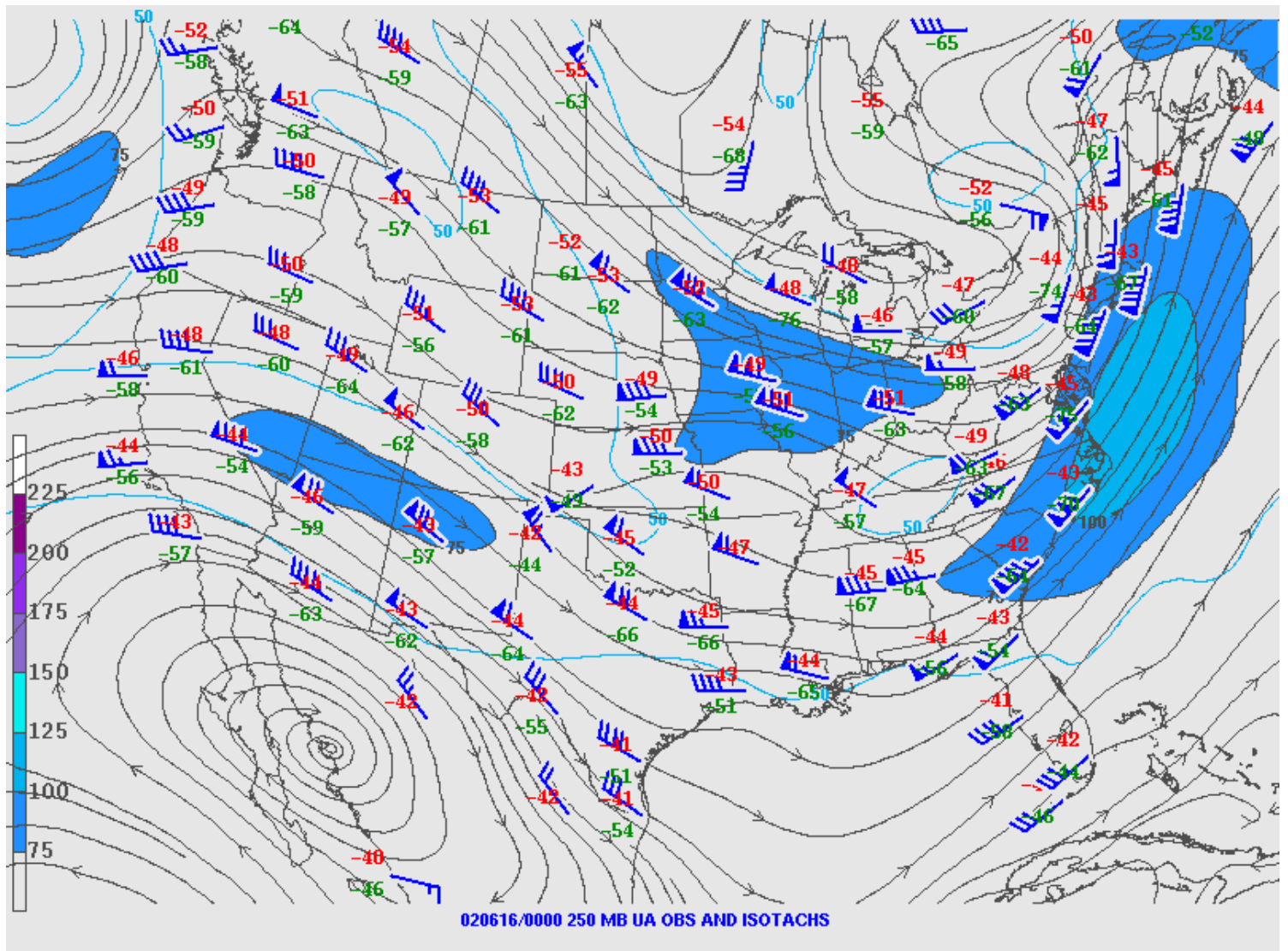

FIG. 42 . $250 \mathrm{hPa}$ analysis for 00 UTC 16 June 2002. Streamlines are solid black lines, wind speeds $\geq 50$ knots are outlined with light blue contours, and wind speeds $\geq 75$ knots are shaded according to the color bar on the left. 


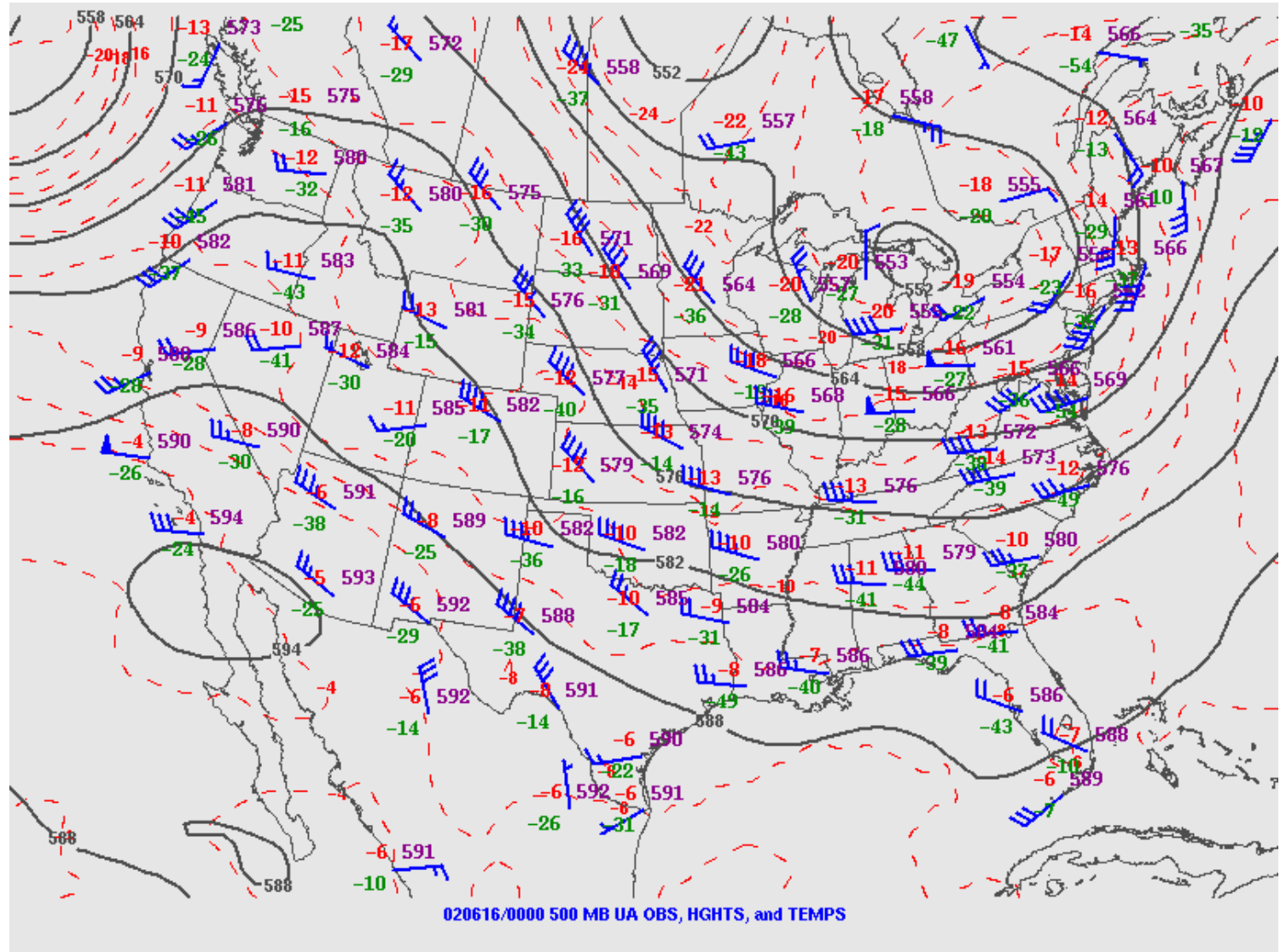

FIG. 43. $500 \mathrm{hPa}$ analysis for $00 \mathrm{UTC} 16$ June 2002. Height contours (dm) are solid black lines and isotherms $\left({ }^{\circ} \mathrm{C}\right)$ are dashed red lines. 


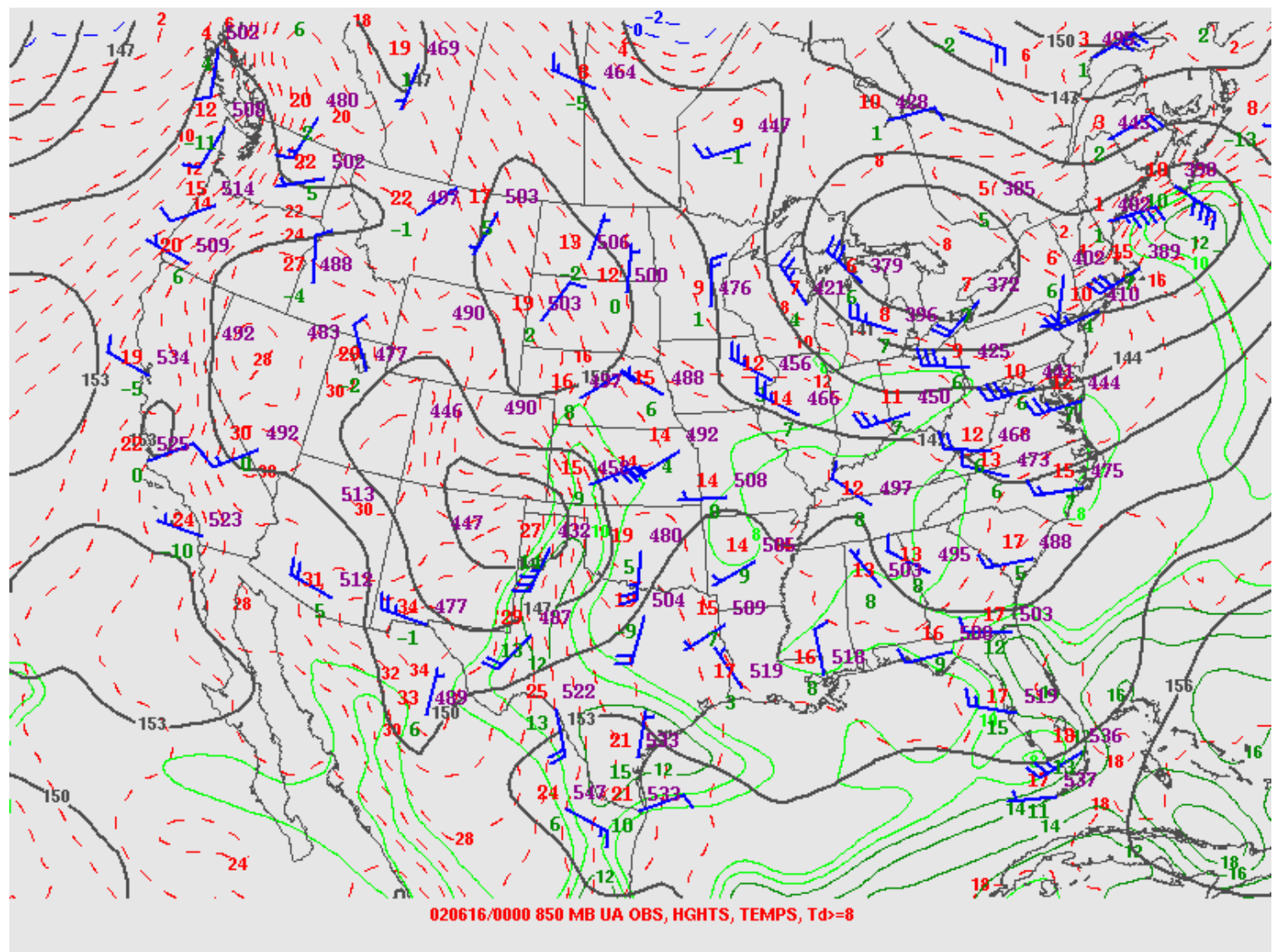

FIG. 44. $850 \mathrm{hPa}$ analysis for 00 UTC 16 June 2002. Height contours (dm) are solid black lines, isotherms $\left({ }^{\circ} \mathrm{C}\right)$ are dashed red and blue lines, and dewpoint contours $\geq 8^{\circ} \mathrm{C}$ are solid green lines. 


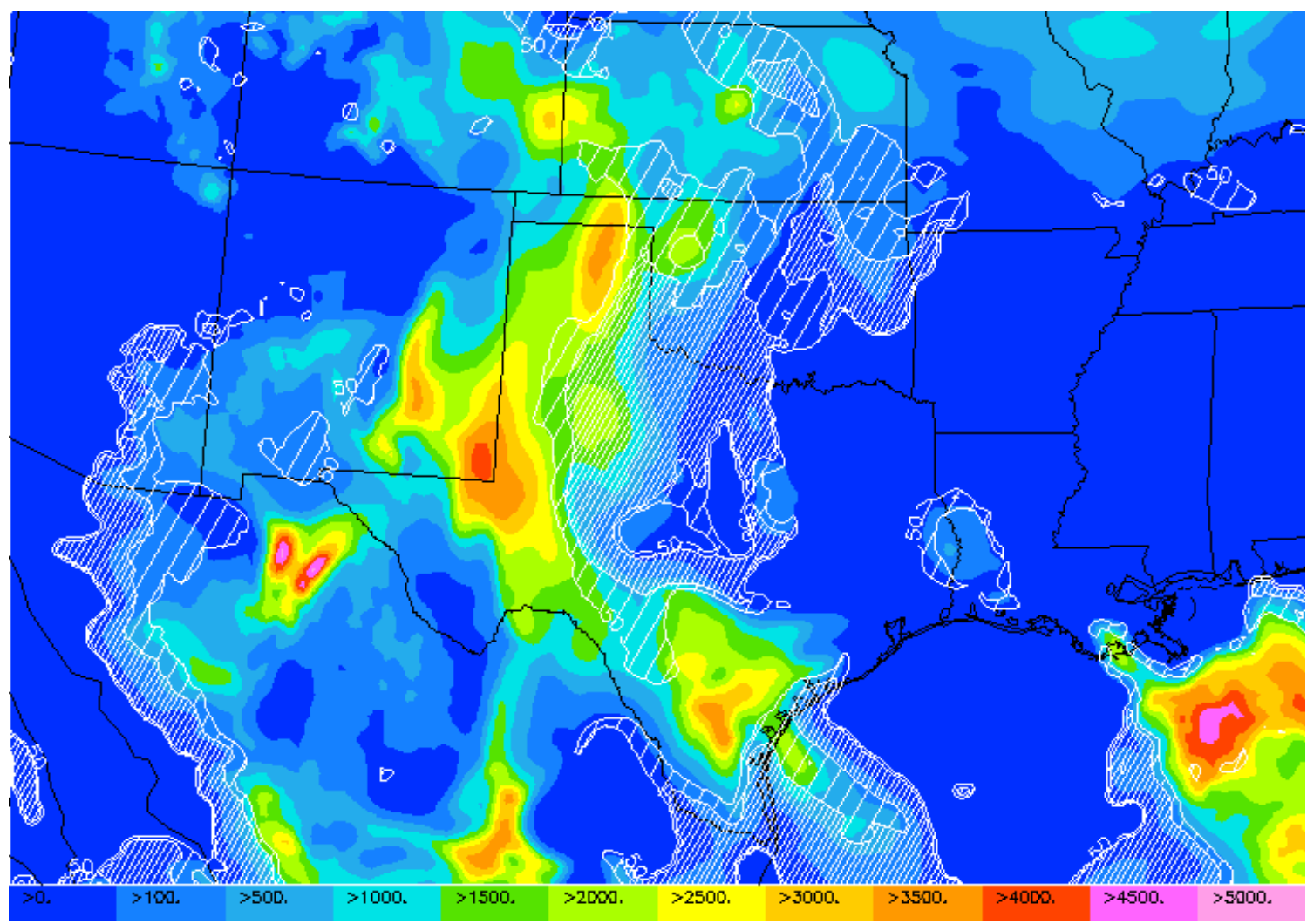

FIG. 45. Analysis of CAPE (J/kg; shaded) and CIN (values $\geq 50 \mathrm{~J} / \mathrm{kg}$ and $\geq 100 \mathrm{~J} / \mathrm{kg}$ hatched) at $21 \mathrm{UTC}$ 15 June 2002 from the FSL RUC model with 10-km resolution. 


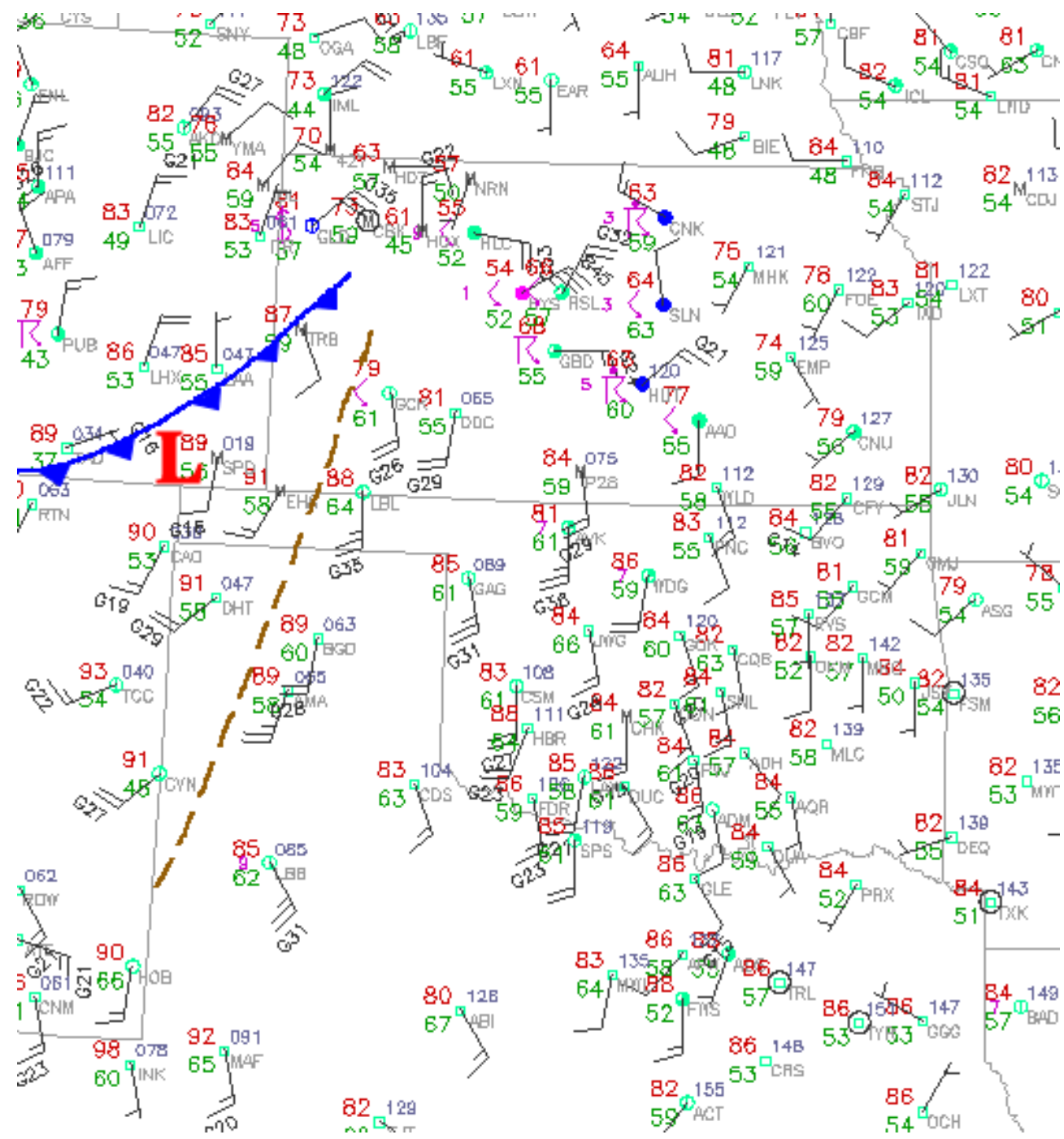

FIG. 46. Surface observations and manual analysis for 20 UTC 15 June 2002. Center of low pressure area is indicated with red ' $\mathrm{L}$ ', trough of low pressure is indicated with dashed brown line, and cold front is indicated with conventional symbol. 


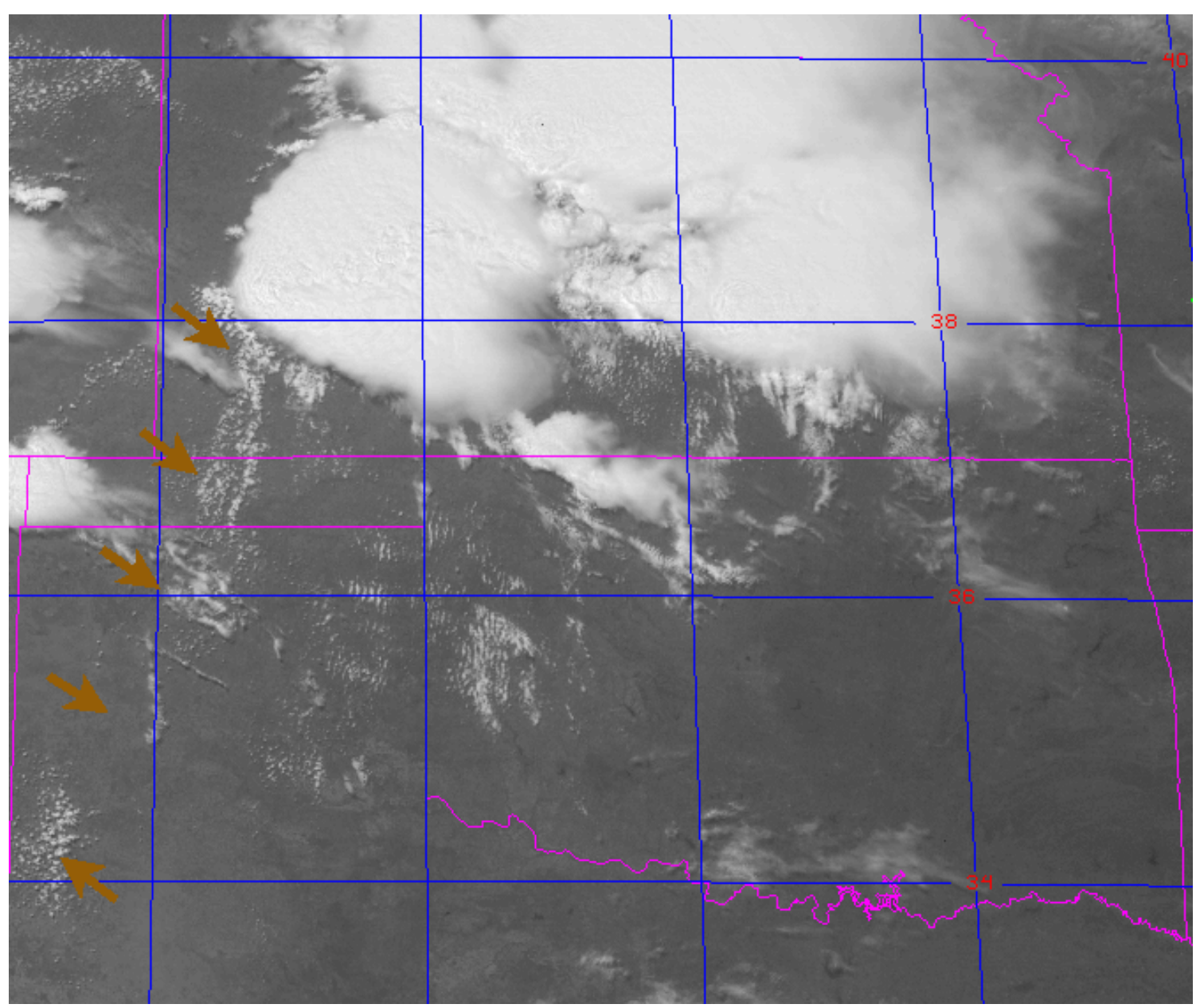

FIG. 47. Visible satellite image from 1955 UTC 15 June 2002. Position of surface trough is indicated with brown arrows.

\section{6) 19 JUNE 2002}

An area of high pressure centered over eastern Kansas and Missouri at mid and upper levels resulted in southwesterly flow aloft across the 19 June positive mesoscale region. Southerly flow at the 700 and $850 \mathrm{hPa}$ levels across Texas and Oklahoma, veering to southwesterly flow across Kansas and Nebraska, advected large quantities of moisture and warm air into western Kansas and much of Nebraska (Figs. 48 and 49). Strong southerly surface winds across Texas, Oklahoma, Kansas, and Nebraska caused 
strong moisture advection and WAA into Kansas and Nebraska at the surface as well. A well-defined $\theta_{\mathrm{e}}$ ridge resulted across western Kansas, stretching southwest to northeast across Nebraska, and is clearly evident in the CAPE field depicted in Fig. 50. The western edge of the $\theta_{\mathrm{e}}$ ridge was bounded by a surface cold front. This cold front stretched from northeast to southwest across Nebraska, northwest Kansas, and southeast Colorado (Fig. 51). A dryline intersected the cold front in southeast Colorado, and extended southwestward into New Mexico. Storms initiated along the cold front in Nebraska, Kansas, and southeast Colorado (Fig. 52), and moved to the east/northeast off the boundary.

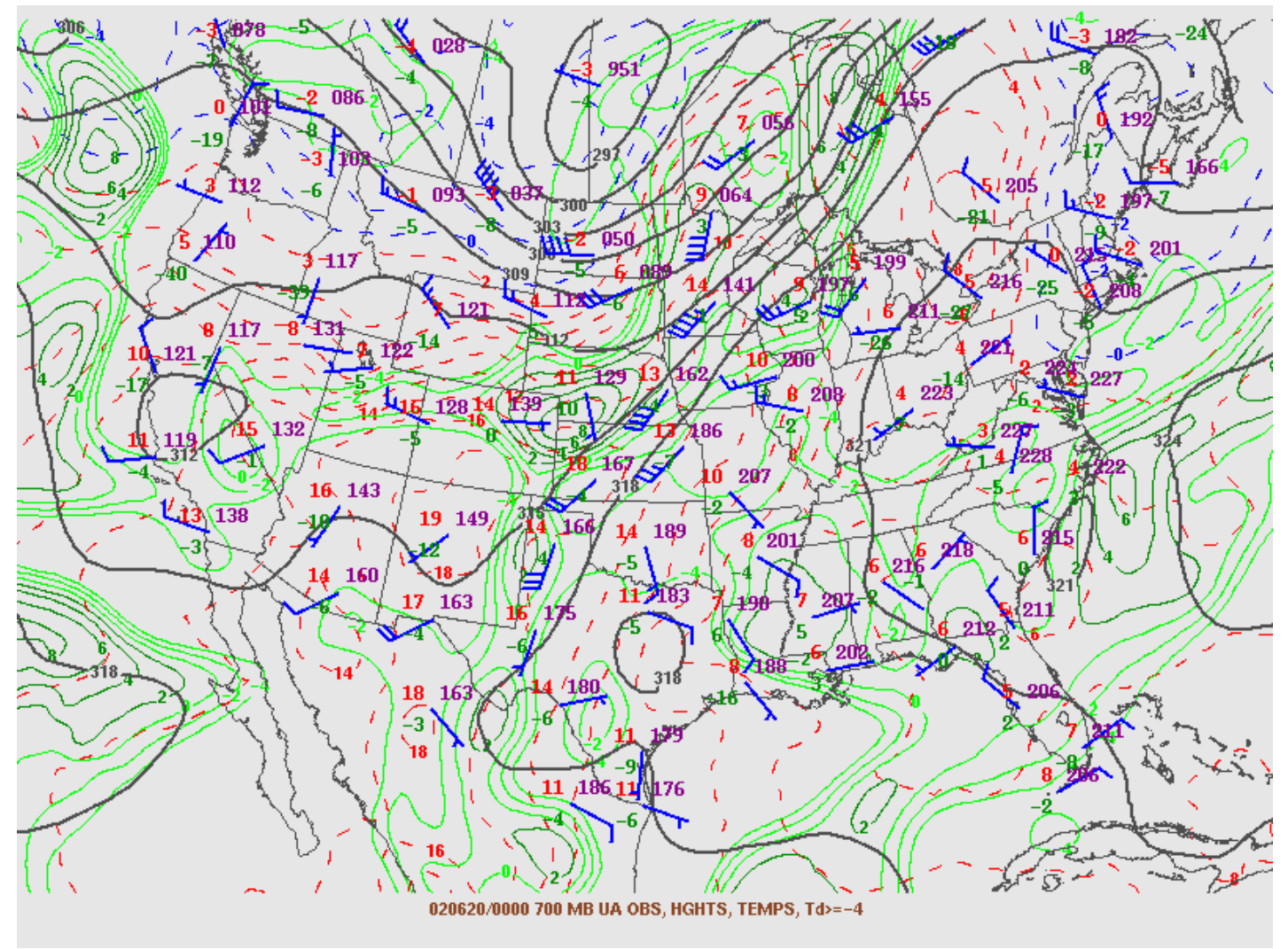

FIG. 48. $700 \mathrm{hPa}$ analysis for $00 \mathrm{UTC} 20$ June 2002. Height contours (dm) are solid black lines, isotherms $\left({ }^{\circ} \mathrm{C}\right)$ are dashed red and blue lines, and dewpoint contours $\geq-4^{\circ} \mathrm{C}$ are solid green lines. 


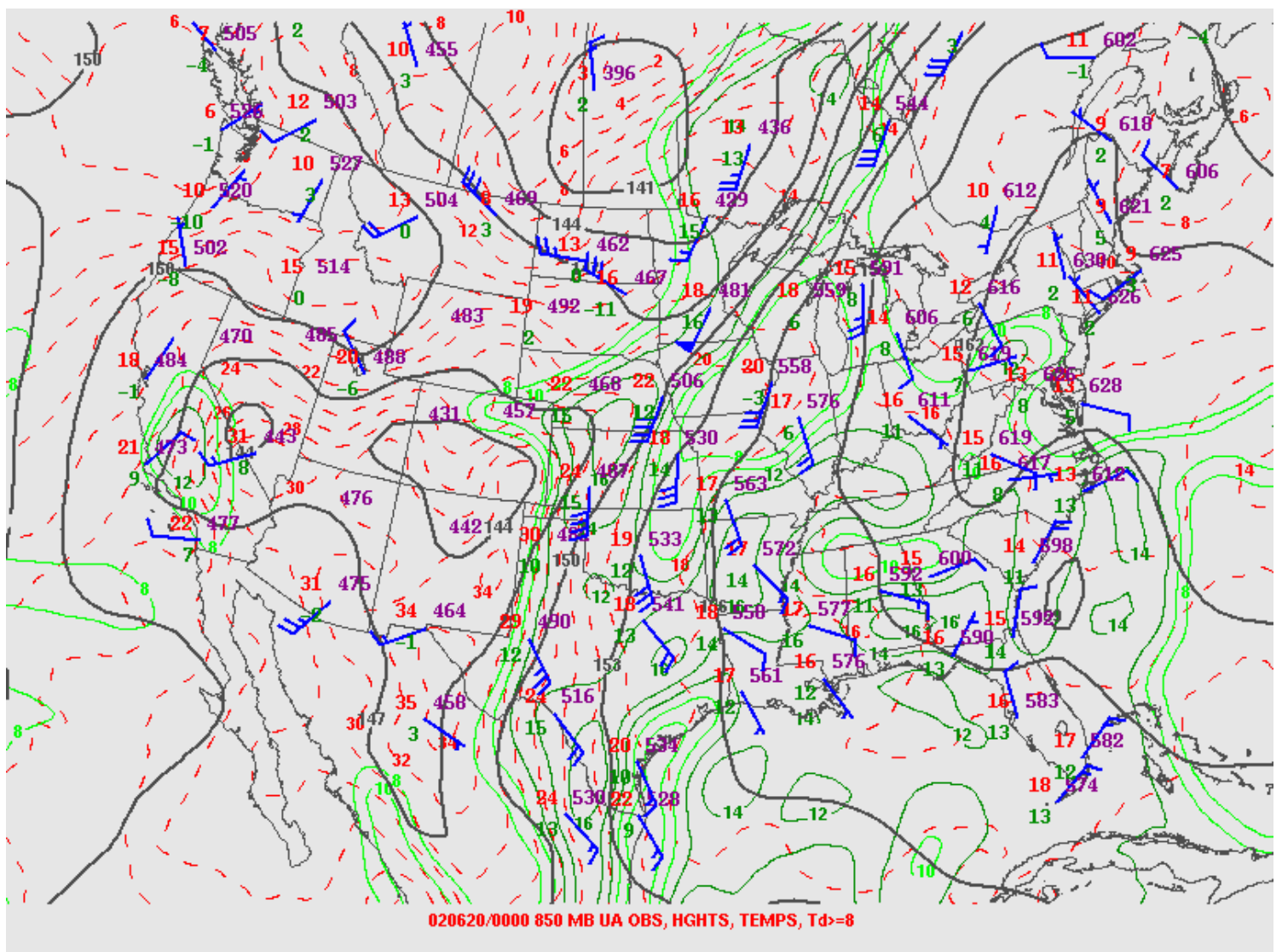

FIG. 49. $850 \mathrm{hPa}$ analysis for 00 UTC 20 June 2002. Height contours (dm) are solid black lines, isotherms $\left({ }^{\circ} \mathrm{C}\right)$ are dashed red and blue lines, and dewpoint contours $\geq 8^{\circ} \mathrm{C}$ are solid green lines. 


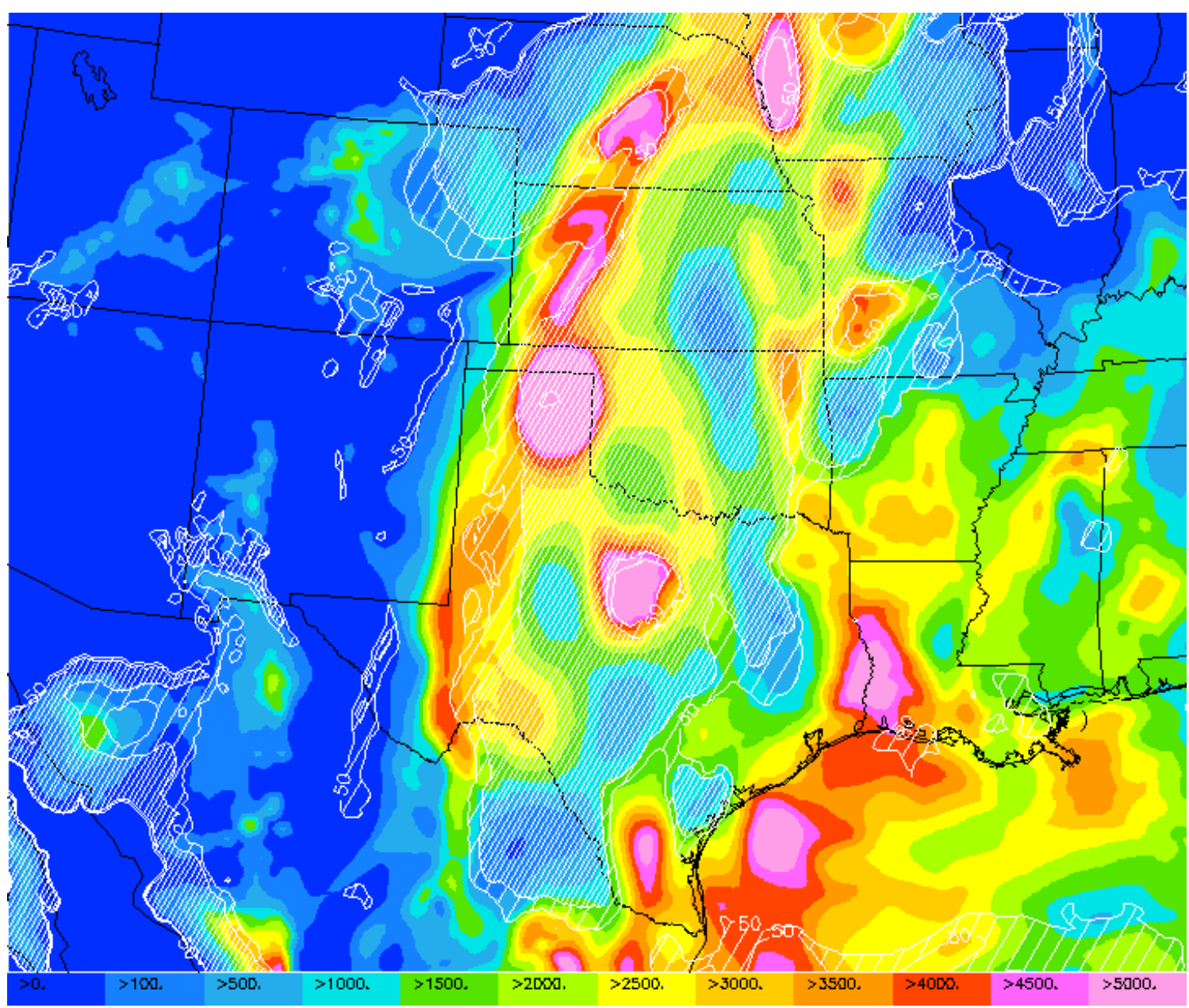

FIG. 50. Analysis of CAPE (J/kg; shaded) and CIN (values $\geq 50 \mathrm{~J} / \mathrm{kg}$ and $\geq 100 \mathrm{~J} / \mathrm{kg}$ hatched) at $21 \mathrm{UTC}$ 19 June 2002 from the FSL RUC model with 10-km resolution. 


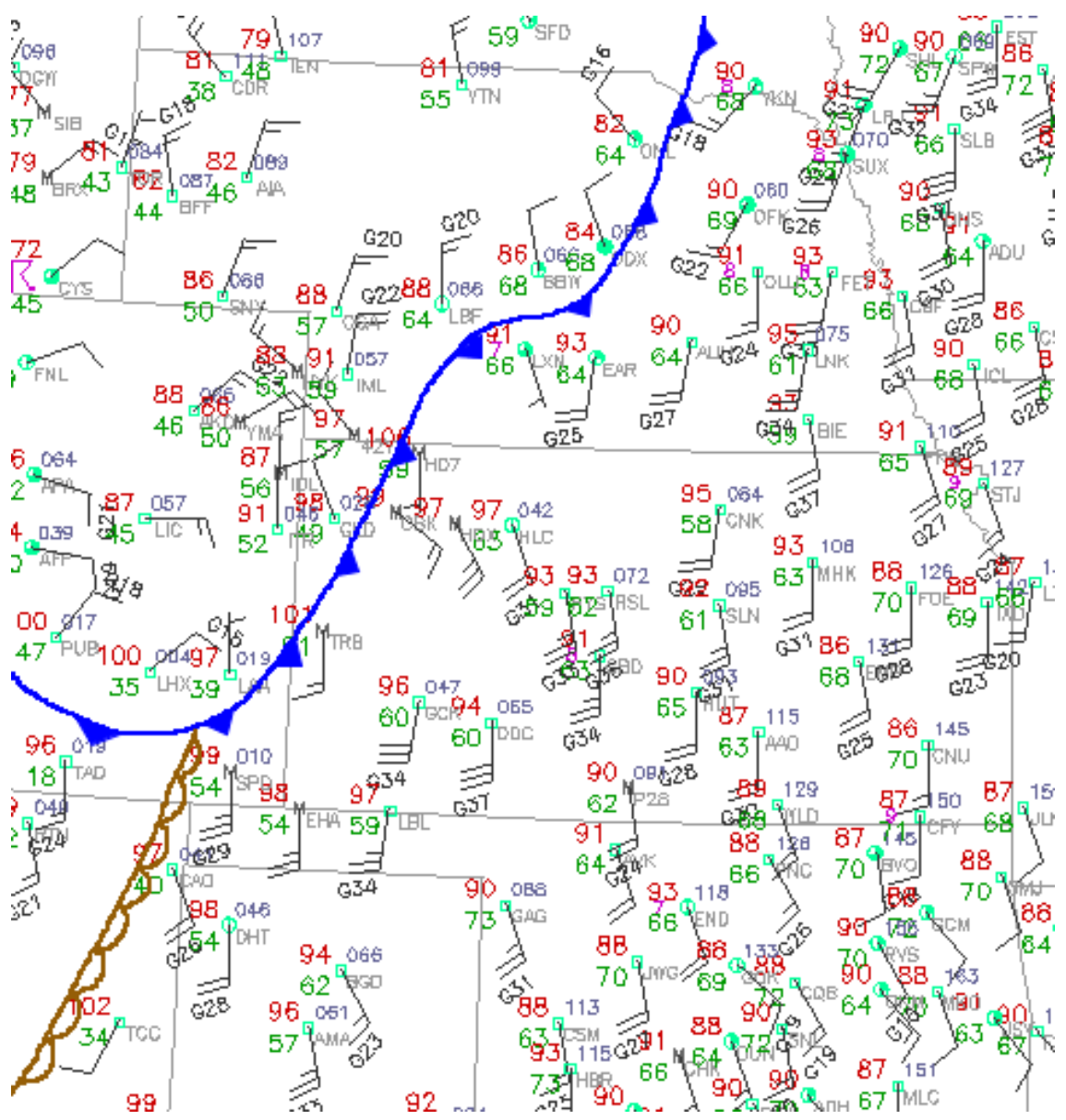

FIG. 51. Surface observations and manual analysis for 21 UTC 19 June 2002. Cold front and dryline are indicated with conventional symbols. 


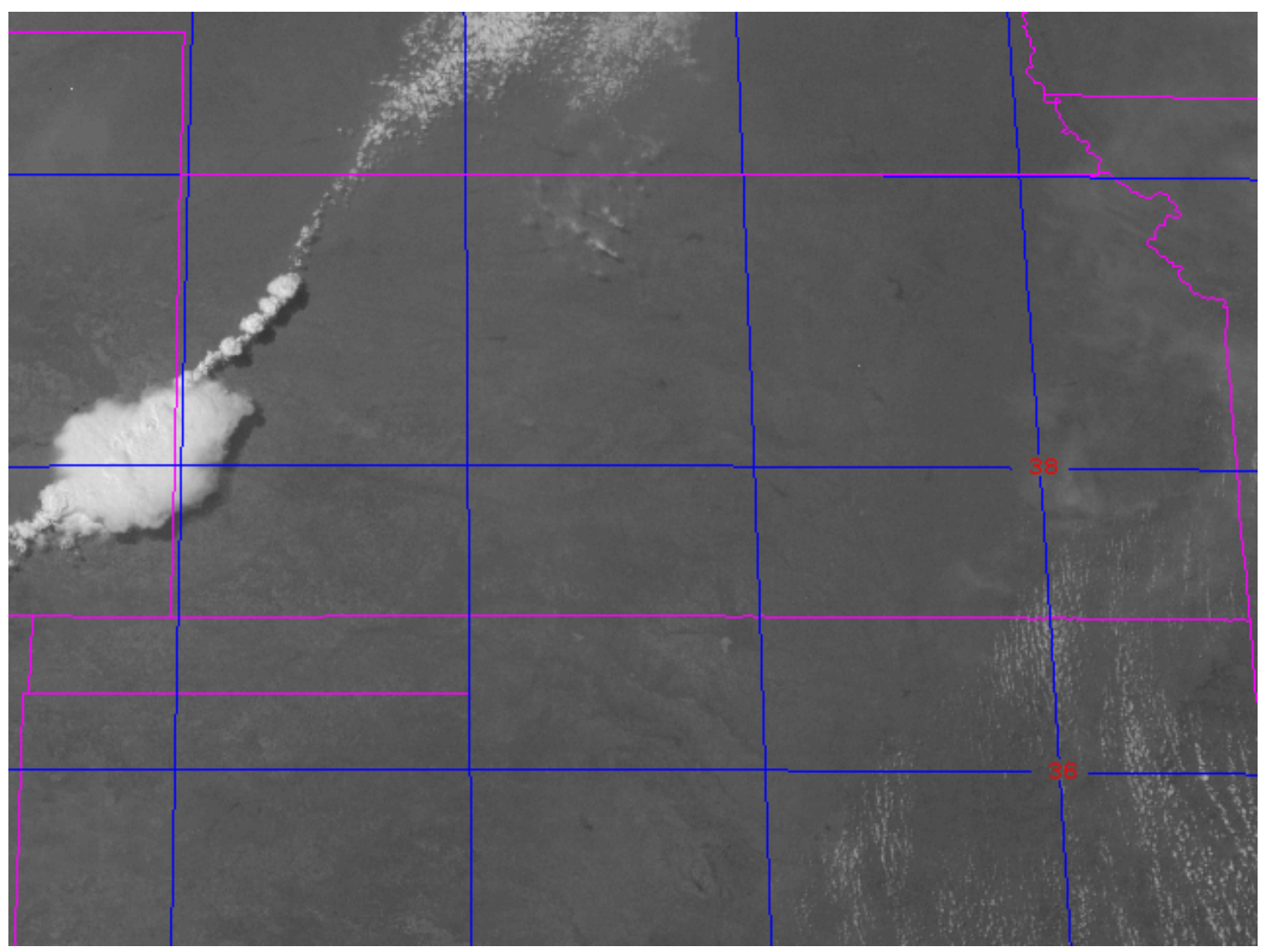

FIG. 52. Visible satellite image from 2103 UTC 19 June 2002. Line of convective clouds forming along surface cold front in Nebraska, northwest Kansas, and southeast Colorado is evident.

\section{c. Storm structure, morphology, and intensity}

1) 23 MAY 2002

A broad cluster of ordinary multicell convection developed over the 23 May negative mesoscale region (Fig. 53). This cluster of convection moved to the northeast across Oklahoma and southeast Kansas throughout the afternoon and evening. The 23 May negative mesoscale region is the only region out of the nine studied that was not associated with severe weather (Table 4). Based on the absence of severe weather and visual inspection of radar imagery, storms across the 23 May negative region were less 


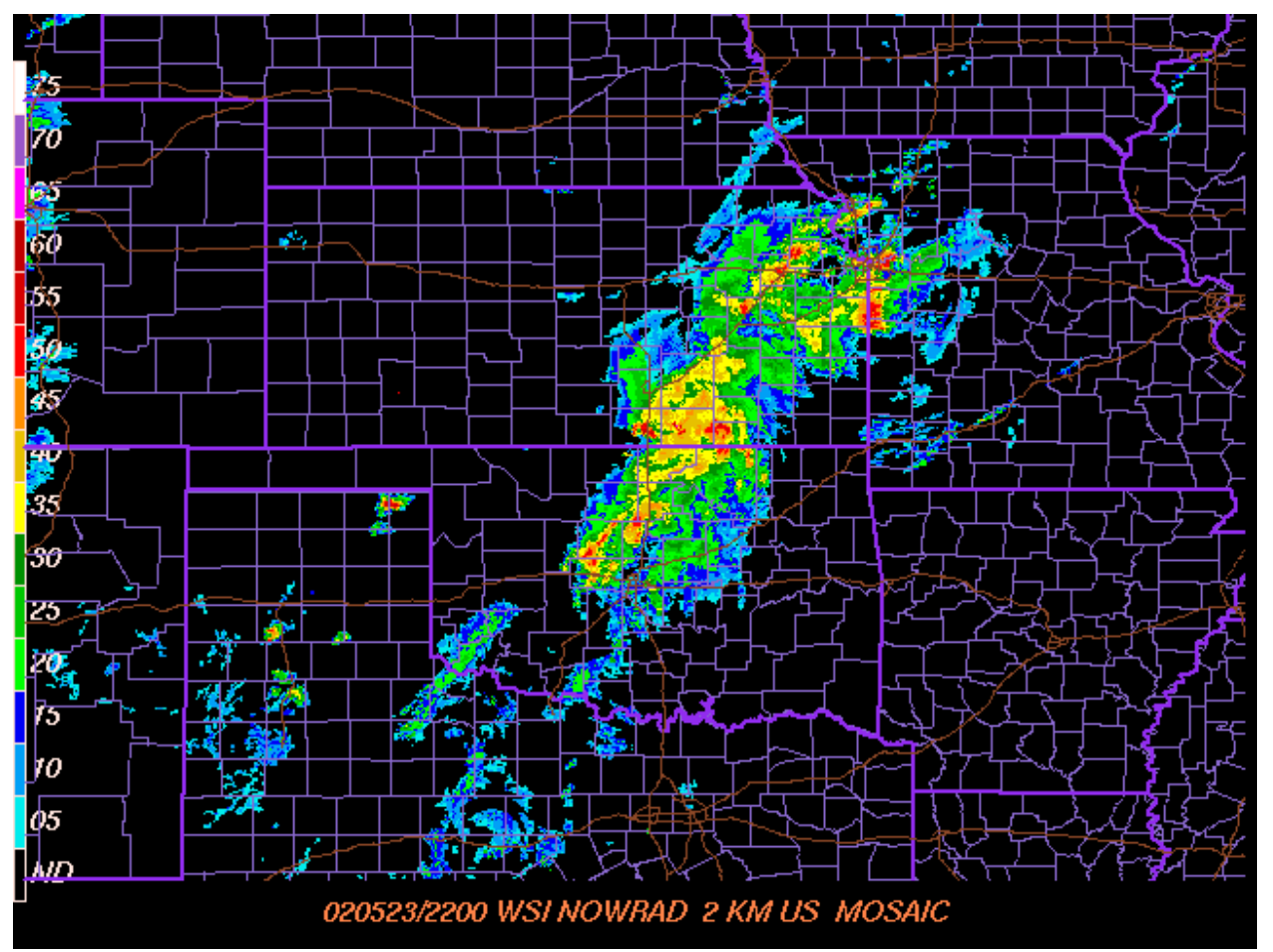

FIG. 53. WSI NOWRAD mosaic of low-level WSR-88D radar reflectivity over the IHOP_2002 domain at 22 UTC 23 May 2002.

intense than those associated with the other eight regions investigated.

Several (approximately five) discrete supercells formed over the Texas panhandle in the 23 May positive mesoscale region. Three F0 tornadoes were reported with these storms, along with numerous severe hail reports and one severe wind report (Table 4). The dominant storm was a large HP supercell that initiated at the triple point near Borger, Texas, and produced two of the three reported tornadoes (Fig. 54). This storm moved slowly off to the east/northeast, and another large HP supercell later developed to its southwest along the cold front. The HP structure of these two supercells was clearly discernible from radar reflectivity imagery, and was confirmed by SPC Mesoscale Discussions issued during the event and online storm chaser accounts of the 
event. These storms represent an exception to the tendency found by earlier studies

(e.g., Curran and Rust 1992; Branick and Doswell 1992; Seimon 1993; MacGorman and

Burgess 1994) for HP supercells to be negative CG flash-dominant, and support the

finding by Bluestein and MacGorman (1998) that positive CG flashes can dominate the

CG lightning activity in HP supercells.

TABLE 4. Description of storm type and severity within each mesoscale region. Number of severe wind $\left(\geq 26 \mathrm{~m} \mathrm{~s}^{-1}\right)$, hail (diameter $\left.\geq 1.9 \mathrm{~cm}\right)$, and tornado (F0-F5) reports during the analysis time period listed in Table 3 for each mesoscale region are given.

\begin{tabular}{|c|c|c|c|c|c|}
\hline \multicolumn{6}{|c|}{ POSITIVE MESOSCALE REGIONS - Mesoscale regions containing >25\% +CG lightning. } \\
\hline Date & Storm Type(s) & Severe? & Wind & Hail & Tornado \\
\hline 23 May & line of supercells & YES & 1 & 37 & 3 (all F0) \\
\hline 24 May & $\begin{array}{l}\text { squall line (ordinary cells with several } \\
\text { embedded supercells) }\end{array}$ & YES & 3 & 49 & 2 (both F0) \\
\hline 15 June & $\begin{array}{l}\text { multicell (ordinary and one supercell) } \\
\text { evolving into squall line }\end{array}$ & YES & 60 & 60 & 3 (all F0) \\
\hline 19 June & $\begin{array}{l}\text { broken squall line of ordinary cells; } \\
\text { isolated supercell }\end{array}$ & YES & 21 & 31 & 9 (6 F0, 3 F1) \\
\hline \multicolumn{6}{|c|}{ NEGATIVE MESOSCALE REGIONS - Mesoscale regions containing $\leq 25 \%+C G$ lightning. } \\
\hline Date & Storm Type(s) & Severe? & Wind & Hail & Tornado \\
\hline 23 May & $\begin{array}{l}\text { broad cluster of ordinary multicell } \\
\text { convection }\end{array}$ & $\mathrm{NO}^{*}$ & 0 & 1 & 0 \\
\hline 24 May & broken squall line of ordinary cells & YES & 4 & 21 & 0 \\
\hline 4 June & $\begin{array}{l}\text { squall line (ordinary cells with two } \\
\text { supercells) evolving into LL/TS MCS }\end{array}$ & YES & 22 & 70 & $1(\mathrm{~F} 0)$ \\
\hline 12 June & $\begin{array}{l}\text { line of supercells evolving into squall } \\
\text { line }\end{array}$ & YES & 40 & 55 & 6 (5 F0, 1 F1) \\
\hline 15 June & $\begin{array}{l}\text { multicell (ordinary and one supercell) } \\
\text { evolving into squall line }\end{array}$ & YES & 66 & 28 & $1(\mathrm{~F} 0)$ \\
\hline
\end{tabular}

* Despite the one severe hail report within the 23 May negative mesoscale region, the region was classified as nonsevere, since this one incidence of severe weather was an exception to the rest of the nonsevere convection in the mesoscale region. 


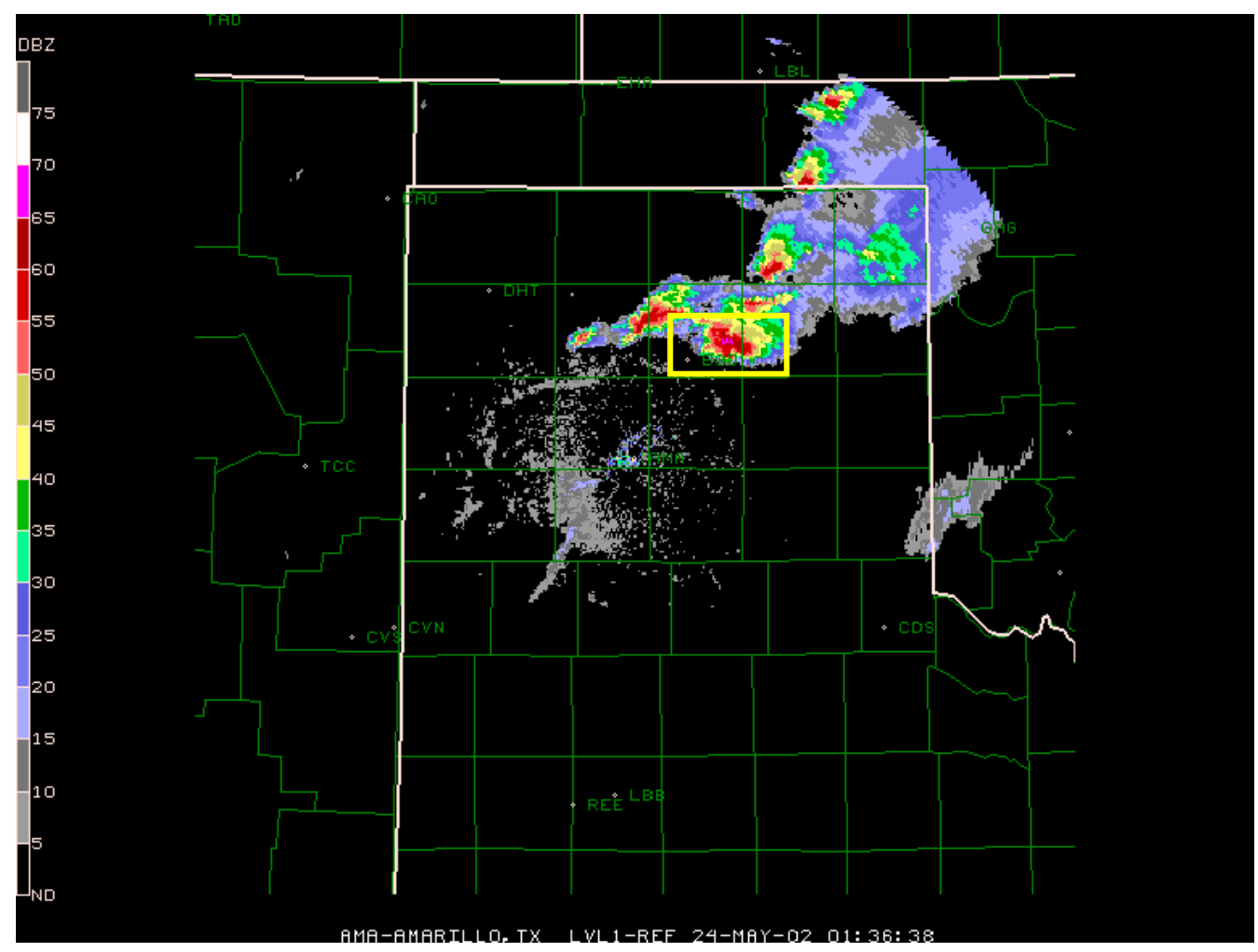

FIG. 54. Low-level WSR-88D radar reflectivity from KAMA (Amarillo, TX) WSR-88D site at 0136 UTC 24 May 2002. Yellow rectangle highlights the large HP supercell northeast of Borger, TX.

\section{2) 24 MAY 2002}

Convection on 24 May initiated at the triple point near the eastern Texas panhandle/Oklahoma border, and then south/southwestward from the triple point along the dryline and northeastward along the cold front. A squall line consisting of both ordinary cells and several (approximately five) embedded supercells resulted (Fig. 55). ${ }^{13}$ This squall line moved east across western Oklahoma and northern Texas, producing two F0 tornadoes, nearly 50 severe hail reports, and a few severe wind reports across the 24 May positive mesoscale region.

\footnotetext{
${ }^{13}$ Supercell structure was determined through the analysis of radar reflectivity and radial velocity data. In particular, Level II WSR-88D radar data were analyzed via WDSS-II to discern supercell storms from ordinary storm cells.
} 


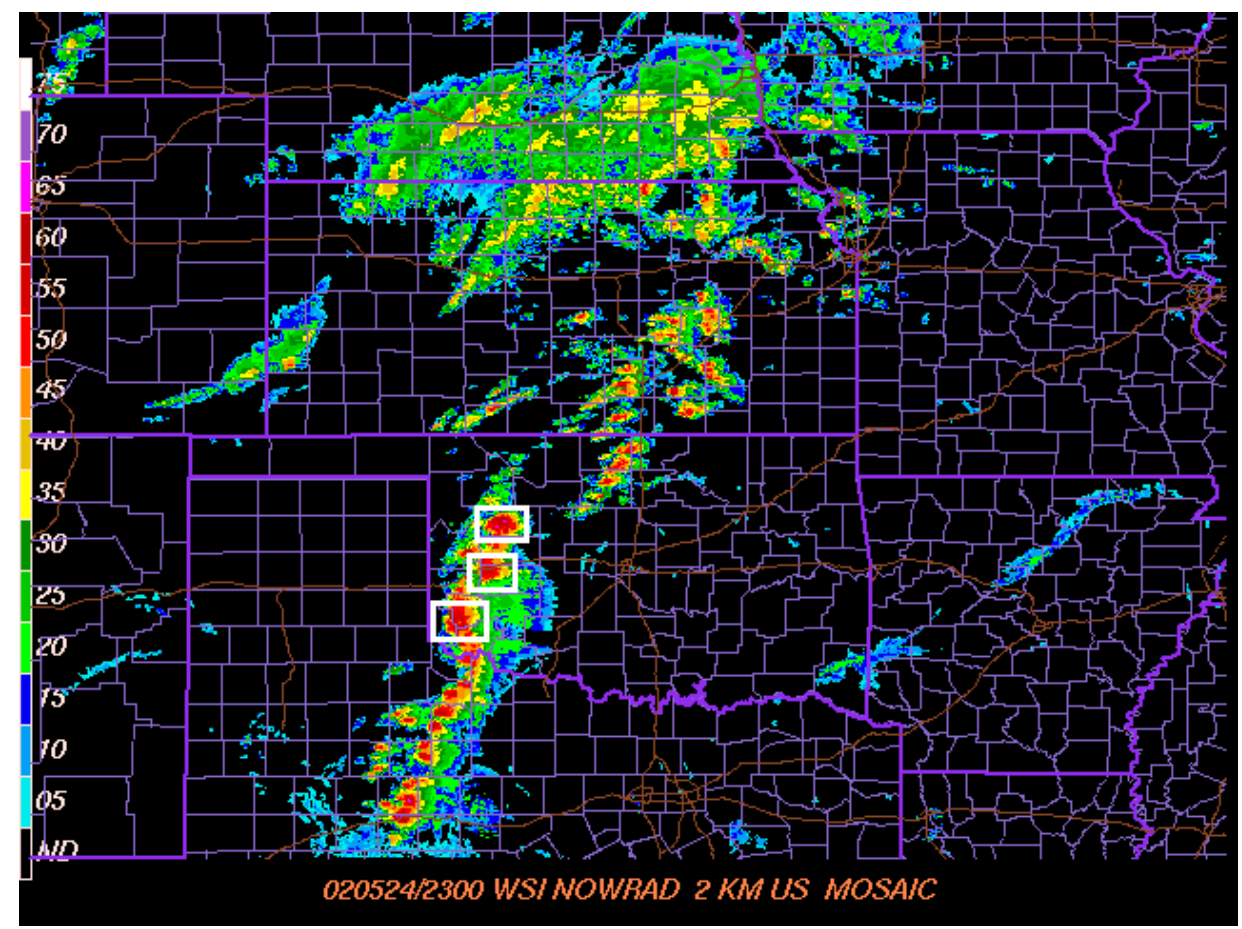

FIG. 55. Same as Fig. 53 except for 23 UTC 24 May 2002. White rectangles highlight the supercells that existed across the 24 May positive mesoscale region at 23 UTC.

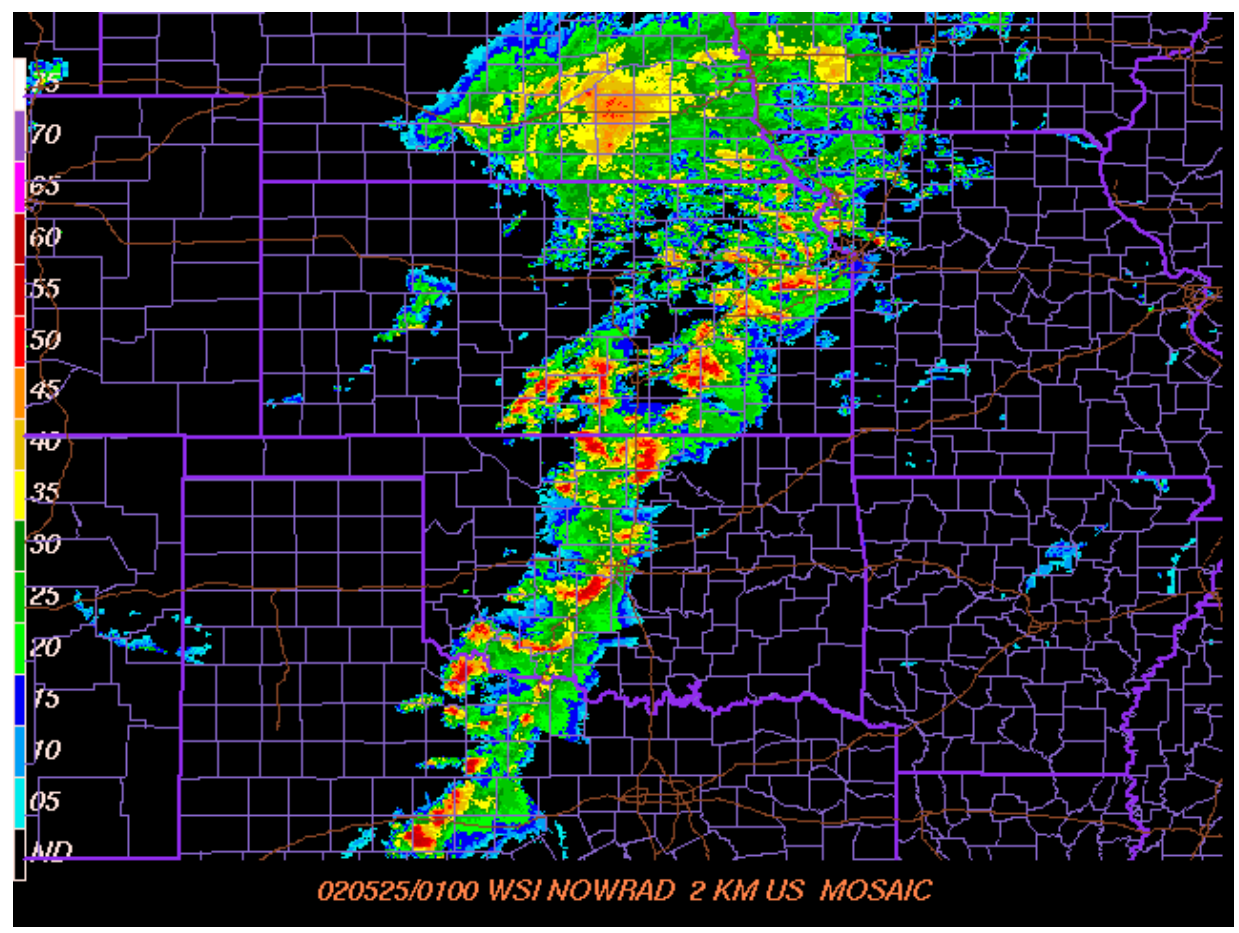

FIG. 56. Same as Fig. 53 except for 01 UTC 25 May 2002. 
As the squall line continued eastward into the 24 May negative mesoscale region, it evolved into a broken squall line (Fig. 56). As a whole, the squall line became less intense than it previously was across the positive region, and was now made up entirely of ordinary cells. However, some intense cells were still embedded in the line, and these storms produced approximately 20 severe hail reports, along with a few severe wind reports across the negative mesoscale region (Table 4).

\section{3) 4 JUNE 2002}

Early-morning convection over the Texas panhandle, Oklahoma, and Kansas developed into a northeast-southwest oriented squall line stretching along a cold front from eastern Kansas across Oklahoma into the Texas panhandle (Fig. 57). This squall line was made up primarily of ordinary multicell convection, although two supercells formed at its southwest end near Lubbock, Texas during the late afternoon and early evening (Fig. 58). The squall line moved to the southeast with the cold front, evolving into an LL/TS MCS (Fig. 58). This storm system was associated with a multitude (70) of severe hail reports and many (22) severe wind reports across the 4 June negative mesoscale region. In addition, an F0 tornado was produced by one of the supercells near Lubbock. The predominance of negative CG flashes with the MCS on 4 June (percentage of positive CG flashes $=9.2 \%$ ) is consistent with the finding by MacGorman and Morgenstern (1998) that most MCSs produce predominantly negative CG lightning. In a study of twenty-five MCSs, MacGorman and Morgenstern (1998) found the median positive CG flash percentage for individual MCSs to be $6 \%$. 


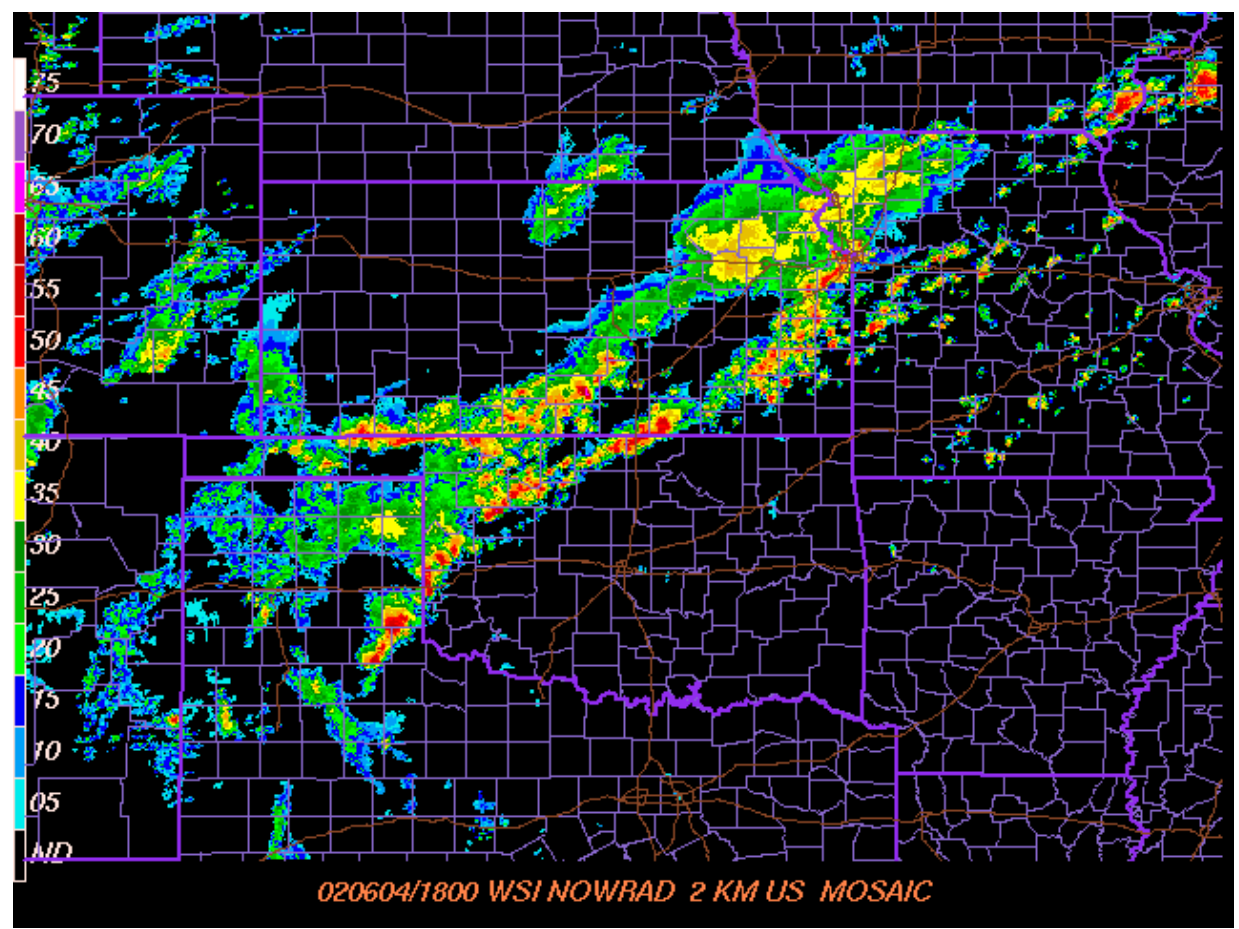

FIG. 57. Same as Fig. 53 except for 18 UTC 4 June 2002.

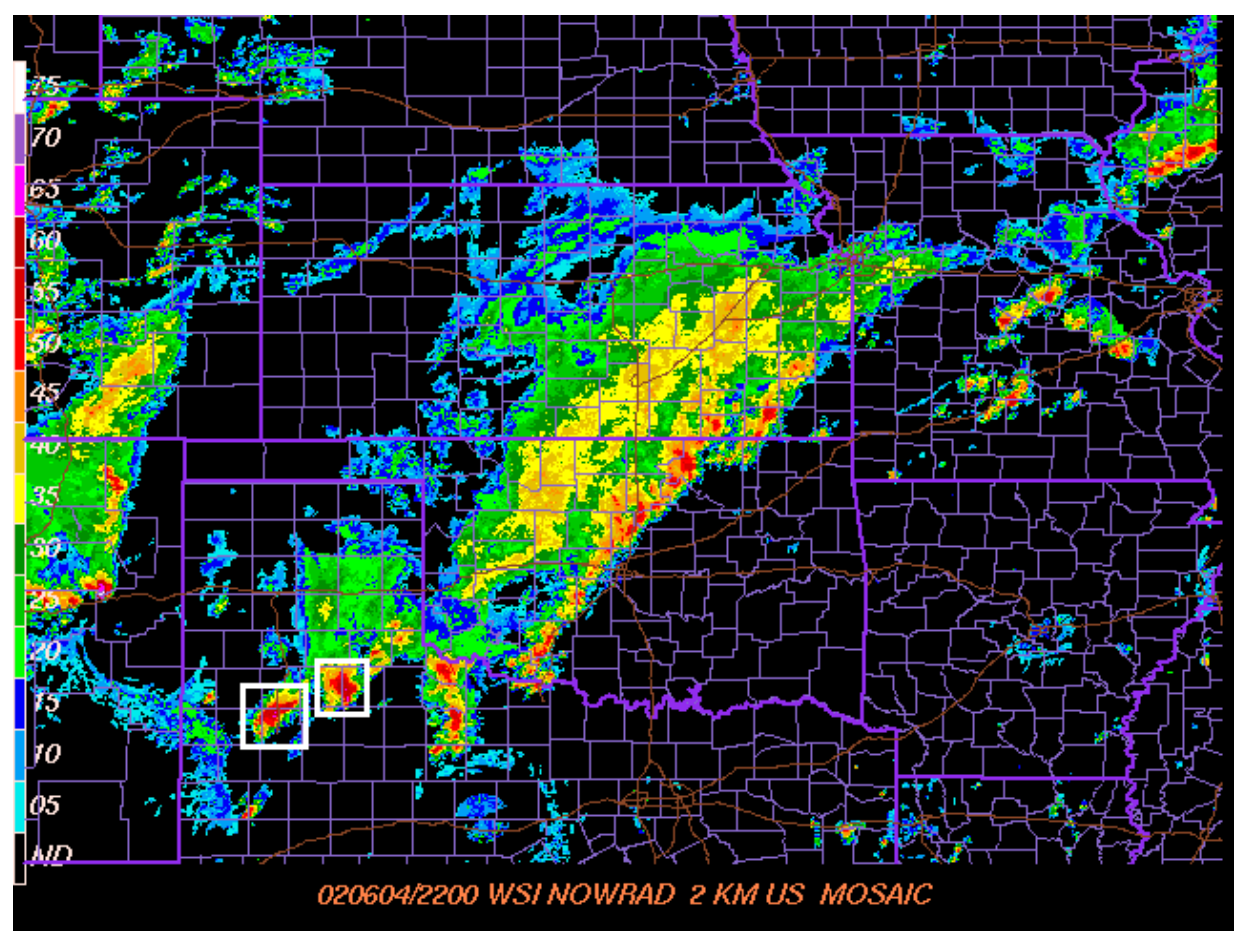

FIG. 58. Same as Fig. 53 except for 22 UTC 4 June 2002. White rectangles highlight the two supercells that developed near Lubbock, Texas. 


\section{4) 12 JUNE 2002}

On 12 June scattered (approximately five) supercells, along with ordinary cells, developed along and at the intersection of the surface trough and MCS outflow boundary depicted in Fig. 39. Storms moved to the east and southeast off these boundaries, merging into a squall line that moved southeast across Oklahoma. Six tornadoes (five F0, one F1) and numerous severe hail reports (Table 4) occurred early in the lifetime of this storm system when several discrete supercells existed (Fig. 59). As the cells evolved into a squall line and moved southeast, losing their supercell characteristics (Fig. 60), this event transformed into primarily a severe wind event, with no more tornadoes reported and only a couple additional severe hail reports.

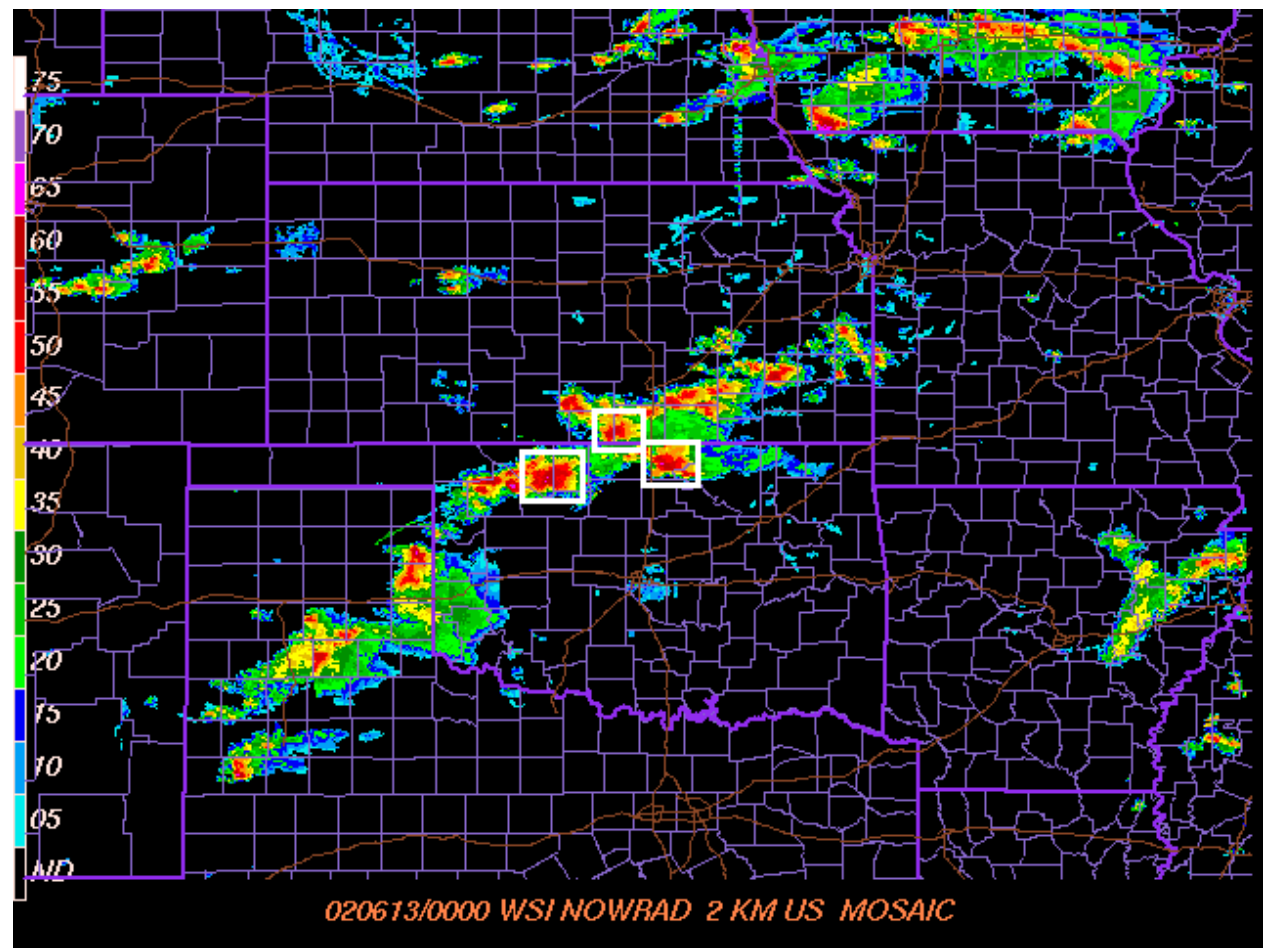

FIG. 59. Same as Fig. 53 except for 00 UTC 13 June 2002. White rectangles highlight the supercells that existed across the 12 June negative mesoscale region at 00 UTC. 


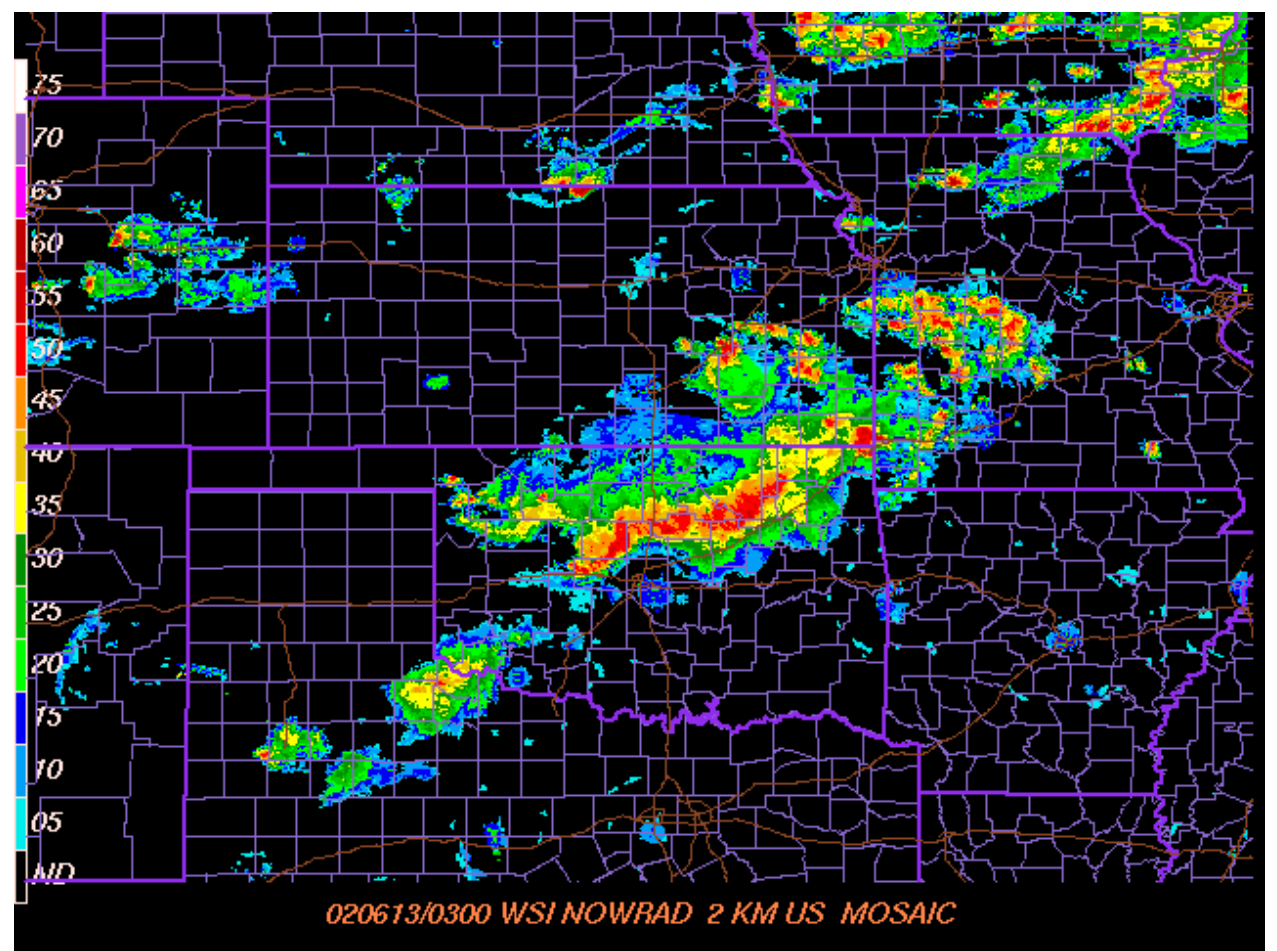

FIG. 60. Same as Fig. 53 except for 03 UTC 13 June 2002.

5) 15 JUNE 2002

As described previously, convection developed across the 15 June positive and negative mesoscale regions in response to several different weather features. This convection was comprised mainly of ordinary multicell storms in both the positive and negative regions, although two supercells developed as well—one in the positive region and one in the negative region. The convection organized into an east-west oriented squall line over Kansas, spanning across both the positive and negative regions (Fig. 61). The squall line moved south-southeast across Kansas, Oklahoma, and the Texas panhandle, evolving into an LL/TS MCS (Fig. 62). Storms moving to the southeast out of southeast Colorado and northeast New Mexico merged with the western edge of the line over the Texas panhandle. Numerous accounts of severe weather were reported 
with this storm system across both the positive and negative mesoscale regions. Three F0 tornadoes were reported in the positive mesoscale region, while one F0 tornado was reported in the negative region. There were over twice as many severe hail reports in the positive mesoscale region (60) than in the negative region (28). The number of severe wind reports was nearly equal in the positive and negative regions (Table 4).

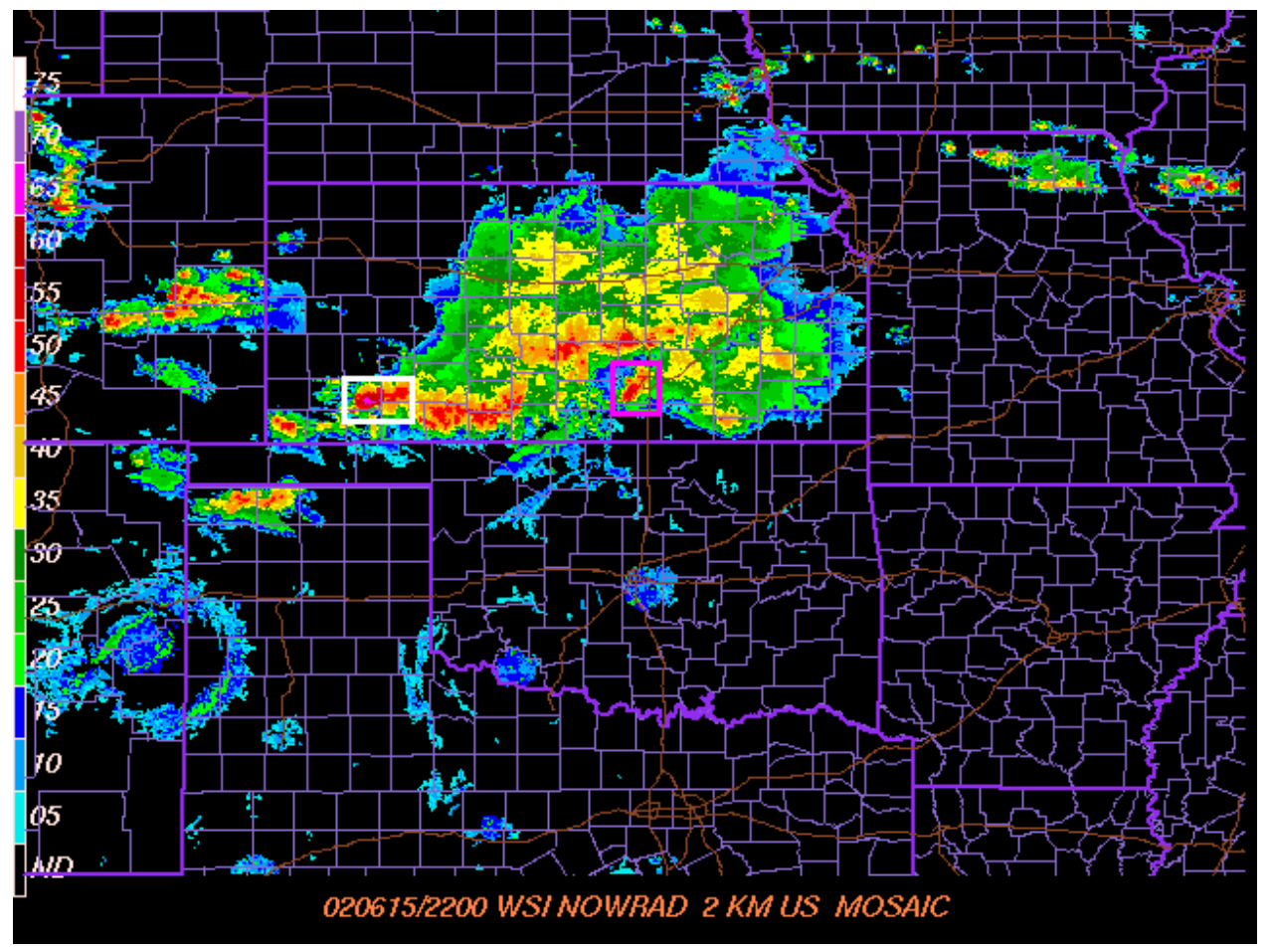

FIG. 61. Same as Fig. 53 except for 22 UTC 15 June 2002. The white rectangle highlights the only supercell that developed in the positive mesoscale region on 15 June. The magenta rectangle highlights the cell that was previously supercellular in the negative mesoscale region, but lost its supercell characteristics prior to the time of this reflectivity image. 


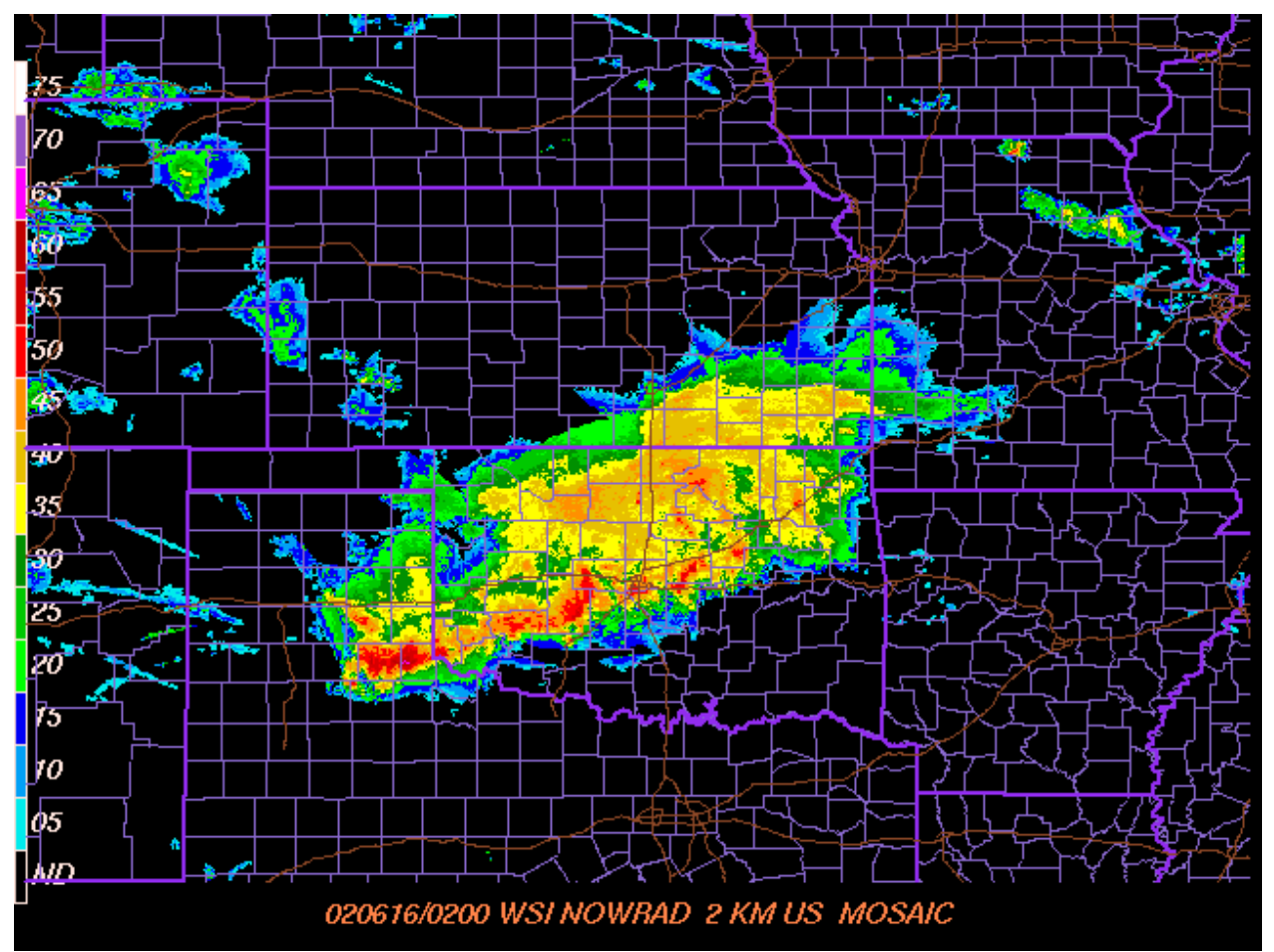

FIG. 62. Same as Fig. 53 except for 02 UTC 16 June 2002.

6) 19 JUNE 2002

A broken squall line comprised of intense ordinary multicell convection formed along the cold front arcing across Nebraska, northwest Kansas, and southeast Colorado (Fig. 63). This squall line moved off the boundary to the east/northeast across Kansas and Nebraska. As some of the initial cells moved off the boundary, their outflow accelerated the relatively weak cold front westward. Proximity soundings revealed that the outflow from these initial cells altered the low-level wind field in extreme northwest Kansas dramatically, backing the low-level winds and increasing their magnitude. Lowlevel (0-3 km AGL) wind shear increased from 5 to $22 \mathrm{~m} \mathrm{~s}^{-1}$ and 0-3 km AGL SREH values increased from 36 to $265 \mathrm{~m}^{2} \mathrm{~s}^{-2}$. One isolated supercell (the intense cell located just south of the Kansas/Nebraska border in Fig. 63) developed in this modified 
environment in northwest Kansas. The supercell propagated to the southwest along the retreating cold front/outflow boundary, producing four F0 and three F1 tornadoes. In addition, two nonsupercell F0 tornadoes were reported in southeast Colorado. Along with these tornadoes, 31 severe hail and 21 severe wind reports were associated with this storm system across the 19 June positive mesoscale region.

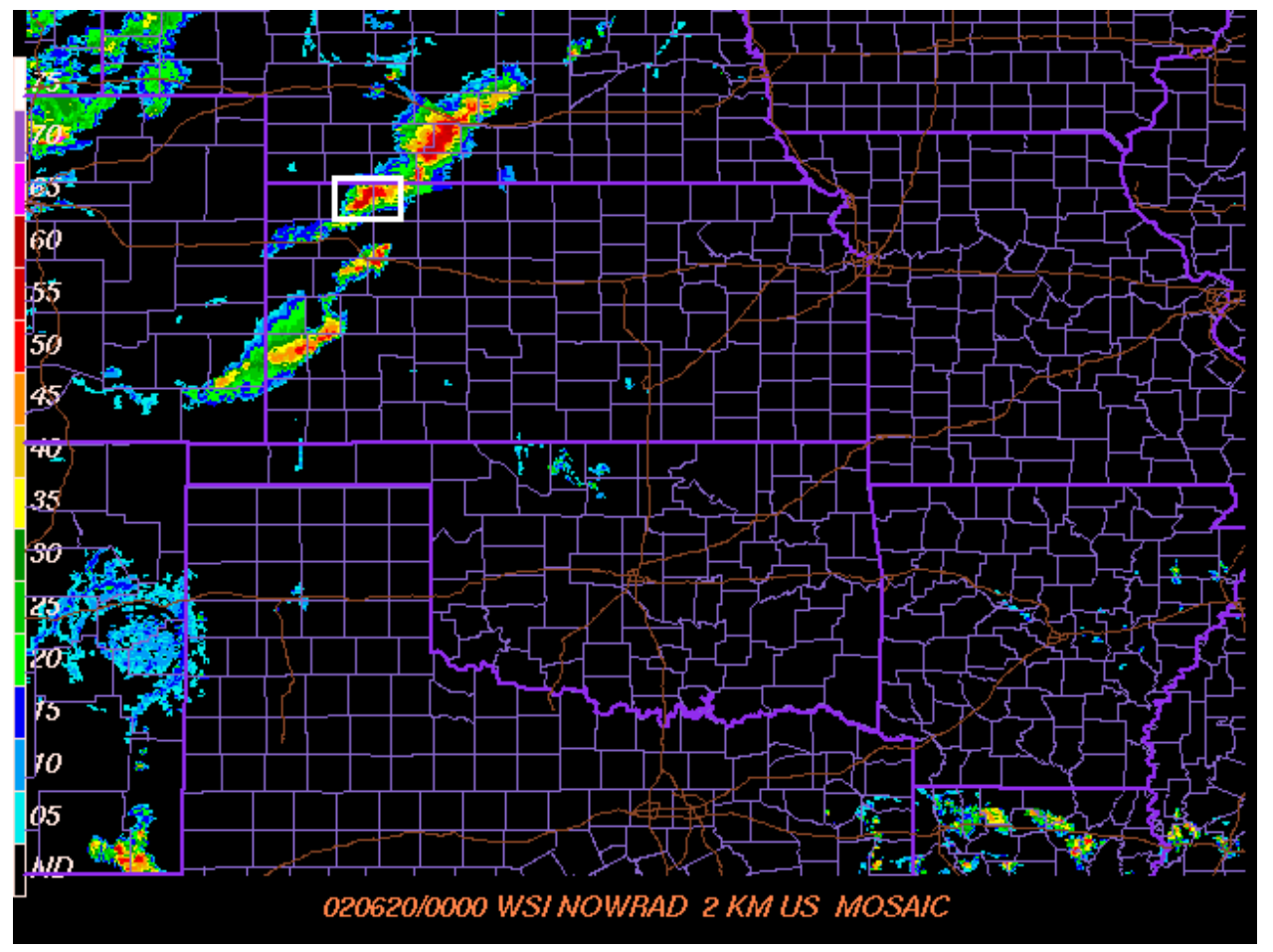

FIG. 63. Same as Fig. 53 except for 00 UTC 20 June 2002. The white rectangle highlights the lone supercell that developed in the 19 June positive mesoscale region.

\section{7) STORM INTENSITY DETERMINED FROM RADAR ANALYSIS}

Visual inspection of radar imagery (including WSI NOWRAD images, low-level radar reflectivity images from individual WSR-88D sites, vertical cross-sections of Level II WSR-88D radar reflectivity data, and composite reflectivity images from Level 
II WSR-88D radar data) revealed no systematic, consistent differences in storm intensity between positive and negative storms. Positive storms and negative storms were both frequently very intense, as determined from subjective visual inspection of radar reflectivity data. There was no systematic tendency for positive storms to be more intense (or less intense) than negative storms. There also was no systematic tendency for greater reflectivity values to extend to greater heights in either positive or negative storms. Many positive and negative cells with comparable intensities were found. Some positive cells were more intense than some negative cells, and some negative cells were more intense than some positive cells. Also, intensities among positive storms and among negative storms varied. These findings held true for positive and negative storms that occurred on different days, as well as for positive and negative storms that occurred on the same day in different mesoscale regions. Simply stated, no systematic differences in storm intensity were detected between positive and negative storms based on subjective visual inspection of radar reflectivity imagery.

A subset of cells inspected is presented in Figs. 64-76. Figs. 64-70 contain examples of positive cells, while Figs. 71-76 contain examples of negative cells. All of the storms shown in Figs. 64-76 produced severe weather (based on severe storm reports) and high percentages of either positive (Figs. 64-70) or negative (Figs. 71-76) CG flashes. The radar reflectivity images shown are from the time of peak intensity of each respective storm (based on radar reflectivity data), to allow for equal comparisons between storms. 


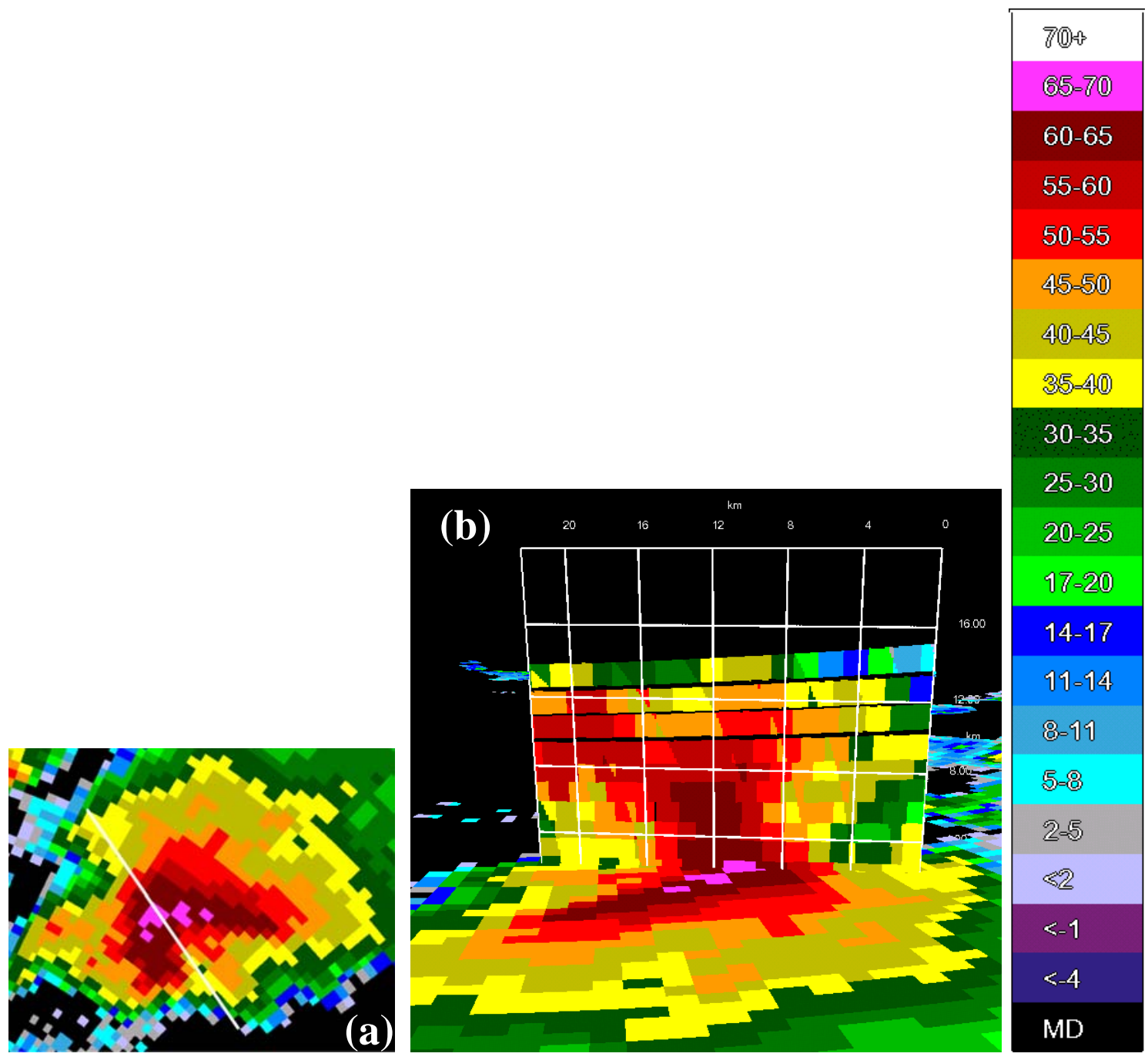

FIG. 64. (a) $0.5^{\circ}$ radar reflectivity and (b) vertical cross-section of radar reflectivity along the white line depicted in (a) at 0116 UTC 24 May 2002 of a positive HP supercell storm in the 23 May positive mesoscale region. The horizontal white lines in (b) indicate height (km) AGL in 4-km increments, while the vertical white lines indicate horizontal distance $(\mathrm{km})$ along the cross-section. The scale for radar reflectivity (dBZ) used in this figure, as well as in Figs. 65-76, is shown on the right. 

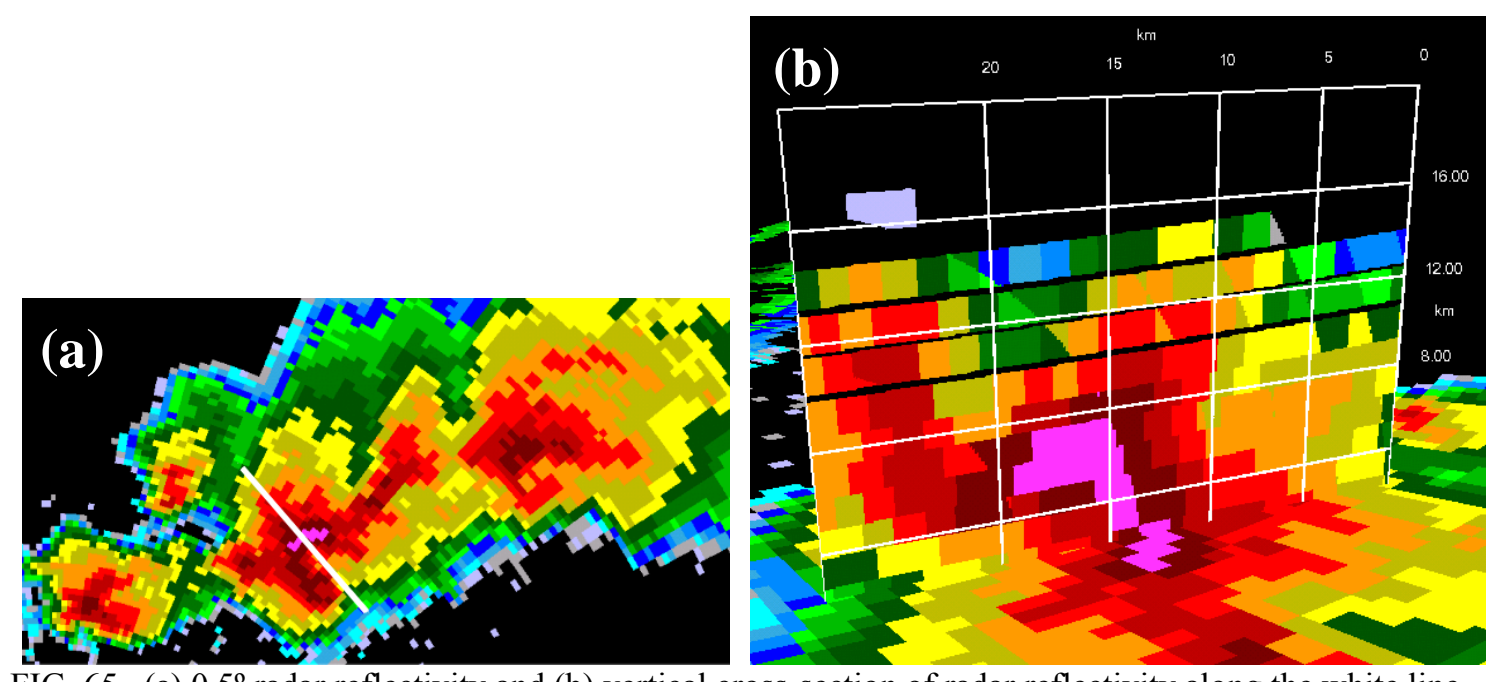

FIG. 65. (a) $0.5^{\circ}$ radar reflectivity and (b) vertical cross-section of radar reflectivity along the white line depicted in (a) at 0327 UTC 24 May 2002 of a second positive HP supercell storm in the 23 May positive mesoscale region. 

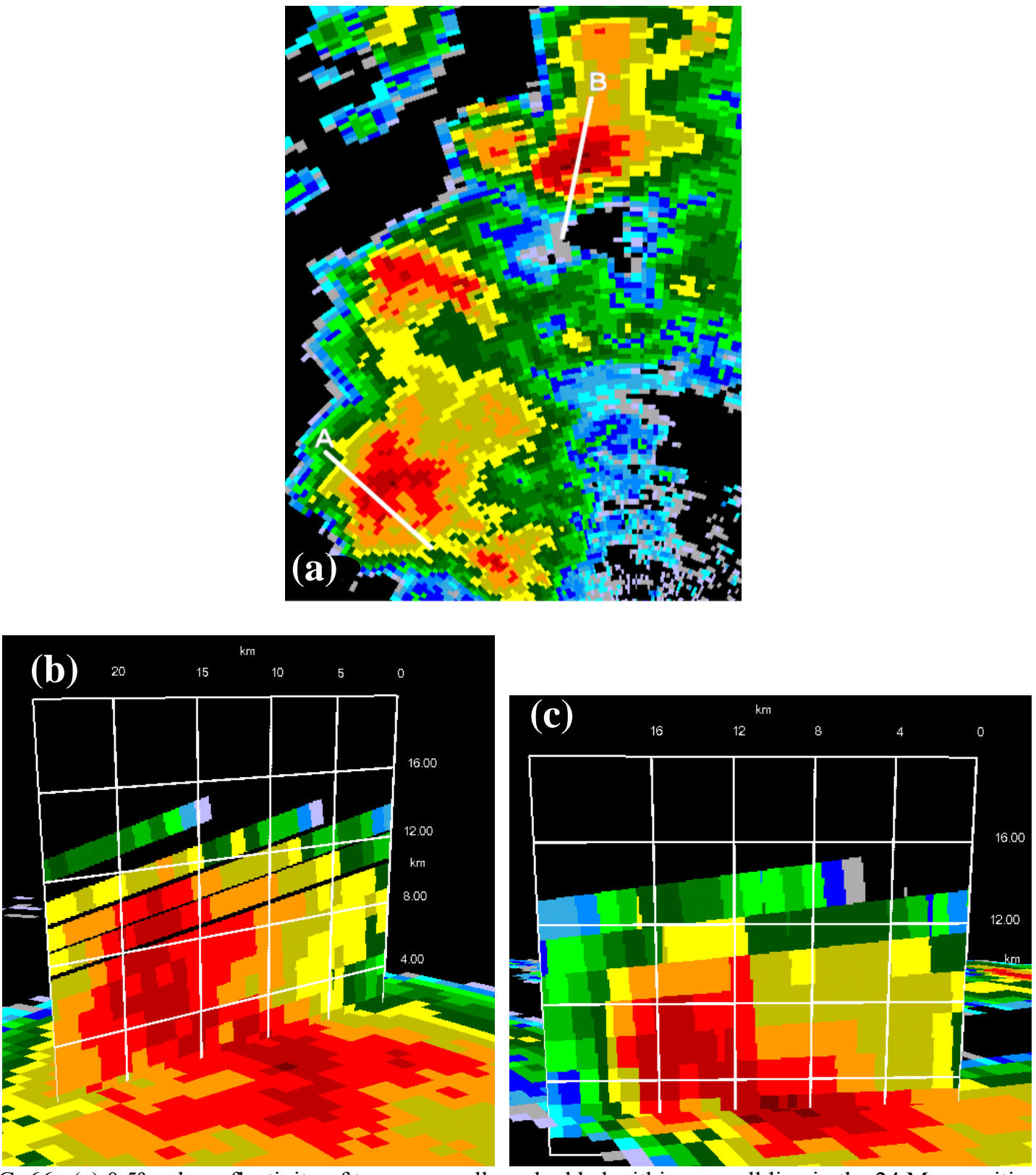

FIG. 66. (a) $0.5^{\circ}$ radar reflectivity of two supercells embedded within a squall line in the 24 May positive mesoscale region at 2321 UTC 24 May 2002. (b) Vertical cross-section of radar reflectivity along the white line denoted as "A" in (a). (c) Vertical cross-section of radar reflectivity along the white line denoted as "B" in (a). 

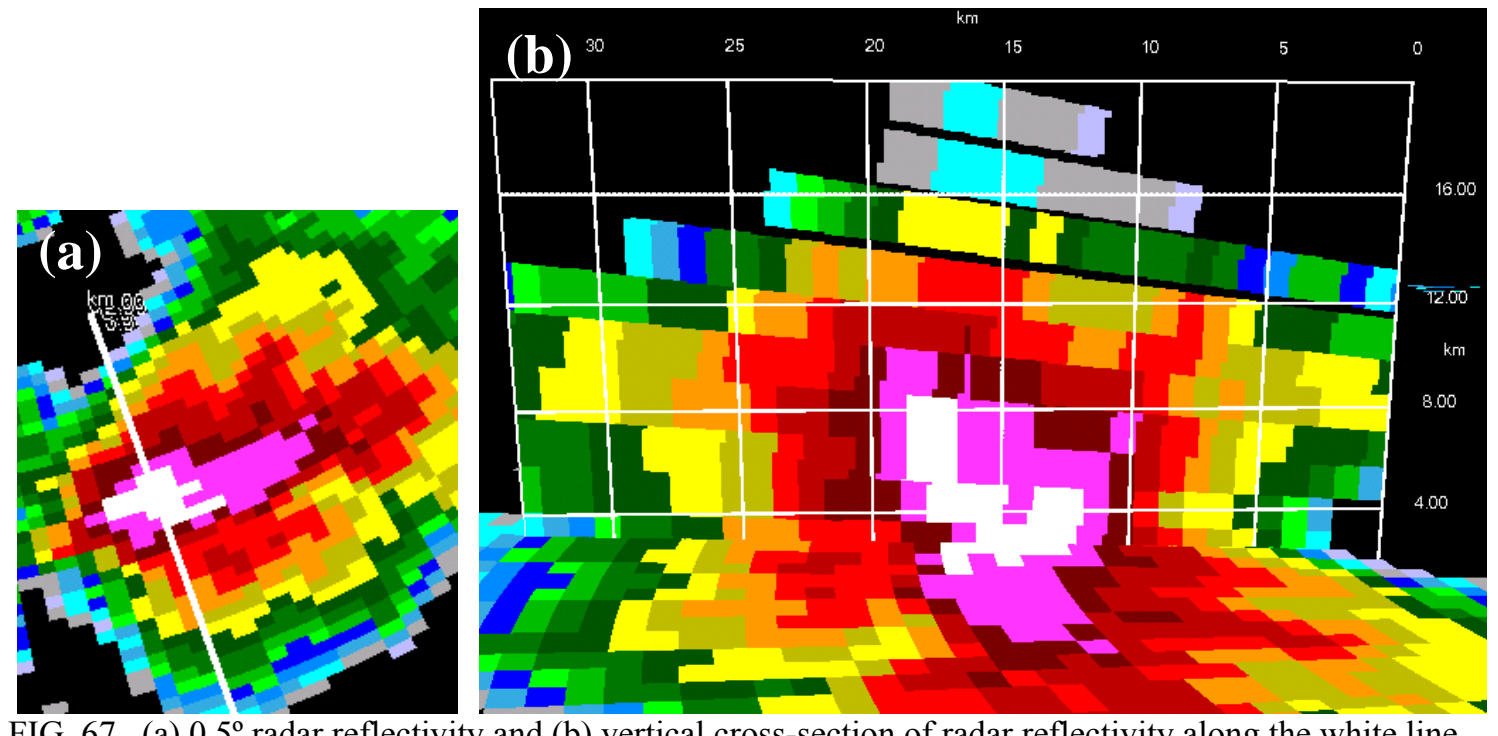

FIG. 67. (a) $0.5^{\circ}$ radar reflectivity and (b) vertical cross-section of radar reflectivity along the white line depicted in (a) at 1848 UTC 15 June 2002 of an intense ordinary multicell storm in the 15 June positive mesoscale region. This storm later evolved into a supercell.
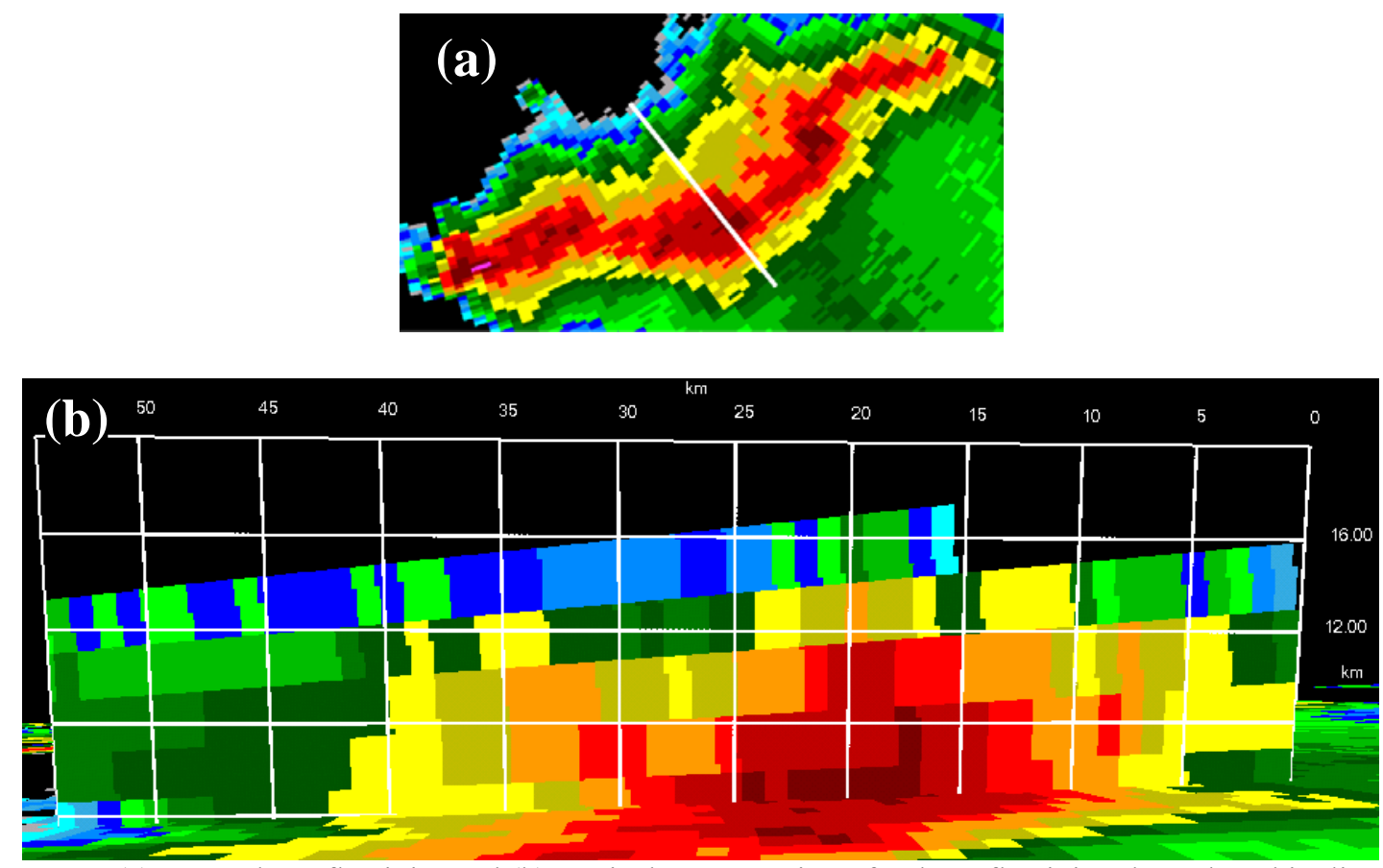

FIG. 68. (a) $0.5^{\circ}$ radar reflectivity and (b) vertical cross-section of radar reflectivity along the white line depicted in (a) at 2003 UTC 15 June 2002 of a line of ordinary multicell convection in the 15 June positive mesoscale region. 


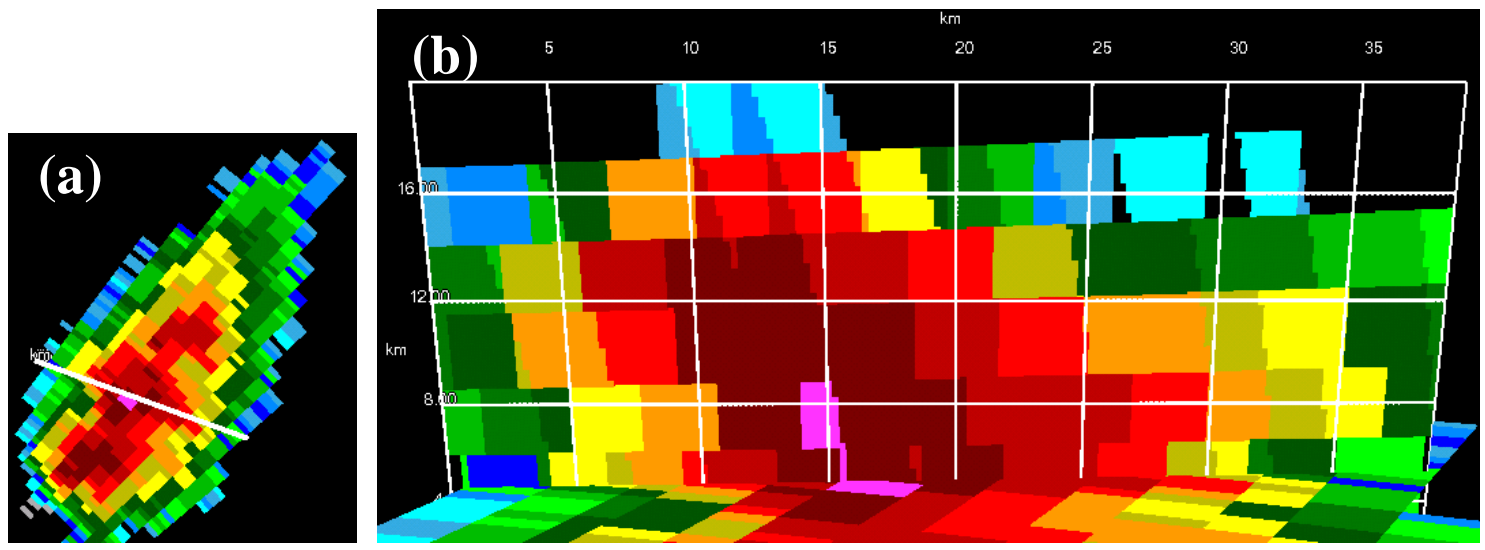

FIG. 69. (a) $0.5^{\circ}$ radar reflectivity and (b) vertical cross-section of radar reflectivity along the white line depicted in (a) at 2222 UTC 19 June 2002 of an ordinary multicell storm in the 19 June positive mesoscale region.
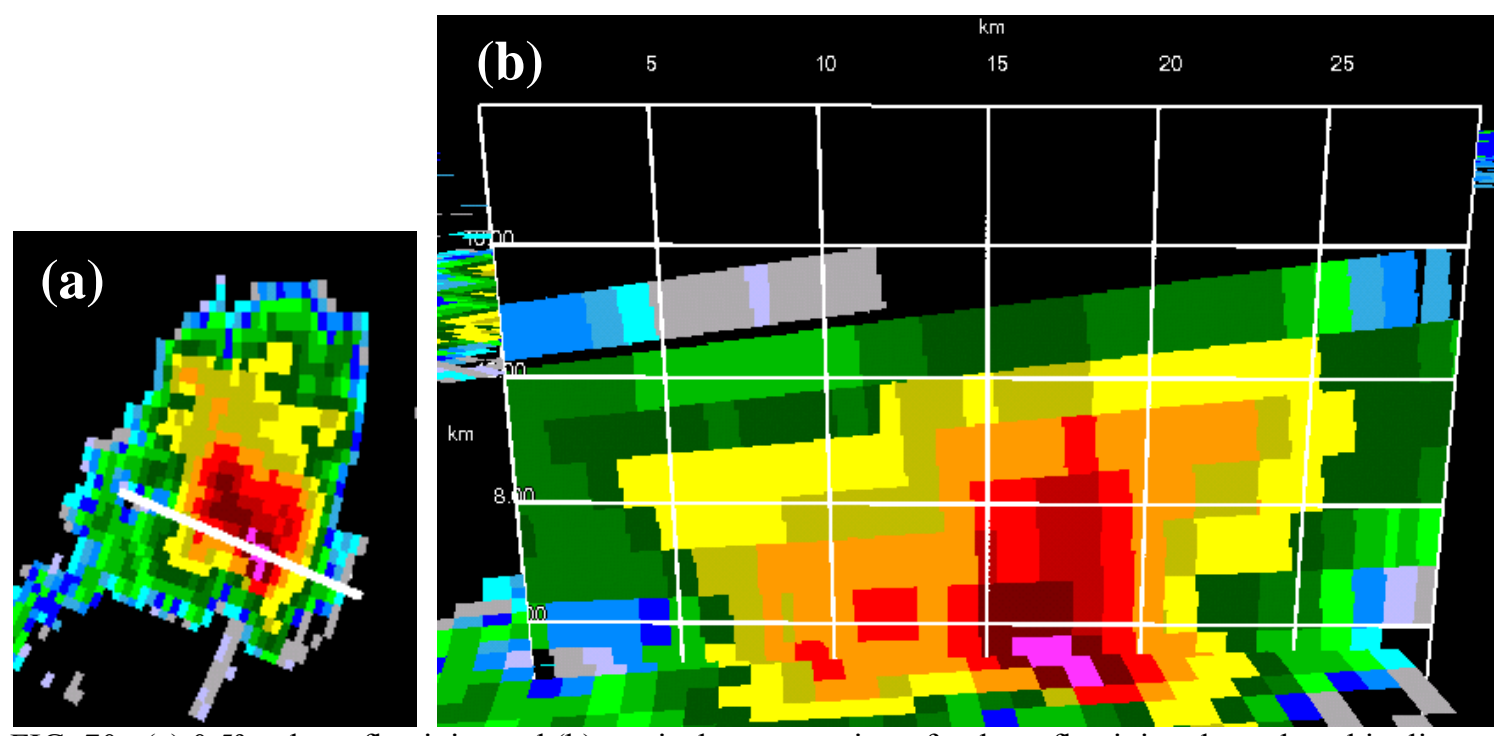

FIG. 70. (a) $0.5^{\circ}$ radar reflectivity and (b) vertical cross-section of radar reflectivity along the white line depicted in (a) at 0028 UTC 20 June 2002 of another ordinary multicell storm in the 19 June positive mesoscale region. 

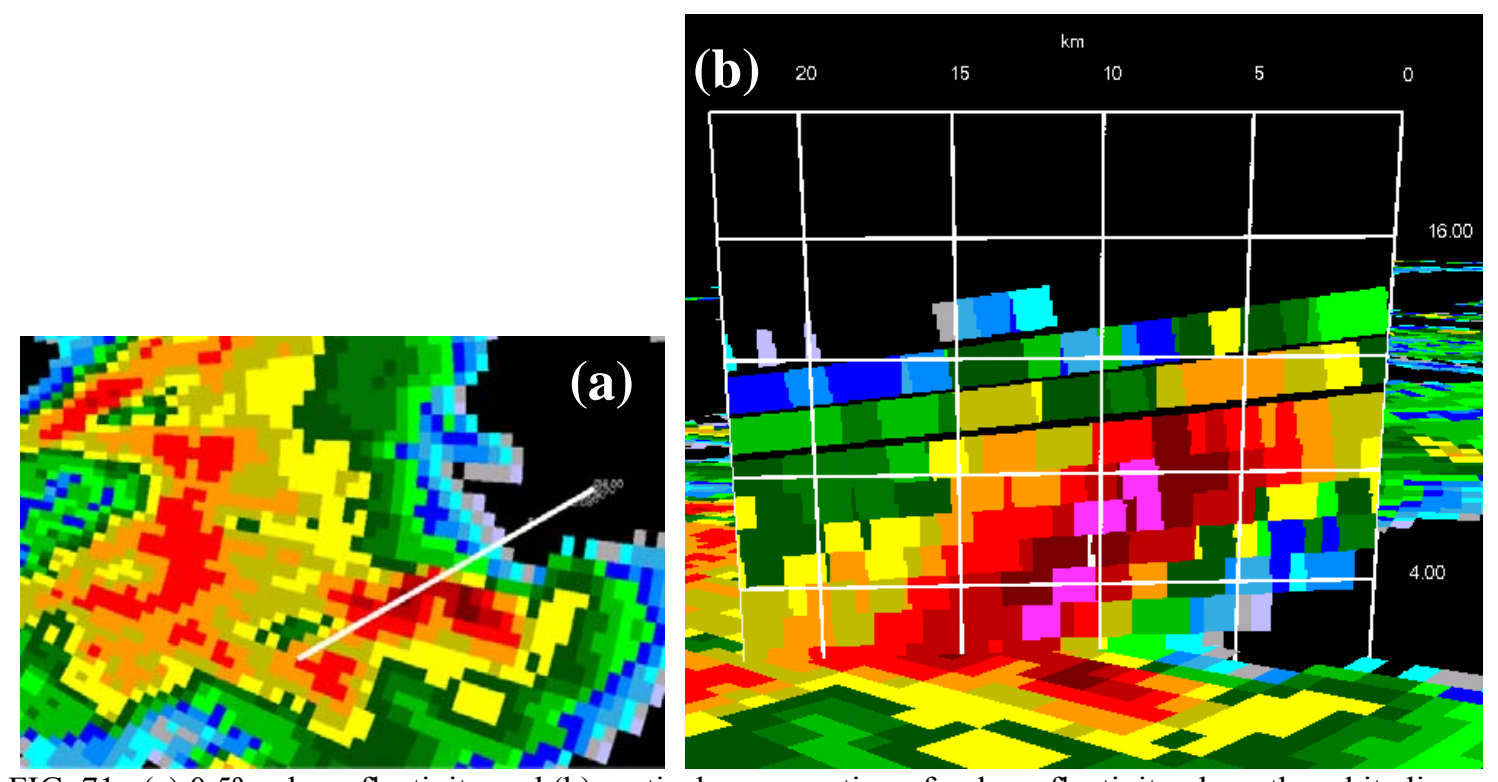

FIG. 71. (a) $0.5^{\circ}$ radar reflectivity and (b) vertical cross-section of radar reflectivity along the white line depicted in (a) at 0027 UTC 25 May 2002 of an ordinary multicell storm in the 24 May negative mesoscale region.

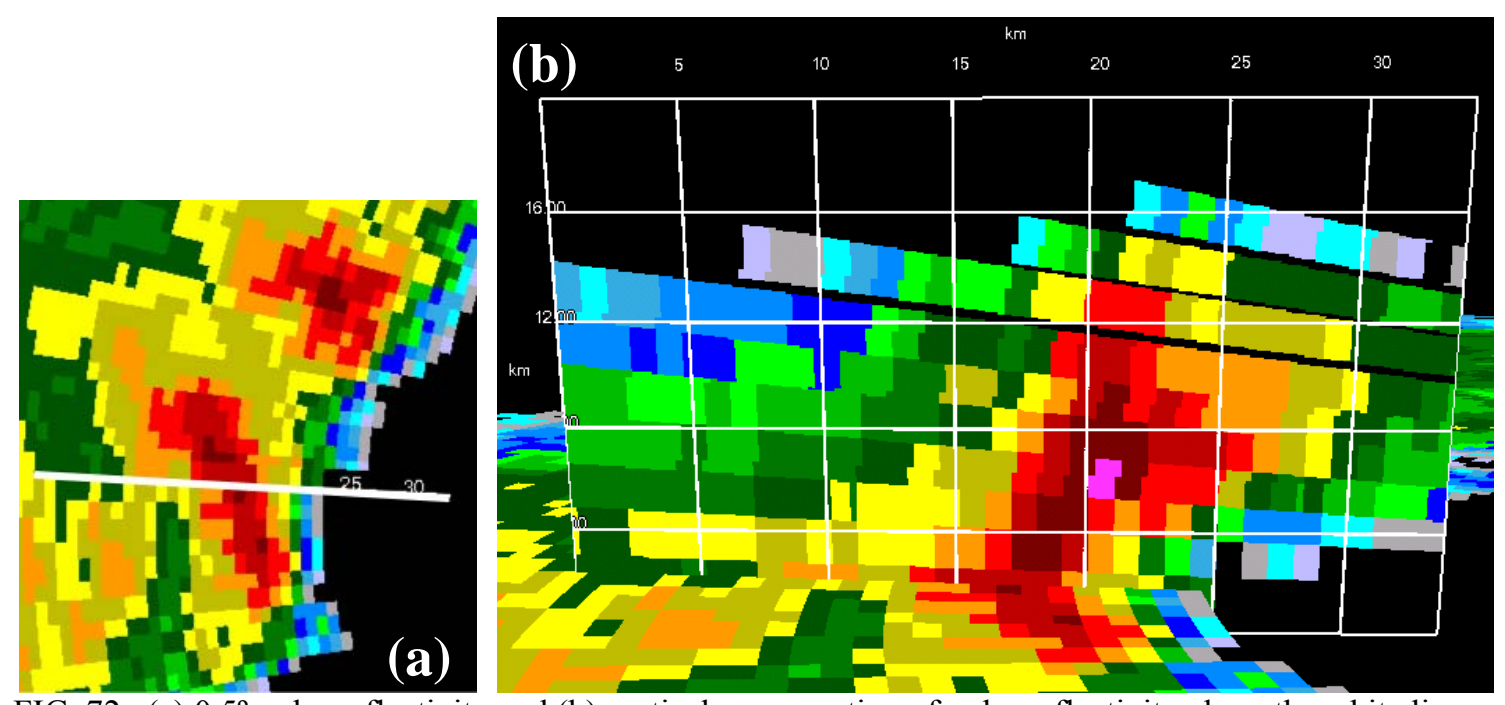

FIG. 72 . (a) $0.5^{\circ}$ radar reflectivity and (b) vertical cross-section of radar reflectivity along the white line depicted in (a) at 1346 UTC 4 June 2002 of an ordinary multicell storm in the 4 June negative mesoscale region. 

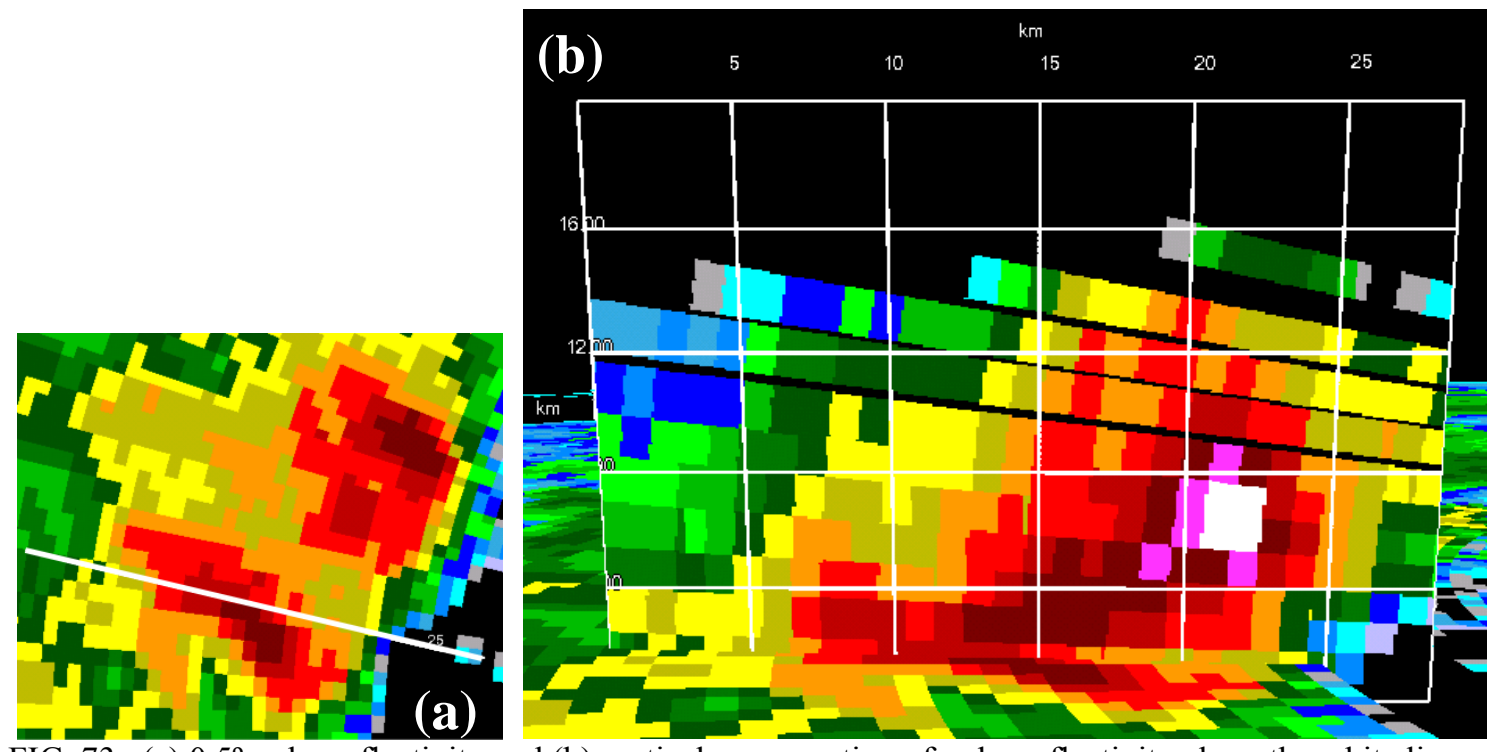

FIG. 73. (a) $0.5^{\circ}$ radar reflectivity and (b) vertical cross-section of radar reflectivity along the white line depicted in (a) at 1411 UTC 4 June 2002 of the same ordinary multicell storm as shown in Fig. 72. Reflectivity values aloft are greater at this time, but the storm was producing severe hail and high percentages of negative CG lightning at the times of both sets of images (i.e., 1346 UTC and 1411 UTC). 

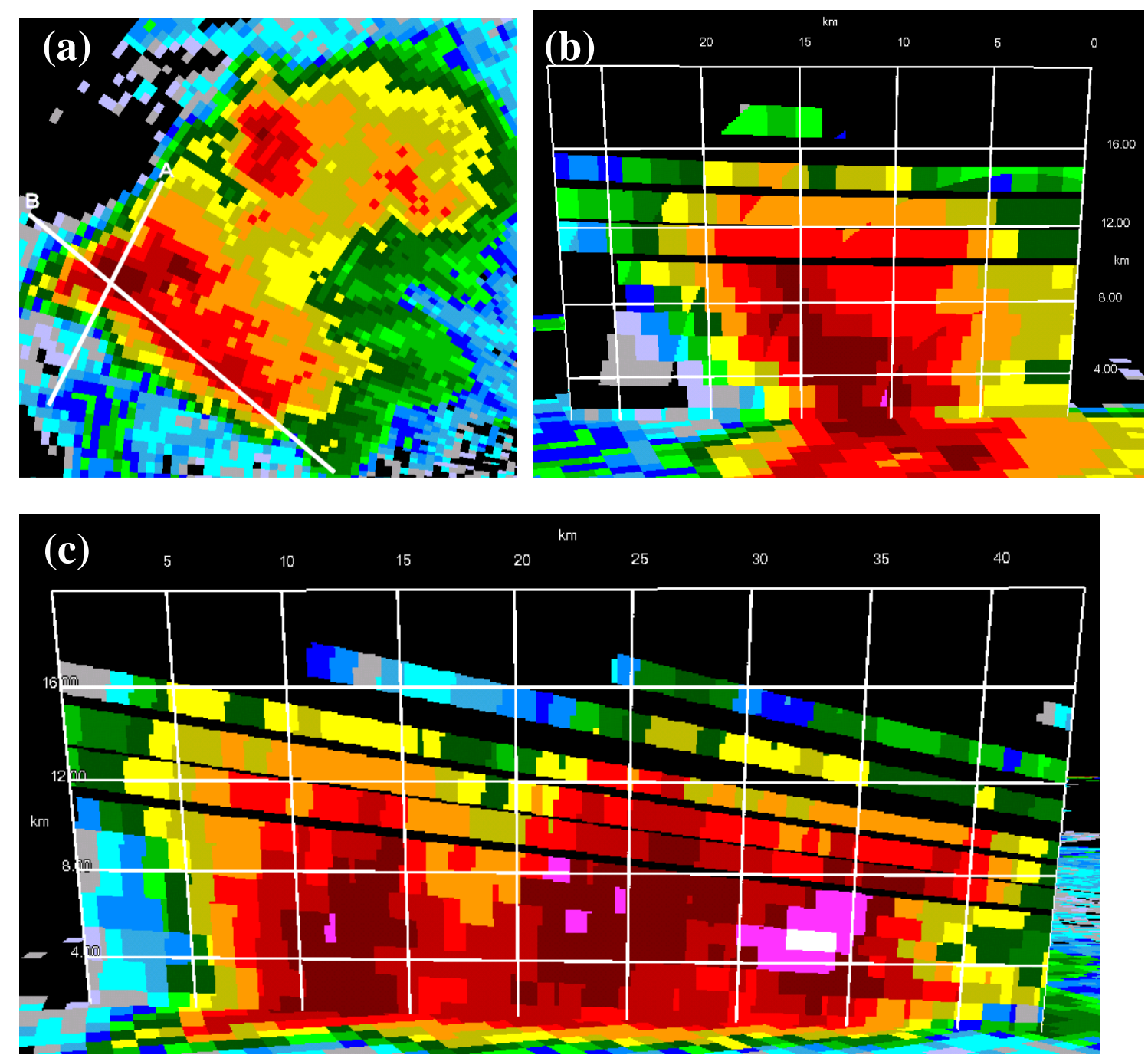

FIG. 74. (a) $0.5^{\circ}$ radar reflectivity of a supercell splitting into left- and right-moving supercells at 2229 UTC 12 June 2002 in the 12 June negative mesoscale region. (b) Radar reflectivity vertical cross-section through the right-moving supercell, along the white line denoted as " $A$ " in (a). (c) Radar reflectivity vertical cross-section through the right-moving supercell, along the white line denoted as " $\mathrm{B}$ " in (a). 


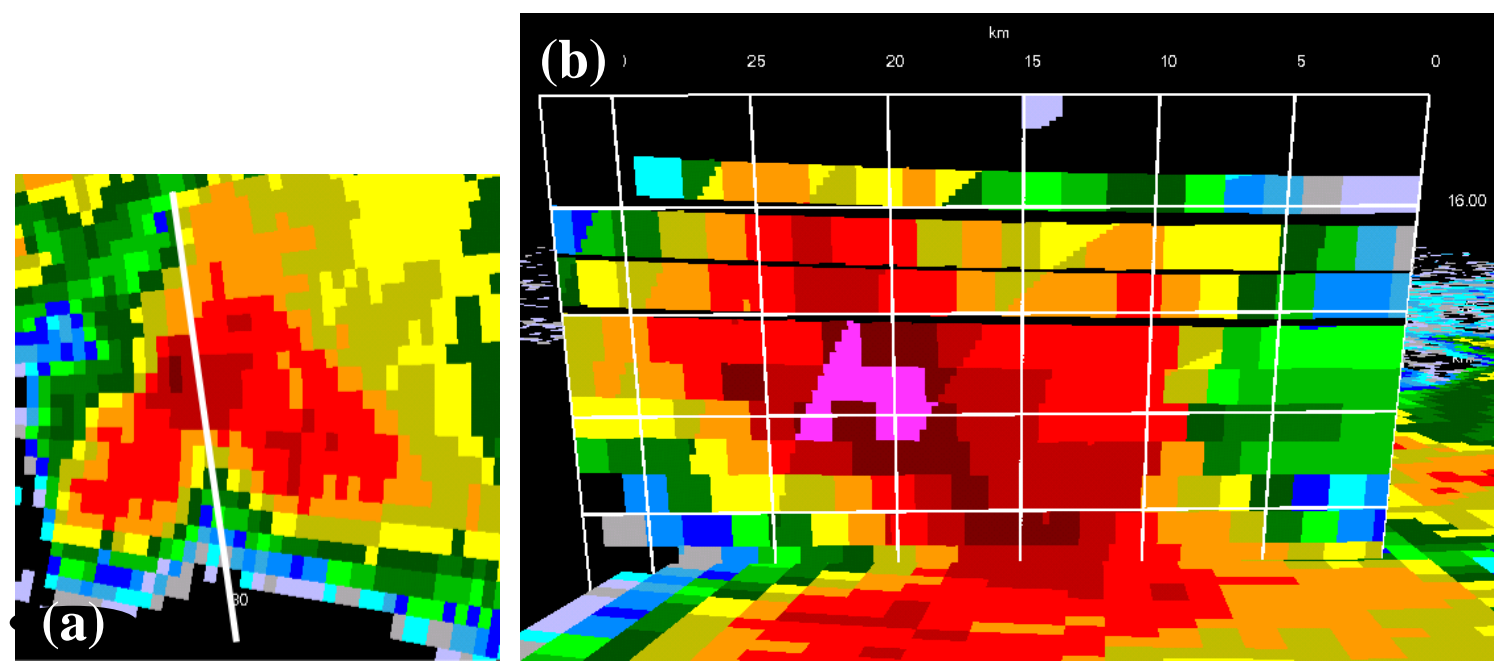

FIG. 75. (a) $0.5^{\circ}$ radar reflectivity and (b) vertical cross-section of radar reflectivity along the white line depicted in (a) at 0011 UTC 13 June 2002 of an HP supercell in the 12 June negative mesoscale region.

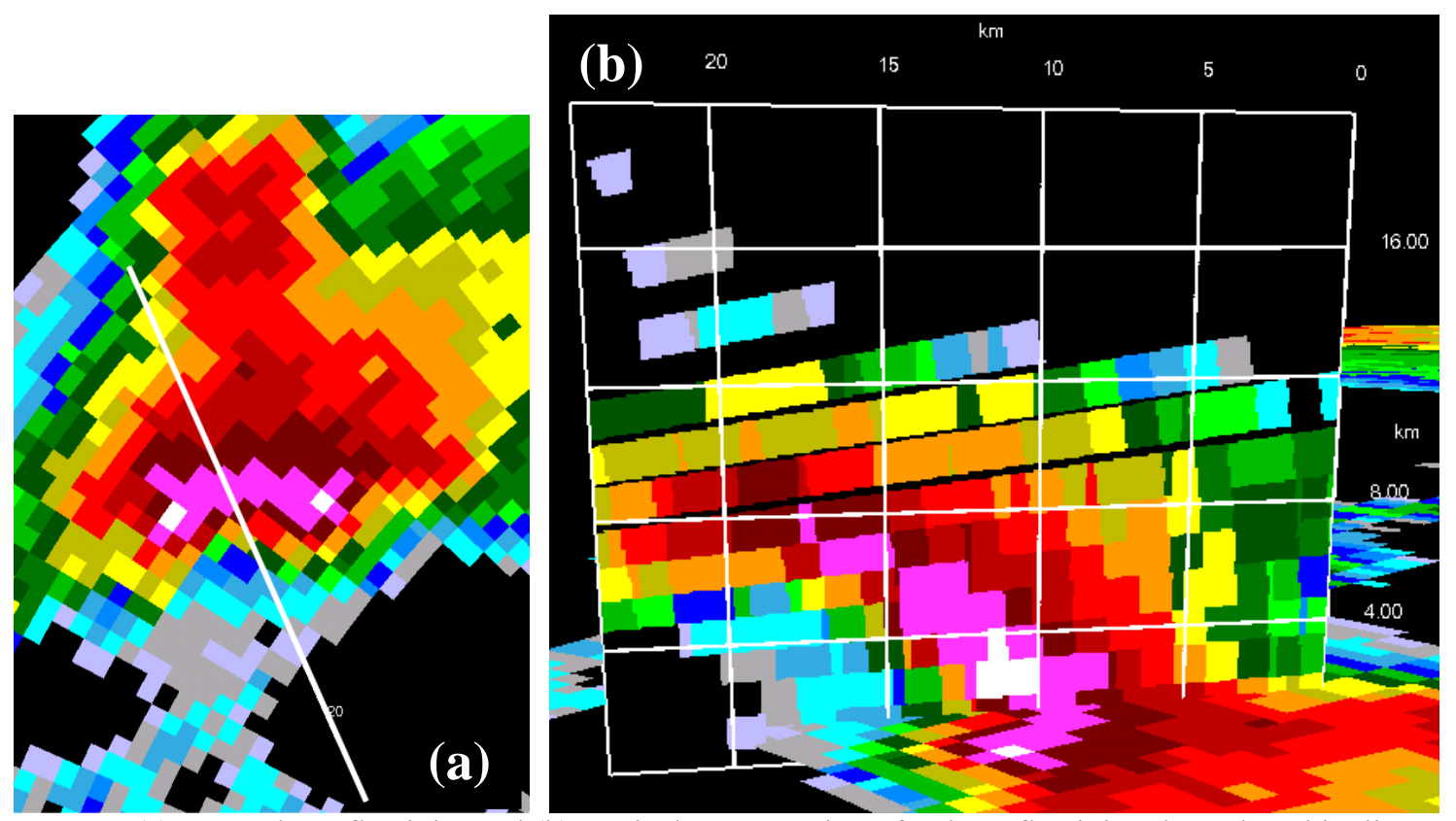

FIG. 76. (a) $0.5^{\circ}$ radar reflectivity and (b) vertical cross-section of radar reflectivity along the white line depicted in (a) at 2032 UTC 15 June 2002 of a supercell in the 15 June negative mesoscale region. 


\section{8) SUMMARY}

No readily identifiable, systematic differences in storm structure, morphology, or intensity existed between positive and negative storms, as determined by visual inspection of radar imagery and comparison of severe storm reports. For example, there was no consistent relationship between cell type (supercell vs. ordinary multicell) and predominant CG lightning polarity (positive or negative storms). Overall, positive mesoscale regions were somewhat more likely to support supercell convection than negative regions. However, positive and negative storms were commonly comprised of both supercell and ordinary multicellular convection, as described above and summarized in Table 4. Thus, it clearly appears that predominant CG flash polarity is not directly related to the organizational mode taken by convection.

It is also apparent from the descriptions above and Table 4 that both positive and negative storms can be very intense and produce widespread accounts of severe weather. Severe wind, hail, and tornado reports were common with all of the positive and negative mesoscale regions investigated, with exception of the 23 May negative region. For the cases examined, tornadoes were more frequent with positive storms than with negative storms. However, several tornadoes did occur with negative storms. Large numbers of severe wind and hail reports were common in positive and negative mesoscale regions alike. Analysis of radar imagery also revealed no systematic differences in intensity between positive and negative storms. 


\section{d. Mesoscale environmental properties of positive and negative storms}

\section{1) OVERALL GROUPED COMPARISONS}

The overall grouped mean (and median) environmental parameters for negative and positive mesoscale regions are presented in Tables 5-9, ranked by significance level according to the Student's $t$ test. The mean (median) values listed for each parameter represent the parameter mean (median) for all soundings characterizing negative storm environments (i.e., all five negative mesoscale regions grouped together) and all soundings characterizing positive storm environments (i.e., all four positive mesoscale regions grouped together).

In agreement with the results of Knapp (1994), negative storms occurred in a moister environment than positive storms as indicated by significantly higher mean lowlevel mixing ratio, precipitable water, and surface dewpoint, along with a significantly lower mean surface dewpoint depression. The difference in means for all of the above moisture parameters was very highly significant $(99.9 \%$ level) as shown in Table 5 . Negative storms also occurred in regions of noticeably higher midlevel relative humidity, although the difference in means was significant only at the $90 \%$ level (Table $8)$.

Consistent with substantially drier low-level environments in the positive mesoscale regions (i.e., lower mean low-level mixing ratio, lower mean surface dewpoint, higher mean surface dewpoint depression), positive regions were characterized by a significantly higher mean LCL as suggested by Williams et al. (2005). In fact, the mean LCL for positive regions (2079 m AGL) was 1.9 times greater than that 
TABLE 5. Mean (median) environmental properties of grouped negative and positive mesoscale regions. The number of soundings in each negative $(\mathrm{N}-)$ and positive $(\mathrm{N}+)$ parameter sample is also shown. For each parameter, the statistical significance level of the difference in means according to the Student's $t$ test was very highly significant $(99.9 \%$ level, $\mathrm{p} \leq 0.001)$.

\begin{tabular}{|c|c|c|c|c|}
\hline \multirow{2}{*}{ Very Highly Significant: 99.9\% Level } & \multicolumn{2}{|c|}{ Grouped Negative Regions } & \multicolumn{2}{|c|}{ Grouped Positive Regions } \\
\hline & Mean (Median) & $N-$ & Mean (Median) & $N+$ \\
\hline Warm cloud depth & $2949(3089) \mathrm{m}$ & 24 & $1699(1646) \mathrm{m}$ & 24 \\
\hline Lifting condensation level & $1121(1077) \mathrm{m} \mathrm{AGL}$ & 24 & $2079(2008) \mathrm{m} \mathrm{AGL}$ & 24 \\
\hline Mean mixing ratio in the lowest $100 \mathrm{hPa}$ & $14.0(14.3) \mathrm{g} \mathrm{kg}^{-1}$ & 24 & $10.9(10.8) \mathrm{g} \mathrm{kg}^{-1}$ & 24 \\
\hline $850-500 \mathrm{hPa}$ lapse rate & $7.1(7.0)^{\circ} \mathrm{C} \mathrm{km}^{-1}$ & 24 & $8.4(8.4)^{\circ} \mathrm{C} \mathrm{km}^{-1}$ & 18 \\
\hline Wet-bulb zero height & $3284(3310) \mathrm{m} \mathrm{AGL}$ & 24 & 2868 (2851) m AGL & 24 \\
\hline Precipitable water in surface to $400 \mathrm{hPa}$ layer & $3.6(3.5) \mathrm{cm}$ & 22 & $2.7(2.6) \mathrm{cm}$ & 13 \\
\hline Surface dewpoint & $18.7(18.7)^{\circ} \mathrm{C}$ & 24 & $14.3(14.3)^{\circ} \mathrm{C}$ & 24 \\
\hline Surface dewpoint depression & $7.8(7.6)^{\circ} \mathrm{C}$ & 24 & $16.7(15.8)^{\circ} \mathrm{C}$ & 24 \\
\hline
\end{tabular}

TABLE 6. Same as Table 5 except the difference in each mean environmental parameter was highly significant $(99 \%$ level, $0.001<\mathrm{p} \leq 0.01)$.

\begin{tabular}{|c|c|c|c|c|}
\hline \multirow{2}{*}{ Highly Significant: 99\% Level } & \multicolumn{2}{|c|}{ Grouped Negative Regions } & \multicolumn{2}{|c|}{ Grouped Positive Regions } \\
\hline & Mean (Median) & $N-$ & Mean (Median) & $N+$ \\
\hline 0-3 km AGL shear & $10.7(9.0) \mathrm{m} \mathrm{s}^{-1}$ & 24 & $14.7(14.9) \mathrm{m} \mathrm{s}^{-1}$ & 24 \\
\hline Freezing level & 4070 (4097) m AGL & 24 & 3777 (3770) m AGL & 24 \\
\hline CAPE between LFC and $-10^{\circ} \mathrm{C}$ level & $397(385) \mathrm{J} \mathrm{kg}^{-1}$ & 24 & $199(202) \mathrm{J} \mathrm{kg}^{-1}$ & 19 \\
\hline Surface temperature & $26.5(27.4)^{\circ} \mathrm{C}$ & 24 & $31.0(29.6)^{\circ} \mathrm{C}$ & 24 \\
\hline
\end{tabular}


TABLE 7. Same as Table 5 except the difference in each mean environmental parameter was significant $(95 \%$ level, $0.01<\mathrm{p} \leq 0.05)$.

\begin{tabular}{|l|c|c|c|c|}
\hline \multicolumn{1}{|c|}{ Significant: 95\% Level } & \multicolumn{2}{c|}{ Grouped Negative Regions } & \multicolumn{2}{c|}{ Grouped Positive Regions } \\
& Mean (Median) & N- & Mean (Median) & $\mathrm{N}+$ \\
\hline Convective inhibition & $67(43) \mathrm{J} \mathrm{kg}^{-1}$ & 24 & $26(10) \mathrm{J} \mathrm{kg}^{-1}$ & 24 \\
\hline Equilibrium level & $12545(12587) \mathrm{m} \mathrm{AGL}^{-1}$ & 22 & $11671(11928) \mathrm{m} \mathrm{AGL}^{\mathrm{A}}$ & 10 \\
\hline $700-500 \mathrm{hPa}$ lapse rate & $7.7(7.9){ }^{\circ} \mathrm{C} \mathrm{km}^{-1}$ & 24 & $8.4(8.3)^{\circ} \mathrm{C} \mathrm{km}$ & 18 \\
\hline $0-2 \mathrm{~km} \mathrm{AGL}$ storm-relative wind speed & $7.0(6.2) \mathrm{m} \mathrm{s}^{-1}$ & 22 & $10.2(9.8) \mathrm{m} \mathrm{s}^{-1}$ & 13 \\
\hline Free convective layer depth & $9811(10089) \mathrm{m}^{-1}$ & 22 & $8604(8712) \mathrm{m}^{-1}$ & 10 \\
\hline CAPE between $-10^{\circ} \mathrm{C}$ and $-40^{\circ} \mathrm{C}$ levels & $957(1010) \mathrm{J} \mathrm{kg}^{-1}$ & 22 & $1210(1266) \mathrm{J} \mathrm{kg}^{-1}$ & 10 \\
\hline NCAPE between LFC and $-40^{\circ} \mathrm{C}$ level & $0.19(0.20) \mathrm{m} \mathrm{s}^{-2}$ & 22 & $0.24(0.25) \mathrm{m} \mathrm{s}^{-2}$ & 10 \\
\hline
\end{tabular}

TABLE 8. Same as Table 5 except the difference in each mean environmental parameter was insignificant at the $95 \%$ level but significant at the $90 \%$ level $(0.05<\mathrm{p} \leq 0.1)$.

\begin{tabular}{|l|c|c|c|c|}
\hline \multicolumn{1}{|c|}{ Significance Level: $\mathbf{9 0 \%}$} & \multicolumn{2}{c|}{ Grouped Negative Regions } & \multicolumn{2}{c|}{ Grouped Positive Regions } \\
& Mean (Median) & $\mathrm{N}-$ & \multicolumn{2}{c|}{ Mean (Median) } \\
\hline 0-3 km AGL storm-relative environmental helicity & $72(67) \mathrm{m}^{2} \mathrm{~s}^{-2}$ & 22 & $163(119) \mathrm{m}^{2} \mathrm{~s}^{-2}$ & 13 \\
\hline Midlevel relative humidity $(700$ to $500 \mathrm{hPa}$ layer) & $42(45) \%$ & 24 & $32(28) \%$ & 18 \\
\hline NCAPE (LFC to EL) & $0.19(0.19) \mathrm{m} \mathrm{s}^{-2}$ & 22 & $0.22(0.22) \mathrm{m} \mathrm{s}^{-2}$ & 10 \\
\hline NCAPE between $-10^{\circ} \mathrm{C}$ and $-40^{\circ} \mathrm{C}$ levels & $0.24(0.25) \mathrm{m} \mathrm{s}^{-2}$ & 22 & $0.29(0.31) \mathrm{m} \mathrm{s}^{-2}$ & 10 \\
\hline
\end{tabular}


TABLE 9. Same as Table 5 except the difference in each mean environmental parameter was insignificant at the $90 \%$ level $(\mathrm{p}>0.1)$.

\begin{tabular}{|c|c|c|c|c|}
\hline \multirow{2}{*}{ Not Significant at the $90 \%$ Level } & \multicolumn{2}{|c|}{ Grouped Negative Regions } & \multicolumn{2}{|c|}{ Grouped Positive Regions } \\
\hline & Mean (Median) & $N-$ & Mean (Median) & $N+$ \\
\hline CAPE (LFC to EL) & $1924(2025) \mathrm{J} \mathrm{kg}^{-1}$ & 22 & $1948(2024) \mathrm{J} \mathrm{kg}^{-1}$ & 10 \\
\hline Lifted index & $-6.9(-6.0)^{\circ} \mathrm{C}$ & 24 & $-6.1(-6.5)^{\circ} \mathrm{C}$ & 18 \\
\hline Level of free convection & $2682(2792)$ m AGL & 24 & 2820 (3066) m AGL & 24 \\
\hline 4-6 km AGL storm-relative wind speed & $10.7(9.8) \mathrm{m} \mathrm{s}^{-1}$ & 22 & $10.6(9.3) \mathrm{m} \mathrm{s}^{-1}$ & 13 \\
\hline 6-10 km AGL storm-relative wind speed & $15.8(14.9) \mathrm{m} \mathrm{s}^{-1}$ & 22 & $15.1(14.4) \mathrm{m} \mathrm{s}^{-1}$ & 10 \\
\hline 9-11 km AGL storm-relative wind speed & $22.8(20.8) \mathrm{m} \mathrm{s}^{-1}$ & 22 & $19.4(18.8) \mathrm{m} \mathrm{s}^{-1}$ & 10 \\
\hline Storm-relative wind speed at EL & $25.8(24.9) \mathrm{m} \mathrm{s}^{-1}$ & 22 & $21.3(22.4) \mathrm{m} \mathrm{s}^{-1}$ & 10 \\
\hline $0-2 \mathrm{~km}$ AGL shear & $8.2(7.7) \mathrm{m} \mathrm{s}^{-1}$ & 24 & $9.2(8.5) \mathrm{m} \mathrm{s}^{-1}$ & 24 \\
\hline $0-6$ km AGL shear & $17.7(17.5) \mathrm{m} \mathrm{s}^{-1}$ & 22 & $18.5(18.5) \mathrm{m} \mathrm{s}^{-1}$ & 13 \\
\hline Bulk Richardson number & $149(82)$ & 22 & $91(49)$ & 10 \\
\hline Energy helicity index (using 0-3 km AGL SREH) & $0.8(0.7)$ & 22 & $2.0(1.4)$ & 10 \\
\hline NCAPE between LFC and $-10^{\circ} \mathrm{C}$ level & $0.13(0.12) \mathrm{m} \mathrm{s}^{-2}$ & 24 & $0.11(0.12) \mathrm{m} \mathrm{s}^{-2}$ & 19 \\
\hline CAPE between LFC and $-40^{\circ} \mathrm{C}$ level & $1335(1338) \mathrm{J} \mathrm{kg}^{-1}$ & 22 & $1405(1442) \mathrm{J} \mathrm{kg}^{-1}$ & 10 \\
\hline Equivalent potential temperature & $73.2(73.0)^{\circ} \mathrm{C}$ & 24 & $71.9(74.1)^{\circ} \mathrm{C}$ & 24 \\
\hline
\end{tabular}


for negative regions (1121 m AGL). A higher mean LCL in combination with a slightly lower mean freezing level (and wet-bulb zero height) resulted in a much shallower mean WCD in positive mesoscale regions as also postulated by Williams et al. (2005). More specifically, the mean WCD was $1250 \mathrm{~m}$ deeper in negative storms (2949 m) than in positive storms $(1699 \mathrm{~m})$. The difference in both mean LCL and WCD between positive and negative regions was very highly significant (99.9\% level; Table 5). In contrast, the LFC was not statistically different between positive and negative regions (mean and median of approximately $3 \mathrm{~km}$ for both; Table 9).

Mean lapse rates in the low to midtroposphere (850-500 and 700-500 hPa) were steeper in positive regions. In fact, mean $850-500 \mathrm{hPa}$ lapse rates were $1.3^{\circ} \mathrm{C} \mathrm{km}^{-1}$ greater in positive storms $\left(8.4^{\circ} \mathrm{C} \mathrm{km}^{-1}\right)$ than in negative storms $\left(7.1^{\circ} \mathrm{C} \mathrm{km}^{-1}\right)$, which was very highly significant (99.9\% level; Table 5). The difference in 700-500 hPa lapse rates was not as large (mean difference of $\left.0.7^{\circ} \mathrm{C} \mathrm{km}^{-1}\right)$, but still significant $(95 \%$ level; Table 7). The mean surface temperature was $4.5^{\circ} \mathrm{C}$ greater in positive regions (highly significant; Table 6). The mean EL was higher in negative regions (Table 7), and thus despite little difference in the LFC between negative and positive regions, the mean depth of the free convective layer (EL-LFC) was roughly $1.2 \mathrm{~km}$ greater in negative regions (Table 7).

Interestingly, there was no significant difference in the mean total CAPE (LFC to EL) or mean lifted index (LI) for positive and negative storms (Table 9). The mean CAPE was moderate (roughly $2000 \mathrm{~J} \mathrm{~kg}^{-1}$ ) and the mean LI was low (-6 to $-7^{\circ} \mathrm{C}$ ), indicating very unstable air masses and ample instability for strong updraft development 
in both positive and negative regions. There was also no significant difference in the deep-layer (0-6 km AGL) vertical wind shear for positive and negative storms (mean and median of roughly $18 \mathrm{~m} \mathrm{~s}^{-1}$ for both; Table 9), consistent with the results of Reap and MacGorman (1989) and Curran and Rust (1992). It is therefore not surprising that the BRN did not differ significantly between positive and negative mesoscale regions either (Table 9). However, the mean CIN was significantly greater for negative regions (95\% level; Table 7). Given recent interest in the relationship between dominant CG lightning polarity and position of the $\theta_{\mathrm{e}}$ ridge (e.g., Smith et al. 2000; Carey et al. 2003b), it is interesting to note that mean $\theta_{\mathrm{e}}$ values did not differ significantly between negative and positive regions, and were in fact very similar (Table 9).

Mean and median CAPE and NCAPE values were calculated for several different vertical layers. In general, there was more CAPE at warmer temperatures (LFC to $\left.10^{\circ} \mathrm{C}\right)$ in negative regions and more $\mathrm{CAPE}$ at colder temperatures $\left(-10^{\circ} \mathrm{C}\right.$ to $\left.-40^{\circ} \mathrm{C}\right)$ in positive regions (Tables 6-8). Mean CAPE between the LFC and $-10^{\circ} \mathrm{C}$ level was about twice as large in negative regions $\left(397 \mathrm{~J} \mathrm{~kg}^{-1}\right)$ compared to positive regions $\left(199 \mathrm{~J} \mathrm{~kg}^{-1}\right.$ ), resulting in a highly significant difference in means ( $99 \%$ level; Table 6). However, mean NCAPE between the LFC and $-10^{\circ} \mathrm{C}$ level was not significantly different between negative and positive regions (Table 9), indicating that the greater mean CAPE for negative storms in the $\mathrm{LFC}$ to $-10^{\circ} \mathrm{C}$ layer was due to a greater mean layer depth between the $\mathrm{LFC}$ and $-10^{\circ} \mathrm{C}$ level in negative regions, rather than to greater mean parcel buoyant acceleration within this layer. Mean CAPE between the $-10^{\circ} \mathrm{C}$ and $-40^{\circ} \mathrm{C}$ levels and mean NCAPE between the LFC and $-40^{\circ} \mathrm{C}$ level were both $26 \%$ greater in positive 
regions, with the difference in means for both parameters significant at the $95 \%$ level (Table 7). Mean NCAPE between the $-10^{\circ} \mathrm{C}$ and $-40^{\circ} \mathrm{C}$ levels was $21 \%$ greater in positive storms but was only significant at the $90 \%$ level (Table 8 ). Mean total NCAPE (LFC to EL) was also greater for positive storms but the difference in means was only significant at the 90\% level (Table 8). Similar to total CAPE, CAPE between the LFC and $-40^{\circ} \mathrm{C}$ level was not significantly different between negative and positive storms (Table 9). In summary, CAPE and more precisely mean buoyant acceleration (NCAPE) was larger for positive storms within the mixed-phase zone $\left(0^{\circ} \mathrm{C}\right.$ to $\left.-40^{\circ} \mathrm{C}\right)$, which is critical for NIC and lightning production.

Consistent with the results of Gilmore and Wicker (2002), the mean 0-3 km AGL vertical wind shear was significantly stronger in positive $\left(14.7 \mathrm{~m} \mathrm{~s}^{-1}\right)$ versus negative $\left(10.7 \mathrm{~m} \mathrm{~s}^{-1}\right)$ mesoscale regions, and hence could imply stronger dynamical updraft forcing in positive storms. The difference in mean 0-3 km AGL shear between negative and positive regions was highly significant (99\% level; Table 6). However, as noted above, 0-6 km AGL shear did not differ significantly between negative and positive storms, nor did 0-2 km AGL shear (Table 9). Low-level (0-2 km AGL) storm-relative wind speed (a proxy for low-level inflow strength) was significantly higher in positive regions (95\% level; Table 7), and this stronger inflow may allow the sustenance of positive storms in the presence of strong outflow. Interestingly, storm-relative wind speeds in the mid and upper troposphere (4-6 km AGL, 6-10 km AGL, 9-11 km AGL, EL) were fairly similar between negative and positive regions (Table 9), despite playing a hypothesized role in supercell microphysics and dynamics (e.g., Brooks et al. 1994b; 
Rasmussen and Straka 1998). The mean 0-3 km AGL SREH was over twice as high in positive regions than in negative regions. However, due to a large variation in $0-3 \mathrm{~km}$ AGL SREH values, this difference in means was only significant at the $90 \%$ level (Table 8). The $0-3 \mathrm{~km}$ AGL shear and SREH results suggest that positive storms apparently experienced stronger dynamical forcing of the updraft than negative storms. Since total CAPE was so similar for positive and negative regions, EHI (using 0-3 km AGL SREH) did not differ significantly between the two types of regions (Table 9).

Relative frequency histograms and scatter plots were used in addition to the mean and median values and associated significance tests described above and summarized in Tables 5-9 to compare the mesoscale environments of positive and negative storms. Histograms and scatter plots of all environmental soundings available for each given parameter were used to verify, through visual inspection, the results of the mean and median value comparisons and significance tests. For instance, the scatter plots and histograms of parameters found to differ significantly via the significance tests were visually inspected to insure that systematic differences were indeed evident in the parameter values between positive and negative regions. Likewise, scatter plots and histograms of parameters found not to differ significantly between the two storm types were inspected to insure that no systematic differences were visible between negative and positive mesoscale regions. For brevity, the histograms and scatter plots are not shown for all parameters, but it should be emphasized that these plots consistently supported the results of the mean and median value comparisons and significance tests discussed above and summarized in Tables 5-9. 
Relative frequency histograms of select environmental parameters that characterize the mesoscale environments of negative and positive storms from individual soundings are shown in the next twelve figures to highlight the differences (i.e., significance level $\geq 90 \%$ or $\mathrm{p} \leq 0.1$ ) in these parameters, and yet assess the degree of overlap in environmental conditions between the two types of regions. The histograms also demonstrate the range of variability in each parameter associated with both negative and positive storms. Histograms for a few commonly-used parameters (total CAPE, 0-6 km AGL shear, equivalent potential temperature) in the study and forecasting of severe storms are presented to illustrate the lack of any systematic differences in these parameters between positive and negative regions.

In agreement with the mean and median value comparisons and significance tests, the histograms in the next fifteen figures make it clearly apparent that LCL (Fig. 77) and especially WCD (Fig. 78) differed much more between positive and negative mesoscale regions than the other parameters investigated. Although the populations were not completely distinct, there was relatively little overlap, especially for WCD. The modal LCL for positive and negative storms was 2000 and $1000 \mathrm{~m}$ AGL, respectively. Approximately $83 \%$ of positive (negative) storm soundings had LCL values greater (less) than $1500 \mathrm{~m}$ AGL. The WCD for positive storms was somewhat bimodal with relative maxima at $1300 \mathrm{~m}$, which was the primary peak, and $2100 \mathrm{~m}$, while the mode for negative storms was $3100 \mathrm{~m}$. WCD was less (greater) than $2400 \mathrm{~m}$ in $88 \%$ (92\%) of positive (negative) storm soundings. There was one outlier sounding launched in the vicinity of negative storms that was characterized by an LCL of 
approximately $2500 \mathrm{~m}$ AGL and a WCD of about $1100 \mathrm{~m}$. While high LCLs and shallow WCDs were not exclusively associated with positive storms, the degree of separation in LCL and WCD between positive and negative regions was noteworthy. As such, these results strongly support a role for LCL and WCD in influencing the CG lightning polarity of severe storms as first suggested by Williams et al. (2005).

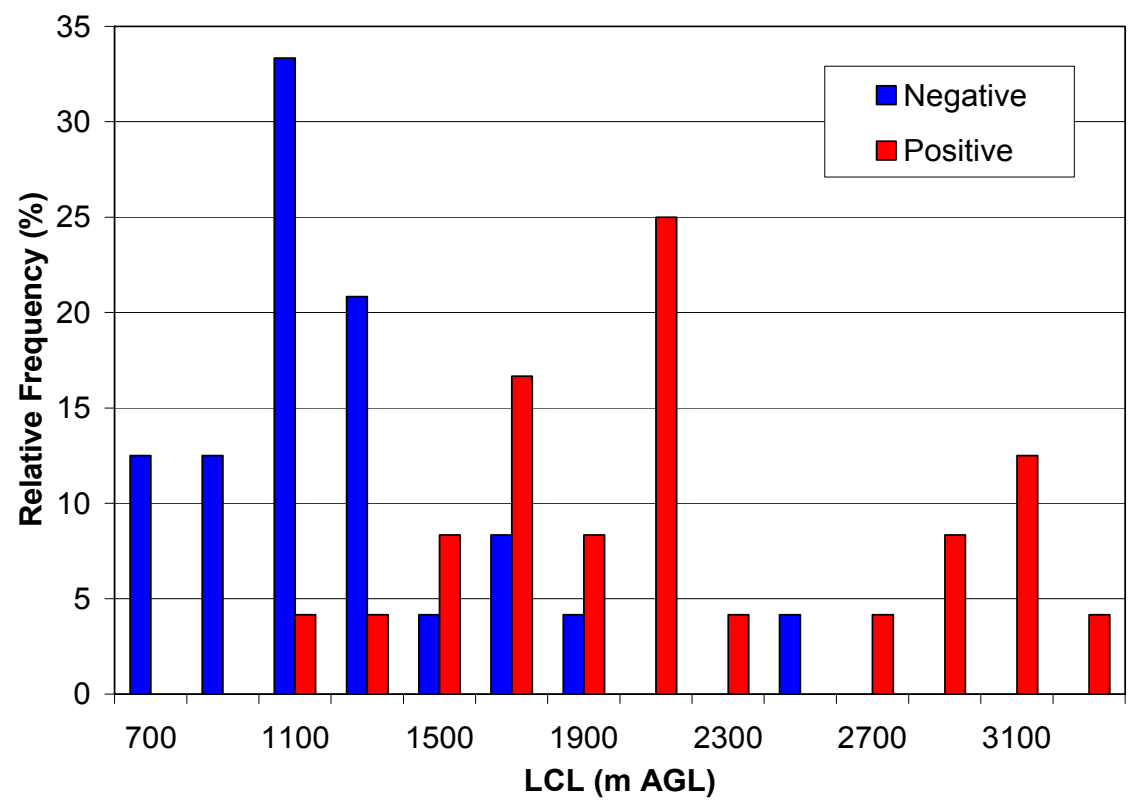

FIG. 77. Relative frequency histogram for LCL. Labels along the horizontal axis represent the maximum value for the bin.

Figures 79-81 illustrate once again that negative storms occurred in more moist environments than positive storms, consistent with the results of Knapp (1994). The moister negative storm environments were apparent in measurements at the surface (Fig. 79), at low levels (Fig. 80), and at low to midtropospheric heights (Fig. 81). The moisture parameters displayed in Figs. 79-81 exhibited more overlap of individual sounding values between negative and positive storms than did LCL (Fig. 77) and WCD 
(Fig. 78), but the respective modes for positive (i.e., relatively dry) and negative storms (i.e., relatively moist) of all three moisture parameters were clearly distinct. The same can be said for 0-3 km AGL shear (Fig. 82). The modes were obviously different ( $7 \mathrm{~m} \mathrm{~s}^{-1}$ for negative storms versus $15 \mathrm{~m} \mathrm{~s}^{-1}$ for positive storms), with the positive sounding population occupying the higher end of the parameter spectrum, and the negative sounding population occupying the lower end, confirming the findings of Gilmore and Wicker (2002).

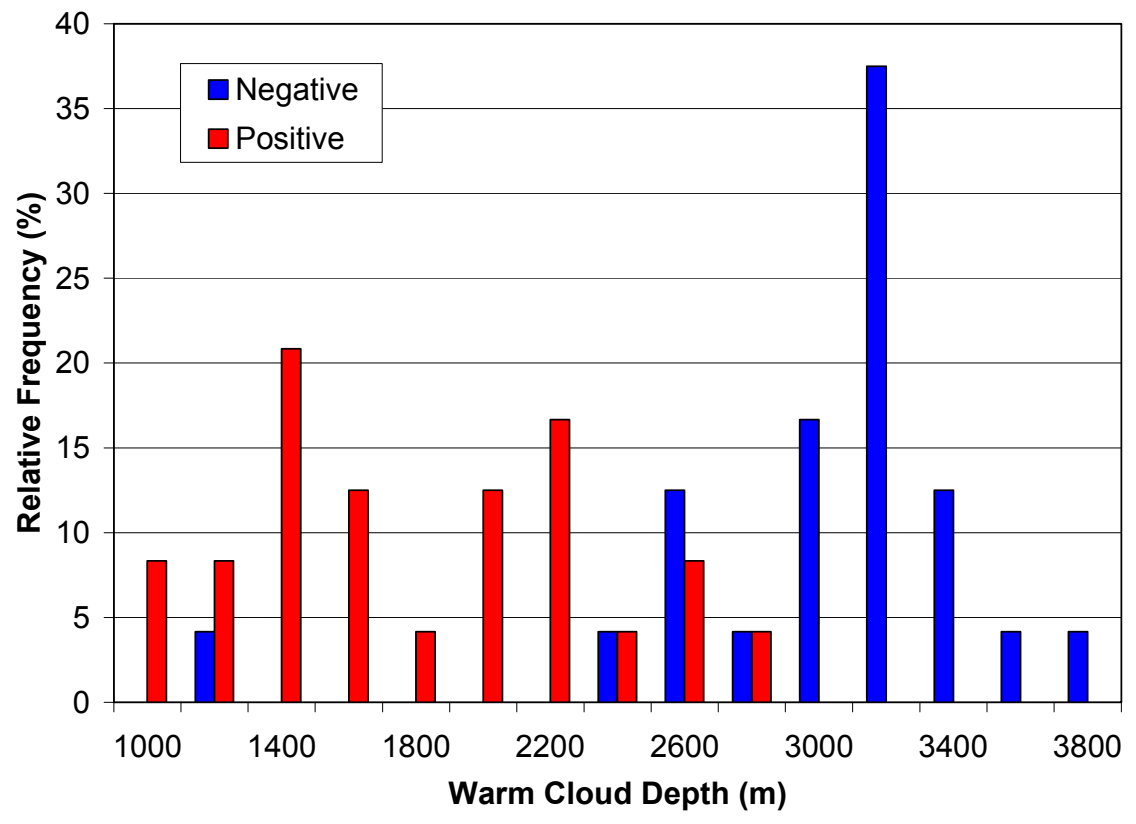

FIG. 78. Same as in Fig. 77 except for WCD. 


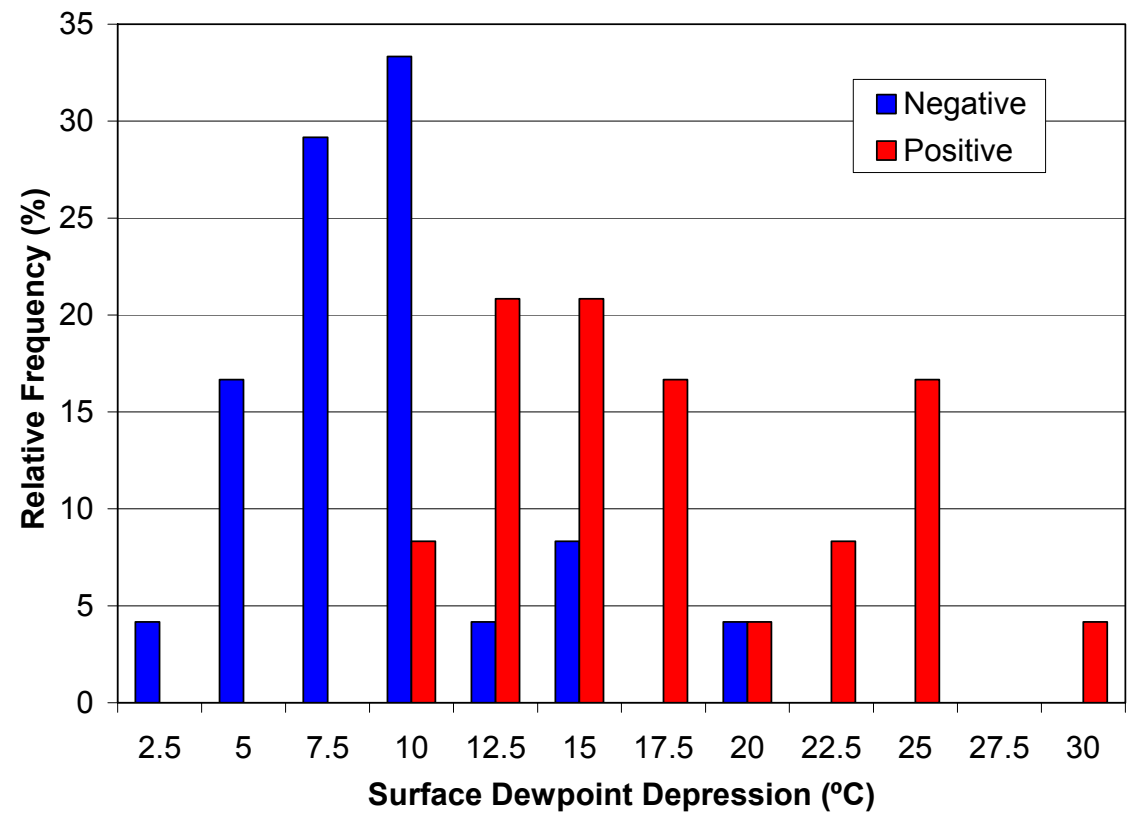

FIG. 79. Same as in Fig. 77 except for surface dewpoint depression.

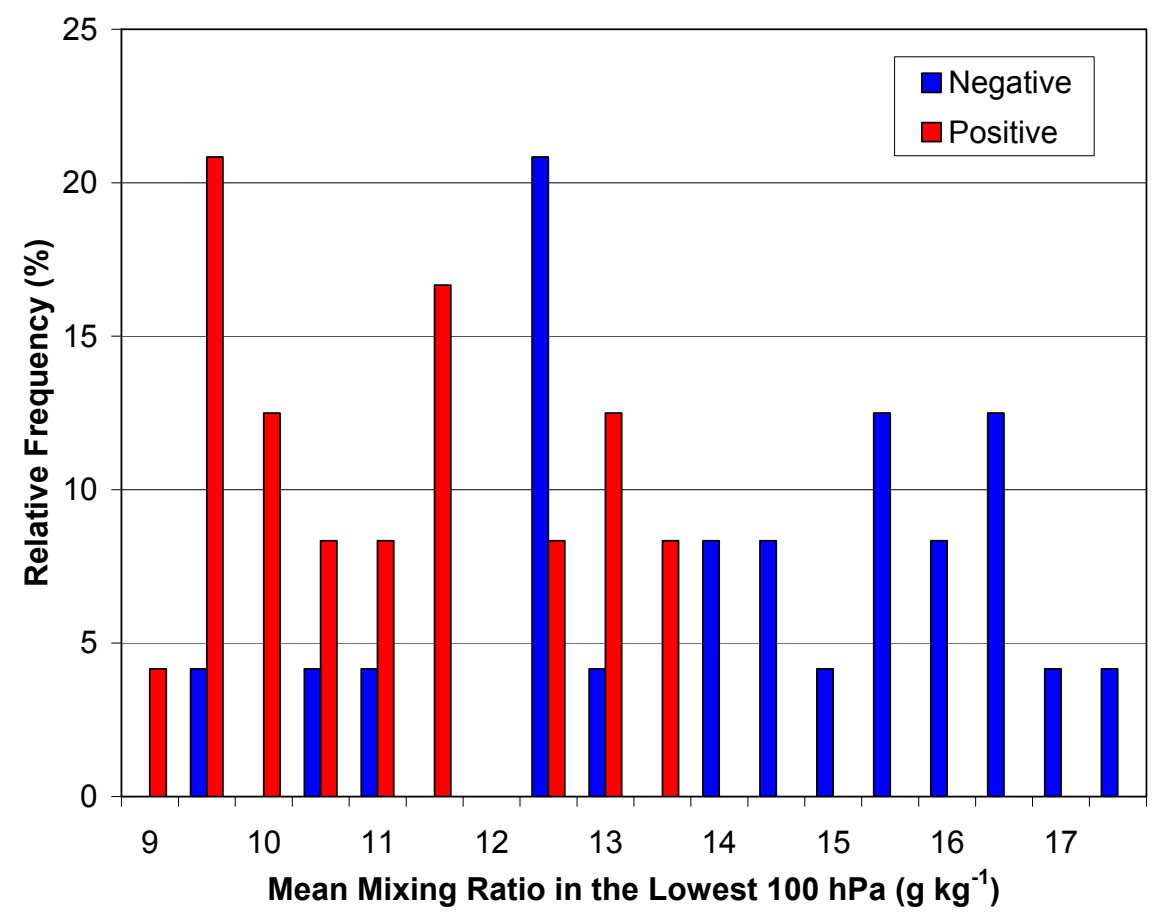

FIG. 80. Same as in Fig. 77 except for mean mixing ratio in the lowest $100 \mathrm{hPa}$. 


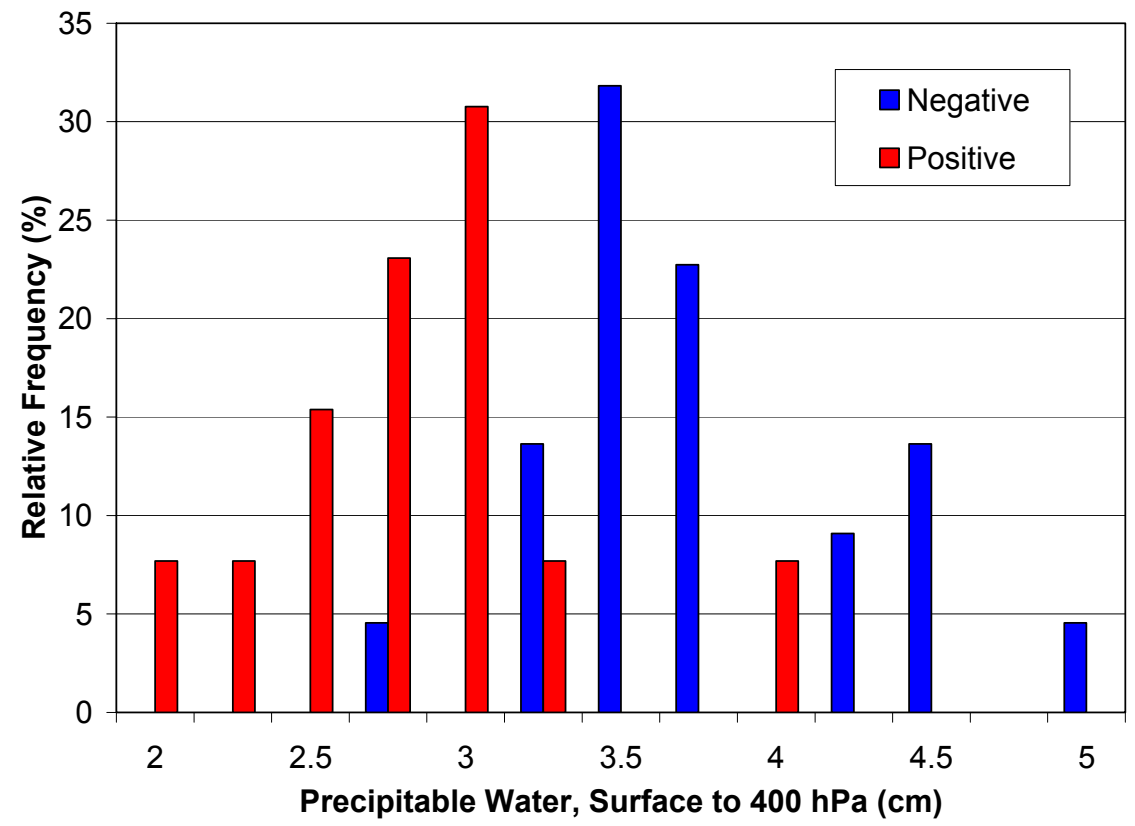

FIG. 81. Same as in Fig. 77 except for precipitable water between the surface and $400 \mathrm{hPa}$.

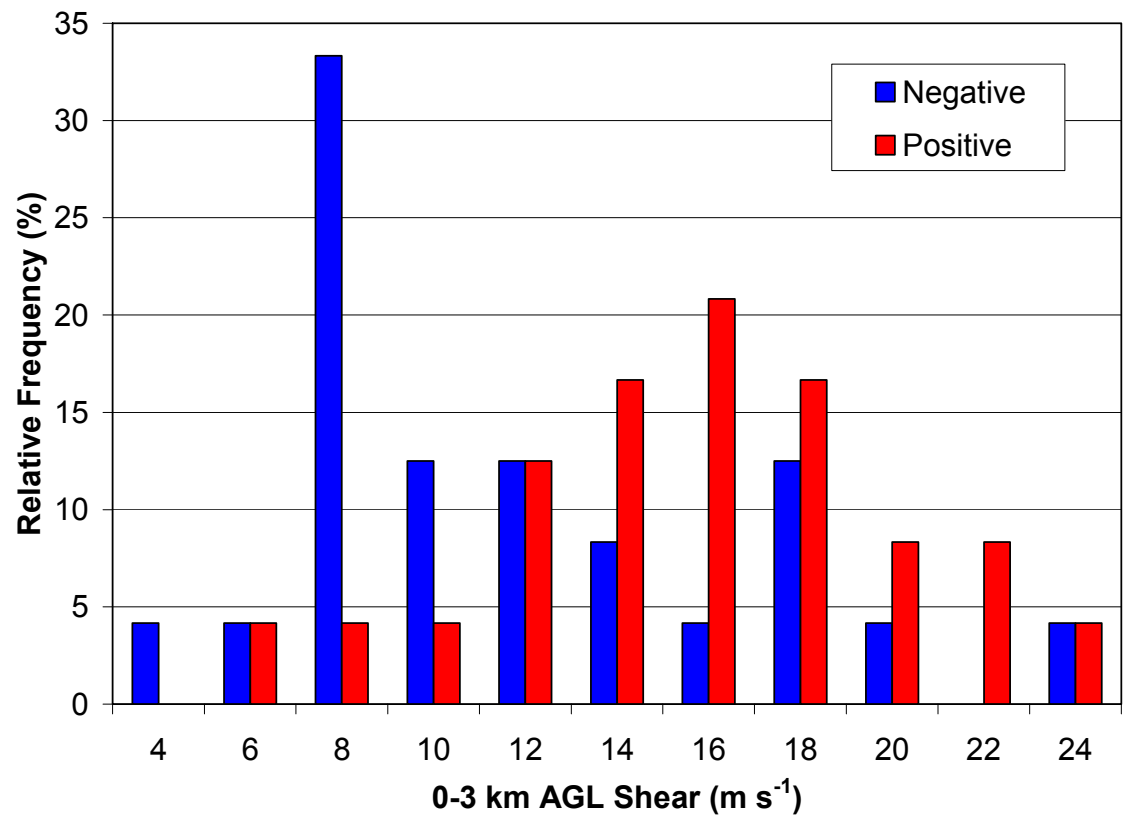

FIG. 82. Same as in Fig. 77 except for low-level (0-3 km AGL) vertical wind shear. 
Looking at 0-2 km AGL storm-relative wind speed (Fig. 83), the separation between sounding populations of negative and positive regions was less defined, as expected based on the decreasing significance level of the difference in means from Tables 5 to 7 . The negative sounding population was bimodal, with one mode $\left(9.5 \mathrm{~m} \mathrm{~s}^{-1}\right)$ greater than and the other mode $\left(3.5 \mathrm{~m} \mathrm{~s}^{-1}\right)$ less than the positive sounding mode $\left(6.5 \mathrm{~m} \mathrm{~s}^{-1}\right)$. The positive sounding population was skewed toward higher stormrelative wind speed values up to $17 \mathrm{~m} \mathrm{~s}^{-1}$. While there was more overlap for this parameter, the positive and negative samples were still distinct.

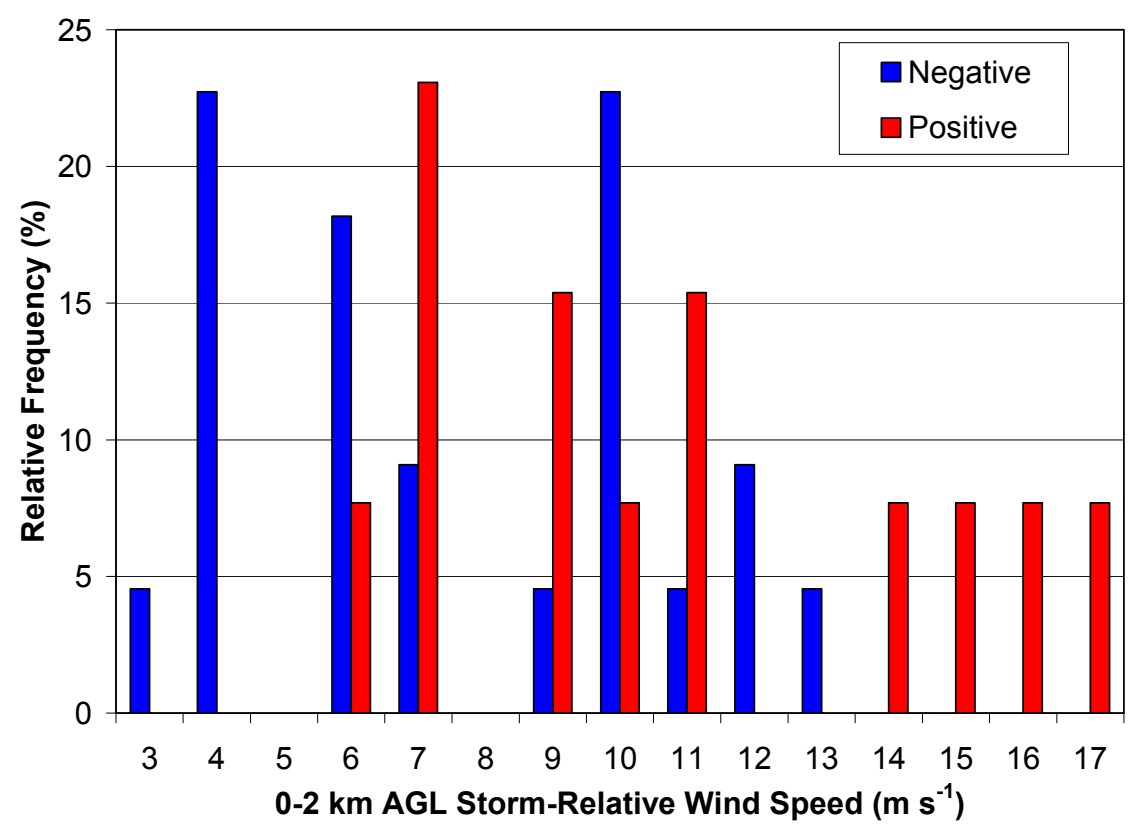

FIG. 83. Same as in Fig. 77 except for 0-2 km AGL storm-relative wind speed.

Relative frequency histograms of parameters related to buoyant or conditional instability are presented in Figs. 84-89. The 850-500 hPa lapse rate samples for positive and negative regions were distinct with negative (positive) region values skewed toward 
lower (higher) values (Fig. 84). Although there was some overlap in the lapse rate samples between $6.9^{\circ} \mathrm{C} \mathrm{km}^{-1}$ and $8.4^{\circ} \mathrm{C} \mathrm{km}^{-1}$, an overwhelming majority of negative (positive) region lapse rates were less (greater) than $7.5^{\circ} \mathrm{C} \mathrm{km}^{-1}$. More specifically, 850 $500 \mathrm{hPa}$ lapse rates were less (greater) than $7.5^{\circ} \mathrm{C} \mathrm{km}^{-1}$ in $79 \%$ (83\%) of negative (positive) storm soundings. There was noticeable overlap between negative and positive region CAPE values calculated between the $-10^{\circ} \mathrm{C}$ and $-40^{\circ} \mathrm{C}$ levels (Fig. 85) with close but distinct modes (negative: $1100 \mathrm{~J} \mathrm{~kg}^{-1}$; positive: $1300 \mathrm{~J} \mathrm{~kg}^{-1}$ ). There was less overlap in the samples of NCAPE from the LFC to $-40^{\circ} \mathrm{C}$ level (Fig. 86) for the two region types (negative mode: $0.21 \mathrm{~m} \mathrm{~s}^{-2}$; positive mode: $0.26 \mathrm{~m} \mathrm{~s}^{-2}$ ). Although less clear, some weak distinction existed between negative and positive storm samples for NCAPE between the $-10^{\circ} \mathrm{C}$ and $-40^{\circ} \mathrm{C}$ levels (Fig. 87) and total NCAPE (NCAPE between the LFC and EL; Fig. 88), with positive (negative) region values skewed toward higher (lower) values in both cases. The samples of total CAPE (CAPE between the LFC and EL; Fig. 89) calculated from soundings in the negative and positive mesoscale regions were indistinguishable. In summary, positive storms generally formed in regions characterized by larger 850-500 hPa lapse rates and larger NCAPE (i.e., mean parcel acceleration associated with buoyancy; Blanchard 1998) up to the top of the mixedphase zone (i.e., $\left.-40^{\circ} \mathrm{C}\right)$. 


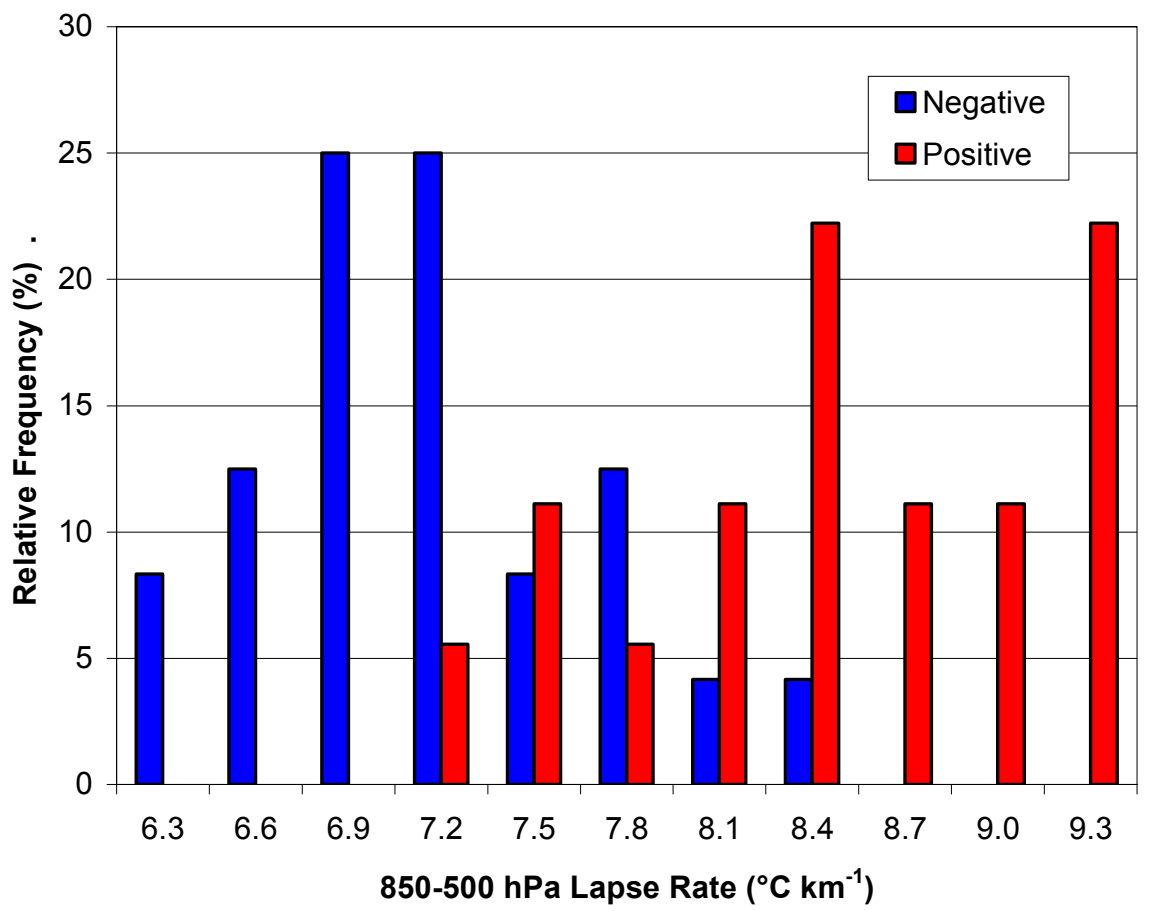

FIG. 84. Same as in Fig. 77 except for $850-500 \mathrm{hPa}$ lapse rate.

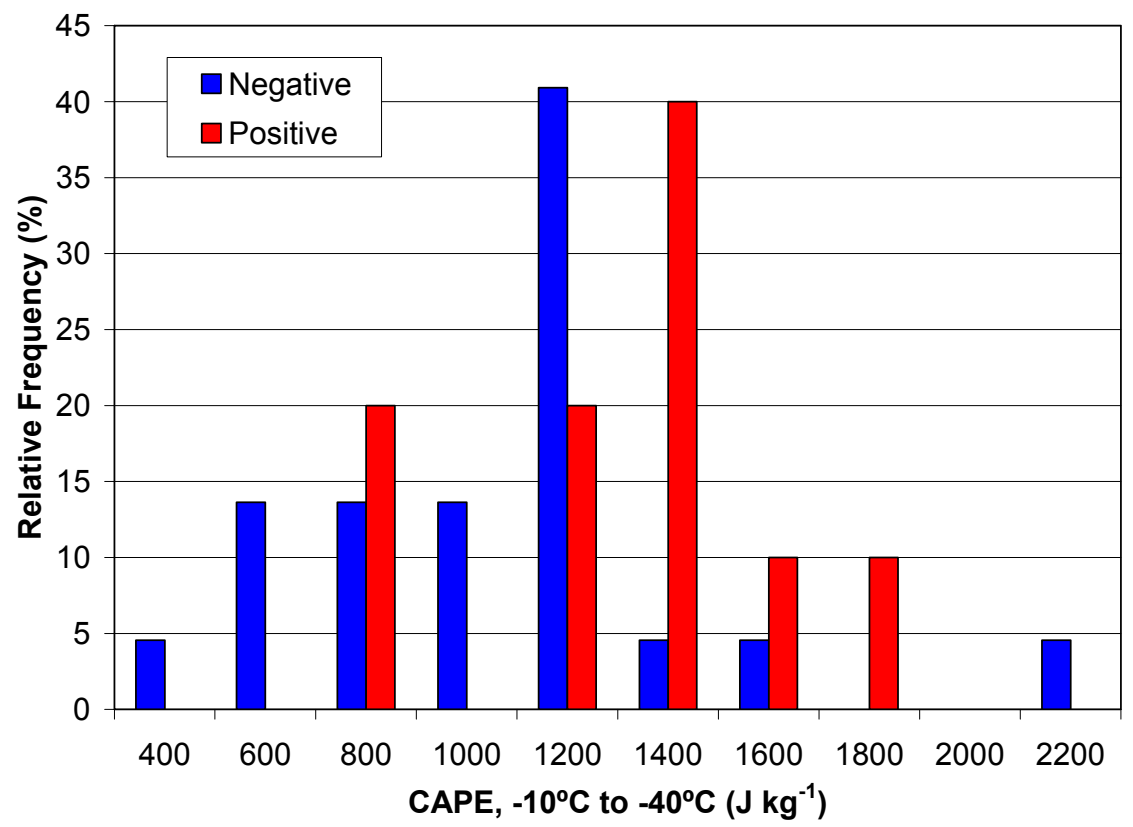

FIG. 85. Same as in Fig. 77 except for CAPE between the $-10^{\circ} \mathrm{C}$ and $-40^{\circ} \mathrm{C}$ levels. 


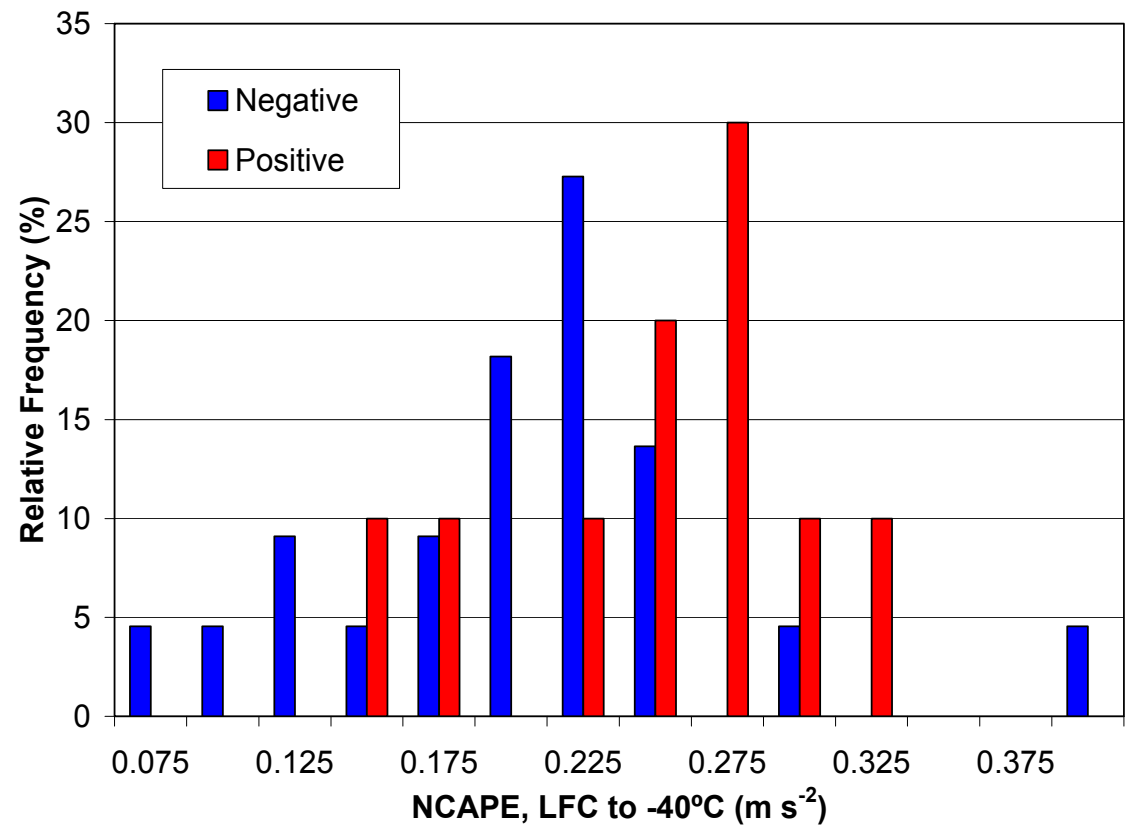

FIG. 86. Same as in Fig. 77 except for NCAPE between the LFC and $-40^{\circ} \mathrm{C}$ level.

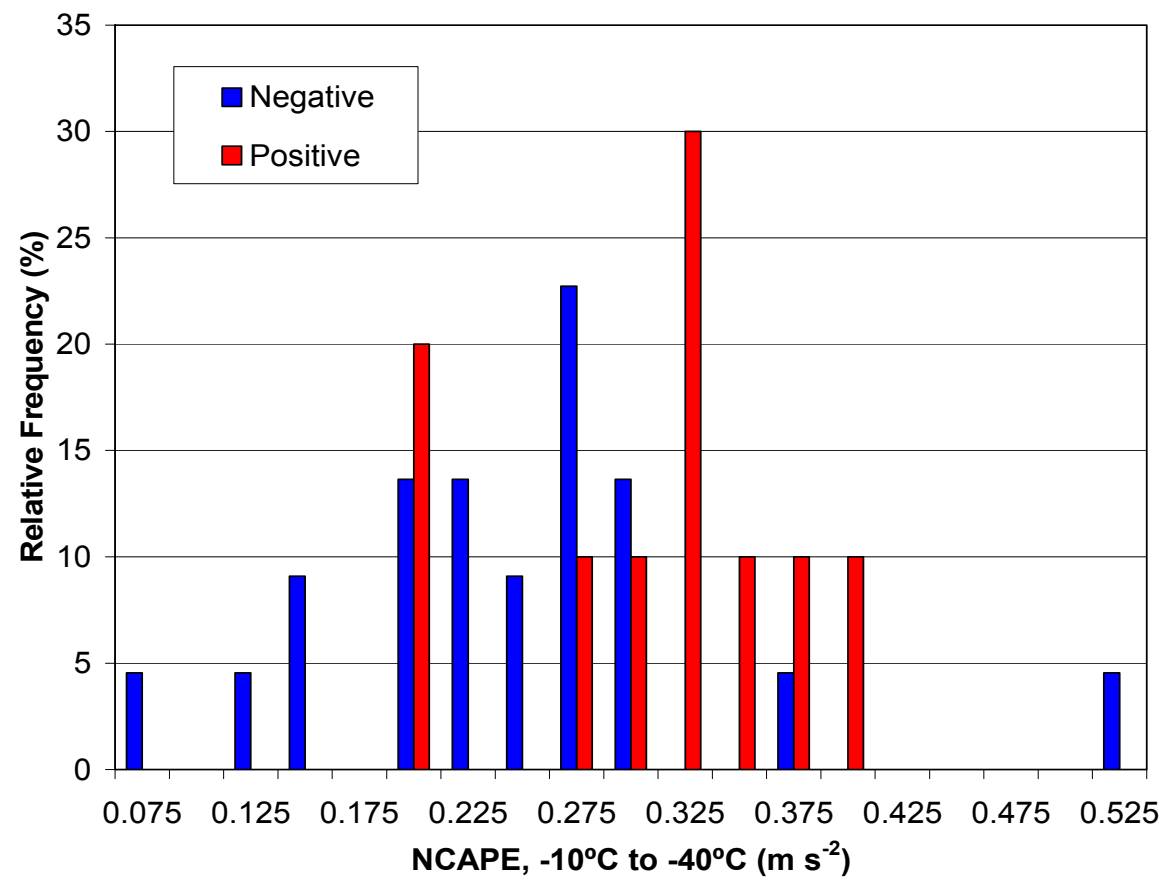

FIG. 87. Same as in Fig. 77 except for NCAPE between the $-10^{\circ} \mathrm{C}$ and $-40^{\circ} \mathrm{C}$ levels. 


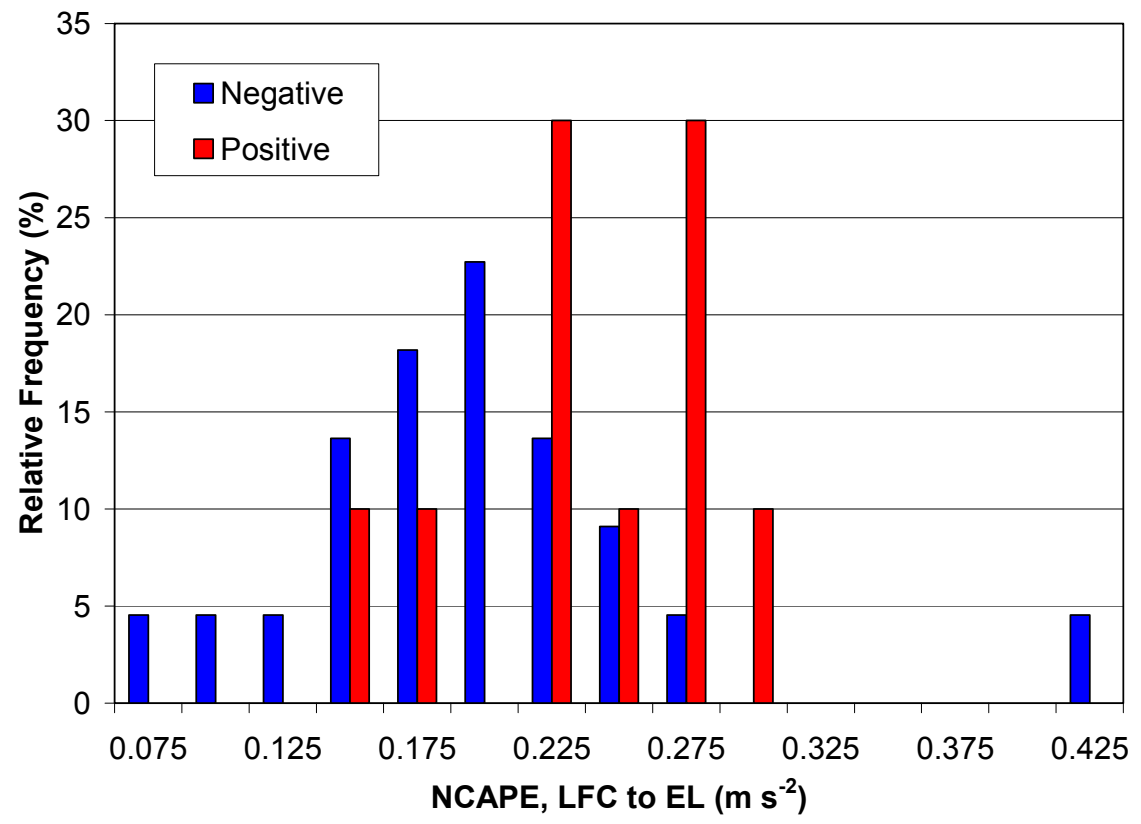

FIG. 88. Same as in Fig. 77 except for NCAPE between the LFC and EL (total NCAPE).

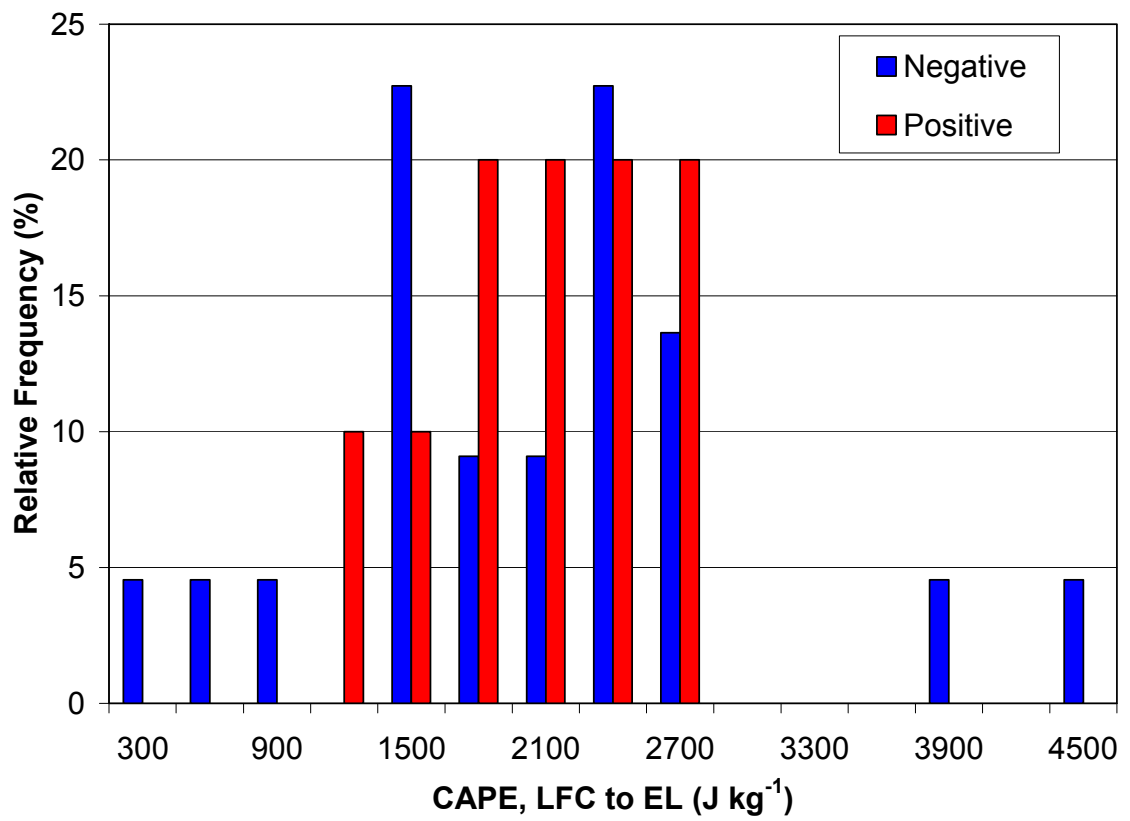

FIG. 89. Same as in Fig. 77 except for CAPE between the LFC and EL (total CAPE). 
The relative frequency histogram for a frequently-used parameter in the study and forecasting of severe convective storms, deep-layer (0-6 km AGL) shear, is presented in Fig. 90. As was the case for total CAPE, 0-6 km AGL shear samples from positive and negative regions were indistinguishable. In light of recent emphasis on the relationship between dominant CG lightning polarity and position of the $\theta_{\mathrm{e}}$ ridge (e.g., Smith et al. 2000; Carey et al. 2003b), it is interesting to note that no distinction was found between the samples of $\theta_{\mathrm{e}}$ values for positive and negative mesoscale regions (Fig. 91).

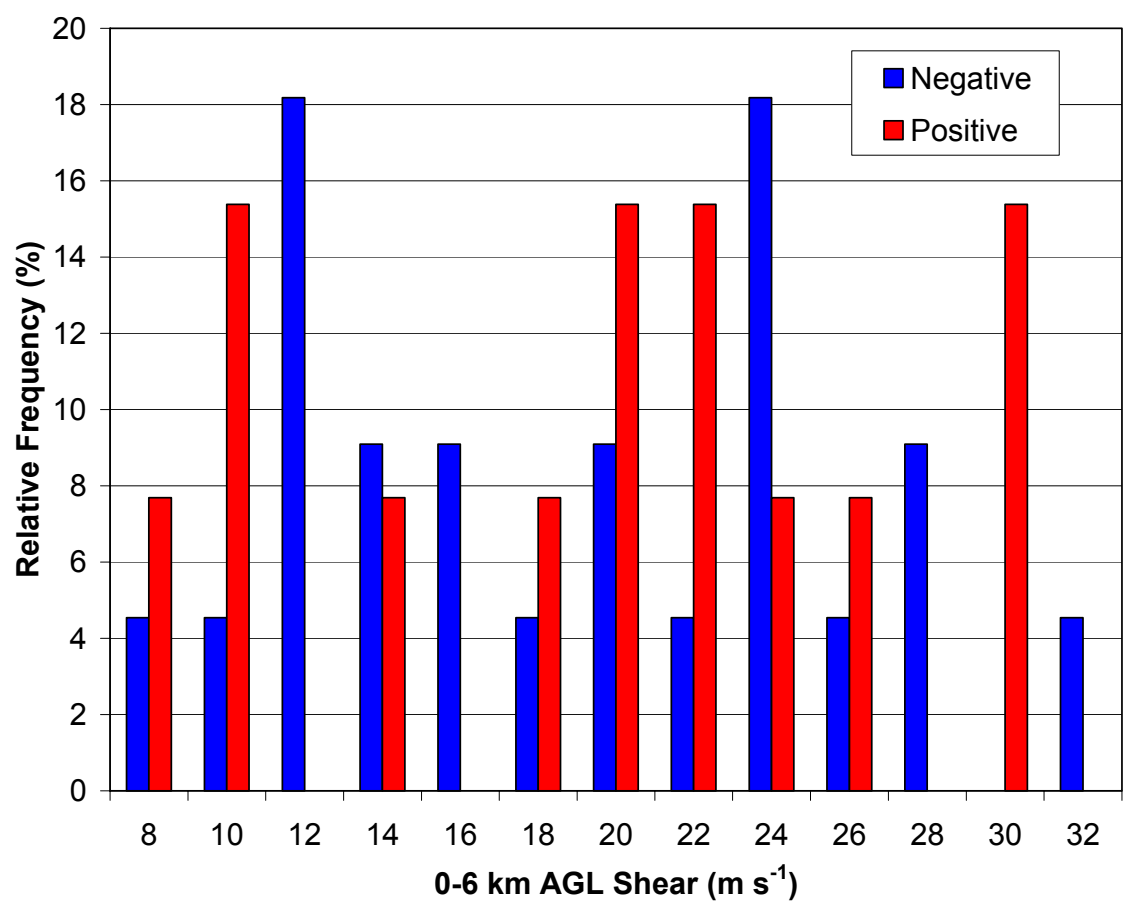

FIG. 90. Same as in Fig. 77 except for deep-layer (0-6 km AGL) vertical wind shear. 


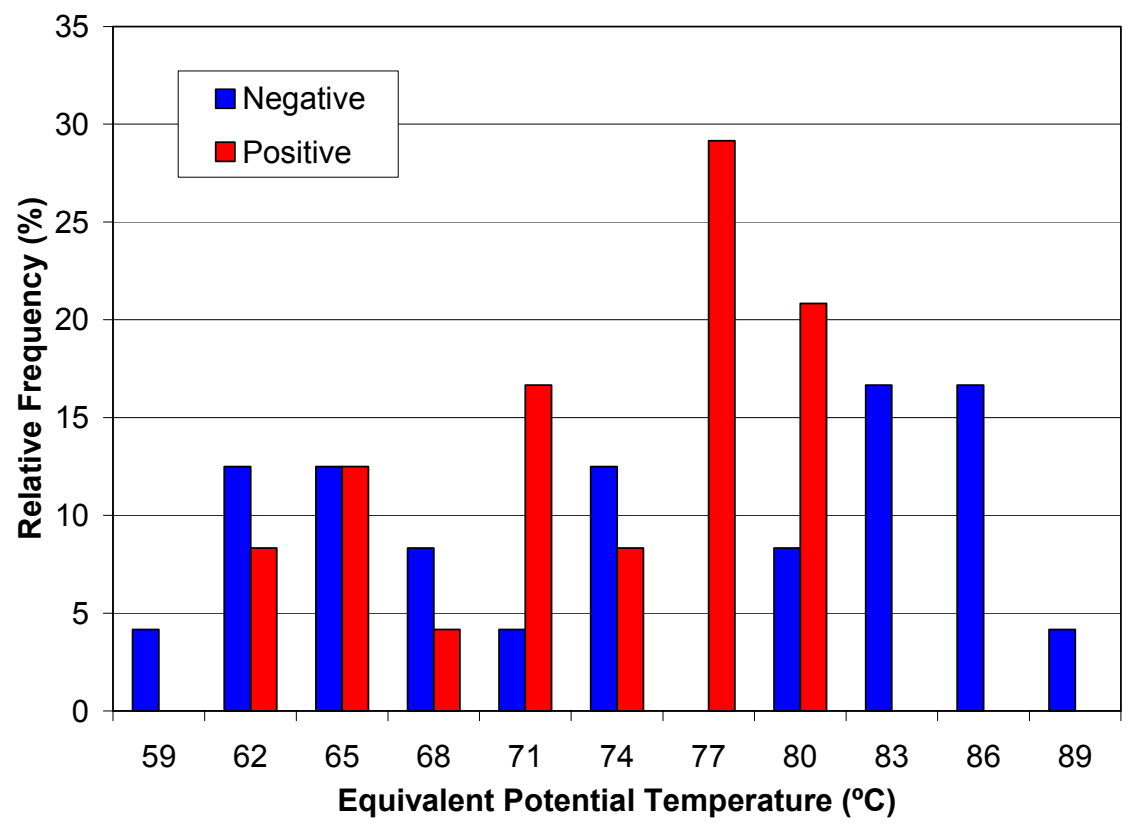

FIG. 91. Same as in Fig. 77 except for equivalent potential temperature $\left(\theta_{\mathrm{e}}\right)$.

Adiabatic LWCs were evaluated to assess the amount of water loading occurring in the updrafts of positive and negative storms. As discussed in Chapter IV, adiabatic LWCs can differ markedly from actual LWCs due to factors such as entrainment of dry environmental air into the cloud and depletion of cloud water by growing precipitation (Rogers and Yau 1989; Knight and Knight 2001). Thus, definitive conclusions cannot be drawn based on adiabatic LWC values, but some interesting differences were discovered between negative and positive regions, which deserve mentioning. Adiabatic LWCs were calculated for two different vertical layers, between the LCL and $0^{\circ} \mathrm{C}$ level (i.e., warm cloud layer) and between the LCL and $-40^{\circ} \mathrm{C}$ level. The adiabatic LWC at $0^{\circ} \mathrm{C}$ was then subtracted from the adiabatic LWC at $-40^{\circ} \mathrm{C}$ to calculate how much 
adiabatic LWC was contributed by the mixed-phase region (i.e., $0^{\circ} \mathrm{C}$ to $-40^{\circ} \mathrm{C}$ ) to the total adiabatic $\mathrm{LWC}$ at $-40^{\circ} \mathrm{C}$.

Adiabatic LWCs in the warm cloud layer were nearly twice as large in negative regions $\left(\right.$ mean $=6.0 \mathrm{~g} \mathrm{~kg}^{-1}$, median $=6.2 \mathrm{~g} \mathrm{~kg}^{-1}$ ) than in positive regions (mean $=3.3 \mathrm{~g}$ $\mathrm{kg}^{-1}$, median $\left.=3.2 \mathrm{~g} \mathrm{~kg}^{-1}\right)$, resulting in a very highly significant $(99.9 \%$ level) difference in means. As displayed in Fig. 92, an overwhelming majority of negative (positive) region adiabatic LWCs in the warm cloud layer were greater (less) than $4.5 \mathrm{~g} \mathrm{~kg}^{-1}$. The nearly twice-as-large mean adiabatic LWC in the warm cloud layer for negative storms is consistent with the nearly doubled mean warm cloud depth and significantly higher mean low-level mixing ratio in negative storms. In contrast, the adiabatic LWC contribution from the mixed-phase region (i.e., the difference in adiabatic LWC between $0^{\circ} \mathrm{C}$ and $-40^{\circ} \mathrm{C}$ ) was very similar for negative $\left(\right.$ mean $=6.9 \mathrm{~g} \mathrm{~kg}^{-1}$, median $\left.=6.7 \mathrm{~g} \mathrm{~kg}^{-1}\right)$ and positive $\left(\right.$ mean $=6.6 \mathrm{~g} \mathrm{~kg}^{-1}$, median $\left.=6.7 \mathrm{~g} \mathrm{~kg}^{-1}\right)$ regions. The difference in means was insignificant at the $90 \%$ level, and Fig. 93 shows that the samples from negative and positive regions of adiabatic LWC difference between $0^{\circ} \mathrm{C}$ and $-40^{\circ} \mathrm{C}$ were indeed indistinguishable. 


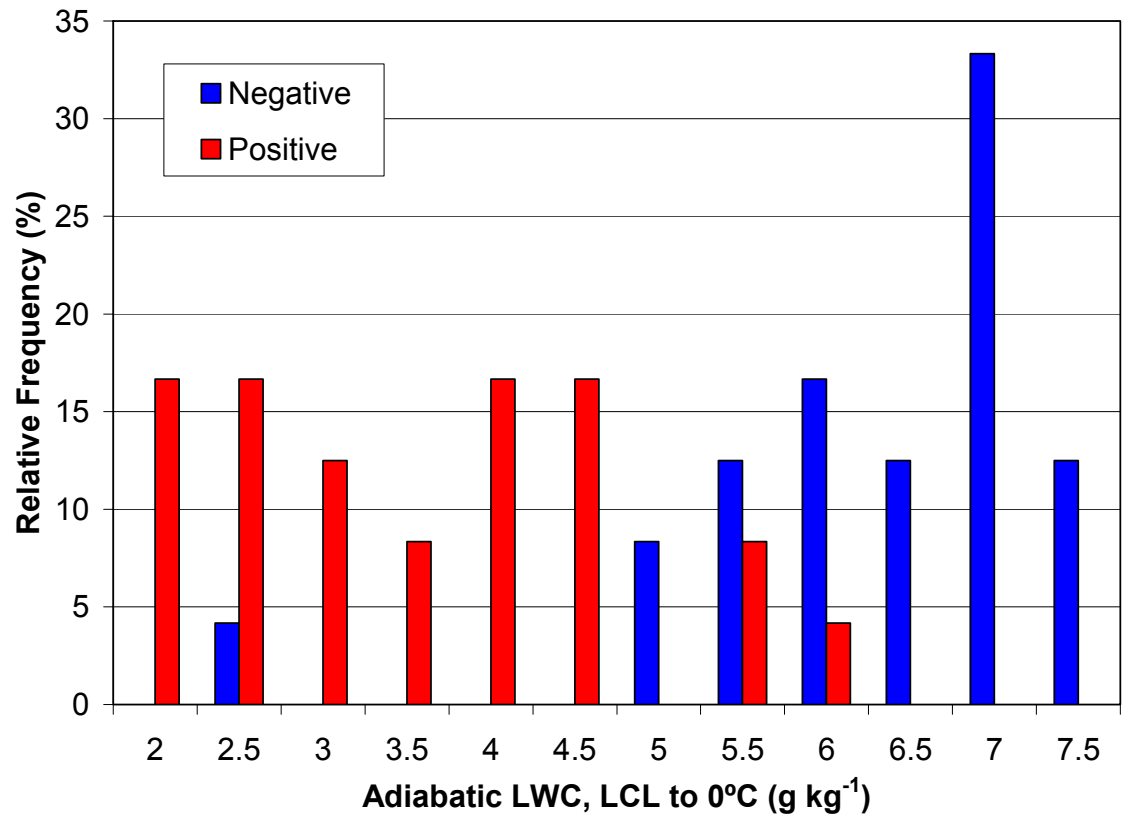

FIG. 92. Same as in Fig. 77 except for adiabatic LWC between the LCL and $0^{\circ} \mathrm{C}$ level.

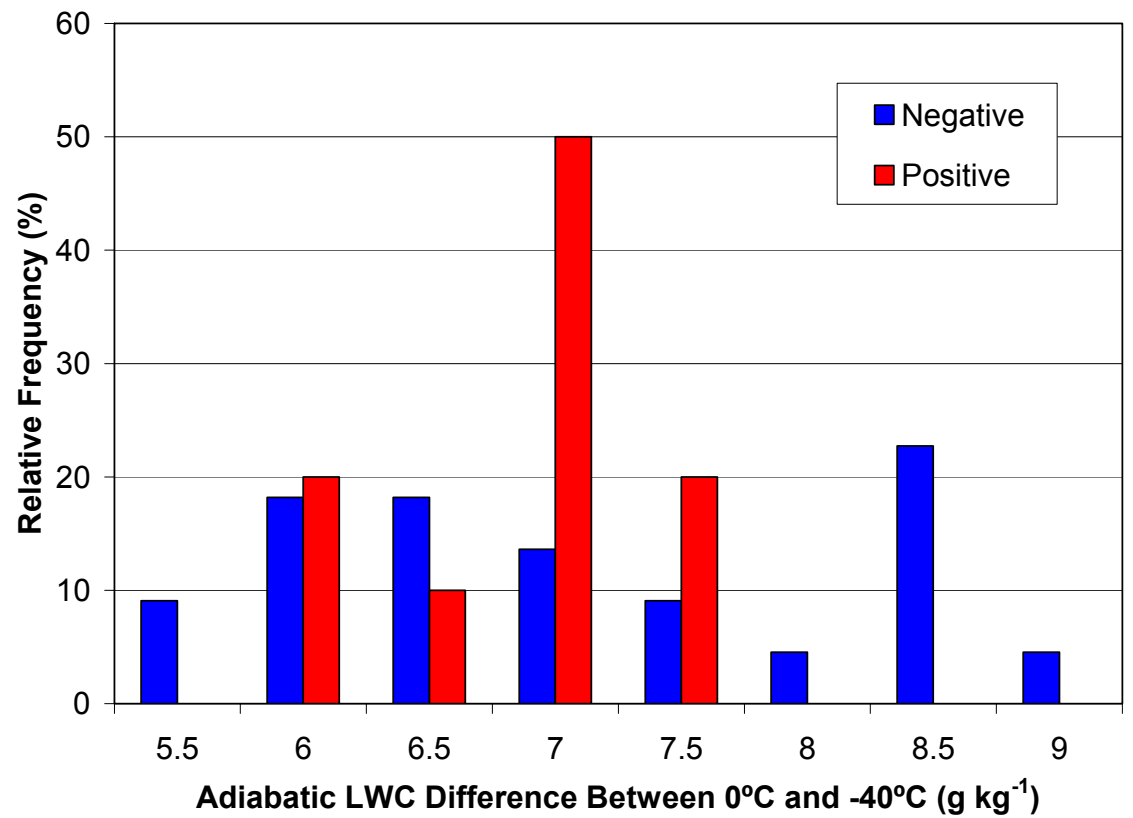

FIG. 93. Same as in Fig. 77 except for the difference in adiabatic LWC between the $0^{\circ} \mathrm{C}$ and $-40^{\circ} \mathrm{C}$ levels. 


\section{2) REGIONAL COMPARISONS}

The nine individual mesoscale regions defined in Table 3 were compared to one another to determine whether the differences discovered between the two region types in the overall grouped comparisons above were also evident between individual mesoscale regions. These regional comparisons focused on select parameters that were found to differ significantly between negative and positive regions in the overall grouped comparisons (Tables 5-8), along with a few other common parameters in the study and forecasting of severe storms (e.g., total CAPE, 0-6 km AGL shear, $\theta_{\mathrm{e}}$ ). Given the small sample size for each individual region, median values were utilized to conduct these regional comparisons (Table 10). As was the case with the overall grouped comparisons, WCD and LCL were the strongest discriminators between individual negative and positive mesoscale regions. The median LCL values for all individual positive and negative regions were distinct with values greater than and less than $1600 \mathrm{~m}$ AGL, respectively (Table 10 and Fig. 94). The median WCDs for individual positive regions were all less than $2000 \mathrm{~m}$, while the corresponding median values for negative regions were all greater than $2500 \mathrm{~m}$ (Table 10 and Fig. 95). 
Negative mesoscale regions were once again noticeably moister than positive mesoscale regions, as indicated by mean mixing ratio in the lowest $100 \mathrm{hPa}$, precipitable water between the surface and $400 \mathrm{hPa}$, and surface dewpoint depression (Table 10). Median precipitable water in negative regions was $>3.3 \mathrm{~cm}$ while it was $<3.0 \mathrm{~cm}$ in positive regions. Median surface dewpoint depression was consistently $<11^{\circ} \mathrm{C}$ in negative regions and $\geq 11^{\circ} \mathrm{C}$ in positive regions, consistent with lower and higher LCLs in each region, respectively. There was slight overlap in the median low-level mixing ratios between the two types of regions, with median values for the large majority of negative (positive) regions greater (less) than $11 \mathrm{~g} \mathrm{~kg}^{-1}$. Lapse rates between 850 and $500 \mathrm{hPa}$ proved to be consistently higher in positive mesoscale regions. Median lapse rates in the $850-500 \mathrm{hPa}$ layer were greater (less) than $7.5^{\circ} \mathrm{C} \mathrm{km}^{-1}$ for all individual positive (negative) mesoscale regions (Table 10). Lapse rates between 700 and $500 \mathrm{hPa}$ proved to be much less effective in differentiating between the two region types, with no systematic differences evident between individual negative and positive regions. 
TABLE 10. Median parameter values for the nine individual mesoscale regions investigated. Parameters listed were found to differ (i.e., significance level $\geq 90 \%$ or $\mathrm{p} \leq 0.1$ ) between negative and positive regions in the overall grouped comparisons (Tables 5-8), or are commonly-used parameters in the study and forecasting of severe storms. Only median values are directly compared here due to the small sample size for each individual region.

\begin{tabular}{|c|c|c|c|c|c|c|c|c|c|}
\hline & \multicolumn{5}{|c|}{$\begin{array}{l}\text { NEGATIVE MESOSCALE } \\
\text { REGIONS }\end{array}$} & \multicolumn{4}{|c|}{$\begin{array}{c}\text { POSITIVE MESOSCALE } \\
\text { REGIONS } \\
\end{array}$} \\
\hline & $\begin{array}{c}23 \\
\text { May }\end{array}$ & $\begin{array}{c}24 \\
\text { May }\end{array}$ & $\begin{array}{c}4 \\
\text { June }\end{array}$ & $\begin{array}{c}12 \\
\text { June }\end{array}$ & $\begin{array}{c}15 \\
\text { June }\end{array}$ & $\begin{array}{c}23 \\
\text { May }\end{array}$ & $\begin{array}{c}24 \\
\text { May }\end{array}$ & $\begin{array}{c}15 \\
\text { June }\end{array}$ & $\begin{array}{c}19 \\
\text { June }\end{array}$ \\
\hline Warm cloud depth (m) & 3140 & 2933 & 3087 & 3107 & 2597 & 1230 & 1777 & 1972 & 1157 \\
\hline LCL (m AGL) & 813 & 798 & 1040 & 1191 & 1568 & 1674 & 1717 & 1953 & 2915 \\
\hline Mean mixing ratio in the lowest $100 \mathrm{hPa}\left(\mathrm{g} \mathrm{kg}^{-1}\right)$ & 12.1 & 12.4 & 14.1 & 16.3 & 10.9 & 9.9 & 10.7 & 11.4 & 10.0 \\
\hline Precipitable water, surface to $400 \mathrm{hPa}(\mathrm{cm})$ & 3.5 & 3.4 & 3.5 & 4.2 & 3.4 & 2.4 & 2.1 & 2.9 & 2.6 \\
\hline Surface dewpoint depression $\left({ }^{\circ} \mathrm{C}\right)$ & 5.1 & 4.4 & 7.3 & 8.8 & 10.7 & 11.0 & 12.6 & 15.0 & 23.5 \\
\hline $850-500 \mathrm{hPa}$ lapse rate $\left({ }^{\circ} \mathrm{C} \mathrm{km}{ }^{-1}\right)$ & 6.5 & 6.8 & 7.1 & 7.3 & 6.9 & 8.5 & 7.9 & 8.2 & 9.1 \\
\hline 0-3 km AGL shear $\left(\mathrm{m} \mathrm{s}^{-1}\right)$ & 9.3 & 7.7 & 6.7 & 13.1 & 17.0 & 15.9 & 15.7 & 16.5 & 11.6 \\
\hline Surface temperature $\left({ }^{\circ} \mathrm{C}\right)$ & 22.0 & 22.7 & 26.4 & 30.5 & 26.8 & 23.6 & 27.1 & 29.6 & 37.0 \\
\hline $\mathrm{CIN}\left(\mathrm{J} \mathrm{kg}^{-1}\right)$ & 100 & 52 & 46 & 11 & 213 & 7 & 2 & 21 & 17 \\
\hline $700-500 \mathrm{hPa}$ lapse rate $\left({ }^{\circ} \mathrm{C} \mathrm{km}{ }^{-1}\right)$ & 8.6 & 7.8 & 7.4 & 8.1 & 7.2 & 8.2 & 7.6 & 7.8 & 9.1 \\
\hline $0-2 \mathrm{~km}$ AGL storm-relative wind speed $\left(\mathrm{m} \mathrm{s}^{-1}\right)$ & 10.0 & 18.0 & 7.0 & 19.5 & 22.0 & 20.0 & 13.0 & 26.0 & 16.0 \\
\hline NCAPE, LFC to $-40^{\circ} \mathrm{C}\left(\mathrm{m} \mathrm{s}^{-2}\right)$ & 0.12 & 0.18 & 0.19 & 0.23 & 0.10 & 0.22 & 0.16 & 0.25 & 0.26 \\
\hline CAPE, $-10^{\circ} \mathrm{C}$ to $-40^{\circ} \mathrm{C}\left(\mathrm{J} \mathrm{kg}^{-1}\right)$ & 546 & 894 & 1005 & 1089 & 458 & 1099 & 772 & 1324 & 1299 \\
\hline NCAPE, $-10^{\circ} \mathrm{C}$ to $-40^{\circ} \mathrm{C}\left(\mathrm{m} \mathrm{s}^{-2}\right)$ & 0.14 & 0.21 & 0.25 & 0.27 & 0.11 & 0.26 & 0.19 & 0.31 & 0.33 \\
\hline NCAPE, LFC to EL $\left(\mathrm{m} \mathrm{s}^{-2}\right)$ & 0.11 & 0.17 & 0.20 & 0.20 & 0.10 & 0.21 & 0.15 & 0.22 & 0.27 \\
\hline CAPE, LFC to EL $\left(\mathrm{J} \mathrm{kg}^{-1}\right)$ & 845 & 1594 & 1972 & 2263 & 490 & 2078 & 1273 & 1778 & 2335 \\
\hline CAPE, LFC to $-40^{\circ} \mathrm{C}\left(\mathrm{J} \mathrm{kg}^{-1}\right)$ & 669 & 1108 & 1294 & 1766 & 489 & 1383 & 874 & 1526 & 1465 \\
\hline 0-6 km AGL shear $\left(\mathrm{m} \mathrm{s}^{-1}\right)$ & 12.9 & 19.5 & 11.8 & 22.9 & 30.9 & 24.7 & 18.0 & 22.1 & 9.3 \\
\hline Equivalent potential temperature $\left({ }^{\circ} \mathrm{C}\right)$ & 59.8 & 63.9 & 72.2 & 83.9 & 62.6 & 66.3 & 66.5 & 75.1 & 76.9 \\
\hline
\end{tabular}




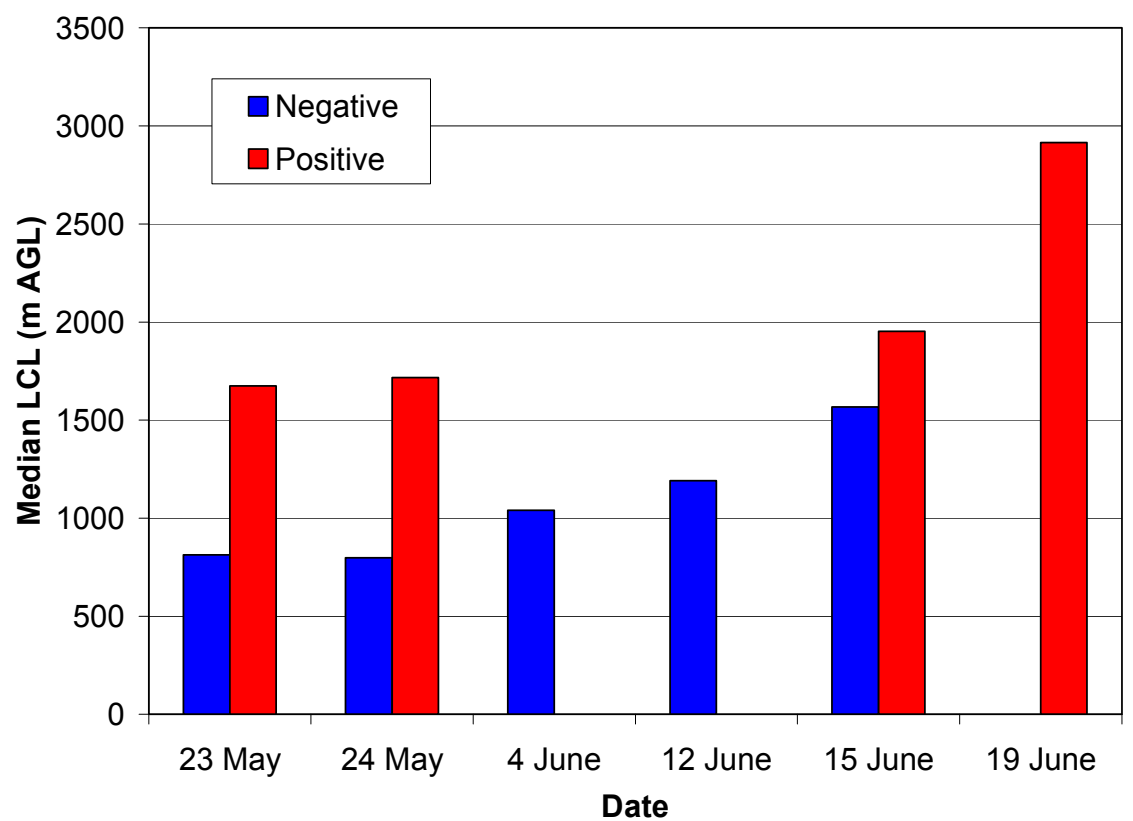

FIG. 94. Median LCL values for the nine individual mesoscale regions.

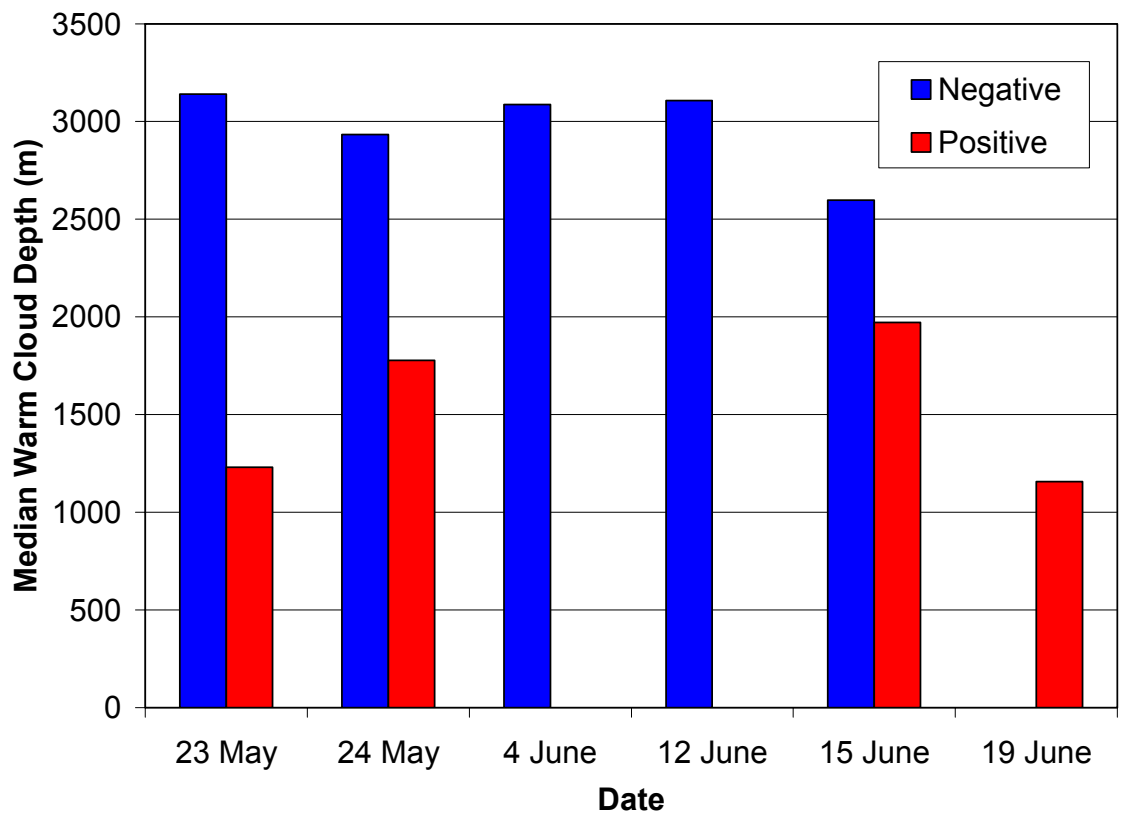

FIG. 95. Median WCD values for the nine individual mesoscale regions. 
While WCD, LCL, moisture parameters (mean mixing ratio in the lowest 100 $\mathrm{hPa}$, precipitable water between the surface and $400 \mathrm{hPa}$, and surface dewpoint depression), and 850-500 $\mathrm{hPa}$ lapse rates most effectively distinguished individual negative and positive regions, other parameters showed some limited ability to differentiate between the two types of CG lightning behavior. However, the differences in these other parameters were less consistent and less distinct than for the parameters just mentioned. For instance, median CIN values tended to be larger in negative regions. However, there were exceptions to this tendency, as the 15 June and 19 June positive mesoscale regions were characterized by greater median CIN values than the 12 June negative mesoscale region. CAPE and NCAPE in the $-10^{\circ} \mathrm{C}$ to $-40^{\circ} \mathrm{C}$ layer, NCAPE between the LFC and $-40^{\circ} \mathrm{C}$ level, and NCAPE between the LFC and EL were generally greater in positive regions. However, this trend was only true in a general sense, as there was considerable intra-category variability in these parameters, and much more overlap in median values between individual negative and positive mesoscale regions than in the overall grouped comparisons (c.f. Tables 7-8 and 10). Low-level (0-3 km AGL) shear also tended to be stronger in individual positive regions than in negative regions, but there were again exceptions to this tendency. For instance, the 15 June negative region was characterized by the strongest median shear of all regions, and low-level shear in the 19 June positive region was weaker than in both the 12 June and 15 June negative regions. There was a weak tendency for surface temperature to be warmer in individual positive mesoscale regions, but this trend was rather ill-defined, with several exceptions to it, along with small differences in magnitude between median values of the two region 
types (with exception of the 19 June positive region). Although 0-2 km AGL stormrelative wind speeds were significantly greater in positive regions in the overall grouped comparisons, there was little evidence of this in the comparisons of individual mesoscale regions (Table 10). Consistent with the results of the overall grouped comparisons, no systematic differences were found in total CAPE (LFC to EL), CAPE between the LFC and $-40^{\circ} \mathrm{C}$ level, deep-layer $(0-6 \mathrm{~km} \mathrm{AGL})$ shear, and $\theta_{\mathrm{e}}$ between individual negative and positive mesoscale regions.

Scatter plots combining some of the parameters found to most effectively distinguish individual negative and positive mesoscale regions are presented in Figs. 96 and 97. These plots include depictions of LCL, NCAPE between the LFC and $-40^{\circ} \mathrm{C}$ level, and 0-3 km AGL shear (Fig. 96); and WCD, 850-500 hPa lapse rates, and 0-3 km AGL shear (Fig. 97). WCD and LCL heights were responsible for much of the separation between negative and positive regions, with $850-500 \mathrm{hPa}$ lapse rates also distinctly separating the two region types. There was more overlap between individual negative and positive regions for medians of 0-3 km AGL shear and NCAPE between the LFC and $-40^{\circ} \mathrm{C}$ level. ${ }^{14}$ WCD produced slightly greater separation between the populations of negative and positive regions than did LCL, while 850-500 hPa lapse rates differentiated more distinctly between the two region types than did NCAPE between the LFC and $-40^{\circ} \mathrm{C}$ level (c.f. Figs. 96 and 97). Hence, the combination of

\footnotetext{
${ }^{14}$ As expected given the strong correlation between low-level moisture and LCL (and thereby WCD), substitution of moisture parameters (mean mixing ratio in the lowest $100 \mathrm{hPa}$, surface dewpoint depression, or precipitable water between the surface and $400 \mathrm{hPa}$ ) for either LCL or WCD produced similar results to the plots shown in Figs. 96 and 97 (not shown). Also, substitution of NCAPE or CAPE in the $-10^{\circ} \mathrm{C}$ to $-40^{\circ} \mathrm{C}$ layer for NCAPE between the LFC and $-40^{\circ} \mathrm{C}$ level yielded similar results to the included plots.
} 
WCD and 850-500 hPa lapse rates served as the strongest two-dimensional discriminator between negative and positive regions, with the tertiary parameter $0-3 \mathrm{~km}$ AGL shear showing some lesser ability to differentiate between the two region types.

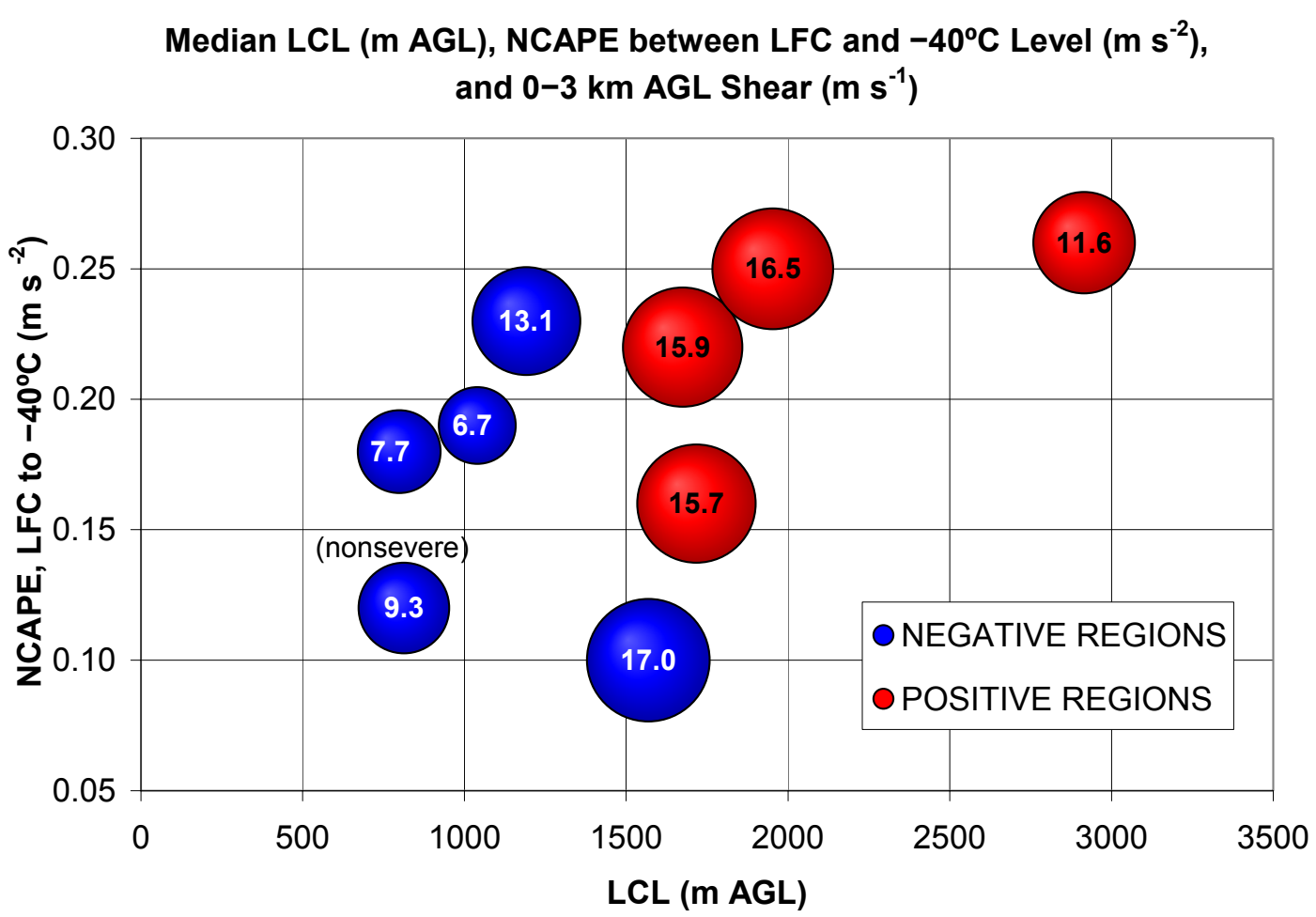

FIG. 96. Scatter plot of the median NCAPE between the LFC and $-40^{\circ} \mathrm{C}$ level versus the median LCL height for each of the nine mesoscale regions. The size of each bubble in the scatter plot is proportional to the median 0-3 km AGL shear magnitude in each region, which is indicated by the label on each bubble. The 23 May negative mesoscale region, which was the only region not characterized by widespread severe storms, is labeled as "nonsevere". 
Median Warm Cloud Depth (m), 850-500 hPa Lapse Rate $\left({ }^{\circ} \mathrm{C} \mathrm{km}^{-1}\right)$, and 0-3 km AGL Shear $\left(\mathrm{m} \mathrm{s}^{-1}\right)$

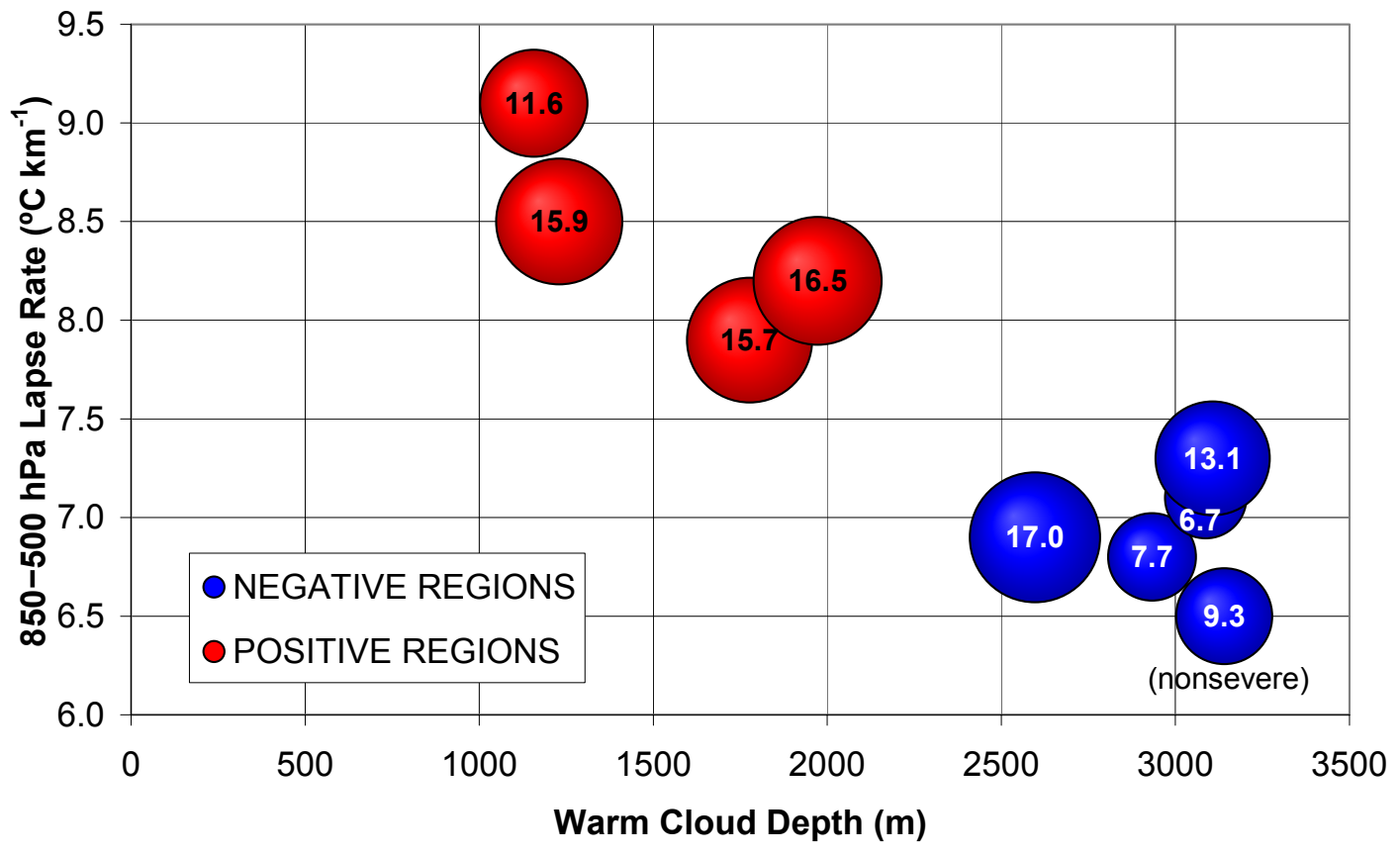

FIG. 97. Same as in Fig. 96 except for median 850-500 hPa lapse rate versus median WCD for each individual mesoscale region. As in Fig. 96, bubble size and labels represent median 0-3 km AGL shear for each region.

The contribution of each parameter to modulating updraft strength and supercooled liquid water content may not be equal, possibly explaining some of the overlap in median values evident in the comparisons of individual positive and negative mesoscale regions (Table 10). Rather, one parameter may compensate for another. For example, on 15 June the positive region LCL (WCD) was only slightly higher (smaller) than in the negative region on the same day. However, the positive region CAPE between $-10^{\circ} \mathrm{C}$ and $-40^{\circ} \mathrm{C}\left(\mathrm{NCAPE}\right.$ from $\mathrm{LFC}$ to $-40^{\circ} \mathrm{C}$ ) was $2.9(2.5)$ times larger than in the negative region on 15 June such that the positive region updraft was apparently still stronger. It is also important to recall that the sample size for each individual region is 
relatively small so that regional differences (or lack thereof) must be viewed with some caution.

\section{(i) Daily Comparisons}

A key finding of previous case studies was the observation that storms on the same day passing over similar mesoscale regions produced similar CG lightning behavior (e.g., Branick and Doswell 1992; MacGorman and Burgess 1994; Smith et al. 2000). To investigate this issue, the environmental conditions in positive and negative storm regions occurring adjacent to each other on the same day were compared.

Opportunities for a daily comparison of positive and negative mesoscale regions were available on 23 and 24 May and 15 June. The median positive and negative region values of WCD, LCL, precipitable water, surface dewpoint depression, 850-500 hPa lapse rate, surface temperature, and CIN were significantly different on a daily basis (Table 10), and these differences were consistent with the overall grouped results (Tables 5-7). The daily comparisons of positive and negative mesoscale regions for the rest of the environmental parameters in Table 10 produced somewhat mixed results, which were not always consistent with the overall grouped results. For example, the median low-level mixing ratio was somewhat larger and the 0-3 $\mathrm{km}$ AGL shear was somewhat smaller in the positive region on 15 June. Similarly, the median 0-2 km AGL storm-relative wind speed, $\mathrm{NCAPE}\left(\mathrm{LFC}\right.$ to $-40^{\circ} \mathrm{C},-10^{\circ} \mathrm{C}$ to $-40^{\circ} \mathrm{C}, \mathrm{LFC}$ to $\mathrm{EL}$ ), and CAPE $\left(-10^{\circ} \mathrm{C}\right.$ to $\left.-40^{\circ} \mathrm{C}\right)$ were all larger in the negative mesoscale region on 24 May. Lapse rates in the 700-500 $\mathrm{hPa}$ layer were larger in the negative mesoscale region on both 23 and 24 May, inconsistent with the overall grouped results. Similar to the overall 
grouped results, no systematic differences in total CAPE (LFC to EL), CAPE between the LFC and $-40^{\circ} \mathrm{C}$ level, or 0-6 km AGL shear were evident in the daily comparisons of negative and positive mesoscale regions (Table 10). Finally, median $\theta_{\mathrm{e}}$ values were higher in positive regions for all three days on which daily comparisons were possible. However, the magnitude of the differences in median $\theta_{\mathrm{e}}$ values between negative and positive regions within the same day varied considerably, from $2.6^{\circ} \mathrm{C}$ on 24 May to $12.5^{\circ} \mathrm{C}$ on 15 June.

Sometimes the daily differences in medians between positive and negative regions were quite dramatic (Table 10). On 23 and 24 May, the median WCD was 2.6 and 1.7 times smaller, the median LCL was 2.1 and 2.2 times higher, the median surface dewpoint depression was 2.2 and 2.9 times larger, and the median 0-3 km AGL shear was 1.7 and 2.0 times larger in the positive mesoscale region, respectively. The median 0-2 km AGL storm-relative wind speed was 2.0 times larger in the positive region on 23 May. On 15 June, the median NCAPE (LFC to $\left.-40^{\circ} \mathrm{C}\right)$ and CAPE $\left(-10^{\circ} \mathrm{C}\right.$ to $\left.-40^{\circ} \mathrm{C}\right)$ values were 2.5 and 2.9 times larger in the positive region, respectively.

\section{3) INTRAREGIONAL VARIATION OF ENVIRONMENTAL CONDITIONS}

Dropsondes released from the FI Learjet on 24 May and 19 June permitted the investigation of two different positive storm environments at a very high spatial and temporal resolution. The 24 May dropsondes were released in the eastern Texas panhandle and southwest Oklahoma (Fig. 98a), while the 19 June dropsondes were released over northwest Kansas (Fig. 98b). The dropsonde lines on both days were 
approximately perpendicular to the surface boundaries associated with convective initiation (CI; Figs. 30, 51, and 98) and the near-surface $\theta_{\mathrm{e}}$ ridge (Figs. 32, 50, and 98). The dropsonde line on 24 May was roughly parallel to subsequent storm motion (i.e., eastward storm motion). On 19 June, individual cell motion was roughly perpendicular to the dropsonde line (i.e., to the northeast), while overall system motion was roughly parallel to the dropsonde line (i.e., to the southeast). As shown in Fig. 99, CG lightning polarity transitioned from positive to negative as storms in the vicinity of the 24 May dropsondes moved from west to east across Oklahoma and away from the dryline. Although the dropsondes were dropped entirely in the positive mesoscale region, the positive CG percentage generally decreased from west to east within the identified positive region (Fig. 99). By contrast, all storms over northwest Kansas and southwest Nebraska on 19 June were strongly positive (Fig. 100).

\section{(i) Dropsonde-derived environmental parameters}

Parameters that were found to differ significantly and consistently between negative and positive regions in the overall grouped and regional comparisons above were calculated for the 24 May and 19 June dropsondes, and their horizontal structures along the Learjet flight tracks are shown in Figs. 101-104. On 24 May, a cold front was located between the locations of the 2025 and 2031 UTC dropsondes. There was also a dryline intersecting the cold front, forming a triple point in the vicinity of the Learjet flight track (Fig. 30). The dryline ran between the 2031 and 2034 UTC dropsondes (Figs. 101, 102), and this is where CI occurred as determined from satellite imagery 
(Fig. 98a). On 19 June, CI occurred (Fig. 98b) along a cold front located between the 2122 and 2125 UTC dropsondes (Figs. 103, 104).
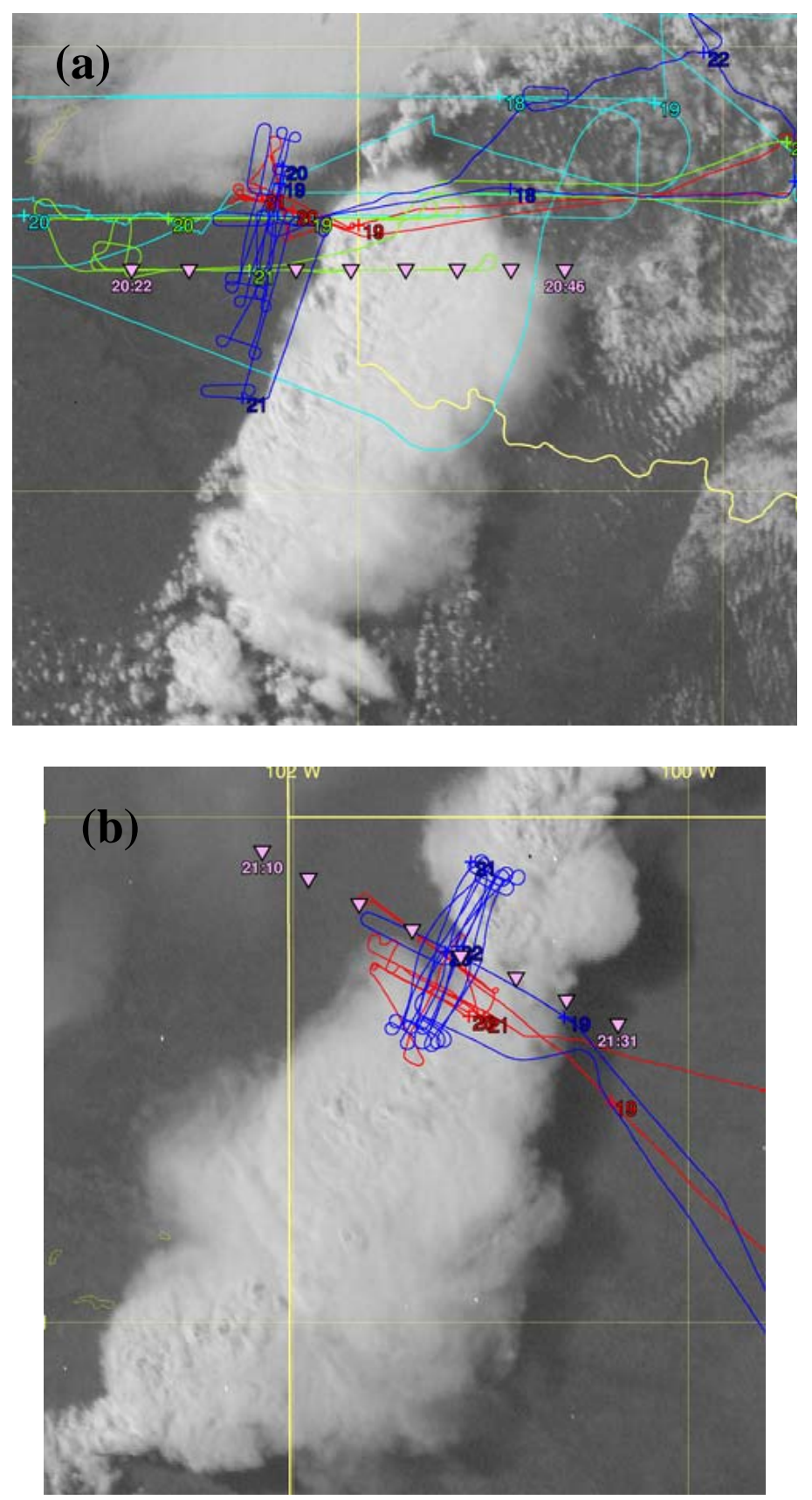

FIG. 98. Visible satellite images in the vicinity of dropsondes released by the Learjet on (a) 24 May 2002 and (b) 19 June 2002. Pink triangles denote dropsonde locations, with the release times (in UTC) of the first and last dropsondes of each run listed. The third dropsonde from the right in (a) was not used in this study due to bad data quality. All dropsondes in (b) were used. 
Percent Positive Flashes 05/24/02 20:00:00-02:00:00Z

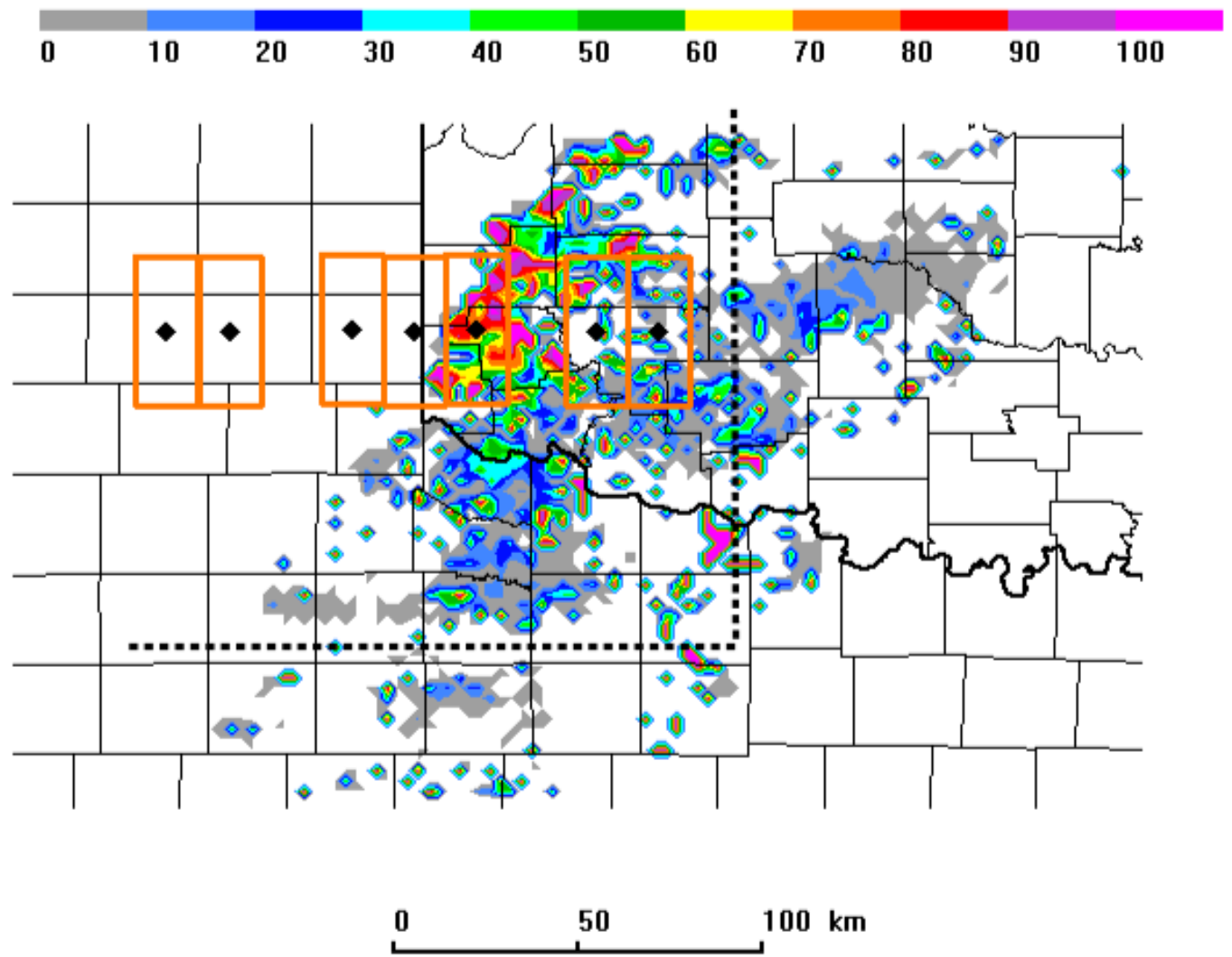

FIG. 99. Percent positive flashes (\%) for 2000 UTC 24 May 2002-0200 UTC 25 May 2002. Black diamonds indicate dropsonde locations (from left to right, dropsonde release times were 2022, 2025, 2031, 2034, 2037, 2043, and 2046 UTC). Dropsondes released at 2028 and 2040 UTC contained bad data and thus were not used. Orange rectangles (north-south dimension $=80 \mathrm{~km}$, east-west dimension $=27.4 \mathrm{~km}$ ) centered on dropsonde locations denote the areas for which CG flash characteristics (number of negative flashes, number of positive flashes, and percent positive flashes) were determined. The area to the north and west of the dashed line is the positive mesoscale region. The plot is centered over the eastern Texas panhandle, north-central Texas, and southwest Oklahoma. 
Percent Positive Flashes 06/19/02 18:00:00-03:00:00Z

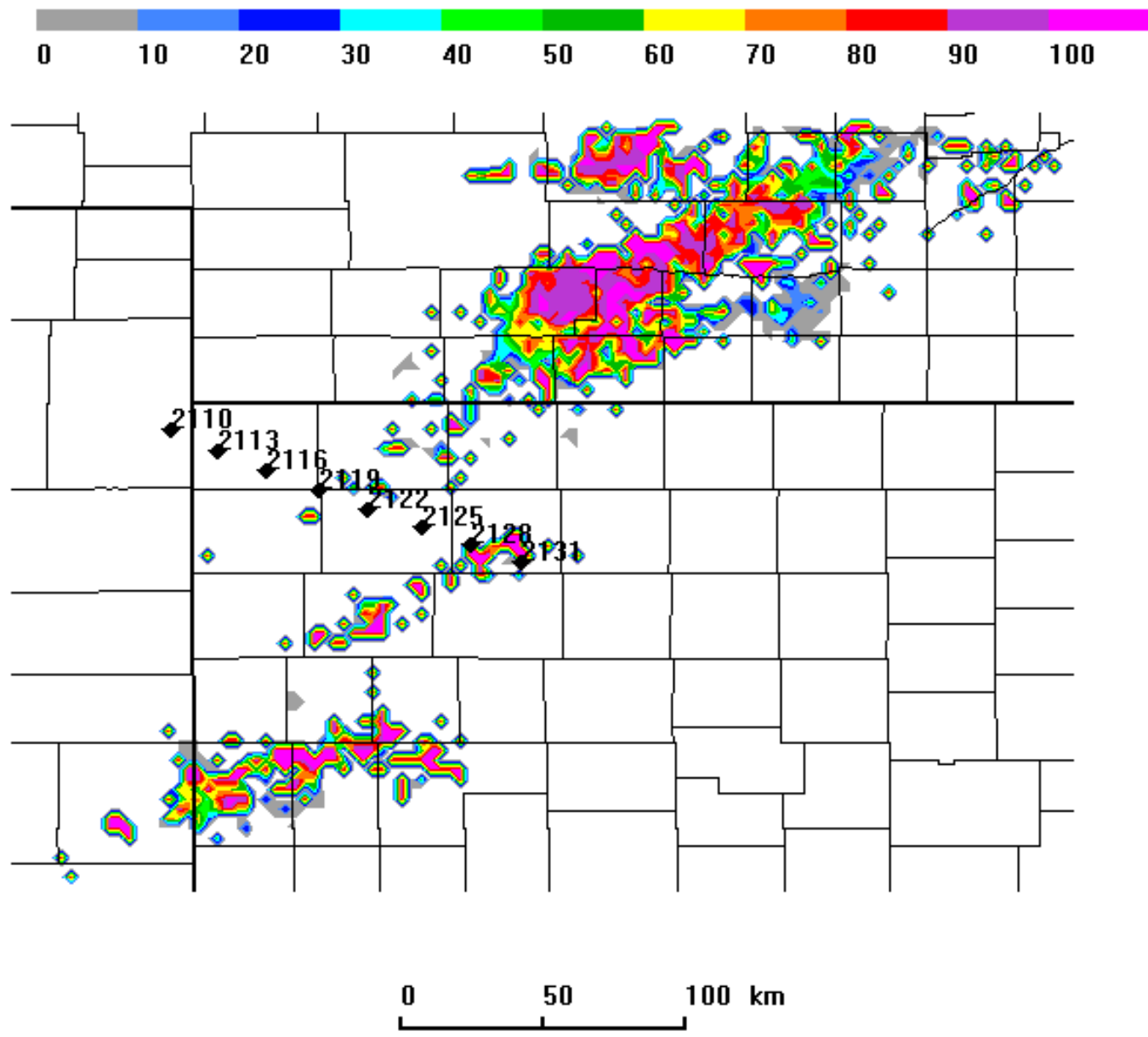

FIG. 100. Percent positive flashes (\%) for 1800 UTC 19 June 2002-0300 UTC 20 June 2002. Black diamonds indicate dropsonde locations, with time (UTC) of each dropsonde release shown. Plot is centered over northwest Kansas and southwest Nebraska. 


\section{May 2002 Dropsondes}

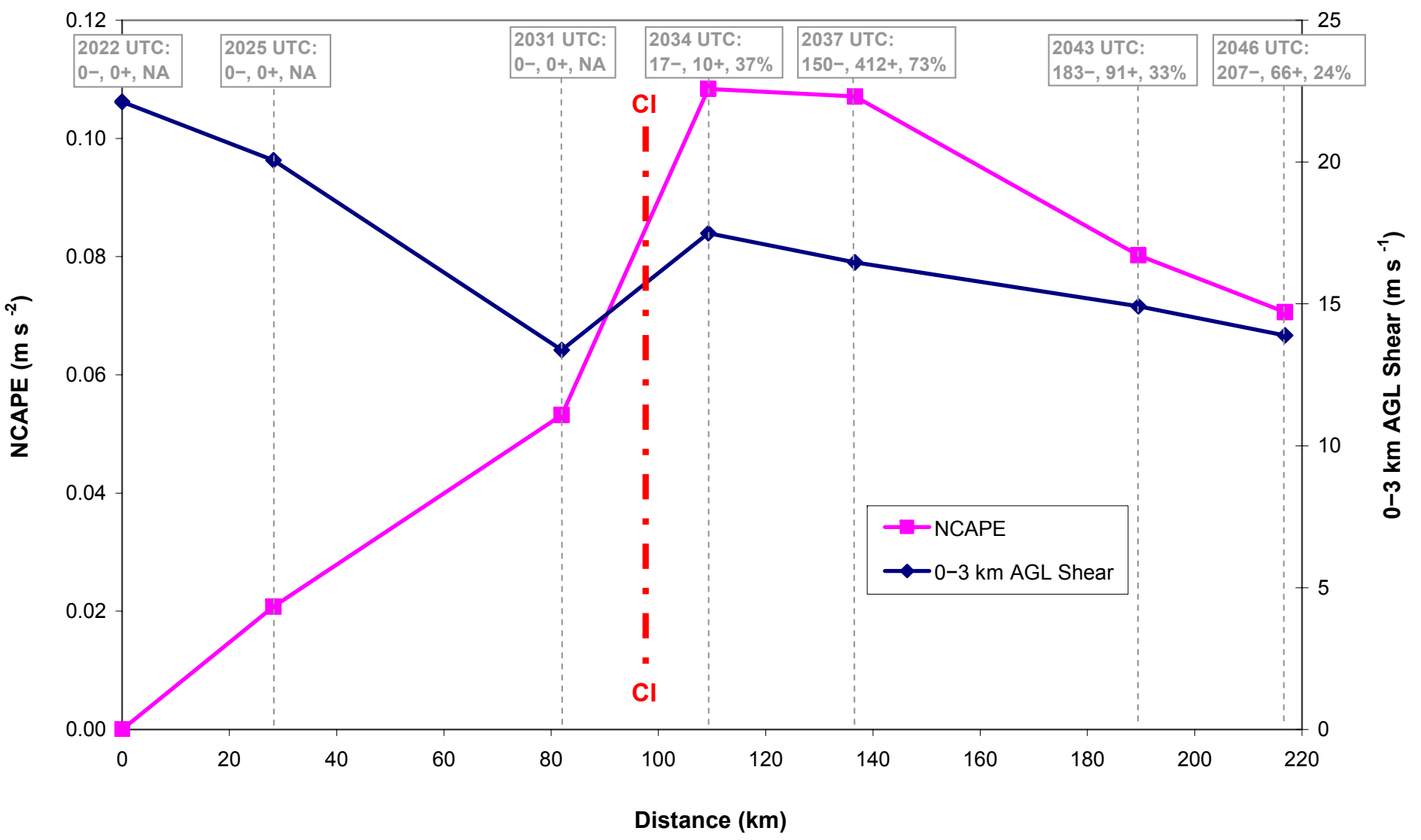

FIG. 101. NCAPE and low-level (0-3 km AGL) shear calculated from the 24 May 2002 dropsondes as a function of distance along the Learjet flight track. The time of each dropsonde release is indicated and annotated by the dashed gray lines. The number of negative and positive CG flashes and percent positive CG flashes for storms within each orange rectangular box in Fig. 99 are shown. The red dash-dot line shows the location of CI along the Learjet flight track. 


\section{May 2002 Dropsondes}

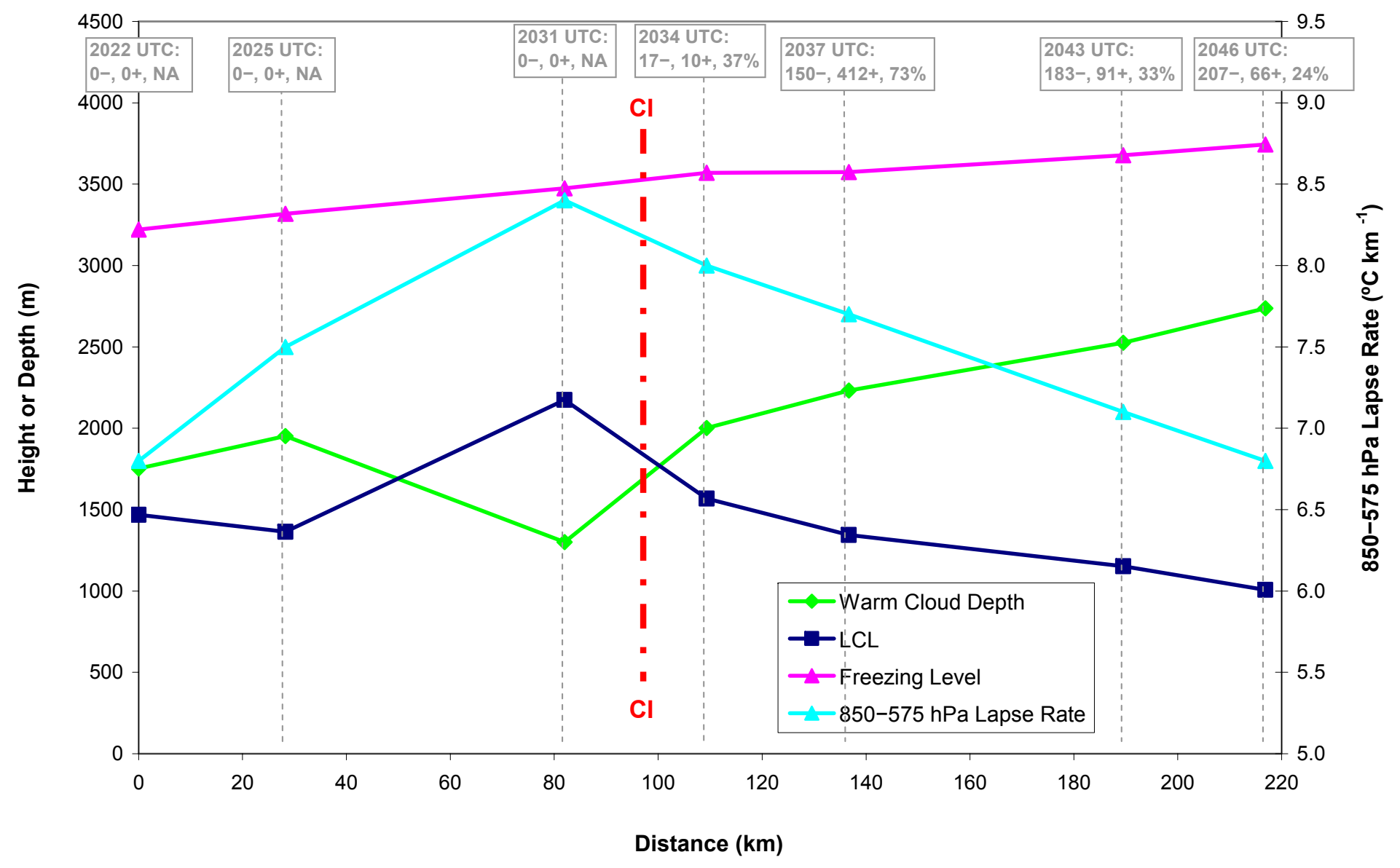

FIG. 102. Same as in Fig. 101 except for WCD, LCL, freezing level, and 850-575 hPa lapse rate. LCL and freezing level heights are AGL. 


\section{June 2002 Dropsondes}

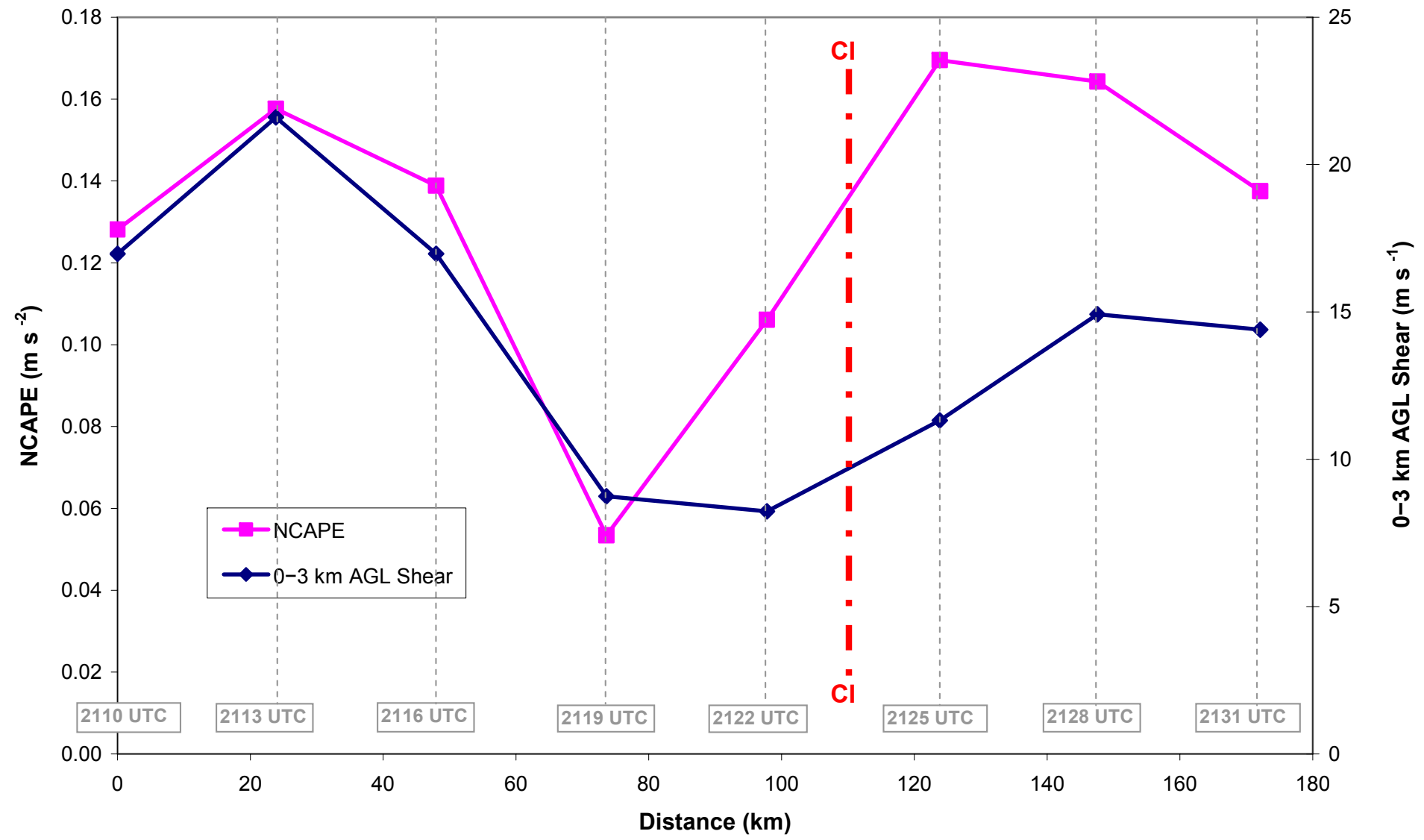

FIG. 103. Same as in Fig. 101 except for the 19 June 2002 dropsondes. The CG lightning polarity was overwhelming positive for the entire region $(+\mathrm{CG} \%=71.5 \%)$. Due to this uniform behavior, CG flash characteristics were not computed for each individual dropsonde location on 19 June 2002. 


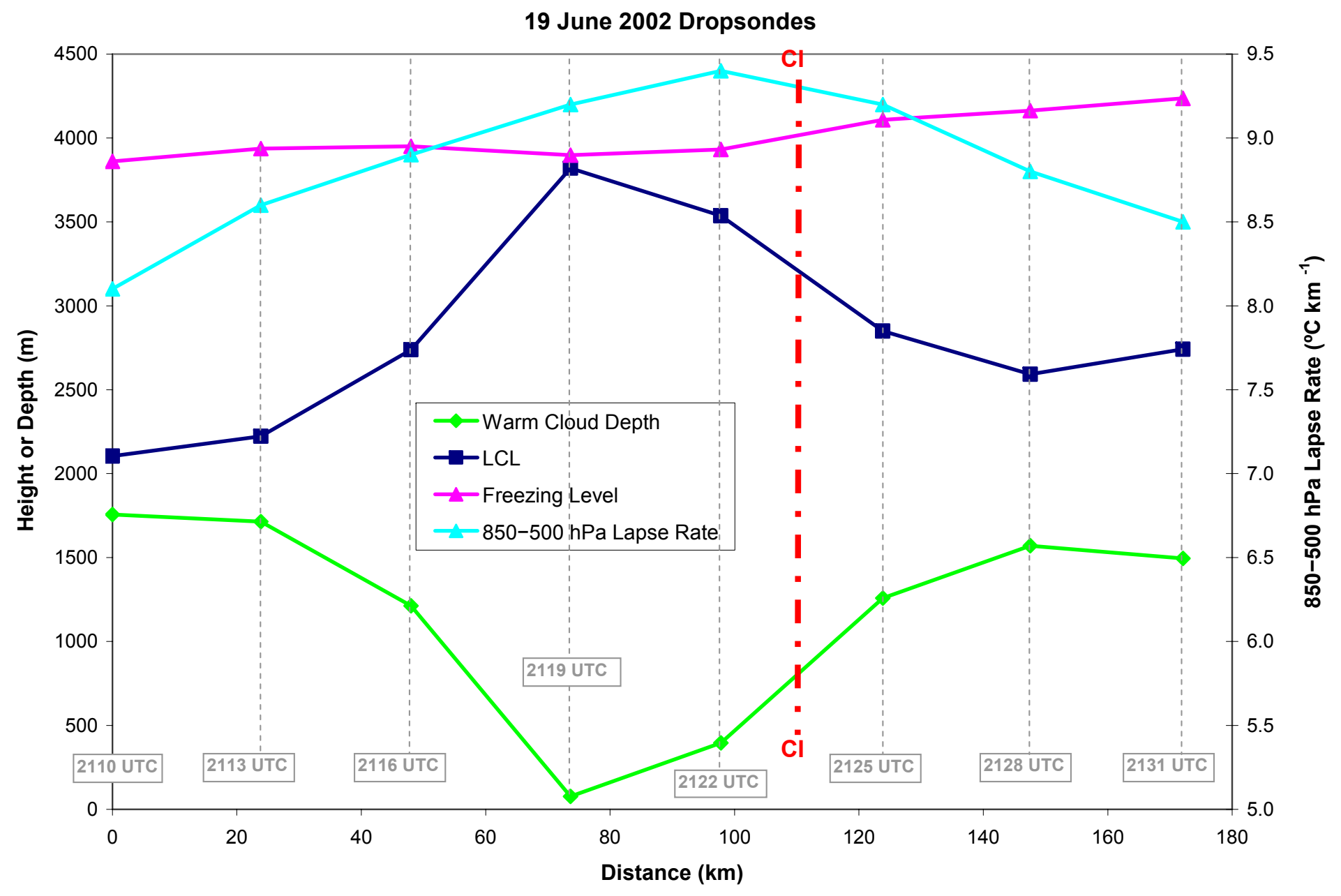

FIG. 104. Same as in Fig. 103 except for WCD, LCL, freezing level, and 850-500 hPa lapse rate. LCL and freezing level heights are AGL. 
On 24 May, NCAPE rapidly increased in the vicinity of the dryline, where convection initiated, and peaked at about $0.11 \mathrm{~m} \mathrm{~s}^{-2}$ just $10-40 \mathrm{~km}$ eastward into the warmer and moister air (Fig. 101). Although low-level shear was stronger rearward (i.e., westward) of the dryline and cold front, a relative maxima in the 0-3 km AGL shear $\left(17.5 \mathrm{~m} \mathrm{~s}^{-1}\right)$ was located just east of the dryline at $110 \mathrm{~km}$ (Fig. 101). As a result, the developing convection on 24 May experienced initially increasing and near peak values of NCAPE and low-level shear. The positive CG flash percentage also rapidly increased eastward of the dryline to a maximum value of $73 \%$ at a point centered just $35 \mathrm{~km}$ eastward (i.e., at $135 \mathrm{~km}$ along the Learjet flight track), apparently in response to these elevated values of NCAPE and low-level shear. Moving farther eastward, the NCAPE decreased dramatically (by 36\%) and the low-level shear dropped slightly. At the same time, the positive CG percentage also decreased significantly from the peak of $73 \%$ to only $24 \%$, which is just below the subjective threshold required for positive storm status. The height of the LCL peaked just $20 \mathrm{~km}$ west of the dryline (Fig. 102). Initial convection on 24 May was associated with an LCL of approximately $1850 \mathrm{~m}$ AGL, based on linear interpolation between the values measured by the 2031 and 2034 UTC dropsondes. The LCL continued to decrease eastward, reaching $1000 \mathrm{~m}$ AGL at the last dropsonde located at $217 \mathrm{~km}$ along the Learjet flight track (i.e., about $120 \mathrm{~km}$ east of where convection initiated). The height of the freezing level gradually increased eastward along the flight track. Combining the LCL and freezing level heights on 24 May in Fig. 102, the WCD increased noticeably eastward of the dryline from about 1700 $\mathrm{m}$ where convection initiated to just above $2700 \mathrm{~m}$ about $120 \mathrm{~km}$ east of the point of CI. 
The $850-575 \mathrm{hPa}$ lapse rates peaked at $8.4^{\circ} \mathrm{C} \mathrm{km}^{-1}$ just west of where convection initiated, and steadily decreased to the east, reaching a value of $6.8^{\circ} \mathrm{C} \mathrm{km}^{-1}$ at the last dropsonde location, about $120 \mathrm{~km}$ east of CI (Fig. 102). The dramatic decrease in the percentage of positive CG flashes eastward of the dryline on 24 May was accompanied by a slight increase in the freezing level, a significant lowering of the LCL, an associated noteworthy increase in the WCD, and a modest decrease in the $850-575 \mathrm{hPa}$ lapse rate. These trends are consistent with the relationships found between CG flash polarity and these environmental parameters in the overall grouped and regional comparisons.

On 19 June, NCAPE and 0-3 km AGL shear were at a minimum just behind (i.e., northwest of) the cold front along which CI occurred and at a maximum within 15 to 40 $\mathrm{km}$ ahead (i.e., southeast) of the front (Fig. 103). Low-level shear increased and then remained steady southeast of the front while NCAPE decreased slightly at first and then more rapidly toward the end of the Learjet flight track. The peak value of NCAPE on 19 June was about $0.17 \mathrm{~m} \mathrm{~s}^{-2}$, which is roughly $50 \%$ larger than for 24 May. The $0-3 \mathrm{~km}$ AGL shear was generally lower on 19 June, with values ranging from 10 to $15 \mathrm{~m} \mathrm{~s}^{-1}$. The LCL peaked behind the cold front, yet was noticeably high just ahead of the cold front where CI occurred (i.e., approximately 3200 m AGL; Fig. 104). The LCL never dropped below $2500 \mathrm{~m}$ AGL in areas associated with convection on 19 June. The freezing level increased by several hundred meters ahead of the cold front (Fig. 104). The WCD in the vicinity of CI on 19 June was very low, about $800 \mathrm{~m}$, and then increased to the southeast. However, the WCD never exceeded $1600 \mathrm{~m}$ in the vicinity of convection along the Learjet flight track on 19 June (Fig. 104), which is significantly 
less than the corresponding maximum WCD on 24 May. The trend in 850-500 hPa lapse rates on 19 June was similar to 24 May, with lapse rates peaking just rearward of where convection initiated and steadily decreasing to the southeast. However, lapse rates were much steeper on 19 June, remaining at or above $8.5^{\circ} \mathrm{C} \mathrm{km}^{-1}$ at all points where convection occurred along the Learjet flight track (Fig. 104). As with the 24 May case, the 19 June dropsonde data support the tendency for elevated LCLs, shallow WCDs, increased NCAPE, stronger low-level shear, and larger 850-500 hPa lapse rates with positive storms, as was found in the overall grouped and regional comparisons.

(ii) Buoyancy and associated horizontal buoyancy gradients

Recent studies (e.g., Markowski et al. 1998; Rasmussen et al. 2000) have suggested the importance of the baroclinic generation of horizontal vorticity along preexisting boundaries for tornado production in supercells. Horizontal vorticity generated in this manner can be stretched by inflow air, tilted into the vertical by the updraft, and further stretched by the updraft. Given the prevalence of positive storms in areas of strong surface $\theta_{\mathrm{e}}$ gradient, Carey et al. (2003b) noted that horizontal buoyancy gradients might also affect storm dynamics and hence updraft strength, cloud electrification, and lightning production in a similar manner.

To investigate this general idea, vertical cross-sections of buoyancy (B) and the horizontal buoyancy gradient $(\mathrm{dB} / \mathrm{dH})$ along the Learjet flight track in the horizontal $(\mathrm{H})$ were created (Figs. 105-108). On 24 May, negative buoyancy was present in the relative cool, stable air behind the cold front $(\mathrm{H}=0-70 \mathrm{~km})$ with a minimum value between 800 and $700 \mathrm{hPa}$ (Fig. 105). Positive buoyancy was located eastward of the dryline $(\mathrm{H}>70$ 
$\mathrm{km}$ ) at pressures less than about $800 \mathrm{hPa}$, with maximum values associated with the flight level pressure $(\sim 575 \mathrm{hPa})$ of the Learjet where the dropsondes originated on 24 May. Contours of positive buoyancy sloped westward and upward in the vicinity of the dryline and cold front where CI occurred, over the top of the negative buoyancy associated with stable air below $(\mathrm{H}=40-110 \mathrm{~km}$; pressure $=750-575 \mathrm{hPa})$. Within about $10-15 \mathrm{~km}$ eastward of where convection initiated, the buoyancy contours associated with the positive maximum were relatively horizontal, or constant at fixed pressure. The sloped buoyancy lines associated with the dryline and cold front aloft resulted in a positive peak $\left(3-4 \times 10^{-6} \mathrm{~s}^{-2}\right)$ in the horizontal buoyancy gradient along the dryline/cold front boundary aloft (Fig. 106), which begins at and extends above cloud base height (LCL) in the vicinity of CI.

On 19 June, the cold front made for a more complex pattern in the buoyancy and horizontal buoyancy gradient in the vertical (Figs. 107, 108). Nonetheless, the general pattern in the vicinity of the cold front aloft where CI occurred is generally the same as on 24 May. A positive buoyancy maximum occurred at flight level ( $455 \mathrm{hPa})$ just forward (i.e., southeastward) of the cold front $(\mathrm{H}=120-150 \mathrm{~km})$ and the buoyancy was generally positive above the LCL. The buoyancy contours sloped rearward (i.e., northwestward) and upward in the vicinity of the cold front $(\mathrm{H}=80-120 \mathrm{~km}$; Fig. 107), resulting in a positive horizontal buoyancy gradient (peak value of 5-6 $610^{-6} \mathrm{~s}^{-2}$ ) over the top of the cold front (Fig. 108) extending from cloud base upward to where the vertical cross-section terminates at flight level (i.e., pressure $=600-455 \mathrm{hPa}$ ). 

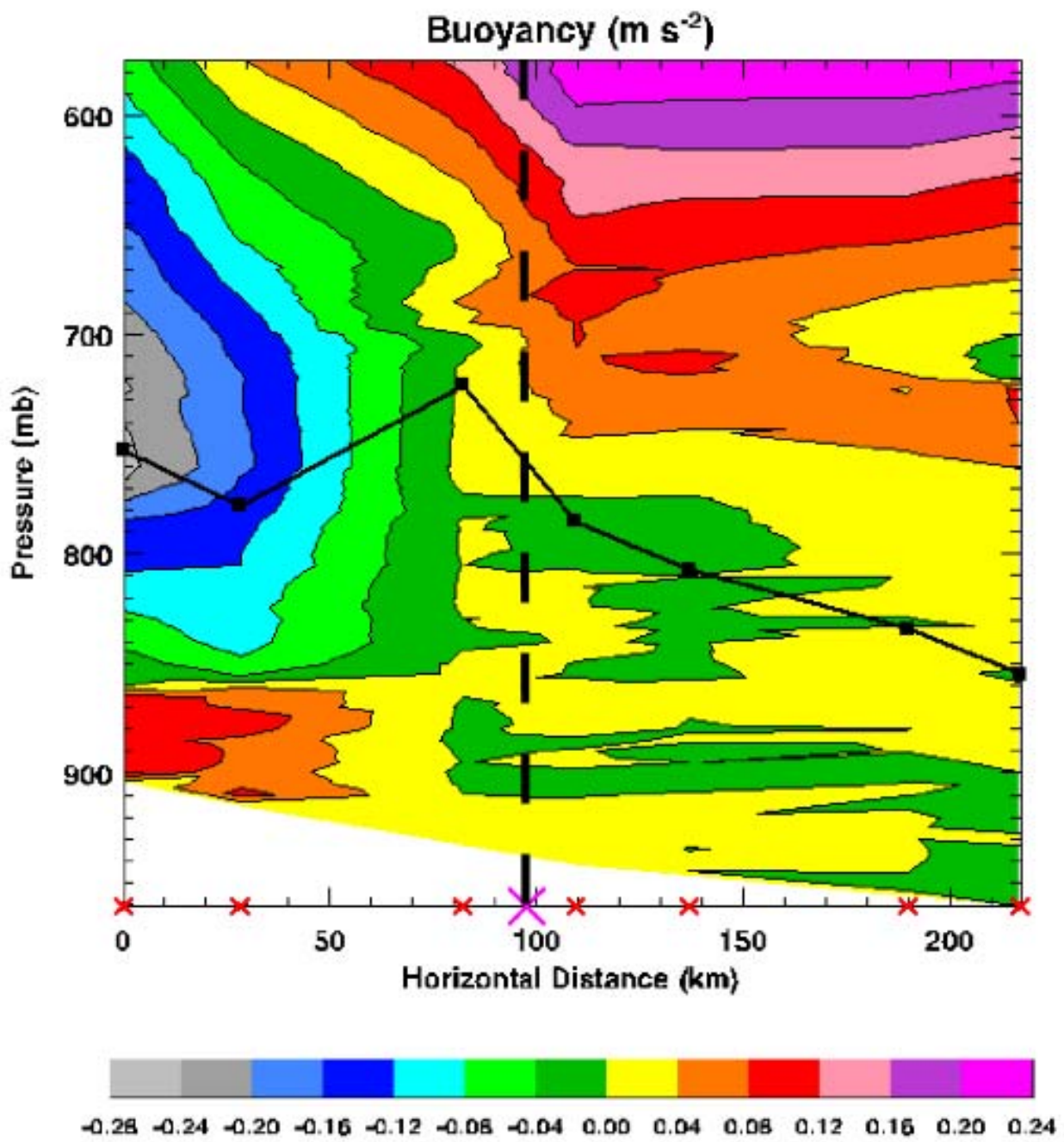

FIG. 105. Vertical cross-section of buoyancy (B) calculated from the dropsonde data as a function of horizontal distance along the Learjet flight track on 24 May 2002. The solid black line indicates LCL height. The large magenta $\mathrm{X}$ and dashed black line mark the location of CI along the Learjet flight track. The small red x's mark the dropsonde positions. 

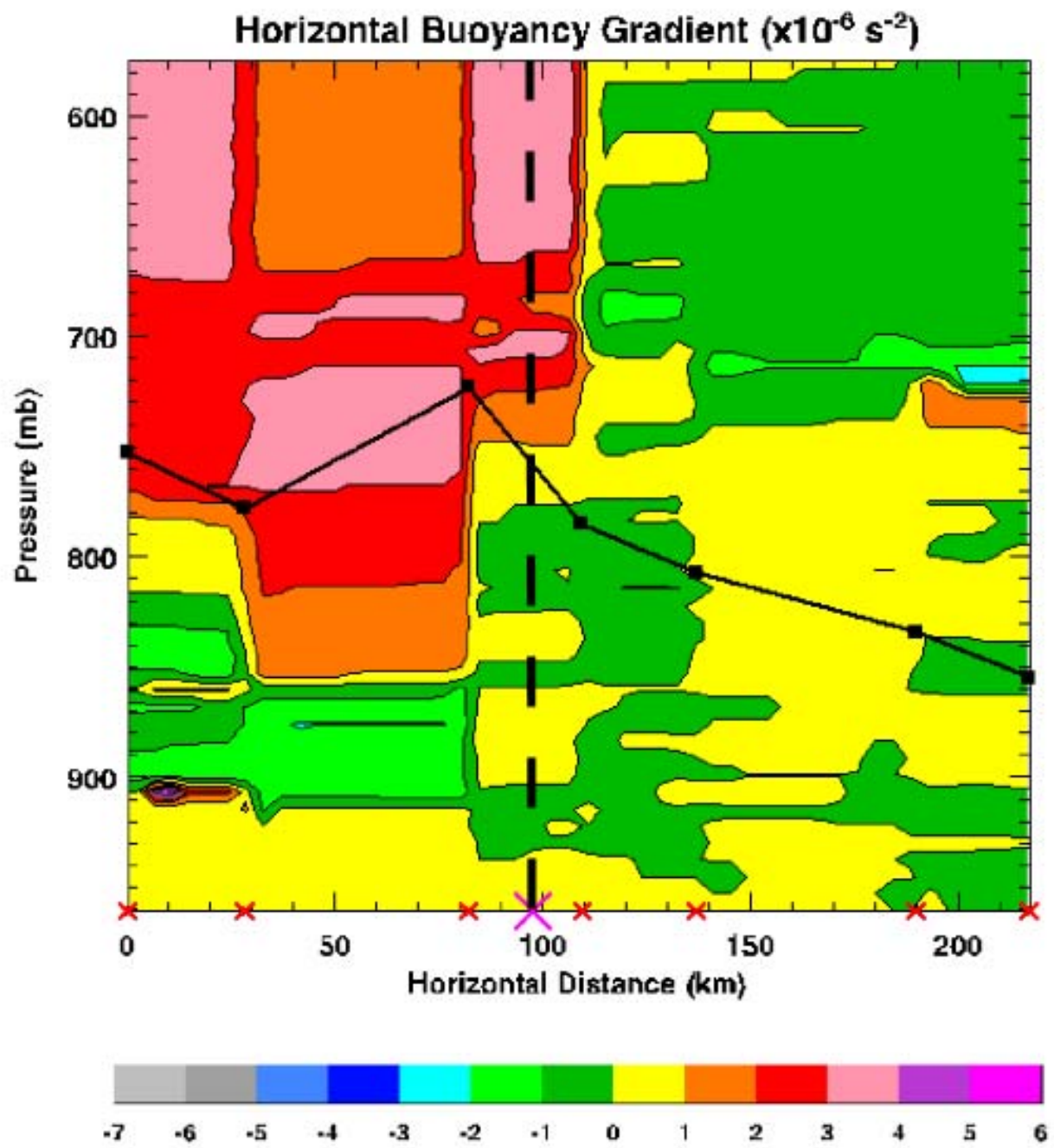

FIG. 106. Same as in Fig. 105 except for horizontal buoyancy gradient (dB/dH) on 24 May 2002, rather than buoyancy (B). 

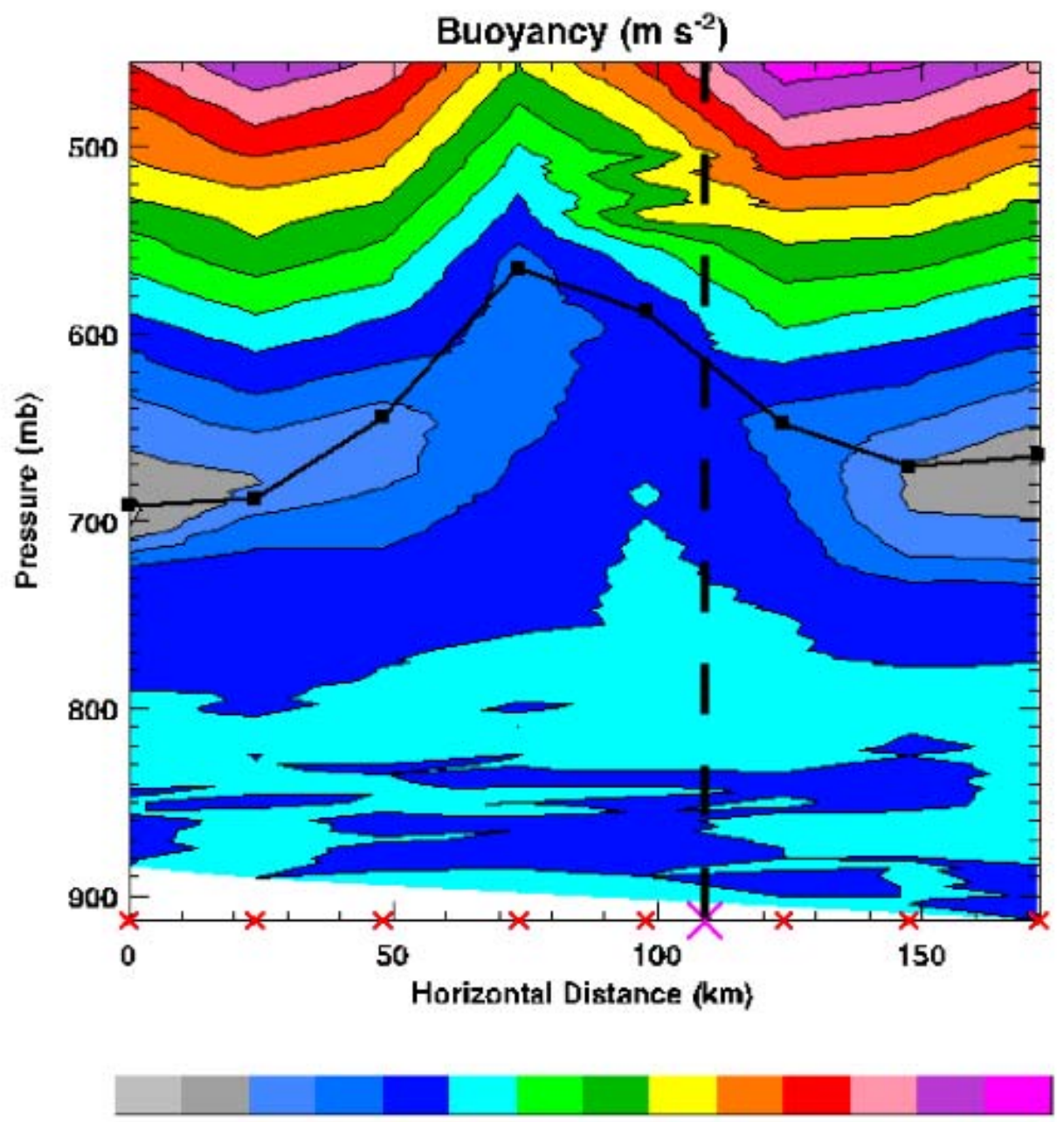

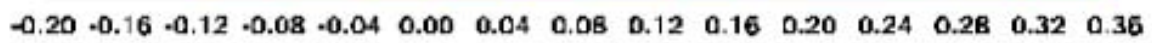

FIG. 107. Same as in Fig. 105 except for 19 June 2002. 

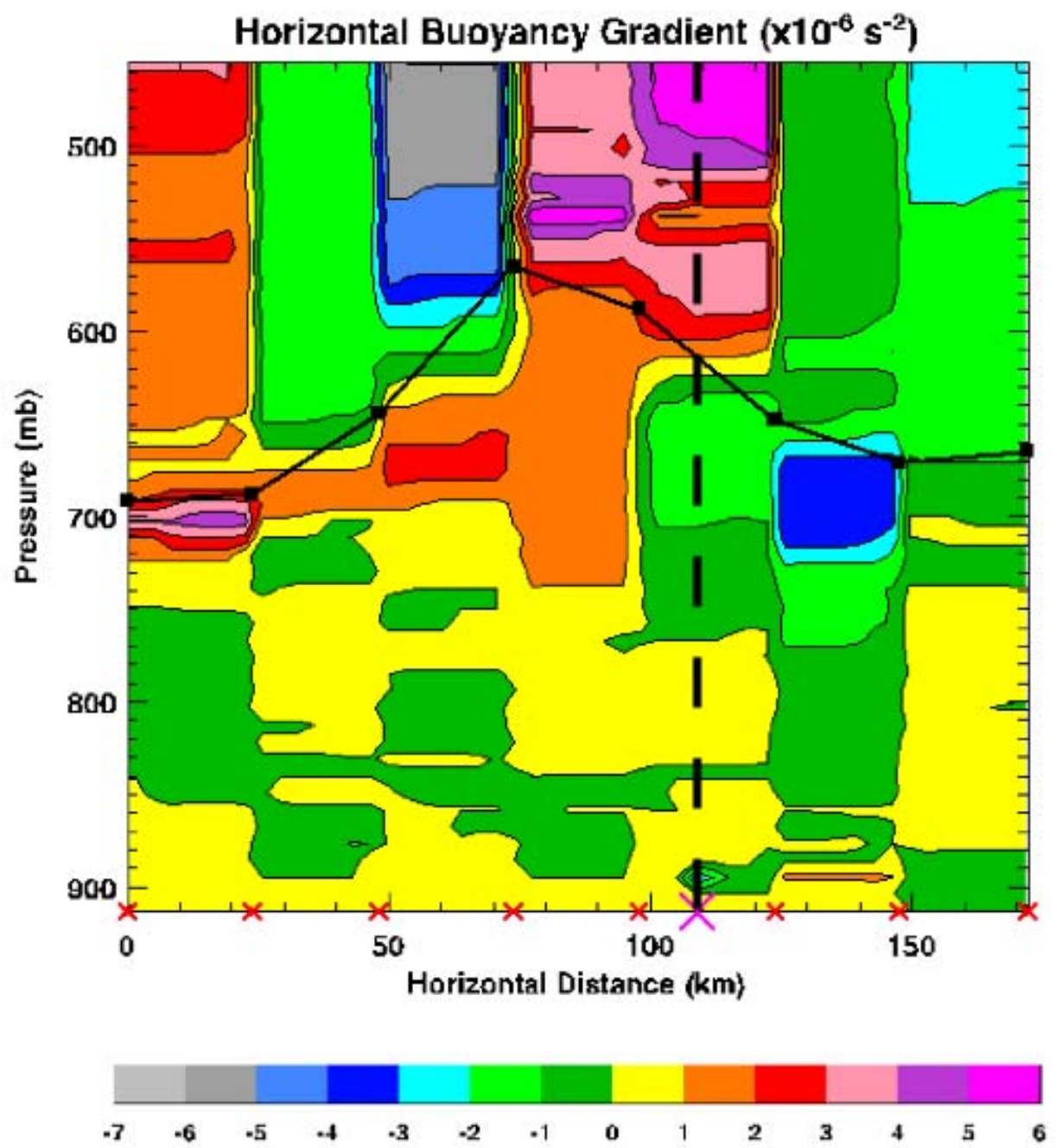

FIG. 108. Same as in Fig. 106 except for 19 June 2002. 
Using Equations (5) and/or (6), a rough estimate of the maximum amount of baroclinically-generated horizontal vorticity can be calculated. As indicated by Equations (5) and (6), vorticity is generated solely by a horizontal buoyancy gradient in this case (e.g., Houze 1993). Equation (6) is approximately valid for calculating the horizontal vorticity in the y-direction $(\xi)$ on 24 May since the dropsonde line was oriented roughly east-to-west and hence $\mathrm{dB} / \mathrm{dH}$ was approximately equal to $\partial \mathrm{B} / \partial \mathrm{x}$. For 19 June, the coordinate system would have to be rotated to be parallel to the Learjet flight track. Nonetheless, Equation (6) still provides a rough estimate of the magnitude of the horizontal vorticity generation on 19 June as well. As indicated by Equation (6), once the horizontal buoyancy gradient at a given pressure level is determined, it can be multiplied by the time the cloud resides within this buoyancy gradient to come up with an estimate of the maximum amount of baroclinically-generated horizontal vorticity.

For 24 May, the horizontal buoyancy gradient was about $3.5 \times 10^{-6} \mathrm{~s}^{-2}$ (Fig. 106). The distance from the point of $\mathrm{CI}$ to the end of the gradient region was approximately 12 $\mathrm{km}$. Based on radar, storms resided in this gradient region for about $15 \mathrm{~min}(900 \mathrm{sec})$, generating a horizontal vorticity of $3.15 \times 10^{-3} \mathrm{~s}^{-1}$. To estimate the horizontal vorticity generated by low-level shear in the same region, the $0-3 \mathrm{~km}$ AGL shear values from the two dropsondes surrounding the location of CI were averaged, giving a value of $15.43 \mathrm{~m}$ $\mathrm{s}^{-1}$. Dividing this value by the depth of the layer (i.e., $\left.\left(15.43 \mathrm{~m} \mathrm{~s}^{-1}\right) /(3000 \mathrm{~m})\right)$ produced a horizontal vorticity of $5.14 \times 10^{-3} \mathrm{~s}^{-1}$. So, the baroclinically-generated horizontal vorticity is comparable to the horizontal vorticity generated by low-level shear. 
For 19 June, the horizontal buoyancy gradient was about $5.5 \times 10^{-6} \mathrm{~s}^{-2}$. The distance from $\mathrm{CI}$ to the end of the buoyancy gradient was about $15 \mathrm{~km}$. From radar, storms resided in this gradient region for approximately 20 minutes (1200 s), resulting in a horizontal vorticity of $6.6 \times 10^{-3} \mathrm{~s}^{-1}$, which is comparable to the horizontal vorticity associated with the $0-3 \mathrm{~km}$ AGL shear in the same region (i.e., $\left(9.78 \mathrm{~m} \mathrm{~s}^{-1}\right) /(3000 \mathrm{~m})=$ $\left.3.26 \times 10^{-3} \mathrm{~s}^{-1}\right)$. 


\section{CHAPTER VI}

\section{DISCUSSION*}

Investigation of the mesoscale environments of both positive and negative severe storms during IHOP_2002 over the central United States clearly demonstrated significant and systematic differences between the mesoscale environments of the two storm types. When compared to negative storms, positive storms occurred in environments associated with a drier low to midlevel troposphere (i.e., lower surface dewpoint, mean mixing ratio in the lowest $100 \mathrm{hPa}$, and precipitable water from the surface to $400 \mathrm{hPa}$ ), higher $\mathrm{CBH}$ (i.e., higher LCL), smaller (i.e., shallower) WCD, stronger conditional instability (i.e., larger 850-500 and 700-500 hPa lapse rates), larger 0-3 km AGL wind shear, stronger 0-2 km AGL storm-relative wind speed, and larger CAPE/NCAPE in the mixed-phase zone (i.e., larger LFC to $-40^{\circ} \mathrm{C}$ NCAPE and $-10^{\circ} \mathrm{C}$ to $-40^{\circ} \mathrm{C}$ CAPE). Differences in the WCD of positive and negative storms were by far the most dramatic, suggesting an important role for this parameter in controlling CG lightning polarity.

These results support the hypothesis that the mesoscale environment indirectly influences the CG lightning polarity of severe storms by directly affecting their structural, dynamical, and microphysical properties, which in turn directly control storm electrification and CG flash polarity. Furthermore, the results support the more specific hypothesis that broad, strong updrafts and associated large supercooled LWCs cause the

\footnotetext{
* Part of this chapter is reprinted with permission from Carey, L. D., and K. M. Buffalo, 2007:

Environmental control of cloud-to-ground lightning polarity in severe storms. Mon. Wea. Rev., 135, 13271353. (c) 2007 American Meteorological Society.
} 
positive charging of graupel and hail via the NIC mechanism (e.g., Saunders and Peck 1998), the generation of an inverted charge structure, and enhanced production of positive CG lightning as has recently been observed (Rust and MacGorman 2002; Lang et al. 2004; MacGorman et al. 2005; Wiens et al. 2005). Stronger updrafts in positive storms were apparently generated thermodynamically from larger and more efficiently utilized conditional instability/buoyancy in the mixed-phase zone and dynamically from stronger low-level shear and storm-relative inflow, similar to the results of Gilmore and Wicker (2002). Higher CBH in positive storms likely resulted in broader updrafts and reduced entrainment, allowing more of the potentially available buoyancy (i.e., CAPE and NCAPE) to be realized and effectively causing stronger updrafts as was first suggested by Williams et al. (2005). Additionally, the lower precipitable water content in positive storms was shown to be generally associated with stronger peak updrafts in simulated convection by McCaul et al. (2005) due to reduced water loading and the lower altitudes at which the latent heat release by freezing and deposition commences in the lower precipitable water environments. The broader and stronger updrafts apparently generated larger supercooled LWCs in the mixed-phase zone of positive storms by increasing condensation rates, suppressing precipitation growth, and reducing dry air entrainment, thus explaining how environmental conditions can systematically control CG lightning polarity. Dramatically reduced WCD in positive storms apparently also increased the supercooled LWC by drastically reducing the rainout of available cloud water via collision/coalescence as was postulated by Williams et al. (2005). 


\section{a. Large supercooled water contents in high-based severe storms: An apparent paradox}

There is an apparent paradox in associating larger supercooled LWCs with the higher CBHs of positive storms in the aforementioned hypothesized scenario. Because of their lower and warmer cloud bases and more moist boundary layers (higher low-level mixing ratios and surface dewpoints), negative storms have higher adiabatic LWCs and hence the potential for higher actual cloud LWCs than positive storms, especially if the cores are nearly undiluted as one might expect in supercell convection. ${ }^{15}$ Hence, to argue that high cloud base (small WCD) positive storms have more supercooled cloud water than negative storms, the greater amount of adiabatic condensate available to negative storms in the first place must be compensated for. The following arguments are offered as factors that might compensate for the more available moisture available in negative storm environments:

1) High $\mathrm{CBH}$ (or LCL) in positive storms may translate into broader updrafts with less entrainment (e.g., McCarthy 1974) since updraft diameter scales with CBH or boundary layer depth (e.g., Lucas et al. 1994; Michaud 1996; Lucas et al. 1996; Williams and Stanfill 2002; Williams et al. 2005). Less entrainment would result in less dilution of cloud water in positive storms, as well as less dilution of buoyancy. Hence, there would also be more efficient processing of CAPE and

\footnotetext{
${ }^{15}$ It is common sense that the updraft core is not where the bulk of the electrification is occurring since there are not sufficient number concentrations of precipitation ice particles in the updraft core or weak echo region (WER) of a supercell. Verification of this common sense idea is the "lightning hole" or absence of lightning and inferred significant charge in VHF-based lightning observations within the supercell WER (e.g., Krehbiel et al. 2000). Since it remains uncertain where the electrification is taking place relative to the draft structure, it would not be safe to assume that the parcel is undiluted where NIC is operative.
} 
resultant stronger updrafts in positive storms, all else being equal (e.g., Williams and Stanfill 2002; Williams et al. 2005).

2) Lower (higher) cloud bases in negative (positive) storms means greater (lesser) depth through which mixing of environmental air can reduce cloud buoyancy and LWC as pointed out by Michaud $(1996,1998)$ and discussed by Lucas et al. (1996).

3) In general, CAPE between positive and negative storms was very similar for the cases investigated in this study. However, CAPE between the $-10^{\circ} \mathrm{C}$ and $-40^{\circ} \mathrm{C}$ levels and NCAPE in nearly all layers was stronger in positive storms, providing stronger vertical accelerations in the mixed-phase zone where NIC is operative. As also found by Gilmore and Wicker (2002), low-level (0-3 km AGL) shear was larger in positive storm environments. Stronger low-level shear could produce stronger dynamic pressure forces and hence stronger vertical motions in supercellular convection (e.g., Klemp 1987), and also stronger vertical motions in multicellular convection by balancing the horizontal vorticity generated baroclinically by the surface cold pool (e.g., Rotunno et al. 1988). These factors in combination with potentially more efficient processing of available CAPE as described above may produce stronger updrafts in positive storms. Postulated stronger updrafts in positive storms would have the effect of increasing condensation rates and suppressing precipitation, thereby increasing the cloud LWC (i.e., (cloud water)/(precipitation) fraction) as suggested by Williams et al. (2005). 
4) Lower CBHs (and to a lesser extent higher freezing levels) in negative storms results in significantly larger WCDs. A larger WCD would tend to increase the efficiency of warm rain (i.e., collision/coalescence) processes (e.g., Rosenfeld and Woodley 2003). Increased collision/coalescence results in lowering of the (cloud water)/(precipitation) fraction. Once precipitation is formed, this condensate is no longer available to be lofted into the mixed-phase region as cloud water where it can affect storm electrification (Williams et al. 2005). Enhanced condensate in the warm portion of negative storms can also increase water loading and frictional drag and reduce the updraft velocity before the rain falls out, which feeds back into the previous point.

5) Although less convincing, there was a weak tendency for more supercell characteristics in positive versus negative storms. It should be emphasized that radar analysis showed that supercell and multicell characteristics were common in both positive and negative storms, and thus it appears that dominant CG flash polarity is not directly related to the organizational mode taken by convection. However, supercells were somewhat more common in positive storms. This result is generally consistent with the environmental data (e.g., lower BRN, larger 0-3 km AGL shear, larger 0-3 km AGL SREH, larger EHI, and roughly equivalent CAPE and 0-6 km AGL shear), which encourage pressure perturbation dynamics associated with quasi-steady (supercell) forcing of the updraft in positive storms. This dynamical forcing could have increased updraft 
strength in positive storms and decreased dilution of buoyancy and cloud water via entrainment, thus feeding back on several of the points above.

The above suggestions are merely hypotheses based on plausible physical mechanisms and not observed facts. Nonetheless, the presented environmental data is consistent with these hypotheses. To gauge how much of a compensating effect might be necessary to increase (decrease) the (cloud water)/(precipitation water) and the (actual supercooled water content)/(adiabatic supercooled water content) fractions in positive (negative) storms sufficiently to result in larger absolute supercooled cloud water contents in positive storms, it is worthwhile to consider differences in the mean adiabatic LWC for the examined positive and negative storms. The mean adiabatic LWCs at $0^{\circ} \mathrm{C}$, $-20^{\circ} \mathrm{C}$, and $-40^{\circ} \mathrm{C}$ for negative storms were $6.0,10.5$, and $12.9 \mathrm{~g} \mathrm{~kg}^{-1}$, respectively, while for positive storms they were $3.3,7.0$, and $9.8 \mathrm{~g} \mathrm{~kg}^{-1}$, respectively. Note that the difference decreases significantly from the bottom $\left(0^{\circ} \mathrm{C}\right)$ to the top $\left(-40^{\circ} \mathrm{C}\right)$ of the mixedphase zone. In the middle of the mixed-phase zone $\left(-20^{\circ} \mathrm{C}\right)$ where NIC is the most effective, the mean adiabatic LWC in positive storms is about two-thirds of the magnitude in negative storms, providing some estimate of the required compensating effects. However, it was shown earlier that the contribution from the mixed-phase region to the total adiabatic $\mathrm{LWC}$ at $-40^{\circ} \mathrm{C}$ was very similar for positive (mean $=6.6 \mathrm{~g}$ $\mathrm{kg}^{-1}$ ) and negative (mean $=6.9 \mathrm{~g} \mathrm{~kg}^{-1}$ ) storms. Thus, if much of the condensate in the warm cloud layer grows into precipitation via collision/coalescence and falls out of the cloud before ever being lofted into the mixed-phase region, the adiabatic LWCs in the mixed-phase region may actually be quite similar between negative and positive storms, 
and could potentially require even less of a compensating factor to produce larger absolute supercooled cloud water contents in positive storms.

b. The relative roles of the various environmental factors in controlling CG lightning polarity

It is important to note that not all of the environmental factors summarized above were always equal in importance for explaining why each individual positive (negative) storm was apparently associated with stronger/broader (weaker/narrower) updrafts and larger (smaller) LWCs in the mixed-phase zone. Sometimes one environmental factor seemingly compensated for another (Table 10 and Figs. 96 and 97), as would be expected since updraft forcing and the production of large supercooled LWCs can come from any combination of the mechanisms discussed above. Nonetheless, based on the observational evidence from IHOP_2002, low-level moisture, LCL, and WCD must be highlighted as likely the most important environmental factors for determining the dominant CG polarity in severe storms. Furthermore, the crucial role of WCD may help explain the apparent paradox that most severe storms actually produce predominantly negative CG lightning (Carey et al. 2003b) despite also likely being associated with vigorous vertical drafts. In fact, radar analysis of multiple negative and positive storms that occurred during IHOP_2002 revealed no systematic tendency for positive storms to be more intense than negative storms. As pointed out by Williams et al. (2005), the climatological overlap of shallow WCD (i.e., high $\mathrm{CBH}$ ) and large instability likely defines the geographic distribution of positive storms shown in Carey et al. (2003b) and 
repeated in Figs. 1 and 2. The findings of this study generally support this view, but suggest that the occurrence of strong 0-3 km AGL wind shear be added to this union of environmental factors, since dynamic can equal or exceed thermodynamic forcing of the updraft within severe supercell storms over the central United States (e.g., Houze 1993). Strong 0-3 km AGL wind shear favors stronger updrafts in multicell storms as well due to the balance generated between the horizontal vorticity generated by the surface cold pool and that generated by the low-level shear (e.g., Rotunno et al. 1988).

In summary, sufficient moisture, instability, and deep-layer shear in combination with enhanced NCAPE at heights below $-40^{\circ} \mathrm{C}$, increased dynamical forcing from enhanced low-level shear and SREH, and a more efficient processing of CAPE and moisture up to and in the mixed-phase zone associated with a higher LCL and smaller WCD is the likely explanation for positive storm occurrence in the central United States. As such, it should be clear that LCL or WCD alone cannot cause the conditions favorable for strong, broad updrafts and high supercooled water contents. For example, in the dry conditions of the desert Southwest CBH is very high and WCD very shallow or perhaps zero but yet positive storms are not common there. Clearly, this is because the other necessary conditions such as sufficient moisture and CAPE are not met. It should also be clear that conditions favorable for severe storms in general (i.e., sufficient moisture, instability, and deep-layer shear) cannot guarantee high supercooled cloud water contents and associated increased positive CG lightning production. For instance, adequate moisture, CAPE, and deep-layer shear are often present in the southeast United 
States but LCLs are typically low (and WCDs deep), such that positive storms are not common in this part of the country either.

As pointed out by Carey et al. (2003b), it is not entirely clear why the $\theta_{\mathrm{e}}$ gradient region is a preferred location for the occurrence of positive storms, as was found to be the case by both Smith et al. (2000) and Carey et al. (2003b). Smith et al. (2000) and Gilmore and Wicker (2002) argued that storms passing through such a $\theta_{\text {e gradient }}$ toward the $\theta_{\mathrm{e}}$ maximum would experience rapid updraft intensification that could lead to positive CG flash dominance. However, this fails to explain why storms that moved adjacent to the $\theta_{\mathrm{e}}$ ridge (i.e., storm track B in Fig. 3) remained positive storms, as they were not likely experiencing rapid updraft intensification. The results from the present study suggest that the $\theta_{\mathrm{e}}$ gradient region (on the western and northern sides) of the $\theta_{\mathrm{e}}$ ridge is a preferred area for positive storms (Smith et al. 2000; Carey et al. 2003b) not simply because of a difference in $\theta_{\mathrm{e}}$ or CAPE values (which were not found to differ significantly between positive and negative mesoscale regions), but rather because the environmental parameters found to be favorable for positive CG flash production are likely to be found in unison there, including sufficient low-level moisture, ample instability that tends to be more concentrated in the mixed-phase zone, high LCL, shallow WCD, and large 0-3 km AGL shear. It appears to be the combination of sufficient values of these parameters that is crucial for the development of positive storms. The dropsonde data detailing the $\theta_{\mathrm{e}}$ gradient regions on 24 May and 19 June at a high spatial and temporal resolution clearly illustrated the juxtaposition of favorable values of these parameters in the $\theta_{\mathrm{e}}$ gradient region. Analysis of the dropsonde data also 
showed that the magnitude of baroclinically-generated horizontal vorticity in the $\theta_{\mathrm{e}}$ gradient region was comparable to that generated by low-level shear. Hence, baroclinically-generated horizontal vorticity could provide additional updraft forcing in the $\theta_{\mathrm{e}}$ gradient region. It is important to note that this combination of environmental conditions likely to be found in unison in the $\theta_{\mathrm{e}}$ gradient region is consistent with the possibility of stronger updrafts and larger supercooled LWCs in positive storms, which could lead to enhanced positive charging of graupel and hail, the generation of an inverted charge structure, and increased positive CG lightning production.

c. Environmental control of supercell type, large hail production, and CG lightning polarity: A comparison of results

As discussed in Chapter II, three supercell types (LP, classic, and HP) have been identified and defined by the amount of precipitation they produce and where the precipitation is deposited relative to their respective updrafts (e.g., Rasmussen and Straka 1998). It was alluded to in Chapter II that the tendency for LP supercell storms to be positive CG dominant and HP supercells to be negative CG dominant ${ }^{16}$ suggests that perhaps similar meteorological conditions are conducive to the development of both LP supercells and increased production of positive CG flashes. There are two studies on the relationship between environmental conditions and supercell type (LP, classic, HP) that are relevant to this discussion: Bluestein and Parks (1983) and Rasmussen and Straka (1998). Bluestein and Parks (1983) found that the LCL was significantly higher in LP

\footnotetext{
${ }^{16}$ Classic supercells appear to be primarily negative CG dominant but can also be associated with positive CG dominant behavior (MacGorman and Nielsen 1991; MacGorman and Burgess 1994).
} 
(1.8 km AGL) than classic (1.4 km AGL) supercells. Mean mixing ratio in the lowest $\mathrm{km}$ was correspondingly lower in LP $\left(11.9 \mathrm{~g} \mathrm{~kg}^{-1}\right)$ versus classic $\left(13.5 \mathrm{~g} \mathrm{~kg}^{-1}\right)$ supercells. Precipitable water was lower in LP $(2.8 \mathrm{~cm})$ than classic $(3.3 \mathrm{~cm})$ supercells. All of these results are consistent with the fact that LP supercells are most common near the dryline (e.g., Bluestein and Parks 1983; Doswell and Burgess 1993) as were two of the four positive storm regions in this study (23 and 24 May). On the other hand, Rasmussen and Straka (1998) did not find statistically significant differences in the LCL or low-level mixing ratio between the three supercell types. They did find that precipitable water was higher in HP versus LP and classic supercells. Rasmussen and Straka (1998) also found that upper-level storm-relative flow at 9-10 km AGL was stronger in LP storms and comparatively weak in HP storms, with classic supercells falling in between. They speculate that precipitation efficiency is relatively lowered (raised) in LP (HP) storms due to the decreased (increased) recirculation of hydrometeors into the supercell updraft associated with the stronger (weaker) anvil-level winds. While on the topic of supercell type and CG polarity, and in particular the environmental influence on both, it is interesting to note that MacGorman and Burgess (1994) found LP supercells tend to occur west of classic or HP supercells on a given day, similar to the finding of the present study that positive storms were located west of negative storms on days when both were present.

Given the general tendency for LP (classic) supercells to be associated with positive (negative) storms, the results of the present study are in good agreement with the Bluestein and Parks (1983) findings regarding the meteorological environments of 
LP and classic supercells. A comparison with Rasmussen and Straka (1998) is less encouraging as only the precipitable water results appear to be consistent with the present study (i.e., high precipitable water is associated with HP supercells and negative storms as expected). Inspection of upper-level storm-relative wind speeds in the present study revealed no statistically significant difference between the 9-11 km AGL stormrelative wind speeds of positive and negative storms during IHOP_2002. Reasons for the discouraging comparisons with Rasmussen and Straka (1998) are unknown but they noted that their soundings may not have adequately sampled the low-level moisture and temperature conditions of the supercells. It also should be noted that there are known exceptions regarding the general tendencies of CG polarity with supercell type so any comparison between the present study and supercell environment studies must be viewed with some caution.

Nonetheless, the fairly consistent relationship between supercell type and CG polarity can apparently be explained by at least one common link: precipitation efficiency. By definition, LP supercells are extremely precipitation inefficient, implying that a relatively large fraction of available condensate remains in cloud form (both water and ice) and is not converted to precipitation. As suggested earlier, the large implied (cloud water)/(precipitation water) fraction in LP supercells could allow for the positive NIC of graupel and hail, the generation of a midlevel (i.e., $-10^{\circ} \mathrm{C}$ to $-20^{\circ} \mathrm{C}$ ) positive charge layer and resultant generally inverted storm charge structure, and positive CG lightning. Based on the results of the present study and Bluestein and Parks (1983), it is hypothesized that high $\mathrm{CBH}$ and shallow WCD in LP storms is likely an important 
causal factor for the precipitation inefficiency, associated LP structure, and positive CG lightning, although other factors likely play a role. The HP supercell is by definition a relatively efficient converter of cloud water to precipitation and hence would be characterized by a relatively smaller (cloud water)/(precipitation water) fraction. Although inconsistent with the findings of Rasmussen and Straka (1998), it is suggested that relatively low $\mathrm{CBH}$ and deep WCD might be preferentially associated with HP supercells and hence could be an important causal mechanism for their precipitation efficiency and negative CG lightning production. Of course, other physical factors such as upper-level storm-relative wind speed as highlighted by Rasmussen and Straka (1998) may also be important for both phenomena.

Similar to the relationship between LP supercells and positive storms, the tendency for positive storms to produce large hail (e.g., Reap and MacGorman 1989; Curran and Rust 1992; Seimon 1993; MacGorman and Burgess 1994; Stolzenburg 1994; Gilmore and Wicker 2002; Lang et al. 2004) despite the fact that large hail does not likely play a direct role in the anomalous electrification of such storms (e.g., Carey and Rutledge 1998; Williams 2001; Carey et al. 2003a; Carey et al. 2003b) suggests that similar meteorological conditions may be necessary for enhanced positive CG lightning production and the formation of large hail. Knight and Knight (2001) state that given an ice nucleus for a hailstone to grow upon, the two most important conditions for hailstone growth are an adequate updraft to keep the hailstone aloft long enough to grow substantially and sufficient supercooled water content to enable the hailstone to grow fast enough before falling out. As previously described, a strong updraft and associated 
large cloud supercooled LWCs also likely lead to positive NIC of graupel and hail, an inverted charge structure, and positive CG lightning. Thus, given these common critical ingredients of a strong updraft and large cloud supercooled LWCs, it is not surprising that positive storms are often producers of large hail.

The relationship between positive storms and large hail also appears to tie back into the common link between supercell type and CG polarity discussed above: precipitation efficiency. Browning (1977) found that supercell hailstorms were the least efficient producers of precipitation out of all High Plains convective storms. As discussed by Knight and Knight (2001), the depletion of cloud water must increase with precipitation efficiency since by definition a precipitation efficient storm is a more efficient converter of cloud water to precipitation water. It is reasonable to expect that this depletion would decrease the size and amount of hail since less cloud water would be left behind to be accreted by a growing hailstone. In contrast, a relatively small fraction of cloud water is converted to precipitation water in precipitation inefficient storms, leaving a large amount of cloud water that can be accreted by a growing hailstone. Based on the results of the present study along with the known characteristics of LP supercell storms and the processes involved in hail formation, it appears likely that the common link between positive storms, LP supercell storms, and large hail-producing storms may be precipitation efficiency, or more precisely, the precipitation inefficient nature of these storms. 


\section{d. Tornadoes, CG lightning polarity reversals, and the $L C L$}

Although not common, an abrupt polarity shift from mostly positive to mostly negative CG lightning is sometimes associated with tornadogenesis and a significant (F2 or greater) tornado on the ground (Seimon 1993; MacGorman and Burgess 1994; Perez et al. 1997; Bluestein and MacGorman 1998). Although the potential causative factors for both significant tornadoes and CG lightning polarity are many, complex, and the subject of current debate, the present study in combination with recent studies on the environmental conditions associated with significant tornadic supercells may help explain the occasional coincidence between tornadogenesis and CG lightning polarity reversals. Among other factors, Rasmussen and Blanchard (1998) found the LCL to be one of the best environmental discriminators between supercells that produce significant tornadoes (tornadic) and those that do not (nontornadic). An LCL $\leq 800 \mathrm{~m}$ was associated with significant tornadoes while an LCL $\geq 1200 \mathrm{~m}$ was associated with a decreasing likelihood of significant tornadoes. More recent studies (Craven et al. 2002b; Rasmussen 2003; Thompson et al. 2003) have confirmed the strong correlation between significant tornadoes in supercells and low LCL heights. Since the present study shows that a low LCL is highly correlated with dominant negative CG lightning, it is possible that sudden $\mathrm{CG}$ polarity shifts from dominant positive to dominant negative are associated with a rapid decrease in the LCL (increase in the low-level humidity) and hence associated with an increased probability of a significant tornado. Clearly, future studies should continue to focus on the correlation between low-level moisture and supercell type, tornado potential, and CG lightning polarity with an emphasis on 
observing and modeling the physical and dynamical factors that could confirm or reject causal relationships.

\section{e. Secondary effects of updraft intensity on CG lightning polarity}

Although the hypothesis of this study focuses primarily on the effect of updraft intensity on cloud LWC and the resultant impacts on NIC and CG flash polarity, updraft intensity impacts additional thermodynamic and microphysical storm properties, which in turn affect storm electrification and CG lightning polarity. In addition to LWC, updraft intensity affects temperature within the cloud, the cloud droplet spectrum, and the relative velocity of colliding hydrometeors, all of which have implications on storm electrification. Latent heat is released as condensation and freezing occur in the updraft, and as discussed in Chapter III, updraft intensity, LWC, and temperature are thus positively correlated (e.g., Rogers and Yau 1989; Knight and Knight 2001) so that a stronger updraft will result in not only higher LWCs, but also warmer in-cloud temperatures. Laboratory studies have shown that graupel and hail charge positively at relatively warm temperatures (e.g., Takahashi 1978; Jayaratne et al. 1983; Saunders et al. 1991; Brooks et al. 1997; Saunders and Peck 1998), so that warmer in-cloud temperatures would favor positive charging of graupel and hail, and the subsequent development of an inverted charge structure and positive CG flash production just as enhanced LWCs do.

Since cloud droplets in an intense updraft have little time to grow due to their short residence time within the updraft, they remain small and the cloud droplet 
spectrum remains narrow (e.g., Rogers and Yau 1989; Avila and Pereyra 2000; Knight and Knight 2001). Avila and Pereyra (2000) determined that the rimer positive charging zone deepens as the cloud droplet spectrum narrows because graupel and hail charge positively at colder temperatures and smaller LWCs when the cloud droplet spectrum is narrow. Due to the larger zone in which positive charge is transferred to graupel and hail, Avila and Pereyra (2000) suggest that a narrow droplet spectrum would favor increased positive CG flash production. This finding is consistent with the enhanced LWC idea, since a narrow droplet spectrum would lead to precipitation inefficiency and more cloud water remaining in the updraft region (e.g., Lucas et al. 1996). Finally, a strong updraft supports the growth of larger rimers with greater terminal fall velocities. Since cloud droplets and ice crystals have negligible terminal fall velocities and can be considered to be traveling at the airflow velocity, the rimer velocity largely controls the relative velocity of colliding hydrometeors (Knight and Knight 2001; Gilmore and Wicker 2002). A greater rimer velocity increases: (1) the RAR which favors positive NIC of the rimer (Brooks et al. 1997), (2) the relative velocity (i.e., impact velocity) between the rimer and ice crystals which increases the magnitude of charge separated per collision (Jayaratne et al. 1983; Keith and Saunders 1990), and (3) the number of charge-separating collisions between the rimer and ice crystals resulting in more overall charge transfer within the cloud (MacGorman and Rust 1998; Gilmore and Wicker 2002). Hence, a greater rimer velocity, which is a by-product of the growth of larger rimers by a strong updraft, favors enhanced positive charging of graupel and hail and in turn, increased positive CG lighting. In summary, stronger updrafts lead to enhanced 
cloud LWCs, warmer in-cloud temperatures, a smaller cloud droplet spectrum, and a greater relative velocity of colliding hydrometeors, all of which favor positive NIC of graupel and hail, the subsequent development of an inverted charge structure, and increased positive CG lighting production.

\section{f. Correlation between CAPE and other parameters}

As presented in the Appendix, some intriguing relationships were discovered in the IHOP_2002 dataset regarding the correlation between CAPE and its contributing factors. With regard to low-level environmental conditions, CAPE was largely controlled by low-level temperature in positive regions ( correlation coefficient $=0.73$ ) and by low-level moisture in negative regions (correlation coefficient $=0.76$ ). Recent studies (e.g., Williams and Stanfill 2002; Williams et al. 2003; Williams and Satori 2004; Williams et al. 2005) have suggested that an enhanced dry bulb temperature is favored over an enhanced dewpoint temperature in influencing instability necessary for lightning activity. An enhanced dry bulb temperature not only increases the instability but also favors higher CBHs. On the other hand, while enhanced low-level moisture (i.e., dewpoint temperature) can also increase the instability, it favors lower CBHs. As discussed previously, higher CBHs favor stronger updrafts, larger LWCs, enhanced positive charging of graupel and hail, the generation of an inverted charge structure, and increased positive CG flash production. Thus, control of CAPE by low-level temperature rather than low-level moisture might favor increased positive CG lightning production. 
Of course, the fact that lightning is much more prevalent over land than ocean is well established (e.g., Brooks 1925; Orville and Henderson 1986; Christian et al. 1999). It has been suggested in the study of tropical convection that higher CBHs are favored over continents, where afternoon dry bulb temperatures are greater and dewpoint temperatures are less than typical values over tropical oceans (e.g., Williams and Stanfill 2002; Williams et al. 2003; Williams and Satori 2004; Williams et al. 2005). It has also been found that CAPE over the tropical ocean is strongly positively correlated with lowlevel moisture (Petersen et al. 1996). Such a strong correlation to either low-level moisture or low-level temperature has not been documented over tropical continental areas, but the results of some studies (e.g., Petersen et al. 2006) show some indication that perhaps CAPE is more strongly correlated with low-level temperature over tropical continental locations. The combination of these findings from the tropics and the present study's findings from IHOP_2002 appear to give some indication that perhaps environments in which CAPE is more strongly controlled by low-level temperature (i.e., positive storms, tropical continental convection) versus low-level moisture (i.e., negative storms, tropical oceanic convection) favor stronger updrafts, which contribute to increased lightning activity in tropical convection and increased positive CG lightning in midlatitude severe convection. As previously argued by others (e.g., Williams et al. 2003; Williams and Satori 2004), the causal connection for this may be that increased low-level temperature can increase not only instability but also $\mathrm{CBH}$, leading to a more efficient conversion of CAPE to updraft kinetic energy, which produces stronger updrafts that in turn stimulate enhanced lightning activity and/or enhanced positive CG 
lightning production. Other factors discussed above that are associated with a higher CBH (e.g., smaller WCD, lesser depth through which mixing of environmental air can reduce buoyancy and LWC) likely play a role as well.

It is interesting to note that the mean surface temperature of positive regions during IHOP_2002 was warmer than that of negative regions to a highly significant level (99\% level; Table 6), and although this trend did not always hold true in the regional comparisons, it was evident in the daily comparisons. It has already been discussed that negative storms during IHOP_2002 occurred in a moister environment than positive storms. Thus, it seems that the dominant low-level parameter (i.e., temperature in warmer environments and moisture in moister environments) may largely control CAPE. This may also be the case for tropical environments, where CAPE is highly correlated with low-level moisture over the ocean (i.e., cooler and moister; Petersen et al. 1996) and possibly low-level temperature over land (i.e., warmer and drier; Petersen et al. 2006). Considering the other contributions to CAPE (lapse rates and FCL depth), a similar theme held although it was not nearly as pronounced as for low-level temperature and moisture. CAPE was more strongly correlated to depth of the FCL for negative storms, which were characterized by significantly deeper FCLs in the mean $(95 \%$ level; Table 7). The correlation between CAPE and both 700-500 and 850-500 hPa lapse rates was stronger for positive storms, which exhibited stronger lapse rates than negative storms (Tables 5 and 7). 


\section{CHAPTER VII}

\section{CONCLUSIONS AND FUTURE WORK*}

The mesoscale environments of nine storm systems (four positive and five negative) that occurred on six different days (23, 24 May; 4, 12, 15, 19 June) during IHOP_2002 were investigated to determine whether systematic differences existed between the environments of positive and negative storms. A multitude of soundings launched during IHOP_2002 permitted the construction of a high spatial and temporal resolution proximity sounding dataset consisting of 48 total soundings, half of which characterized positive storm environments and the other half characteristic of negative storm environments. These comparisons revealed significant, systematic differences between positive and negative storm environments, thereby supporting the hypothesis that the mesoscale environment can indirectly control the CG lightning polarity of severe storms by directly affecting their structural, dynamical, and microphysical properties, which in turn directly control cloud electrification and CG flash polarity.

Positive storm environments featured a drier low to midtroposphere, higher $\mathrm{CBH}$, smaller WCD, stronger conditional instability, larger 0-3 km AGL wind shear, stronger 0-2 km AGL storm-relative wind speed, and larger buoyancy in the mixedphase zone compared to negative storm environments. Differences in the WCD of positive and negative storms were by far the most dramatic, indicating an important role for this parameter in controlling CG lightning polarity. These differences between

\footnotetext{
* Part of this chapter is reprinted with permission from Carey, L. D., and K. M. Buffalo, 2007: Environmental control of cloud-to-ground lightning polarity in severe storms. Mon. Wea. Rev., 135, 13271353. (c) 2007 American Meteorological Society.
} 
positive and negative storm environments are consistent with the more specific hypothesis that broad, strong updrafts and associated large LWCs in severe storms lead to enhanced positive charging of graupel and hail, the generation of an inverted charge structure, and increased positive CG lightning production. Four levels of comparison were conducted to evaluate the differences between positive and negative storm environments, all of which supported the differences highlighted above. Overall grouped comparisons revealed statistically significant differences in the aforementioned parameters between positive and negative storm environments using the Student's $t$ test. These differences remained evident in comparisons of the median parameter values for the nine individual mesoscale regions, both between days and within the same day for those days (23, 24 May; 15 June) when positive and negative storms both occurred. Dropsonde data permitted the investigation of the local mesoscale environments on 24 May and 19 June at a very high spatial and temporal resolution, and provided further evidence of systematic differences between the environments of positive and negative storms consistent with the differences gleaned from the overall grouped, regional, and daily comparisons. The dropsonde data, which detailed the $\theta_{\mathrm{e}}$ gradient regions on 24 May and 19 June, also provided further support that the $\theta_{\mathrm{e}}$ gradient region is a preferred location for positive storms (e.g., Smith et al. 2000; Carey et al. 2003b) not simply because of a difference in $\theta_{\mathrm{e}}$ or CAPE values, but because the environmental parameters found to be favorable for positive CG flash production in this study are likely to be found in unison there. It was also determined from the dropsonde data that baroclinically-generated horizontal vorticity in the $\theta_{\mathrm{e}}$ gradient region could provide 
additional updraft forcing comparable to that produced by low-level shear. Comparisons of the individual mesoscale regions showed that the various parameters found to differ significantly between positive and negative regions (i.e., low to midlevel moisture, $\mathrm{CBH}$, WCD, low to midlevel lapse rates, 0-3 km AGL wind shear, 0-2 km AGL storm-relative wind speed, CAPE/NCAPE in the mixed-phase zone) appeared to play a greater role in influencing CG lightning polarity on some days than others, which is to be expected given that updraft forcing and the production of large supercooled LWCs can come from any combination of these mechanisms. However, low-level moisture, LCL, and WCD consistently stood out as likely the most influential parameters on CG lightning polarity.

Visual inspection of radar imagery suggested that dominant CG lightning polarity is not directly related to the organizational mode taken by convection, as multicellular and supercellular convection was common with both positive and negative storms. Rather, environmental conditions appeared to dictate CG flash polarity. Subjective visual inspection of radar imagery also revealed no systematic differences between positive and negative storm intensity. Positive and negative storms alike were found to be very intense, which is not surprising given the common production of severe weather by both storm types (e.g., Carey et al. 2003b). While this finding of similar intensities between positive and negative storms based on visual inspection of radar imagery could signify a leading role for WCD in modulating cloud LWC and CG flash polarity, it should also be noted that it is very difficult, if not impossible, to determine accurate, reliable measurements of updraft intensity based on subjective visual inspection of radar imagery. The goal of the radar analysis in this study was simply to 
determine if any obvious differences in overall storm intensity were evident between positive and negative storms. Multi-Doppler data, from which the three-dimensional wind field of a storm can be synthesized, is really necessary to provide an accurate measure of actual updraft velocity. Also, the present study made no attempt to measure updraft width via the radar data.

While helping to provide insight into the differences in the mesoscale environments of positive and negative storms and the potential impacts on cloud electrification and CG lightning polarity, this study has also highlighted the need for future research to further the understanding of dominant positive CG flash production by some severe storms. First of all, this study demonstrated strong correlations between the mesoscale environment and CG lightning polarity, but causality could not be verified due to a lack of in situ observations to confirm the hypothesized microphysical, dynamical, and electrical responses to variations in environmental conditions that ultimately determined the dominant CG lightning polarity. Thus, future observational field programs and numerical cloud modeling studies should focus on these critical intermediary processes. The STEPS field campaign (e.g., Lang et al. 2004) produced an excellent dataset to study the kinematic, microphysical, electrical, and environmental properties of positive CG flash-dominant storms. A similar field program, but with a greater emphasis placed on detailed measurements of the mesoscale environment, conducted in a location where negative severe storms are common such as the southeast United States or ideally, where both positive and negative severe storms are common such as Nebraska, Kansas, or Oklahoma as shown by this study and Carey et al. (2003b), 
would help provide the resources and data necessary to conduct a robust comparison between positive and negative storms, and would greatly help to identify the causal factors that link certain environmental conditions and CG lightning polarity. However, more accurate and robust estimates of updraft velocity and LWC are needed to truly resolve this issue, and severe limitations exist in our ability to measure these quantities with current in-situ and remote technology. Simultaneous aerosol measurements of the thunderstorm inflow air should also be taken to evaluate the impact of CCN concentrations on CG lightning polarity. Such a study would greatly help to solve the standing paradox that most severe storms produce negative CG lightning (e.g., Carey et al. 2003b) despite also likely being associated with intense updrafts.

Given that several of the analyzed environmental parameters are highly correlated (i.e., not independent such as surface dewpoint, low-level mixing ratio, LCL, and WCD), it would be worthwhile to construct a multiple-linear regression model and analysis of variance to determine the relative importance of several parameters simultaneously and to eliminate redundant variables not responsible for causality. The results of this study illustrated that the size of the proximity sounding dataset used was sufficiently large to produce statistically significant and robust results, but it would be worthwhile for subsequent studies to verify these results with a larger dataset containing cases from a variety of locations. Furthermore, additional investigation is needed to determine whether CAPE in positive (negative) storm environments is typically more strongly correlated to low-level temperature (moisture) as appeared to be the case during IHOP_2002. 


\section{REFERENCES}

Albright, J. C., 1939: Summer Weather Data. The Marley Company, 153 pp.

Avila, E. E., and R. G. Pereyra, 2000: Charge transfer during crystal-graupel collisions for two different cloud droplet size distributions. Geophys. Res. Lett., 27, 38373840 .

Blanchard, D. O., 1998: Assessing the vertical distribution of convective available potential energy. Wea. Forecasting, 13, 870-877.

Bluestein, H. B., 1993: Observations and Theory of Weather Systems, Synoptic-Dynamic Meteorology in Midlatitudes. Vol. II. Oxford University Press, 594 pp.

_ - and C. R. Parks, 1983: A synoptic and photographic climatology of low-precipitation severe thunderstorms in the southern plains. Mon. Wea. Rev., 111, 2034-2046.

— characteristics and storm structure in the Spearman, Texas, tornadic supercells of 31 May 1990. Mon. Wea. Rev., 126, 1451-1467.

Bolton, D., 1980: The computation of equivalent potential temperature. Mon. Wea. Rev., 108, 1046-1053.

Branick, M. L., and C. A. Doswell III, 1992: An observation of the relationship between supercell structure and lightning ground-strike polarity. Wea. Forecasting, 7, 143149.

Brooks, C. E. P., 1925: The distribution of thunderstorms over the globe. Geophys. Mem. London, 24, 147-164.

Brooks, H. E., C. A. Doswell III, and J. Cooper, 1994a: On the environments of tornadic and nontornadic mesocyclones. Wea. Forecasting, 9, 606-618.

- — - _ and R. B. Wilhelmson, 1994b: The role of midtropospheric winds in the evolution and maintenance of low-level mesocyclones. Mon. Wea. Rev., 122, 126136.

Brooks, I. M., C. P. R. Saunders, R. P. Mitzeva, and S. L. Peck, 1997: The effect on thunderstorm charging of the rate of rime accretion by graupel. J. Atmos. Res., 43, 277-295. 
Browning, K. A., 1964: Airflow and precipitation trajectories within severe local storms which travel to the right of the winds. J. Atmos. Sci., 21, 634-639.

__ 1977: The structure and mechanisms of hailstorms. Hail: A Review of Hail Science and Hail Suppression, Meteor. Monogr., No. 38, Amer. Meteor. Soc., 1-43.

Carey, L. D., and S. A. Rutledge, 1998: Electrical and multiparameter radar observations of a severe hailstorm. J. Geophys. Res., 103, 13 979-14 000.

— , and — 2003: Characteristics of cloud-to-ground lightning in severe and nonsevere storms over the central United States from 1989-1998. J. Geophys. Res., 108, 4483, doi:10.1029/2002JD002951.

_ _ and K. M. Buffalo, 2007: Environmental control of cloud-to-ground lightning polarity in severe storms. Mon. Wea. Rev., 135, 1327-1353.

— W. A. Petersen, and S. A. Rutledge, 2003a: Evolution of cloud-to-ground lightning and storm structure in the Spencer, South Dakota, tornadic supercell of 30 May 1998. Mon. Wea. Rev., 131, 1811-1831.

— S. A. Rutledge, and W. A. Petersen, 2003b: The relationship between severe storm reports and cloud-to-ground lightning polarity in the contiguous United States from 1989 to 1998. Mon. Wea. Rev., 131, 1211-1228.

Christian, H. J., and Coauthors, 1999: The Lightning Imaging Sensor. Proc. 11th Int. Conf. on Atmospheric Electricity, Guntersville, AL, NASA/CP-1999-209261, 746749.

Craven, J. P., R. E. Jewell, and H. E. Brooks, 2002a: Comparison between observed convective cloud-base heights and lifting condensation level for two different lifted parcels. Wea. Forecasting, 17, 885-890.

— , H. E. Brooks, and J. A. Hart, 2002b: Baseline climatology of sounding derived parameters associated with deep, moist convection. Preprints, 21st Conf. on Severe Local Storms, San Antonio, TX, Amer. Meteor. Soc., 643-646.

Cummins, K. L., M. J. Murphy, E. A. Bardo, W. L. Hiscox, R. B. Pyle, and A. E. Pifer, 1998: A combined TOA/MDF technology upgrade of the U.S. National Lightning Detection Network. J. Geophys. Res., 103, 9035-9044.

— , J. A. Cramer, C. J. Biagi, E. P. Krider, J. Jerauld, M. Uman, and V. Rakov, 2006: The U.S. National Lightning Detection Network: Post-upgrade status. Preprints, Second Conf. on the Meteorological Applications of Lightning Data, Atlanta, GA, Amer. Meteor. Soc., CD-ROM, P6.1. 
Curran, E. B., and W. D. Rust, 1992: Positive ground flashes produced by lowprecipitation thunderstorms in Oklahoma on 26 April 1984. Mon. Wea. Rev., 120, $544-553$.

Davies-Jones, R. P., D. Burgess, and M. Foster, 1990: Test of helicity as a tornado forecast parameter. Preprints, 16th Conf. on Severe Local Storms, Kananaskis Park, AB, Canada, Amer. Meteor. Soc., 588-592.

Doswell, C. A., III, and H. E. Brooks, 1993: Comments on "Anomalous cloud-to-ground lightning in an F5-tornado-producing supercell thunderstorm on 28 August 1990." Bull. Amer. Meteor. Soc., 74, 2213-2218.

— models. The Tornado: Its Structure, Dynamics, Prediction, and Hazards, Geophys. Monogr., Vol. 28, Amer. Geophys. Union, 161-172.

— , and E. N. Rasmussen, 1994: The effect of neglecting the virtual temperature correction on CAPE calculations. Wea. Forecasting, 9, 619-623.

— , and P. M. Markowski, 2004: Is buoyancy a relative quantity? Mon. Wea. Rev., 132, 853-863.

Emanuel, K. A., 1994: Atmospheric Convection. Oxford University Press, 580 pp.

Gaskell, W., and A. J. Illingworth, 1980: Charge transfer accompanying individual collisions between ice particles and its role in thunderstorm electrification. Quart. J. Roy. Meteor. Soc., 106, 841-854.

Gilmore, M. S., and L. J. Wicker, 2002: Influences of the local environment on supercell cloud-to-ground lightning, radar characteristics, and severe weather on 2 June 1995. Mon. Wea. Rev., 130, 2349-2372.

Glickman, T. S., Ed., 2000: Glossary of Meteorology. $2^{\text {nd }}$ ed. Amer. Meteor. Soc., 855 pp.

Hart, J. A., and W. D. Korotky, 1991: The SHARP workstation v1.50 user's guide. National Weather Service, NOAA, 30 pp. [Available from NWS Eastern Region Headquarters, Scientific Services Division, 630 Johnson Ave., Bohemia, NY 11716.]

Houze, R. A., Jr., 1993: Cloud Dynamics. Academic Press, 573 pp.

Jayaratne, E. R., 1993: The heat balance of a riming graupel pellet and the charge separation during ice-ice collisions. J. Atmos. Sci., 50, 3185-3193. 
_- 2003: Thunderstorm electrification mechanisms. The Lightning Flash, G.V. Cooray, Ed., The Institution of Electrical Engineers, 17-44.

— C. P. R. Saunders, and J. Hallett, 1983: Laboratory studies of the charging of soft hail during ice crystal interactions. Quart. J. Roy. Meteor. Soc., 109, 609-630.

Johns, R. H., and C. A. Doswell III, 1992: Severe local storms forecasting. Wea. Forecasting, 7, 588-612.

Keith, W. D., and C. P. R. Saunders, 1990: Further laboratory studies of the charging of graupel during ice crystal interactions. J. Atmos. Res., 25, 445-464.

Kelly, D. L., J. T. Schaefer, R. P. McNulty, C. A. Doswell III, and R. F. Abbey Jr., 1978: An augmented tornado climatology. Mon. Wea. Rev., 106, 1172-1183.

$\longrightarrow,-$, and C. A. Doswell III, 1985: Climatology of nontornadic severe thunderstorm events in the United States. Mon. Wea. Rev., 113, 1997-2014.

Klemp, J. B., 1987: Dynamics of tornadic thunderstorms. Annu. Rev. Fluid Mech., 19, 369-402.

Knapp, D. I., 1994: Using cloud-to-ground lightning data to identify tornadic thunderstorm signatures and nowcast severe weather. Natl. Wea. Digest, 19, 35-42.

Knight, C. A., and N. C. Knight, 2001: Hailstorms. Severe Convective Storms, Meteor. Monogr., No. 50, Amer. Meteor. Soc., 223-249.

Krehbiel, P. R., 1986: The electrical structure of thunderstorms. The Earth's Electrical Environment, E. P. Krider and R. G. Roble, Eds., National Academy Press, 90-113.

— , R. J. Thomas, W. Rison, T. Hamlin, J. Harlin, and M. Davis, 2000: GPS-based mapping system reveals lightning inside storms. Eos, Trans. Amer. Geophys. Union, 81, 21-25.

Kuhlman, K. M., 2004: Numerical simulations of the 29 June 2000 STEPS tornadic supercell: Microphysics, electrification, and lightning. Master's thesis, Dept. of Meteorology, University of Oklahoma, 72 pp.

Lang, T. J., and S. A. Rutledge, 2002: Relationships between convective storm kinematics, precipitation, and lightning. Mon. Wea. Rev., 130, 2492-2506.

— fire in Colorado. Geophys. Res. Lett., 33, L03804, doi:10.1029/2005GL024608. 
—_, and Coauthors, 2004: The Severe Thunderstorm Electrification and Precipitation Study. Bull. Amer. Meteor. Soc., 85, 1107-1126.

Lucas, C., E. J. Zipser, and M. A. LeMone, 1994: Vertical velocity in oceanic convection off tropical Australia. J. Atmos. Sci., 51, 3183-3193.

$\longrightarrow,-$, and —, 1996: Reply. J. Atmos. Sci., 53, 1212-1214.

Lyons, W. A., T. E. Nelson, E. R. Williams, J. Cramer, and T. Turner, 1998: Enhanced positive cloud-to-ground lightning in thunderstorms ingesting smoke. Science, 282, $77-81$.

MacGorman, D. R., and K. E. Nielsen, 1991: Cloud-to-ground lightning in a tornadic storm on 8 May 1986. Mon. Wea. Rev., 119, 1557-1574.

— and hailstorms. Mon. Wea. Rev., 122, 1671-1697.

— mesoscale convective systems. J. Geophys. Res., 103, 14 011-14 023.

— $422 \mathrm{pp}$.

—, W. D. Rust, P. Krehbiel, W. Rison, E. Bruning, and K. Wiens, 2005: The electrical structure of two supercell storms during STEPS. Mon. Wea. Rev., 133, 2583-2607.

Mansell, E. R., D. R. MacGorman, C. L. Ziegler, and J. M. Straka, 2002: Simulated three-dimensional branched lightning in a numerical thunderstorm model. $J$. Geophys. Res., 107, 4075, doi:10.1029/2000JD000244.

,,--- , and,- 2003 : Recent results from thunderstorm electrification modeling. Preprints, $12^{\text {th }}$ International Conference on Atmospheric Electricity, Versailles, France, 1, 119-122.

Markowski, P. M., E. N. Rasmussen, and J. M. Straka, 1998: The occurrence of tornadoes in supercells interacting with boundaries during VORTEX-95. Wea. Forecasting, 13, 852-859.

McCarthy, J., 1974: Field verification of the relationship between entrainment rate and cumulus cloud diameter. J. Atmos. Sci., 31, 1028-1039. 
McCaul, E. W., Jr., and M. L. Weisman, 2001: The sensitivity of simulated supercell structure and intensity to variations in the shapes of environmental buoyancy and shear profiles. Mon. Wea. Rev., 129, 664-687.

- and C. Cohen, 2002: The impact on simulated storm structure and intensity of variations in the mixed layer and moist layer depths. Mon. Wea. Rev., 130, 17221748 .

- — - and C. Kirkpatrick, 2005: The sensitivity of simulated storm structure, intensity, and precipitation efficiency to environmental temperature. Mon. Wea. Rev., 133, 3015-3037.

Michaud, L. M., 1996: Comments on "Convective available potential energy in the environment of oceanic and continental clouds.” J. Atmos. Sci., 53, 1209-1211.

— 1998: Entrainment and detrainment required to explain updraft properties and work dissipation. Tellus, 50A, 283-301.

Moller, A. R., C. A. Doswell III, M. P. Foster, and G. R. Woodall, 1994: The operational recognition of supercell thunderstorm environments and storm structures. Wea. Forecasting, 9, 327-347.

Murray, N. D., R. E. Orville, and G. R. Huffines, 2000: Effect of pollution from Central American fires on cloud-to-ground lightning in May 1998. Geophys. Res. Lett., 27, 2249-2252.

Orville, R. E., and R. W. Henderson, 1986: Global distribution of midnight lightning: December 1977 to August 1978. Mon. Wea. Rev., 114, 2640-2653.

— , and G. R. Huffines, 2001: Cloud-to-ground lightning in the United States: NLDN results in the first decade, 1989-98. Mon. Wea. Rev., 129, 1179-1193.

Perez, A. H., L. J. Wicker, and R. E. Orville, 1997: Characteristics of cloud-to-ground lightning associated with violent tornadoes. Wea. Forecasting, 12, 428-437.

Petersen, W. A., S. A. Rutledge, and R. E. Orville, 1996: Cloud-to-ground lightning observations from TOGA COARE: Selected results and lightning location algorithms. Mon. Wea. Rev, 124, 602-620.

_ R. Fu, M. Chen, and R. Blakeslee, 2006: Intraseasonal forcing of convection and lightning activity in the southern Amazon as a function of cross-equatorial flow. $J$. Climate, 19, 3180-3196. 
Rakov, V. A., and M. A. Uman, 2003: Lightning: Physics and Effects. Cambridge University Press, 687 pp.

Rasmussen, E. N., 2003: Refined supercell and tornado forecast parameters. Wea. Forecasting, 18, 530-535.

— and tornado forecast parameters. Wea. Forecasting, 13, 1148-1164.

— of the role of upper-level storm-relative flow. Mon. Wea. Rev., 126, 2406-2421.

— , S. Richardson, J. M. Straka, P. M. Markowski, and D. O. Blanchard, 2000: The association of significant tornadoes with a baroclinic boundary on 2 June 1995. Mon. Wea. Rev., 128, 174-191.

Reap, R. M., and D. R. MacGorman, 1989: Cloud-to-ground lightning: Climatological characteristics and relationships to model fields, radar observations, and severe local storms. Mon. Wea. Rev., 117, 518-535.

Reynolds, S. E., M. Brook, and M. F. Gourley, 1957: Thunderstorm charge separation. J. Meteor., 14, 426-436.

Rogers, R. R., and M. K. Yau, 1989: A Short Course in Cloud Physics. Pergamon Press, $293 \mathrm{pp}$.

Rosenfeld, D., and W. L. Woodley, 2003: Spaceborne inferences of cloud microstructure and precipitation processes: synthesis, insights, and implications. Cloud Systems, Hurricanes, and the Tropical Rainfall Measuring Mission (TRMM): A Tribute to Dr. Joanne Simpson, Meteor. Monogr., No. 51, Amer. Meteor. Soc., 59-80.

Rotunno, R., 1981: On the evolution of thunderstorm rotation. Mon. Wea. Rev., 109, $577-586$.

— thunderstorm motion. Mon. Wea. Rev., 110, 136-151.

,-- , and M. L. Weisman, 1988: A theory for strong, long-lived squall lines. $J$. Atmos. Sci., 45, 463-485.

Rust, W. D., and D. R. MacGorman, 2002: Possibly inverted-polarity electrical structures in thunderstorms during STEPS. Geophys. Res. Lett., 29, 1571, doi:10.1029/2001GL014303. 
,-- , and R. T. Arnold, 1981a: Positive cloud-to-ground lightning flashes in severe storms. Geophys. Res. Lett., 8, 791-794.

— , W. L. Taylor, D. R. MacGorman, and R. T. Arnold, 1981b: Research on electrical properties of severe thunderstorms in the Great Plains. Bull. Amer. Meteor. Soc., 62, 1286-1293.

— D. R. MacGorman, and S. J. Goodman, 1985: Unusual positive cloud-to-ground lightning in Oklahoma storms on 13 May 1983. Preprints, 14th Conf. on Severe Local Storms, Indianapolis, IN, Amer. Meteor. Soc., 372-375.

Saunders, C. P. R., and I. M. Brooks, 1992: The effects of high liquid water content on thunderstorm charging. J. Geophys. Res., 97, 14 671-14 676.

— on charge transfer during crystal/graupel collisions. J. Geophys. Res., 103, 13 94913956.

—, W. D. Keith, and R. P. Mitzeva, 1991: The effect of liquid water on thunderstorm charging. J. Geophys. Res., 96, $11007-11017$.

Seimon, A., 1993: Anomalous cloud-to-ground lightning in an F5-tornado-producing supercell thunderstorm on 28 August 1990. Bull. Amer. Meteor. Soc., 74, 189-203.

Smith, J. A., M. B. Baker, and J. A. Weinman, 2003: Do forest fires affect lightning? Quart. J. Roy. Meteor. Soc., 129, 2651-2670.

Smith, S. B., J. G. LaDue, and D. R. MacGorman, 2000: The relationship between cloud-to-ground lightning polarity and surface equivalent potential temperature during three tornadic outbreaks. Mon. Wea. Rev., 128, 3320-3328.

Stolzenburg, M., 1994: Observations of high ground flash densities of positive lightning in summertime thunderstorms. Mon. Wea. Rev., 122, 1740-1750.

—, W. D. Rust, and T. C. Marshall, 1998: Electrical structure in thunderstorm convective regions. 3. Synthesis. J. Geophys. Res., 103, 14 097-14 108.

Takahashi, T., 1978: Riming electrification as a charge generation mechanism in thunderstorms. J. Atmos. Sci., 35, 1536-1548.

Tessendorf, S. A., L. J. Miller, K. C. Wiens, and S. A. Rutledge, 2005: The 29 June 2000 supercell observed during STEPS. Part I: Kinematics and microphysics. J. Atmos. Sci., 62, 4127-4150. 
Thompson, R. L., R. Edwards, J. A. Hart, K. L. Elmore, and P. Markowski, 2003: Close proximity soundings within supercell environments obtained from the Rapid Update Cycle. Wea. Forecasting, 18, 1243-1261.

Uman, M. A., 1987: The Lightning Discharge. Academic Press, 377 pp.

Wacker, R. S., and R. E. Orville, 1999a: Changes in measured lightning flash count and return stroke peak current after the 1994 U.S. National Lightning Detection Network upgrade, 1, Observations. J. Geophys. Res., 104, 2151-2158.

$\longrightarrow$, and — 1999b: Changes in measured lightning flash count and return stroke peak current after the 1994 U.S. National Lightning Detection Network upgrade, 2, Theory. J. Geophys. Res., 104, 2159-2162.

Weckwerth, T. M., and Coauthors, 2004: An overview of the International $\mathrm{H}_{2} \mathrm{O}$ Project (IHOP_2002) and some preliminary highlights. Bull. Amer. Meteor. Soc., 85, 253277.

Weisman, M. L., and J. B. Klemp, 1982: The dependence of numerically simulated convective storms on vertical wind shear and buoyancy. Mon. Wea. Rev., 110, 504520.

- , and — 1984: The structure and classification of numerically simulated convective storms in directionally varying wind shears. Mon. Wea. Rev., 112, 2479-2498.

- , and - 1986: Characteristics of isolated convective storms. Mesoscale Meteorology and Forecasting, P. S. Ray, Ed., Amer. Meteor. Soc., 331-358.

— , and R. Rotunno, 2004: "A theory for strong long-lived squall lines" revisited. $J$. Atmos. Sci., 61, 361-382.

Wiens, K. C., S. A. Rutledge, and S. A. Tessendorf, 2005: The 29 June 2000 supercell observed during STEPS. Part II: Lightning and charge structure. J. Atmos. Sci., 62, 4151-4177.

Wilks, D. S., 1995: Statistical Methods in the Atmospheric Sciences. Academic Press, $467 \mathrm{pp}$.

Williams, E. R., 1989: The tripole structure of thunderstorms. J. Geophys. Res., 94, 13 151-13 167.

_- 1995: Meteorological aspects of thunderstorms. CRC Handbook on Atmospheric Electrodynamics, Vol. I., H. Volland, Ed., CRC Press, 27-60. 
_ 2001: The electrification of severe storms. Severe Convective Storms, Meteor. Monogr., No. 50, Amer. Meteor. Soc., 527-561.

— 2004: The role of elevated cloud base height in the inverted electrical polarity of severe storms. Preprints, $22^{\text {nd }}$ Conference on Severe Local Storms, Hyannis, MA, Amer. Meteor. Soc., P16B.4.

- - and N. Renno, 1993: An analysis of the conditional instability of the tropical atmosphere. Mon. Wea. Rev., 121, 21-36.

— activity. C. R. Physique, 3, 1277-1292.

— - and G. Satori, 2004: Lightning, thermodynamic and hydrological comparison of the two tropical continental chimneys. J. Atmos. Solar-Terr. Phys., 66, 1213-1231.

—- and Coauthors, 2002: Contrasting convective regimes over the Amazon: Implications for cloud electrification. J. Geophys. Res.. 107, 8082, doi:10.1029/2001JD000380.

— , V. Mushtak, and D. Boccippio, 2003: Another look at the dependence of lightning flash rate on the temperature of the boundary layer in the present climate. Preprints, $12^{\text {th }}$ International Conference on Atmospheric Electricity, Versailles, France, 2, $777-780$.

$\longrightarrow,-$ D. Rosenfeld, S. Goodman, and D. Boccippio, 2005: Thermodynamic conditions favorable to superlative thunderstorm updraft, mixed-phase microphysics and lightning flash rate. Atmos. Res., 76, 288-306.

Zipser, E. J., 2003: Some views on "Hot Towers" after 50 years of tropical field programs and two years of TRMM data. Cloud Systems, Hurricanes, and the Tropical Rainfall Measuring Mission (TRMM): A Tribute to Dr. Joanne Simpson, Meteor. Monogr., No. 51, Amer. Meteor. Soc., 49-58. 


\section{APPENDIX \\ CORRELATION BETWEEN CAPE AND OTHER PARAMETERS}

In investigating the relationship between the local mesoscale environment and CG lightning behavior, some interesting correlations between CAPE and other parameters were discovered. The primary factors that govern the amount of CAPE present are low-level temperature, low-level moisture, environmental lapse rates, and depth of the FCL. On a Skew-T/Log P diagram, low-level temperature and moisture determine the parcel path. The parcel path, in combination with environmental lapse rates, dictates the magnitude of buoyancy at each vertical level. Meanwhile, the depth of the FCL dictates the depth over which the buoyancy is integrated to calculate the amount of CAPE present (i.e, the limits of integration in Equation (10)).

Equivalent potential temperature is a combined measure of temperature and moisture, as shown in Equation (7) from Bolton (1980). As indicated by Fig. 109, total CAPE (LFC to EL) was reasonably correlated to low-level $\theta_{\mathrm{e}}$ for both negative and positive mesoscale regions. The correlation coefficients were very similar for the two types of regions, 0.81 for negative regions and 0.80 for positive regions. However, when the correlation between CAPE and the individual contributions to $\theta_{\mathrm{e}}$ (i.e., low-level temperature and moisture) was investigated, dramatic differences were revealed between positive and negative mesoscale regions. For negative regions, CAPE was reasonably correlated to mean mixing ratio in the lowest $100 \mathrm{hPa}$ (correlation coefficient $=0.76$; Fig. 110), while the correlation to mean temperature in the lowest $100 \mathrm{hPa}$ was much weaker (correlation coefficient $=0.49$; Fig. 111). The opposite was true for positive 


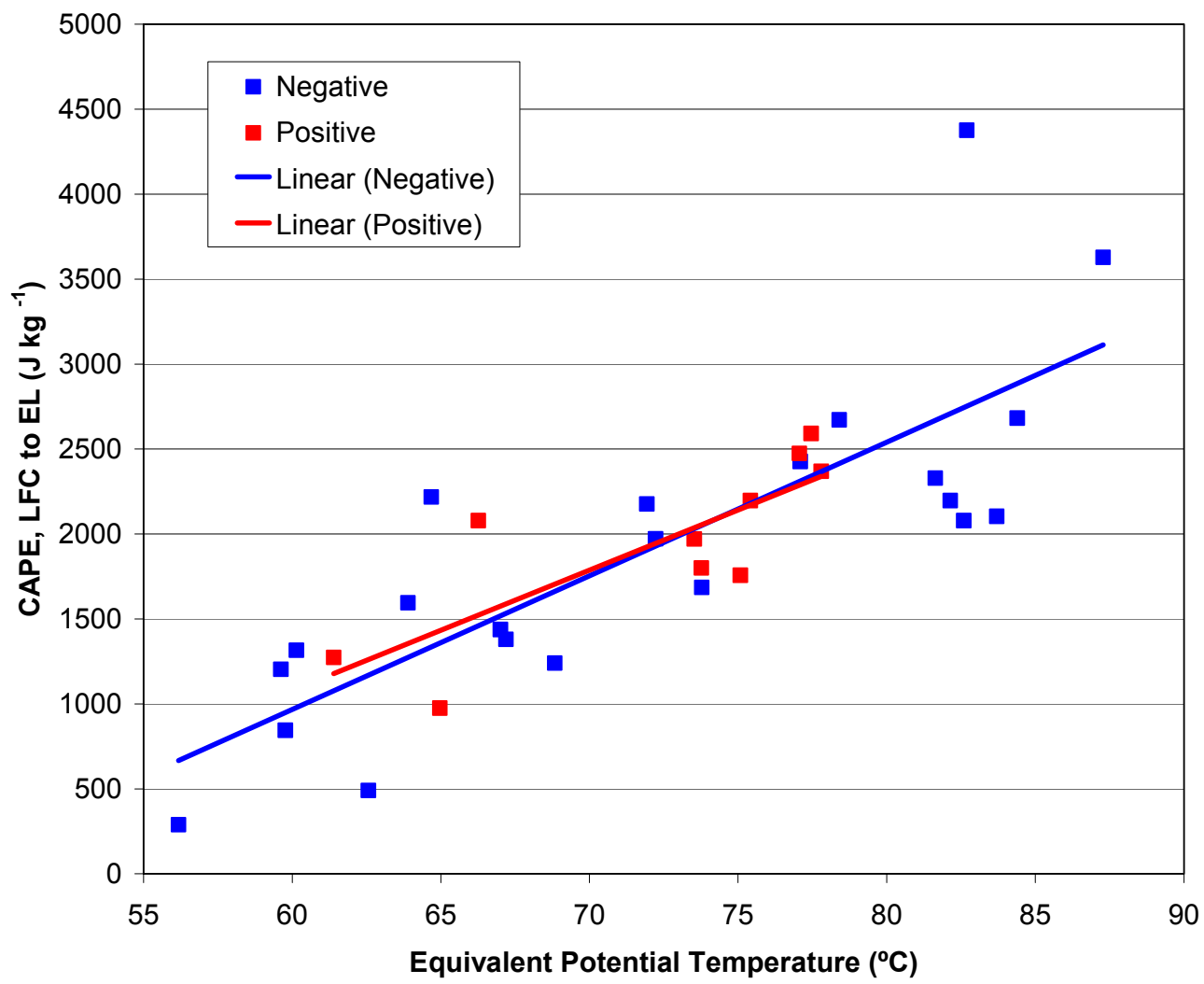

FIG. 109. Scatter plot of total CAPE (LFC to EL) versus low-level equivalent potential temperature $\left(\theta_{\mathrm{e}}\right)$ for individual soundings within negative (blue) and positive (red) mesoscale regions. Overlaid on the plot are linear trendlines for the respective negative and positive datasets. 


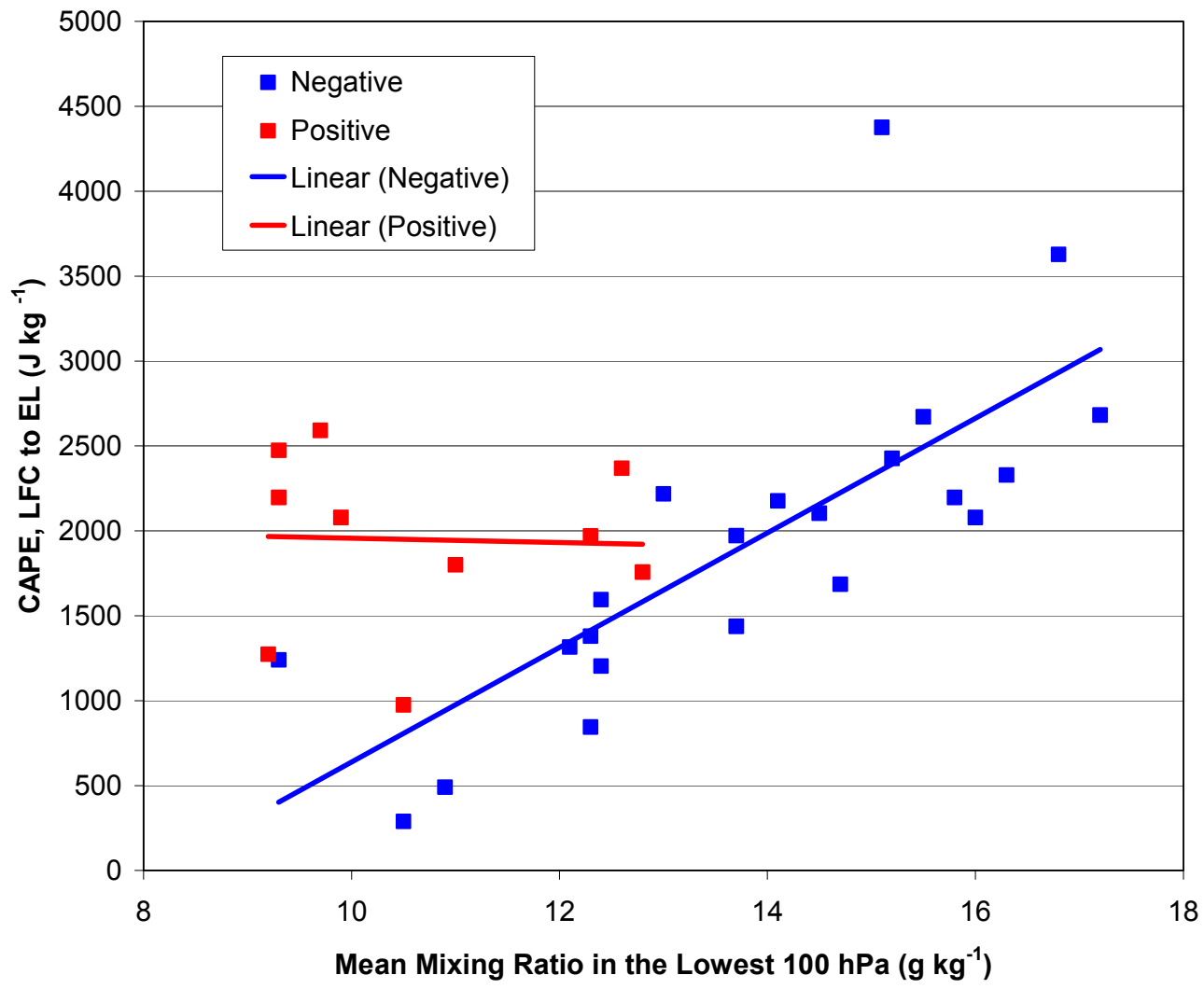

FIG. 110. Same as in Fig. 109 except for total CAPE (LFC to EL) versus mean mixing ratio in the lowest $100 \mathrm{hPa}$. 


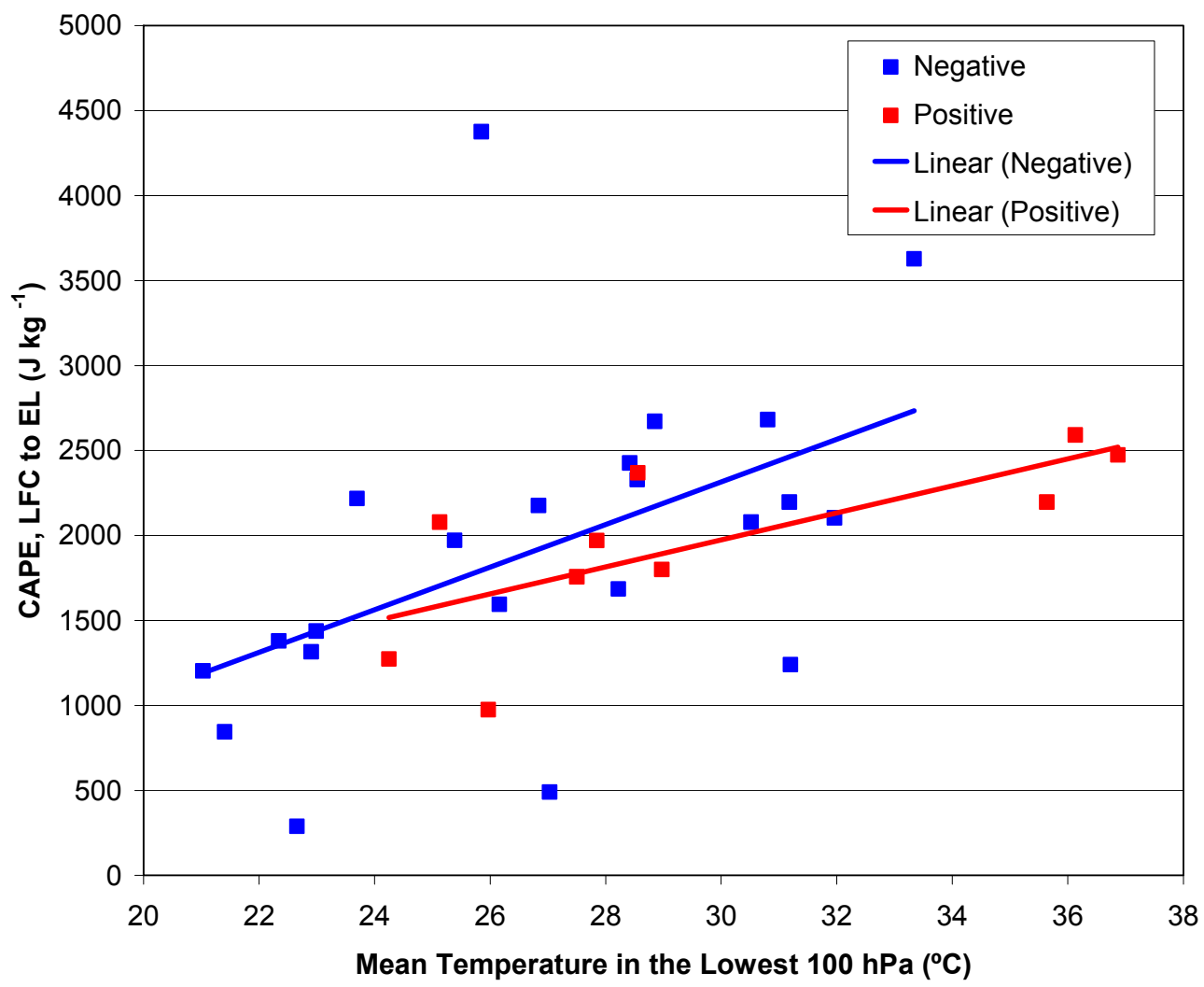

FIG. 111. Same as in Fig. 109 except for total CAPE (LFC to EL) versus mean temperature in the lowest $100 \mathrm{hPa}$.

regions. CAPE was reasonably correlated to mean temperature in the lowest $100 \mathrm{hPa}$ (correlation coefficient $=0.73$; Fig. 111) in positive regions, with essentially no correlation to mean mixing ratio in the lowest $100 \mathrm{hPa}$ (correlation coefficient $=-0.04$; Fig. 110). These results suggest that with regard to low-level environmental conditions, CAPE was largely controlled by low-level moisture in negative regions and by low-level temperature in positive regions for the cases investigated in this study. In fact, mean mixing ratio in the lowest $100 \mathrm{hPa}$ explained $58 \%$ of the variance in CAPE in negative regions, versus $0 \%$ in positive regions. Mean temperature in the lowest $100 \mathrm{hPa}$ 
explained only $24 \%$ of the variance in CAPE in negative regions, but explained $53 \%$ of the variance in positive regions. Since temperature and moisture both factor into $\theta_{\mathrm{e}}$, the correlation between CAPE and low-level $\theta_{\mathrm{e}}$ was very similar for the two region types.

As would be expected, CAPE was correlated fairly well to depth of the FCL in both negative and positive regions, with a slightly stronger correlation for negative regions (correlation coefficient of 0.79 for negative regions and 0.69 for positive regions). In positive mesoscale regions, which were characterized by significantly stronger 850-500 and 700-500 hPa lapse rates (Tables 5 and 7), the correlation between CAPE and lapse rates was dramatically stronger than in negative regions. The correlation coefficient between CAPE and 850-500 hPa lapse rates was $0.80(0.44)$ for positive (negative) regions, and the correlation coefficient between CAPE and 700-500 $\mathrm{hPa}$ lapse rates was $0.68(0.04)$ for positive (negative) regions. 


\section{VITA}

Kurt Matthew Buffalo received his Bachelor of Science degree in Earth Sciences-Meteorology with a minor in Mathematics from the University of Northern Colorado in May 2002. He began graduate school at Texas A\&M University in the Department of Atmospheric Sciences in August 2002, and received his Master of Science degree in Atmospheric Sciences in December 2007. Kurt worked intermittently as a SCEP student at the National Weather Service Forecast Office in Pueblo, CO between the years of 2000 and 2005, before accepting a Meteorologist Intern position at the National Weather Service Forecast Office in Hastings, NE in May 2005. He was promoted to a General Forecaster at the Hastings, NE National Weather Service Forecast Office in November 2005, and is currently working in this position. Kurt may be reached at National Weather Service, 6365 Osborne Drive West, Hastings, NE 68901. His email address is Kurt.Buffalo@noaa.gov. 